UNIVERSIDAD NACIONAL DE LA PLATA

FACULTAD DE CIENCIAS JURÍDICAS Y SOCIALES

INSTITUTO DE INTEGRACIÓN LATINOAMERICANA

\title{
Un nuevo papel para el Mercosur: \\ La integración regional subordinada a la política de poder brasileña (2003-2010)
}

Celeste Box

Tesis propuesta para el grado Magíster en Integración Latinoamericana por el Instituto de Integración Latinoamericana (FCJyS) de la Universidad Nacional de La Plata*.

Director: Dr. Raúl Bernal-Meza

\footnotetext{
*Versión revisada posterior a la entregada y publicada por el IIL - UNLP (con autorización expresa de la autora)
} 
Esta tesis está dedicada a la Doctora Gloria Edel Mendicoa, quien a lo largo de la carrera me impresionó con esa combinación de solidez conceptual a una inusual calidez. 


\section{Agradecimientos}

Al Instituto de Integración Latinoamericana, por la coordinación de una carrera que cuenta con docentes de primero nivel, una adecuada disposición de asignaturas y un equipo administrativo siempre solícito para cualquier tipo de cuestión operativa.

Al Doctor Raúl Bernal-Meza por permitirme con sus clases y producción teórica encauzar inquietudes que derivaron en el problema central de esta tesis, gracias a su capacidad para condensar diferentes dimensiones de la integración regional. Atesoro en lo profesional y personal que aceptase dirigir una labor tan modesta.

A los docentes que conformaron mi interés en estos temas -a muchos de los cuales consulté para la elaboración de esta tesis-, como el Doctor Alejandro Simonoff, la Doctora Noemí Mellado, el Doctor René Nicoletti, el Doctor Marcelo Halperin, Doctor Aníbal Viguera, la Doctora Mónica Hirst y la Doctora Rita Giacalone.

A quienes también conformaron mi experiencia formativa-compañeros, profesores ayudantes, personal no docente-, imposible de enumerar pero que también valoro especialmente.

A todos ellos, muchas, muchísimas gracias. 


\section{Resumen}

En estas líneas nos centraremos en un sector de la política exterior de la República Federal de Brasil durante la gestión del Presidente Luiz Inácio Lula da Silva (2003-2010), caracterizada por la búsqueda de una posición de liderazgo creciente extra regional (que aquí denominaremos estrategia de poder global brasileña). Ella requirió del despliegue de un rol hegemónico determinado en el bloque suramericano, y a su vez, le imprimió una función específica al servicio de su interés nacional en la acumulación de poder global. Este nuevo papel del Mercosur, diferente de aquél para el que fue proyectado y ha venido recorriendo a lo largo de su cuarto de siglo de vida, oficiará de norte para el recorrido de estas páginas. 


\section{Resumo}

Nestas páginas focaremos nosso trabalho num espaço da política exterior da República Federativa do Brasil na gestão do Presidente Luiz Inácio Lula da Silva (2003-2010), engajada na procura ativa de uma posição de liderança global cada vez maior (que aqui chamaremos de estratégia de poder global brasileña. Esta estratégia de acumulação de poder norteada para o cenário global, claro que concordante com o interesse nacional brasileiro, tem requerido do exercício da hegemonia sub-regional. $O$ novo papel para o Mercosul, completamente diferente daquele para a qual foi pensado, projetado e construído há vinte e cinco anos, é o alvo destas linhas. 


\section{Abstract}

These pages will aim at the Brazilian foreign policy in Luiz Inácio Lula Da Silva's administration (2003-2010), which had a firmly and sustained seeking for global leadership. This objective couldn't be achieved without a robust work in a South American leadership construction to finally transform it in its natural political ecosystem. This regional hegemony practice gave to Mercosur a new kind of dynamic -very different of that it was made for, or even guide these last twenty five years. Analyse come of the consequences of this phenomenon to the regional integration will lead this thesis. 


\section{Índice}

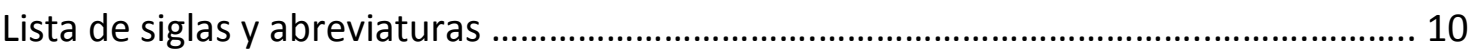

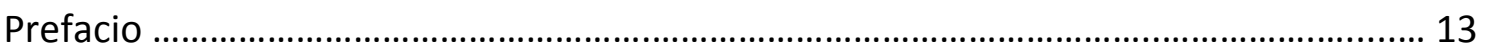

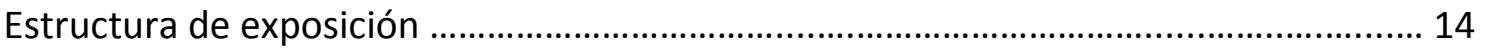

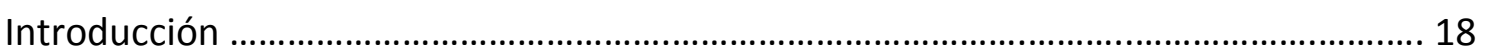

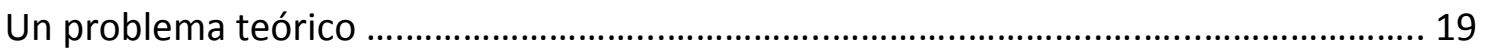

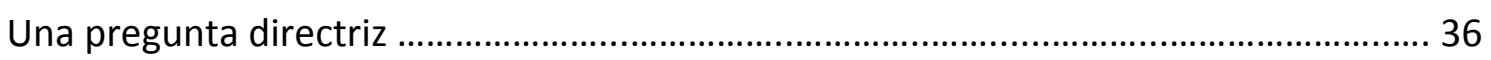

Fines y motivaciones de la integración suramericana ........................................................ 39

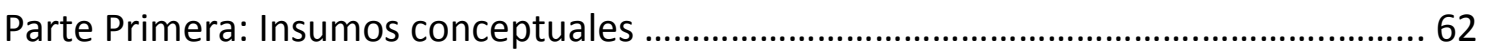

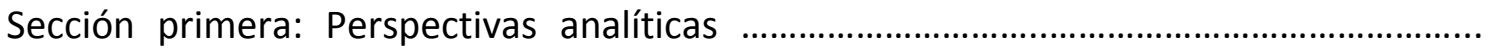

63

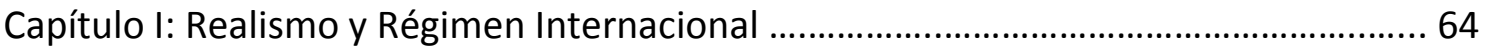

Paradigma tradicional y realismo

65

Interés Nacional

83

Neorrealismo

96 
Anarquía e integración regional

104

Regímenes de integración regional

115

Capítulo II: Política de Poder

122

Un poder realista

123

Power politics

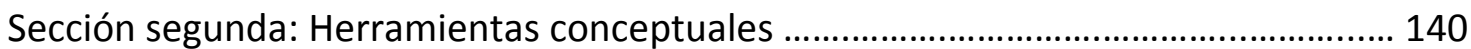

Capítulo III: Regionalización e integración regional ....................................................... 141

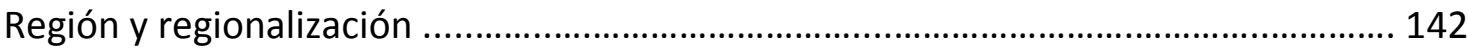

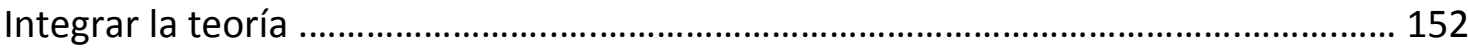

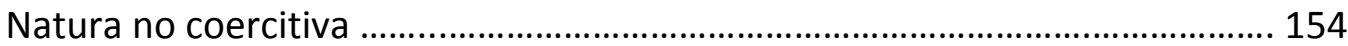

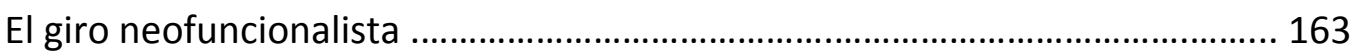

Las fisuras neofuncionalistas

171

Integración regional mercosureña

175

Regionalismo suramericano 180

Cooperación regional 
Capítulo IV: Hegemonía Regional

196

Hegemonía

197

Potencia regional

204

Parte Segunda: Análisis dinámico

Capítulo V: Estrategia de Poder Global Brasileña (2003 - 2010)

211

Poder como medio y fin

212

Medio subregional

La relación con Estados Unidos

228

Estrategia de acumulación

236

Autonomía

Diplomacia presidencial

Autopercepción 250

Poder global como objetivo

260

Capítulo VI: EI Mercosur en la EPGB

Cooperación hegemónica híbrida 
Sobre lo expuesto

Sobre lo pendiente

282

Referencias

286 


\section{Lista de siglas y abreviaturas}

ACE: Acuerdo de Complementación Económica

AEC: Arancel Externo Común

ARC: Acuerdos Regionales de Comercio

ALADI: Asociación Latinoamericana de Integración

ALALC: Asociación Latinoamericana de Libre Comercio

ALBA-TCP: Alianza para los Pueblos de Nuestra América - Tratado de Comercio de los Pueblos

Alianza Bolivariana para los Pueblos de Nuestra América

ALCSA: Área de Libre Comercio Sudamericana

APEC: Cooperación Económica Ásia-Pacífico

ASEAN: Asociación de Países del Sudeste Asiático

BNA: Barreras No Arancelarias

BNDES: Banco Nacional de Desarrollo Económico y Social (Brasil)

BID: Banco Interamericano de Desarrollo

BM: Banco Mundial

CAN: Comunidad Andina de Naciones

CARC: Comité de Acuerdos Regionales de Comercio

CAF: Corporación Andina de Fomento 
CARICOM: Comunidad del Caribe

CCM: Comisión de Comercio del Mercosur

CEE: Comunidad Económica Europea

CEPAL: Comisión Económica de las Naciones Unidas para América Latina y el Caribe

CH: Cláusula de Habilitación

CMC: Consejo Mercado Común

CNMF: Cláusula Nación Más Favorecida

CSD: Consejo Sudamericano de Defensa

CSN: Comunidad Sudamericana de Naciones

COSIPLAN: Consejo Suramericano de Infraestructura y Planeamiento

EPGB: Estrategia de Poder Global Brasileña

FMI: Fondo Monetario Internacional

FOCEM: Fondo de Convergencia Estructural del Mercosur

FONAPLA: Fondo Nacional de Desarrollo de la Cuenca del Plata

GATT: Acuerdo General sobre Tarifas y Aranceles

GATS: Acuerdo General sobre Comercio de Servicios

GMC: Grupo Mercado Común

IED: Inversión Extranjera Directa

IIRSA: Integración de la Infraestructura Regional de Sudamérica

MCCA: Mercado Común Centroamericano

MERCOSUR: Mercado Común del Sur

OCDE: Organización de Cooperación Económica y Desarrollo

OEA: Organización de los Estados Americanos 
OMC: Organización Mundial del Comercio

OPEP: Organización de Países Exportadores de Petróleo.

PICEAB: Programa de Integración y Cooperación Económica Argentino-Brasileño

PN: Preferencia Nacional

PNUD: Programa de Naciones Unidas para el Desarrollo

PR: Preferencia Regional

PTBR: Portugués brasileño

RdFB: República Federal de Brasil

SGP: Sistema Generalizado de Preferencias

SGPC: Sistema Global de Preferencias Comerciales

TIAR: Tratado Interamericano de Asistencia Recíproca

TLCAN: Tratado de Libre Comercio de América del Norte

UNCTAD: Organización de las Naciones Unidas para el Comercio y el Desarrollo

UNESCO: Organización de las Naciones Unidas para la Educación, la Ciencia y la Cultura

UA: Unión Aduanera

UE: Unión Europea

UNASUR: Unión de Naciones Suramericanas

ZLC: Zona de Libre Comercio 
Prefacio 
Estructura de exposición

Esta tesis de maestría encuentra su disparador en el viraje denominado (neo)realista que caracteriza a la política exterior brasileña en el período 2003-2010, centrada en la conformación de una posición de liderazgo global creciente imposible de ejercer sin una ingeniería de poder en la región sudamericana. Esta carrera típica de un perfil de política de poder imprimió un nuevo papel para la integración sudamericana, orientada en su inicio hacia el desarrollo endógeno, su avance posterior hacia la apertura como su evolución hacia la búsqueda de grados de autonomía regional.

Antes de comenzar con el desarrollo conceptual y analítico de este tema, tomaremos algunas líneas del prefacio para comentar cuestiones referidas a la presentación de ese desarrollo. Hemos escogido una estructura en extremo simple para la disposición de los contenidos, constituida por cuatro componentes: una introducción precedente a una primera parte con insumos conceptuales (dividida en dos secciones: la primera de perspectivas analíticas ${ }^{1}$, la segunda de herramientas conceptuales), seguida de una

\footnotetext{
${ }^{1}$ La denominamos perspectivas analíticas porque no referiremos a meros conceptos operativos para el análisis, sino que trabajaremos con enfoques, con grandes posiciones epistemológicas, teóricas e históricas con el suficiente nivel de generalidad como para estar presentes no sólo en la política exterior, sino que inervan cosmovisiones epistemológicas de las relaciones internacionales, y residen en la base de análisis de diverso nivel en otras áreas de conocimiento relacionadas. Tal vez la manera más sintética y efectiva de graficar esas implicaciones es una expresión muy conocida que Celestino Del Arenal utiliza para caracterizar la discusión realismo versus idealismo: el debate, por encima de todo, es ideológico (1994: 109). Con esto no pretendemos resolver sus implicancias -no alcanzaría más que para inaugurar un debate, que requiere un celoso análisis multinivel- sino enfatizar que referir a conceptos de esta
} 
segunda parte donde presentaremos el análisis dinámico de nuestra hipótesis, y, por último, un epílogo. En la introducción se condensan aspectos cotejados en el diseño de esta investigación y de los que no quisiéramos prescindir en esta tesis, dado que reflejan un camino heurístico muy intuitivo que acabó por encaminar estas líneas desde las primeras inquietudes hasta la construcción del problema de investigación (la conformación de nuestra hipótesis -en esencia, la pregunta por el impacto en el Mercosur dentro de lo que introduciremos como estrategia de poder global brasileñapor supuesto que requirió mayor elaboración, pero sin esos textos, dicha estrategia no hubiese existido).

En cuanto a la sección primera, en ella abordaremos los insumos conceptuales que nos dan el perfil general de aquella estrategia brasileña, planteados en una progresión que nos lleva desde el paradigma tradicional realista en relaciones internacionales para recorrer la noción de interés nacional -determinante en nuestra hipótesis-, llegar al neorrealismo -el que nos dará un perfil más cercano que el realismo clásico para el proceder de Brasil en nuestro período-, y así incorporar dos aspectos más: por un lado, algunas aclaraciones que creemos necesarias en el acápite que aborda el poder en clave realista; y por otro, una precisión que necesitamos para caracterizar la acumulación de poder brasileña en la década pasada, como es la noción de power politics. Paso seguido, restringimos el supuesto de anarquía del realismo, para incorporar la noción de régimen internacional. El fin no es sólo trabajar sobre ellos, sino establecer un puente lógico -no sólo teórico- con la sección siguiente: por eso complejidad implica, siempre, lidiar con más componentes que los explícitos. Y sin sombra de duda, todos ellos en extremo complejos. 
incorporaremos la noción de régimen de integración regional, y así marcar un nexo entre una sección en la que nos centramos en el realismo como paradigma y del que proyectamos la sección siguiente, centrada en la integración regional. Esta bisagra, nos llevará hacia la sección segunda, donde se presentan las herramientas conceptuales de menor nivel de generalidad, pero imprescindibles al análisis de nuestro caso: comenzaremos con la noción de región y regionalización, luego introduciremos la caracterización de la integración regional -en clave neofuncionalista-, el regionalismo suramericano y la cooperación regional. Finalizamos aquí recuperando la noción de hegemonía y potencia regional. y así repetimos el patrón de transición lógico-teórica de la sección anterior, estableciendo con ella un nexo con la segunda parte de la tesis, donde trabajaremos sobre las características de la política exterior brasileña.

En la segunda parte, objeto del análisis dinámico de nuestra pregunta directriz, presentaremos los insumos previos a con un capítulo que presente lo que consideraremos la estrategia de poder global brasileña (EPGB). De este modo, para ver el poder como un medio y fin, comenzamos con un esbozo general de la política exterior brasileña, y exponemos dos vectores de ella: el uno horizontal, centrado en el medio subregional; y el vertical, centrado en la relación con Estados Unidos. Para recolocar en términos adecuados a nuestra argumentación, aquí caracterizamos lo que creemos constituye el patrón de relacionamiento externo, usualmente denominado (neo)realista: una estrategia de acumulación de poder orientada al concierto global, determinada por la preexistente búsqueda de autonomía, la diplomacia presidencial y una autopercepción ineludible. Realizado esto, podremos plantear el camino brasileño 
denominado estrategia de poder global. Inmediatamente introduciremos la estrategia de cooperación hegemónica brasileña para el Mercosur. Y así, abordaremos nuestra hipótesis a partir de un constructo analítico (la EPGB) para hacer foco sobre la integración suramericana y caracterizar el rol que el vecino luso parlante le imprimió.

Todo lo anterior se condensa en un epílogo donde nos dedicaremos a dos tareas: por un lado recuperar parte de lo expuesto para reflexionar sobre algunos de sus aspectos y derivar una consideración principal acerca de nuestra hipótesis, y, por el otro, cotejar las cuestiones que este recorrido analítico deja de lado (fuere por cuestiones intrínsecas, como avanzar ajustados a una hipótesis -todo lo que queda por fuera de ella resulta improcedente- o extrínsecas, como la posibilidad de articular aspectos que quedarán excluidos principalmente por las limitaciones de espacio). Pretendemos con esta inclusión dejar la posibilidad abierta para su recuperación en análisis postreros. 
Introducción 
Las consecuencias regionales que pudo revestir para el Mercosur la carrera de acrecentamiento de poder regional y emergencia en el tablero mundial brasileña en la administración iniciada en 2003, condensa diversos temas de nuestro interés que aparecieron principalmente dentro de los desarrollos de Bernal-Meza $(2007,2008)$ pero también de Baumann (2001) y Saraiva (2007). Ese recorrido preliminar, tentativo y sin ningún recorte problemático siquiera a futuro, despertó una idea que luego siguió cincelando una inquietud determinante: las versatilidades y reconfiguraciones dinámicas que la integración regional tuvo, a la luz de decisiones de política externa de sus miembros -y de entre ellos, Brasil, el más preeminente de entre ellos-. Así, un campo, un sector de interés donde construir un objeto de investigación a futuro, se fue delimitando: la política externa del mayor país de la región, producto de las decisiones de una gestión de gobierno -variable por definición-, se combina con un proceso integrador de un cuarto de siglo que la excede, pero que se ve notablemente modificado por ella.

Lo que por entonces resultaba curiosidad devino en inquietud teórica, y conllevó más labor heurística -en principio asistemática e intuitiva-, donde encontramos algunas particularidades de una política exterior brasileña pragmática y proactiva (Hirst, Soares de Lima, Pinheiro, 2010), presta a subsumir la integración regional a lo que desde 
entonces vimos como una clara política de poder (power politics) ${ }^{2}$, apoyada en alianzas estratégicas (parcerias estratégicas) (Bernal Meza, 2006a; 2008; 2009), para concretar la denominada nova asertividade (Souto Maior, 2006) de un país otrora sólo activo, y ahora decidido a proyectar un perfil de potencia emergente (Sean, 2009; Grabendorff, 2010). La nueva asertividad define el cambio deliberado y explícito de Brasil a principios del milenio, de buscar una presencia soberana en el mundo (Da Silva, 2002) y subordinar la actividad diplomática al desarrollo nacional. Esto último, no sólo en términos económicos, sino también en el fortalecimiento institucional que la gestión Da Silva traducía en el desarrollo progresivo de una política externa común y la coordinación con el proceso integrador latinoamericano como tal (Souto Maior, 2006). De este modo la nueva asertividad expresaba el cambio de un Brasil antes afirmado como un miembro activo de los países en desarrollo, a un Brasil ahora asentado en el rol de potencia emergente (aspiración a la que se consideró con derecho en la comunidad internacional). Vale mencionar que Souto Maior no presenta este escenario como una mera carrera de acumulación de poder, sino que menciona sus limitaciones: por un lado, la aceptación de los pares, y por el otro la institucionalidad misma del Mercosur. Era, según sus palabras:

\footnotetext{
${ }^{2}$ Más adelante volveremos sobre esto -es determinante para nuestra caracterización del realismo-, pero sólo para que no quede en suspenso, adelantemos que lo que llamamos 'política de poder' (del original power-politics) es usualmente asociado con lo que se denomina realpolitik en política externa (Finnemore y Goldstein, 2013) e incluso con la machtpolitik (Knapp, 2005). Esa sinonimia no es del todo exacta (Behr, Rösch y Morgenthau, 2012), a la que nos referiremos ut infra. Además, debemos agregar la distorsión que le imprime el sentido común (cierta connotación negativa intrínseca, basada en la amenaza del uso de la fuerza y persecución del interés individual sin dar cuenta de normas o prácticas que contemplen la cooperación o la mera existencia de otros actores). Allende estas cuestiones, afirmemos sólo por ahora, que la política de poder implica la decisión de un estado de considerarse a sí mismo como fin último, por lo que empleará los medios más efectivos a su disposición para alcanzar aquello que haya designado como propósito vital (Schwarzenberger, 1951); y, el peso de esa política de poder se medirá en el eventual caso de uso de la fuerza.
} 
Una actitud osada y cautelosa al mismo tiempo (Souto Maior, 2006: 43).

En esencia, fueron tres perspectivas analíticas -una suerte de vías teóricas, por así decirlo- las que precipitaron nuestro interés y por ello resultaron determinantes para lograr problematizar lo que hasta ese momento era una inquietud, casi una mera curiosidad. Expuestos en orden de importancia, comenzamos con parte de la producción de Raúl Bernal-Meza (1998, 1999, 2001, 2002, 2007), donde encontramos los primeros conceptos que permitirían recortar un sector de la realidad regional en que pudiésemos elaborar un problema preliminar operativo. Su presentación de las relaciones regionales hemisféricas pensadas en su relación con el actor extra regional más influyente -los Estados Unidos-, señala la particularidad de un modelo de política exterior para la región producto de cuestiones de índole interna -concepciones sobre estrategias de desarrollo nacional- antes que a una respuesta a los acontecimientos por fuera de la región (1998). Si bien el decurso de la argumentación del autor no permite que se explaye sobre la relación de Argentina y Brasil en la segunda mitad del siglo pasado, es preciso remarcar que ella no se da en vacío: tiene una historia. A partir de la posguerra, ambos países se consideraban mutuamente una amenaza -en términos geopolíticos y militares sobre todo en cuanto al control de la Cuenca del Plata y el liderazgo subregional-. Sólo a principios de los ochentas del siglo pasado el recelo se reconvierte hacia el camino de la cooperación, y lo hace por tres cuestiones: La firma del Acuerdo Tripartito para las represas entre Argentina, Brasil y Paraguay en 1979 (Bizzozero Revelez, 2008), el apoyo de Brasil al reclamo argentino por Malvinas (Botto y Tussie, 2007) y una mayor cooperación comercial, en gran parte, potenciada 
por la coyuntura externa de toda la región a partir de la crisis del petróleo (Jaguaribe, 1982). A este cambio cualitativo hacia la cooperación debe agregarse la aspiración de Brasil al rol que pretende jugar en la política mundial -desde los noventas del siglo pasado-, lo que no es escindible de su relación con la Argentina (1999): De este modo, hacia el inicio del milenio, la estrategia de construcción de poder hacia el escenario internacional se comienza a perfilar en las parcerias estratégicas y el Mercosur (2002) no permite soslayar a nuestro país del esquema.

Ya en un trabajo posterior encontramos algunos insumos conceptuales que impulsarían nuestro futuro problema sobre todo en la estrategia brasileña acerca de sus objetivos para el Mercosur (esbozados también en Bernal-Meza 2000, 2001), en términos de desarrollo y ampliación de mercados, pero también sus objetivos de búsqueda de poder. Esta pretensión de liderazgo que imprimió Da Silva no era una búsqueda individual a cualquier costo y efectivamente requería de un telón de fondo asentado en la integración, cooperación regional y acuerdos económicos regionalespero que debía cumplir con el requisito de tener a Brasil por centro.

Es interesante destacar un aspecto que obtiene de Souto Maior: en su texto de 2006, afirma que por definición un país en desarrollo aspira a una mayor proyección externa regional y/o internacional pero también requiere del auxilio de pares, hecho que justifica los arreglos regionales bilaterales de Brasil. Allende que sus consideraciones se asemejan más a afirmaciones que a argumentaciones, agrega que esos entendimientos contribuirían a aumentar el peso específico de cada contraparte (sin esbozar 
conceptualmente por qué razones específicas, países de diferente perfil y tamaño pueden obtener esa ventaja al acordar con la RFdB). Y no conforme con ello, afirma que esa red puede inhibir a una potencia -interna o externa a la región- que muestre una influencia excesiva (Souto Maior, 2006). Notable resulta que no precisa para qué actor de la región puede resultar efectivamente una influencia excesiva (si para uno de los miembros del acuerdo, para el Mercosur como tal, o para otro bloque regional). Algo sí no puede dudarse: la dimensión de defensa otorgada a acuerdos comerciales presentados también como reaseguro para la paz en la región:

Por definición, un país en desarrollo que pretende una mayor proyección externa -fuere en el ámbito regional o internacional- no tiene los medios de alcanzar ese objetivo sin la participación de otros pares. Esa circunstancia es uno de los factores que ha llevado a multiplicar los acuerdos económicos regionales. Ellos pueden contribuir a aumentar, en diferentes grados, el peso específico de cada uno de los participantes. Pueden también ser utilizados para inhibir a una potencia interna o externa a la región de ejercer una influencia excesiva en asuntos regionales (Souto Maior, 2006: 51 [traducción propia] ${ }^{3}$.

Si continuamos con el texto, deducimos cuál es la influencia específica que Brasil -no necesariamente las contrapartes- quiere evitar: Estados Unidos. El autor comenta la decisión de no invitarlo a la Primera Reunión de la Cúpula de Asia Oriental donde se reunió la ASEAN, China, Japón y Corea del Sur a la que se sumó Australia, India y Nueva

\footnotetext{
${ }^{3}$ Del original: Por definição, um país em desenvolvimento que aspira a uma maior projeção externa seja em âmbito regional, seja internacional - não tem os meios de conseguir tal objetivo sem o concurso de outros. Tal circunstância é um dos fatores que têm levado à multiplicação dos arranjos econômicos regionais. Eles podem contribuir para aumentar, ainda que em diferentes graus, o peso específico dos participantes individuais. Podem também ser utilizados para inibir uma potência de dentro ou de fora da área de exercer uma influência considerada excessiva em assuntos da região.
} 
Zelandia. Y asegura que la exclusión no reviste hostilidad hacia Washington sino la limitación de su intrusión considerada actual o potencialmente intrusiva:

La primera reunión de la Cumbre de Asia Oriental (...) es un buen ejemplo de este último caso (...) Aparentemente, la mayoría acordó evitar una presencia norteamericana que pudiese alterar las bases de una 'Comunidad del Asia Oriental' dotada de 'valores comunes' (...) Dados los lazos políticos entre los Estados Unidos de Norteamérica y algunos países presentes, no se iba a poder hablar de la hostilidad en relación a Washington sino de un supuesto deseo de limitar una intrusión considerada potencial o actualmente excesiva, por lo menos por algunos países de la región (ibídem, página 52 [traducción propia] $\left.^{4}\right)$.

Así, designó al Mercosur como la plataforma de construcción hemisférica que le permitía extender mercados al abrirlos y hacer competitiva internacionalmente a su economía desde una zona geoeconómica del Cono Sur. Lo que, además, permitía resguardar un margen para ejercer un mayor proteccionismo (imposible en un esquema como el del ALCA). Esta estrategia intermedia tenía por fin construir prestigio y poder frente a Estados Unidos, sólo que estaba pensada sin consensuar con la Argentina (a pesar de reconocerla y seguir afirmando esta relación como el eje de la integración del bloque).

Así, Brasil atrajo a la Comunidad Sudamericana de Naciones a Chile, Surinam y Guyana, para lograr la posterior UNASUR centrada en el desarrollo del proyecto IIRSA. Pero esta

\footnotetext{
${ }^{4}$ Del original: A primeira reunião de Cúpula da Ásia Oriental, realizada na Malásia (...) é um bom exemplo deste último caso (...) Aparentemente, a maioria concordou em evitar uma presença americana que poderia perturbar as bases de uma "comunidade da Ásia oriental" dotada de "valores comuns" (...) Dados os laços políticos entre os EUA, e alguns dos países presentes, não se poderia falar de hostilidade em relação a Washington, mas de um aparente desejo de limitar uma intrusão considerada potencial ou atualmente excessiva, pelo menos por alguns países da região.
} 
construcción de liderazgo no se agotaba en Sudamérica, sino que era la base de un norte depositado en el ejercicio efectivo de una potencia emergente. Bernal-Meza (2008) refiere a esto señalando como un error haber asumido esa estrategia carente de costos económicos (aspecto también mencionado en un trabajo previo de 2006):

Las aspiraciones del gobierno Lula, de reforzar la vocación internacional del país, sin ataduras que menoscaban su capacidad de decisión autónoma sobre la economía nacional, crearon limitaciones al progreso institucional del Tratado de Asunción, a pesar de las sucesivas negociaciones. A pesar de los objetivos estratégicos que el Brasil se ha propuesto con el Mercosur, paradójicamente, ese país mantiene la presunción de que puede asumir un liderazgo regional sin pagar costos económicos (Bernal-Meza, 2006[a]). Sin embargo, para el proceso de integración el eje del Mercosur sigue siendo la relación Brasil-Argentina, cuestión que el gobierno de Lula se ha esforzado en dejar en evidencia, tanto en sus viajes fuera de la región como a la Argentina (Bernal-Meza, 2008: 162)

En esencia, este trabajo de Bernal-Meza nos permitió vislumbrar factores clave en la construcción de nuestra hipótesis: por un lado, la imbricación de la política regional y la mundial brasileña expresada en su estrategia de cooperación Sur-Sur sudamericana y potencias regionales (China, India, Rusia, África del Sur y la celebración de la Cumbre entre países sudamericanos y los países de la Liga Árabe); y por otro lado, sus pretensiones extra regionales (como la conducción de la Organización Mundial del Comercio (OMC), la aspiración al Concejo de Seguridad, la preeminencia en las negociaciones Unión Europea - Mercosur, entre otras demostraciones de una actividad determinada por el poder en política exterior).

El segundo factor clave para la construcción de nuestra hipótesis se encuentra en un trabajo de 2009, en el que mientras indaga la política exterior de Brasil y Argentina en 
relación a los procesos de integración y cooperación hacia el Mercosur, nos aporta las características generales del perfil del regionalismo brasileño: una orientación sudamericana (que no latinoamericano, por lo que excluye a América Central), un perfil contra hegemónico (en tanto que su finalidad, pero esto no le impidió incluir países que no poseen ese perfil como lo fueron sus buenas relaciones con la Colombia de Uribe), y por último, la característica que ya hemos esbozado, es decir, la de ser una herramienta activa -e invaluable- al servicio de la instrumentación de la política exterior brasileña.

El segundo impulso para la construcción de un objeto aún muy tentativo, fue un tramo del desarrollo de Luiz Souto Maior (2006) acerca de la postura brasileña con respecto al regionalismo continental. Aquí retoma la noción ya referida ${ }^{5}$ como nueva asertividad de la política externa brasileña bajo la gestión nacional 2003-2010, para el pasaje -y la decisión- desde un Brasil proactivo en el escenario externo a su explícita aspiración de devenir potencia emergente. El carácter explícito de este norte para su política exterior tiene tres características que creemos determinantes: En primero lugar, la 'naturalidad' (sic) que reviste en un país de las magnitudes de Brasil al concebirse primus inter pares:

Es normal que un país con las dimensiones territoriales, demográficas y económicas alcanzadas por Brasil aspire a tener, en la escena internacional,

\footnotetext{
${ }^{5}$ Cf. Souto Maior, Luiz (2003): Desafios de uma Política Externa Assertiva en Revista Brasileira de Política Internacional, año 46, Número. 1. pp: 12-34. Si bien en este trabajo el autor aborda la plataforma del entonces flamante presidente, escogimos, en cambio, la caracterización que realiza en 2006, donde encontramos notas de la implementación concreta de la nueva orientación de política exterior.
} 
un papel más determinante y se perciba primus inter pares en América del Sur (Souto Maior, 2006: 57 [traducción propia] ${ }^{6}$ )

En segundo lugar, el alejamiento de la práctica tradicional brasileña de negar ambiciones de liderazgo subcontinental; y en tercero, asumir las consecuencias que tal cambio podría acarrear: es decir, potenciar rivalidades y recelos regionales preexistentes (Souto Maior ilustra esta cuestión con las resistencias -aunque no especifica qué países- con respecto a su aspiración al Consejo de Seguridad o el apoyo al candidato oriental en vez del brasileño a la candidatura de la dirección de la Organización Mundial del Comercio), que, eventualmente, alcancen conflictos de interés y el surgimiento de liderazgos subregionales en disputa con Brasil (aquí señala la retórica fluctuante de Morales -que osciló entre colocar a Bolivia como su principal abastecedor energético hasta declarar que Petrobras operaba en su país en condiciones ilegales e inconstitucionales, para luego dejar más lugar a Venezuela).

Además, hace una consideración muy importante para nuestra hipótesis: considera la expresión potência emergente para los países en desarrollo que implementan una política exterior no sólo circunspecta al progreso económico sino además a una mayor proyección externa (Souto Maior, 2006). Es necesario enfatizar las implicancias que creemos tiene esta idea: la política exterior deviene también en juego [de política] de poder -es decir, la búsqueda de la acumulación de poder subregional/regional/

\footnotetext{
${ }^{6}$ Del original: É normal que um país com as dimensões territorial, demográfica e econômica alcançadas pelo Brasil aspire a ter, na cena internacional, um papel mais marcante e se perceba primus inter pares na América do Sul.
} 
hemisférico o global-, y no sólo un medio de colocar al país en determinado lugar y plantear objetivos que hagan a un fin extra-político (como puede ser el desarrollo):

Para Brasil - que se percibe como una potencia emergente y es progresivamente apreciado como tal internacionalmente - (Souto Maior, 2006: 54 [traducción propia] ${ }^{7}$ ).

Este rol no podía ser construido en vacío, por lo que necesitaba también de un fortalecimiento institucional del Mercosur junto con la demanda de una progresiva conformación de una política exterior consistente entre sus miembros, e imbricar también el avance de la integración de toda América del Sur. Eran precisamente todos estos componentes los que determinaban las aspiraciones de Brasil que, si bien ambiciosas, no podían ser logradas en soledad o basado en su exclusiva (individual) voluntad de liderazgo externo. Y con esto enlazamos la mentada democratización de las relaciones internacionales ${ }^{8}$, que conforma una plataforma de la mayor amplitud posible sentada bajo fuertes vínculos bilaterales con países desarrollados y en desarrollo (aquéllos con la suficiente importancia geopolítica y económica), red que permitiría a Brasil una futura cooperación en organismos multilaterales. Así, la asertividad no se orientaba sólo al interior de la región, sino que colocaba a Brasil en la tarea de estimular la multipolaridad extra regional:

\footnotetext{
${ }^{7}$ Del original: Para o Brasil - que se percebe como uma potência emergente e é crescentemente visto como tal internacionalmente-.

${ }^{8}$ Esta expresión pertenece al discurso de asunción del mando de Da Silva: en mi gobierno, la diplomacia de Brasil estará orientada por una perspectiva humanista y será principalmente un instrumento de desarrollo nacional (...) La democratización de las relaciones internacionales sin hegemonías de cualquier tipo es tan importante para el futuro de la humanidad como la consolidación y el desarrollo de la democracia al interior de cada Estado. Valorizamos a las organizaciones multilaterales, en especial a las Naciones Unidas, a la que le cabe la primacía en la preservación de la paz y la seguridad internacional" [traducción propia] (Ministerio das Relações Exteriores, 2003)
} 
Tal aproximación refiere no sólo a los beneficios mutuos directos, sino también a la cooperación en organismos multilaterales, de cara a la consecución de los ya mencionados objetivos más amplios de reforma de la vida internacional. La creación del G-20, en la víspera de la reunión ministerial de la Organización Mundial del Comercio (OMC), en Cancún, y la del G4, en la esfera de la ONU, con miras a la reforma del Consejo de Seguridad, en el cual nuestro país aspira a tener un asiento permanente, grafican la nueva orientación de la política exterior brasileña (Souto Maior, 2006: 43 [traducción propia] ${ }^{9}$ ).

Esta evolución hacia la potencia emergente tendría algún tipo de refracción en el Mercosur. A su interior, el problema principal residía en que un política exterior hiperactiva y de alto perfil no haría más que azuzar conflictos pre-existentes, como, al interior, la falta de una instancia de solución de controversias ante las fricciones por el proteccionismo argentino o la asimetría entre los dos socios mayores frente a los menores $-\sin$ mecanismos compensatorios eficaces- ${ }^{10}$. $Y$ a su exterior, encontramos a Washington resignando la idea de un área de libre comercio para el continente, pero negociando por separado con diferentes países de la región, lo que por supuesto afectaría de manera mediata al Mercosur. En esta suerte de encrucijada -o, mejor dicho, en la coyuntura de procesos que no evolucionarán de manera inmediata por la magnitud de las trabas que los condicionan-, el autor afirma que sin perjuicio de

\footnotetext{
${ }^{9}$ Del original: Tal aproximação visaria não apenas a benefícios mútuos diretos, mas também à cooperação em organismos multilaterais, com vistas à consecução daqueles mencionados objetivos mais amplos de reforma da vida internacional. A criação do $G-20$, às vésperas da reunião ministerial da Organização Mundial de Comércio (OMC), em Cancun, e a do G-4, no âmbito da ONU, com vistas à reforma do Conselho de Segurança, no qual nosso país aspira a um assento permanente, ilustram a nova orientação da política externa brasileira.

${ }^{10}$ El autor señala aquí la lejanía que parece revestir para Brasil lograr impulsar una política externa común, sin haber logrado alcanzar el cumplimiento de algunos compromisos del Tratado de Asunción siquiera. A ello agrega dos condiciones para avanzar (no logradas): la primera, los acuerdos políticoeconómicos más profundos con la Argentina, y la segunda es una suerte de compensación a la falta mecanismos que atiendan las asimetrías: la creación de condiciones más favorables en las zonas más problemáticas tomando el modelo europeo de integración.
} 
fortalecer el Mercado Común del Sur, Brasil debería avanzar bilateralmente gracias a su poder de atracción regional económica, fundado en el incentivo de los demás países a acordar por el acceso a su mercado (siempre y cuando se limasen algunas cuestiones de las reglas de origen y se estableciese una red infraestructural -energética, de transporte terrestre y fluvial-, que mejorase los intercambios). De este modo, se abandonaría el gran proyecto plurinacional sudamericano por la competición bilateral, para lo que Souto Maior asegura que el éxito de esa sinergia de intereses bilaterales diversos podría derivar en la eventual conformación de un arreglo plurilateral sudamericano o de diversos esquemas subregionales de cooperación e integración. Y, claro está, Brasil debía ser el foco de esa red bilateral, pieza clave de la 'cercanía regional' (aproximação regional), sin tener que reparar en una estructura institucional o en el establecimiento de un sistema multilateral de integración económica suramericano para avanzar al único tipo de integración que lo favorece netamente:

Esa base debería ser provista por la única forma de regionalismo continental que, con realismo, es conveniente: un sudamericanismo que promueva los intereses brasileños dentro del respeto a las particularidades, sensibilidades y susceptibilidades de nuestros vecinos (Souto Maior, 2006: 58 y 59 [traducción propia] $^{11}$ )

Souto Maior asegura que esta configuración acabaría por desactivar la aspiración a un liderazgo brasileño del discurso político o de eventuales proyectos regionales -no aclara cuáles $^{12}$ - pero, paso seguido, lo reafirma como una práctica, sólo que derivada

\footnotetext{
${ }^{11}$ Del original: Tal base teria de ser dada pela única forma de regionalismo continental que realisticamente nos convém - um sul americanismo que promova os interesses brasileiros dentro do respeito às peculiaridades, sensibilidades e suscetibilidades de nossos vizinhos

${ }^{12}$ Literalmente: De nosso discurso político ou de eventuais projetos brasileiros de âmbito regional (ibidem, página 58)
} 
de condiciones objetivas a partir de iniciativas limitadas exitosas -no aclara cuáles pueden ser- que harían que los demás miembros no hagan lo que el líder dice, sino que quieran lo que él quiere:

En tanto que aún existiese en la práctica, esa noción derivaría de las condiciones objetivas creadas por iniciativas limitadas que, si son exitosas se orientaron (...) a conseguir que otros quieran lo que el líder quiere y no sólo que hagan lo que éste desea que sea hecho (ibídem, página 58 y 59

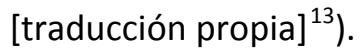

Si bien en estos dos autores ya pudimos condensar unas intuiciones sólidas para nuestro avance, aún restaba conformar un espacio analítico de lo que luego sería la primera parte de la hipótesis: la noción de alianzas estratégicas (parcerias estratégicas). Para ello, el texto de 1999 de Alcides Costa Vaz fue ineludible: aun cuando no es tan reciente, resiste perfectamente el tiempo.

Costa Vaz otorga importancia basal a los patrones de relacionamiento bilateral con países y bloques consolidados (por los cimientos efectivos que producen en una estrategia de emergencia al mundo), lo que para el Brasil de fin de siglo se justificaba en permitir realizar los intereses nacionales $a d h^{14}$ que los objetivos internos y/o

\footnotetext{
${ }^{13}$ Del original: na medida em que ainda existisse na prática, tal noção derivaria das condições objetivas criadas por iniciativas limitadas que, se bem-sucedidas, iriam no sentido (...) de conseguir que outros querem o que o líder quer e não apenas que façam o que ele deseja seja feito.

${ }^{14}$ La lógica de las alianzas estratégicas implica no definición previa de su función y contenidos (es decir, no puede decirse taxativamente a qué fines intermedios se orientarán para luego a partir de ellos abonar a los intereses brasileños): son producto de la coyuntura dinámica -interna y externa- y del modelo de desarrollo escogido. Sin estar determinadas por consideraciones ideológicas o culturales, las
} 
externos de los involucrados dictasen. Brasil ha concebido antaño la construcción de parcerias estratégicas para acceder a recursos, insumos y oportunidades funcionales al proceso de desarrollo nacional, por lo que esto no es nuevo ${ }^{15}$. Pero el autor (nos) brinda la dimensión regional y propone que ellas sean pensadas como una herramienta aplicable al Mercosur (aun cuando sus bondades puedan no ser automáticas y no quede excluido el riesgo de alguna molestia entre sus socios). Dado que son de carácter instrumental, Costa Vaz asegura que mantienen una perspectiva universalista, son versátiles, oportunas, y demuestran su pragmatismo -que el autor denomina realismo- (página 76). Esta disponibilidad obliga a que el contenido que se les dé durante una determinada gestión, observe los impactos sobre el Mercosur en términos del grado de convergencia entre los objetivos brasileños a los que apuntan vis à vis los impactos que provocan en otros miembros -principalmente Argentina-:

En ese sentido, sus consecuencias para el Mercosur deben ser consideradas según condiciones especificas, considerando el grado de convergencia entre las prioridades que se vinculan y aquellas definidas por los demás socios del Mercosur, con especial énfasis en la Argentina. De forma general, el esfuerzo brasileño en dirección de refuerzo y diversificación de las alianzas no es compatible con la prioridad dada a la profundización del Mercosur, al contrario, despliega posibilidades importantes en términos de las relaciones externas del bloque (Costa Vaz, 1999: 76 y 77 [traducción propia] ${ }^{16}$ )

hubo orientadas al desarrollo nacional, a un entendimiento con países centrales y en desarrollo, como también existieron formas mixtas que combinan diferentes objetivos (Costa-Vaz, 1999)

${ }^{15}$ Como China en los ochentas del siglo pasado (Cf. ABDENUR, Roberto. O Brasil e a nova realidade asiática: uma estratégia de aproximação. Política Externa, 2 (3): 43-69, 1994), o bine España (Cf. MARLOVA, Noleto (2000): Parcerias e Alianças Estratégicas: uma abordagem prática, São Paulo: Instituto Fonte; y LORANGE, Peter (1996): Alianças Estratégicas: formação, implementação e evolução, São Paulo: Atlas)

16 Del original: Nesse sentido, suas implicações para o Mercosul devem ser consideradas a partir de condições específicas, considerando o grau de convergência entre as prioridades a que se vinculam e aquelas definidas pelos demais sócios do Mercosul, com particular ênfase à Argentina. De forma geral, o esforço brasileiro no sentido de reforçar e diversificar parcerias não é incompatível com a prioridade 
Si bien este trabajo es de 1999 y no reconoce el perfil que la política externa tendría post 2003, sí menciona un aspecto interesante para que veamos, gracias a la perspectiva histórica, a la luz de la política exterior de la gestión Da Silva y el Mercosur: Costa Vaz asegura que reforzar y diversificar las alianzas no sería incompatible con la prioridad de la profundización del Mercosur e incluso puede abrir posibilidades en términos de las relaciones externas del bloque como un todo. Sólo se precisa un requisito:

Lo que es necesario revisar de aquí en más, será en qué medida estos avances están también reflejados en la disposición y las posibilidades de cada país del Mercosur, y en especial de Brasil, de incorporar el espacio comunitario a los distintos ejes bilaterales que conforman las opciones de alianzas estratégicas en el presente ${ }^{17}$ (Costa Vaz, 1999: 77 [traducción propia $^{18}$ )

Lo destacable de este trabajo es la constante afirmación de la necesidad legítima de apelar a un instrumento pragmático (como herramienta nacional o regional, es decir, implementada por países o bloques) que requiere de mayor coordinación entre las acciones bilaterales y objetivos regionales. La razón es obvia: por un lado, la mayor

conferida ao aprofundamento do Mercosul; ao contrário, abre possibilidades importantes em termos das relações externas do bloco

${ }^{17}$ Además, Costa Vaz aclara que no se trata de uniformizar agendas políticas externas, sino de coordinar esfuerzos lo suficientemente flexibles para no chocar con los intereses y necesidades de cada miembro, y los compromisos de ellos al interior del Mercosur. A fines del milenio anterior, el autor veía una agenda creciente para el Mercosur, y pensaba las alianzas estratégicas también como un desafío para Brasil, quien debería congeniar su vocación universalista y conservar grados de libertad para la construcción de las propias alianzas, con la coordinación y el equilibrio que precisa la dinámica del Mercosur

${ }^{18}$ Del original: $O$ que é necessário avaliar doravante é em que medida esses avanços estão também refletidos na disposição e nas possibilidades de parte de cada país do Mercosul, e sobretudo do Brasil, de incorporar o âmbito comunitário aos distintos eixos bilaterais que conformam opções de parcerias estratégicas no presente (Costa Vaz, 1999: 77) 
complejidad que revisten relaciones mediadas por acuerdos de diferente alcance, pero, por otro lado, y aún en un escenario complejizado, vemos que una estrategia pragmática no excluye acuerdos centrados, también, en el beneficio que unos países integrados. Más aún, al referirse a las negociaciones con la Unión Europea y el ALCA, Costa Vaz ve plausible la dinámica de sostener acuerdos bilaterales mientras se integra un bloque, y pone en relación: los bilaterales pueden favorecer -y ser instrumentados con armonía- con los regionales, y éstos pueden ser tenidos en cuenta a la hora de diseñar los intereses de aquéllos.

Desde ya que las indagaciones -al principio fragmentarias, luego más consistentesjunto con la labor heurística que requirió la construcción problemática de un sector de la realidad regional de nuestro interés, fueron mayores que estos tres trabajos aquí señalados ( $y$ en gran parte pueden ser cotejadas en la bibliografía final). Pero decidimos exponer y condensar ese proceso en esta tríada -su orden de exposición tampoco es azaroso- porque reflejan la primera parte de nuestra hipótesis: la especificidad de la política exterior brasileña en general, y como ella se imprimiría en la integración en particular, dentro del período recortado con Souto Maior, la ampliación de ese foco para obtener contexto en la visión general y procesual de los trabajos de Bernal-Meza, y, el de Costa Vaz nos brindó el comienzo de una especificidad analítica de la búsqueda de herramientas concretas- con que captar aquél universo (por supuesto no nos quedaríamos con esta sola, sino que sería la primera herramienta, pero el sólo hecho de recuperarla nos permite plantear una piedra de toque). 
Sin poner en relación estas tres cuestiones (nuestro foco de interés, contexto y herramienta analítica que nos permita comenzar un camino práctico), no hubiésemos podido avanzar al momento teórico-práctico donde reside la construcción propia de nuestro problema: cotejar el impacto de la política de poder del socio con más peso relativo en el bloque (y de la región y subregión) en un proyecto de integración regional creado para fines muy diferentes de ese tipo de política que aquí denominaremos, sólo provisoriamente, (neo)realismo. 
De manera general, en estas líneas nos interesará el rol que Brasil otorga al Mercosur en su esquema de política externa durante la gestión Da Silva vis à vis los fines de la integración regional suramericana a lo largo de su cuarto de siglo de historia. Pero para precisar esta cuestión necesitamos destacar el núcleo problemático que recorreremos, donde se hace imperioso recuperar primero algunas cuestiones teóricas acerca del regionalismo como tal -su devenir, sus características- para luego poder plantear el problema de investigación que guiará estas líneas. Éste no es otro que nuestra pregunta principal: las consecuencias del ejercicio pragmático de la política externa de uno de sus miembros para un bloque regional orientado a otros fines.

Para respondernos esta cuestión, precisamos de un insumo teórico previo, implícito en esta pregunta, y que fuera determinante en el proyecto de investigación de esta tesis: las reconfiguraciones que la integración suramericana ha recorrido en el tiempo. Este primero (gran) insumo teórico, nos permitirá, luego, a lo largo del cuerpo de la tesis, presentar un recorrido teórico-conceptual de la conducta brasileña durante la gestión 2003-2010. Para la resolución de este abordaje, introduciremos un constructo analítico que denominamos estrategia de poder global brasileña, la cual define el perfil de la acumulación de poder del vecino luso parlante. Por supuesto, ese perfil alcanza a 
muchos más aspectos y dimensiones que el Mercado Común del Sur (los cuales serán referidos sintéticamente), pero en estas líneas sólo especificaremos el caso de la integración suramericana.

En el siguiente apartado nos interesará especialmente las motivaciones depositadas en esas diferentes configuraciones de la integración regional (fuere que se hayan concretado o no), para así poder cotejar los diferentes fines a los que la integración puede servir. Ver sus características, sus continuidades y rupturas nos mostrará procesos colectivos sostenidos por unidades individuales en extremo complejas como son los Estado-miembro, los que conllevan fines que, si bien resultan muy diferentes a lo largo de las décadas, aún se basan en los potenciales beneficios que puede reportar para cada uno, el participar y sostener el bloque.

Para estas líneas, la dimensión individual/colectiva es el gran divisor de aguas para los fines que la integración revistió en el período 2003-2010. En esta coyuntura, la voluntad colectiva de una región -a fines de autoafirmación regional - bañó los bloques, por la vía del perfil contra hegemónico de las y los presidentes de la región (e incluso motivó la conformación de esquemas nuevos como la UNASUR, nacidos a la luz de esa impronta). De este modo, si bien autoafirmación puede ser una manera lo bastante adecuada de caracterizar el perfil de la integración del nuevo milenio (aunque no por ello infalible, dado que es un pilar magro para sostener la complejidad de un proyecto integrador, como podemos cotejar en la ALBA-TCP), tal cualidad siempre implicó a los miembros en bloque frente a diferentes actores -individuales y colectivos- 
, del sistema internacional. En nuestro período, una integración surgida a la luz del regionalismo abierto como lo fue el Mercosur, resultó ser parte de los intereses nacionales de un sólo miembro, para una carrera que no tenía necesariamente por fin el engrandecimiento de la región, sino otro sector del espectro que ese interés nacional recorre: el de forjar en el mediano plazo un nuevo rol para Brasil en el concierto global. 
Fines y motivaciones de la integración suramericana

La integración regional en América del Sur se ha mantenido, en su mayor parte, dentro del horizonte económico (lo que por supuesto no obsta avances de menor alcance en otras dimensiones (Pey y Riquelme, 2007)). Esto no reviste necesariamente algo negativo, de hecho, creemos como Bernal-Meza (2009), que la integración económica resulta muchas veces un factor movilizador de otras esferas de las cuales, además, no está escindida (tanto en una región como fuera de ella), y esto no es otra cosa que las dimensiones políticas, culturales, sociales. Asimismo, esa afirmación no obsta destacar que el camino de la integración debería haber excedido este horizonte: América Latina ha decidido centrar su integración regional en la conformación de zonas de libre comercio (y la ha visto como la precondición para las otras integraciones posibles) ${ }^{19}$.

Dado el grado de integración alcanzado (se lo considere una unión aduanera 'imperfecta' o alguna forma de área de libre comercio ${ }^{20}$ (Cabarcas; González Arana;

\footnotetext{
${ }^{19}$ Con esto nos hacemos eco de la idea de Vieira Posada (2008), acerca de la identificación entre integración regional y articulación en zonas de libre comercio, sin dar cuenta de un debate teórico que podría conducir a una integración multidimensional. Cf Vieira Posada, Edgar (2008): La formación de espacios temporales en la integración de América Latina, Bogotá: Convenio Andrés Bello)

${ }^{20}$ La nominación de ZLC para el Mercosur resulta, cuando menos, discutible: mientras se lo suele indicar como una UA imperfecta (por la cobertura parcial del Arancel Externo Común -AEC-, pervivencia de aranceles intrarregionales y régimen de incentivos a exportaciones entre los miembros (González-Arias, 2013)), también podemos afirmar que el bloque efectivamente posee una tarifa externa común imperfecciones incluidas- (Bartesaghi. 2014). Por otro lado, el argumento complementario también sería cierto: el adjetivo 'imperfecta' (o 'incompleta', incluso 'flexible') agrega poco si pensamos en la poca voluntad de renunciar a funciones soberanas aduaneras de los miembros (Cardona Montoya, 2013).
} 
Galofre Charris, 2013)), y sin dudar que la integración es más ventajosa que inconveniente para sus miembros (Alonso, 2013), podemos afirmar que a lo largo del tiempo el bloque atravesó diferentes configuraciones. Esos cambios en el tiempo son reconocidos en la teoría como generaciones (Langenhove y Coesta, 2004; citado en Giacalone, 2006), donde la regionalización aparece con rostros diferentes (French Davis, 2000).

Si nos remontamos a los comienzos, encontramos al regionalismo de primera generación (Botto, 2004) o primer regionalismo (Bhagwati, 1999), nacido en un mundo aún bipolar y determinado por un modelo de desarrollo compartido de corte cepalino (es decir, de 'desarrollo hacia adentro' sostenido por la voluntad (Rosenthal, 1991)). Este regionalismo tenía intereses en seguridad, dada su coyuntura en el conflicto EsteOeste (Hettne, 2002; Rodríguez Suárez, 2012). Y dentro de este aspecto, señalemos la cuestión ineludible: la exclusión sin oposición directa de Estados Unidos (y es un factor intrínseco a la integración latinoamericana, dado que todos los regionalismos -y esta primera generación no es la excepción- han tenido que oscilar y lidiar en la conformación de bloques con o sin la inclusión del hegemón (Bernal-Meza y Masera, 2008)). Si bien en esta primera oleada, los grados de autonomía residen en las políticas de desarrollo, pero las organizaciones regionales de seguridad están presentes dada la

Bouzas se ha referido a la cuestión de la adjetivación y su utilidad $(2002,2003)$ pero recientemente lo ha denominado 'precaria área de libre comercio' (2013). La razón reside no ya en las excepciones -azúcar, automotriz- sino de la inestabilidad de acceso a los mercados, las restricciones no tarifarias distorsionantes y la ineficacia normativa. En este texto Bouzas se desembaraza de la discusión académica acerca de la clasificación en una u otra categoría, y mira lo alcanzado: un Mercosur de más de veinte años mucho menos profundo que la CEE cuando tenía sólo una década (e incluso menos que el propio NAFTA). 
bipolaridad: Sanahuja (2012) referencia aquí el rol de la Organización de Estados Americanos (OEA) y la importancia insoslayable del Tratado Interamericano de Asistencia Recíproca (TIAR).

Por la activa intervención estatal, se ganó la cualidad de regionalismo desde arriba (Hettne, 2002)-, en un período en que el Estado tenía la injerencia social suficiente para velar por el bienestar: desde los cincuentas al final de los ochentas del siglo pasado (Santos Carrillo y Caldentey del Pozo, 2014). Por supuesto tuvo como parámetro -y quizás norte- al proceso de integración progresivo de la entonces Comunidad Económica Europea (patrón presente en el segundo regionalismo también). Tuvo como motor una industrialización por sustitución de importaciones (ISI) por lo que asumió así un rol proteccionista ante las exportaciones de países desarrollados, con fines político-estratégicos (Barbeiro y Chaloult, 2003).

Esta primera generación procuraba el desarrollo económico en clave cepalina -por lo que la integración regional económica era uno más entre otros medios para alcanzarloeliminando las barreras internas al comercio, junto con mantener o aumentar los niveles de protección externa: por esta razón, instrumentó aranceles más altos que los esquemas posteriores (y además poseían reservas políticas y sectoriales). Incluso fijaba excepciones a la masa pasible de liberalización (Mellado, 2006) junto con la extensión de la planificación industrial a escala regional (Sanahuja, 2012) para desviar las importaciones de terceros países hacia la producción intrarregional (Devlin y Estevadeordal, 2001). 
El primero regionalismo se desarrollaba entre países con niveles de desarrollo relativamente similares (Rueda Junquera, 2006) ${ }^{21}$, por lo que los acuerdos resultaban horizontales (es decir, Sur-Sur/Norte-Norte, lo que de suyo implica similares condiciones de desarrollo y un perfil determinado por esa condición). Y, por cierto, cada uno de los miembros pertenecía a un sólo esquema integrador. De esta estructura surge la Asociación Latinoamericana de Libre Comercio (ALALC), el Mercado Común Centroamericano (MCCA), el Pacto Andino (PA), la Comunidad del Caribe (CARICOM) (Vera-Fluixá, 2000), todos ellos acorde las figuras de unión aduanera y zona de libre comercio, excepciones aceptadas en la cláusula de nación más favorecida del conocido artículo XXIV del GATT (Mellado, 2006).

Es necesario no uniformizar en exceso este período: a principios de los setenta, el modelo ISI comenzó a trastabillar en la esfera de la ALALC -crisis del petróleo, desempleo e inflación creciente, exceso de liquidez y por tanto creciente endeudamiento-, a lo que debemos agregar una constante inestabilidad política. Esto contribuyó a que la ALALC pierda fuerza y se conformen grupos regionales más acotados como el Pacto Andino, el CARICOM y el Mercado Común Centroamericano,

\footnotetext{
${ }^{21}$ Esto implicaba también el tratamiento preferencial para las naciones más desfavorecidas (acuerdos asimétricos). Un gran ejemplo para graficar este perfil es el artículo 22 del Tratado de Montevideo: (...) podrán establecerse, dentro de los tratamientos a favor de los países de menor desarrollo económico relativo, acciones de cooperación colectiva y parcial, que contemplen mecanismos eficaces destinados a compensar la situación desventajosa que afrontan Bolivia y Paraguay por su mediterraneidad (...) mediante desgravaciones acumulativas (...) fórmulas de compensación tanto en la preferencia arancelaria regional (...). No obstante, la existencia de este tipo de mecanismo no asegura que las desigualdades sean evitadas. De hecho, Argentina, Brasil y México obtuvieron los mayores beneficios de la ALALC y así incentivaron la formación del Pacto Andino, el que existe para mejorar/compensar la capacidad negociadora de sus miembros (De Prado Alcalde, 1986).
} 
mientras aquélla devino en la Asociación Latinoamericana de Integración (ALADI) hacia 1980. Este relanzamiento en clave neo-estructuralista de la arquitectura regionalizadora, procuró una industrialización con mayor productividad (pero, aun así, sustentable) para alcanzar mayor competitividad sin desatender la equidad. Para esto requería de especial atención especial al sistema educativo, infraestructural, al desarrollo de tecnología, transporte, entre otros (Garrido Carrasco, 2008).

Si los sometemos a balance, estos intentos sólo completaron parcialmente una ZLC -sin AEC-, y tuvieron un desempeño insuficiente en la creación de comercio intrarregional para compensar la potencial ${ }^{22}$ desviación de comercio (Santos Carrillo y Caldentey del Pozo, 2014): recordemos que la desviación ocurre por el aumento de las importaciones intrazona desde los países más grandes hacia los pequeños, lo que implica que el costo lo asumen éstos (mayor salida de divisas y menos percepción fiscal para bienes industriales (BID, 1966)) ${ }^{23}$. Schaposnik, refiriéndose a ALAC, resulta contundente en este aspecto:

\footnotetext{
${ }^{22}$ Planteamos esta cuestión como potencial dado que la afirmación acerca del desvío de comercio como una consecuencia directa y casi inevitable de la integración acarrea compromisos teóricos (en el debate multilateralismo/regionalismo, el primero defiende las bondades del libre comercio para la maximización del bienestar viendo los acuerdos regionales -desde ZLC hasta UA-como focos de desvío de comercio (Bhagwati, Greenway y Panagariya, 1998)). No obstante, las teorías ortodoxas han incorporado las nociones de creación / desvío de comercio, lo que permitió reingresar -e incluso defender- al regionalismo (Ethier, 1998). Aquí lo concebimos una ventaja del sistema multilateral -y una herramienta para su expansión al simplificar negociaciones entre menos actores (Maesso Corral, 2011)-, como el avance de ARC junto a la liberalización multilateral, reduciendo así el potencial discriminatorio. Maesso Corral afirma que la conformación del propio Mercosur indujo a los miembros a reducir aranceles a terceros en sectores donde los efectos potenciales de desviación de comercio eran significativos.

${ }^{23} \mathrm{Y}$ es una de las razones de los países medianos para acordar en Cartagena (Schaposnik, 1989).
} 
El alegado crecimiento comercial de los primeros años, que permitía justificar la utilidad del modelo, es un dato relativo. Creció el comercio sobre cifras tan exiguas, que aún hoy [en 1989] el intercambio intra-latinoamericano es insignificante como si ni hubiera existido la ALALC (1989: 18).

Las razones residieron en las dificultades para conformar un mercado ampliado entre economías poco interdependientes -por la ausencia de canales comerciales y financieros- y subdesarrolladas. La integración no alcanzó para incentivar la expansión del intercambio, tampoco para estimular la especialización intraindustrial (Ferrer, 1978). Además, la falta de desarrollo armónico, de programación industrial común (sin regulación de qué empresas ingresarían al mercado, las corporaciones trasnacionales seguían prevaleciendo), de políticas comunitarias con relación a la IDE y de atención a las asimetrías (Schaposnik, 1989) ${ }^{24}$, el fracaso era previsible. Así, sin atender productividad, tecnología y salarios, la rebaja arancelaria resultó un factor de diferentes consecuencias para cada país (ibídem), y cada uno tenía incentivos a priorizar el bienestar individual.

Haas, en 1966, mencionó que el modelo de la ALALC entraba en estancamiento gracias a que las desgravaciones no iban acompañadas de creación de empresas, y los grupos políticos y sociales no daban la posibilidad de apoyar la integración más allá de los avatares de la política doméstica. Esto originó asimetrías que no desembocaron nunca en una plataforma común de los integrantes para seguir avanzando. Y no sólo fueron

\footnotetext{
${ }^{24}$ Resulta especialmente grave una mención que hace Schaposnik (1989) a la hora de evaluar el proceso: a finales de la década de los ochentas, década del (re)lanzamiento de la ALADI, no se disponían de datos empíricos como para evaluar desempeño, tendencias o resultados macroeconómicos.
} 
cuestiones intrínsecas al diseño del esquema y su devenir dinámico regional lo que desdibujó las esperanzas iniciales: como señala Russell y Kalinsky (1986), existieron factores externos que influyen de manera indirecta estos procesos, como la transnacionalización de la economía en los setentas -lo que dio impulso a sectores opuestos a la integración- y la emergencia de dictaduras militares en la región, también poco favorables a ella.

Pero allende lo anterior, no todo es resto: es innegable que esos procesos dinamizaron (algunos) intercambios regionales y crearon instituciones basales que promoverán el impulso integracionista de la generación siguiente. En este regionalismo primigenio, el norte residía en la implementación estatal de esquemas de integración al servicio de la optimización endógena de procesos económicos (Giacalone, 2006), pensados a la luz del logro futuro de la unidad política (Hettne, 2002).

Si ahora avanzamos hacia finales de los años ochenta (sin detenernos hasta el primero lustro del nuevo milenio (Sanahuja, 2009)), encontraremos el segundo regionalismo (Bhagwati, 1999) o nuevo regionalismo (Bouzas, 2005; Rueda-Junquera, 2009), regionalismo estratégico (Briceño Ruiz, 2001), regionalismo más abierto (Bernal-Meza, 2009) o bien, la acepción más conocida tanto en la literatura académica y el discurso no especializado: regionalismo abierto. Esta nueva oleada, profundiza el objetivo del aumento de la competitividad -aspecto que ya estaba presente en la transición de la 
ALALC a la ALADI-, por vía de una mayor apertura acorde a la dinámica comercial y financiera exterior de entonces, pero manteniendo la compatibilidad de los acuerdos regionales. Esta apertura externa de los acuerdos era selectiva, mientras se potenciaba aún más la apertura intrarregional -y otros aspectos como la armonización de normas comerciales y laborales-, acción que debía ser acompañada por un fortalecimiento institucional regional (creación de mecanismos de consulta, resolución de conflictos) y una mayor atención sobre cuestiones pertinentes que no sólo recaen sobre la esfera regional como las normas migratorias (Garrido Carrasco, 2008)) ${ }^{25}$.

A diferencia del casi lugar común que lo señala como neoliberal de manera neta, la CEPAL no se retira de su promoción (antes, por el contrario, la vehicula). Sólo que lo que escoge como pilar para el fomento de la integración resulta diferente a lo que las décadas anteriores había guiado el proceso. Así, el estructuralismo es reemplazado por la transformación productiva entendida como apertura gradual y progresiva ${ }^{26}$ en clave neoliberal (Bernal-Meza, 2005a), que en América Latina se encajaba con un pasado reciente signado por el Consenso de Washington post-crisis de la deuda. De este modo, llama a ese cambio de dinámica interdependencia económica a nivel regional, alcanzando la combinación de acuerdos preferenciales de integración con otras

\footnotetext{
${ }^{25}$ En la reconfiguración externa que brinda la coyuntura para el regionalismo abierto no se encuentra solamente la globalización, sino también el fin del mundo bipolar. Ello tiene consecuencias en múltiples niveles: al mayor nivel, relaja las rigideces diplomáticas. Pero también disminuye la enorme atención de antaño en cuestiones militares para desplazarse hacia las económicas, a través de la competencia interestatal y la economía de mercado que se asienta progresivamente como el único patrón de intercambio global (Ibáñez, 2000).

26 El regionalismo abierto como tal era un aspecto concreto de la CEE con terceros países: se procuraba compatibilizar la consolidación de una UA fuerte, compatible con los marcos multilaterales de la OMC (Caldentey del Pozo y Santos Carrillo, 2014).
} 
políticas en un contexto de apertura y desreglamentación para avanzar a una economía

internacional más abierta y transparente:

Lo que aquí se ha denominado "regionalismo abierto", es decir, un proceso de creciente interdependencia económica a nivel regional, impulsado tanto por acuerdos preferenciales de integración como por otras políticas en un contexto de apertura y desreglamentación [sic], con el objeto de aumentar la competitividad de los países de la región y de constituir, en lo posible, un cimiento para una economía internacional más abierta y transparente. Con todo, de no producirse ese escenario óptimo, el regionalismo abierto de todas maneras cumpliría una función importante, en este caso un mecanismo de defensa de los efectos de eventuales presiones proteccionistas en mercados extra regionales (CEPAL, 1994: 3)

Lo cierto es que el regionalismo abierto podría resultar más fácil de caracterizar al viejo regionalismo por oposición que por semejanza. Resulta más una reorientación, un punto de inflexión, que una progresión de su precedente. Aún al atender los aspectos similares -como su base en la dimensión económica-, más temprano que tarde afloran diferencias, y resultan críticas: los objetivos económicos aquí están asociados al comercio $^{27}$-pierde peso el interés en el desarrollo estructural-, el crecimiento se proyecta en la promoción de exportaciones y liberalización del comercio intra e interregional, y la IDE adquiere más peso que antaño (Gil, Caballero Sierra, Corral Strassman, 2002)). No obstante, suele señalarse el factor económico como el divisor de aguas creemos que la cualificación de un regionalismo 'más economicista' sea del todo

\footnotetext{
${ }^{27}$ Es interesante el señalador que coloca Caldente del Pozo y Santos Carrillo (2014) acerca de la lógica controvertida del regionalismo abierto, al indicar que los primeros procesos de integración latinoamericana no contaban con UA o incluso ZLC. Con la segunda oleada de regionalismo se conjuga un bajo nivel de protección con la [esperanza de] preferencia por el comercio intrarregional en un espacio poco integrado (la inserción que prometía la apertura acabaría, en los hechos, por ser más nacional que regional. Lo que, a su vez, debilita progresivamente los incentivos a fortalecer la región).
} 
correcta, dado que el precedente también estaba anclado en esa dimensión. Claro está, somos conscientes que estaba articulada con el desarrollo, y en este caso resultan desplazados hacia la conformación de un bloque como complemento de las políticas aperturistas y así propendería a una mejor inserción en el mercado mundial (Mellado, 2006). De este modo, la diferencia no reside en la dimensión económica igual de importante en ambos-, sino en la orientación de esa dimensión. Vale mencionar que, el hecho que la integración encuentre su fuente en procesos de mercado, tampoco necesariamente excluye a los gobiernos, sólo los coloca en el rol de favorecer la lógica de mercado (por eso encontramos fenómenos como, por ejemplo, una cooperación regional al servicio de la reducción de las BNA (Gil, Caballero Sierra, Corral Strassman, 2002)).

No podemos olvidar que una de las características primordiales de este regionalismo reside en la ambición de construir una coherencia regional o regionalidad (Hettne, 2002), en un proyecto amplio y multidimensional que incluye aspectos económicos, de seguridad, sociales, ambientales y hasta estratégicas. Esta enunciación no es meramente retórica: el Mercosur mismo encarnó este tipo de aspiraciones. Como menciona Bizzozero Revelez (2008) el sólo hecho de haberse gestado en un clima de regionalismo abierto le permitió su participación en negociaciones birregionales con la UE y las interamericanas en el ALCA (Mellado, 2007). Para el autor, esto implicó una articulación entre el plano político -el bloque en el sistema internacional-, el plano económico -inserción competitiva y regulación- y lo social - participación de la sociedad civil-. Escenarios de política doméstica de los miembros muy desfavorables a 
fin de siglo pasado frustrarán avanzar en este sentido, pero los alcances estratégicos -y la proyección de la integración como herramienta plausible para este tipo de finesfueron innegables.

A diferencia del antecesor, este nuevo regionalismo presenta acuerdos de perfil simétrico (se establecen reglas uniformes para todos los miembros), verticales (existen muchos acuerdos Norte-Sur que articulan miembros de diferente grado de desarrollo) y a eso se agrega una gran superposición de ellos (Robert, 1999) con reglas diferentes que acarrean potenciales controversias (además de una escasa atención al tratamiento especial, diferencial, y a la arquitectura institucional (Devlin y Estevadeordal, 2001) ${ }^{28}$ ). A esta complejidad interna se le agrega la propensión a extenderse geográficamente los procesos subregionales alcanzan dimensiones continentales (Mellado, 2006)- y también se articula en espacios interregionales -sin contigüidad geográfica- como los acuerdos Mercosur y Unión Europea.

Los Estados tampoco desaparecen como agente movilizador, aun cuando lo hagan en otra clave y bajo otros objetivos que los de la primera oleada (a su vez, el Consenso de Washington tiene un impacto determinante al interior de los Estados, por lo que ellos

\footnotetext{
${ }^{28}$ Es imperioso mencionar que el regionalismo abierto tampoco reviste un perfil homogéneo: el modelo asiático difiere del europeo, y éstos dos, a su vez, del latinoamericano. Incluso los esquemas en éste último, resultan difíciles de comparar: diverge en objetivos -la aspiración de constituir una ZLC, un mercado común o una UA-, la institucionalización -estructura y competencias cedidas a los órganos regionales- (Ibáñez, 2010), y a esto podemos agregar la condición de existir acuerdos verticales que involucran países de diferente grado de desarrollo. Encontramos una posible razón para esta diversidad en una afirmación de Hettne (2002): los procesos de regionalización acontecen en zonas muy diferentes, las que imprimen un perfil distinto para unas notas comunes (son esas notas las que solemos usar como definición, pero en aras de la precisión deberían ser señaladas como parámetros mínimos, que luego serán instrumentados de diversas maneras sobre los casos concretos).
} 
también reorientan objetivos y modifican su estructura interna). Si bien la reconfiguración posee una gran influencia de un factor exógeno -la globalización- que opera en una complejidad multidimensional y más sustantiva que la formal estadocéntrica (Hettne, 2002). Hettne señala un aspecto sobrerrepresentado -o al menos, no del todo bien instrumentado teóricamente- en el regionalismo abierto: la globalización (la razón de hacerlo fue la contraposición con el viejo regionalismo, que llevó a verla casi como una causa mecánica). Hettne propone verlo desde una perspectiva endógena, donde la regionalización y la globalización son fenómenos entrelazados, lo que, creemos, implica una consecuencia teórica: una vinculación entre el viejo y el nuevo regionalismo (a través de las perspectivas funcionalista y neofuncionalista sobre la integración europea).

Si bien las relaciones entre actores se reconfiguran, los Estados detentan un rol en el proceso (de hecho, en América Latina el regionalismo abierto surgió a iniciativa y manos gubernamentales -a diferencia del caso asiático- y la propia regionalización, aun cuando no era nueva, resultaba magra antes de impulsar este proceso (Ibáñez, 2000)). Lo que sí no podemos dejar de mencionar es que la acción estatal se articula con una mayor preponderancia del sector privado ${ }^{29}$, en lo que sería una nueva articulación

\footnotetext{
${ }^{29}$ Ibáñez (2000) señala los incentivos que el regionalismo abierto representaba para el empresariado: implicaba una potencial mejora en la inserción económica internacional por vía de la adaptación a las condiciones de competencia global (preferencia de comercio regional sin resignar la liberalización multilateral), un mayor poder de negociación en diversos escenarios (al hacerlo en bloque) y un mecanismo más para la estabilidad económica (un proceso integrador precisa sostenimiento de compromisos de política económica por parte de los Estados). Pero a esta perspectiva sectorial debemos agregar algunas cuestiones que muestran consecuencias más sistémicas, señaladas por Mellado (2006): se produce una intensificación de la competencia entre países, regiones, sectores y actores sociales por el dominio de los mercados (existe mayor incidencia de prácticas de actuación
} 
entre las elites políticas y empresariales, ambas identificadas con el neoliberalismo (Mellado, 2006). Eso no sólo describe el predominio de políticas de apertura y desregulación (desde ya que no sólo en el ámbito regional, fue más bien un signo de la década), sino que también nos permite hacer un contrapunto con el anterior regionalismo, donde el empresariado fue uno de las grandes limitantes al estímulo del comercio y la fortaleza de la ampliación de mercados a la dimensión regional, aceptando, en su momento, los riesgos de competir en un mercado ampliado (Schaposnik, 1989).

Caracterizar al regionalismo abierto obliga a señalar algunas cuestiones sobre lo que distingue a esta etapa -no sólo en la integración regional, sino en la economía mundial: el multilateralismo. Recuperar conceptualmente al multilateralismo nos obligaría a ponerlo también en relación con la noción de regionalismo (región, regionalización), cuestión la que nos abocaremos más adelante de modo específico y detallado. Por eso, y de manera sumarísima, el primero día de la mitad de la década de los noventas, el GATT deviene en la actual OMC, organismo que se ocupa de la normativa que rige y organiza el comercio mundial para que este sea libre, previsible y fluido (OMC, 2016). Si bien ha habido discusiones teóricas contrapuestas (Bhagwati, 1999; Zissimos y Vines, 2000) que señalan los ACR como manifiestamente discriminatorios y peligrosos para el multilateralismo. La OMC los promueve (la organización descansa en el principio de no-discriminación a través del principio de no-discriminación encarnado en la cláusula

mono y oligopólica de grupos económicos trasnacionales, y el mercado regional resulta, también, un área de expansión comercial y financiera de economías desarrolladas). 
NMF que garantiza el equivalente a todos los miembros, y está prevista en el artículo primero del GATT) ${ }^{30}$.

Para la OMC, los ACR resultan, por un lado, un mecanismo coexistente con el sistema multilateral, y por el otro, un medio para impulsar y contribuir a la liberalización del comercio (artículo XXIV, numeral 8 - GATT (Gil, Caballero Sierra, Corral Strassman, 2002; Acevêdo, 2014)). Es por ello que si la creación de comercio intrarregional (artículo XXIV, numeral 4 - GATT) excede a la desviación con terceros, resulta compatible e impulsa el buen desempeño multilateral.

Esto no obsta que se presente también algunos problemas: desde los años del GATT, los ACR aumentaron y se complejizan (lo que impacta en la interpretación del famoso artículo XXIV, redactado en 1947, momento en que los ACR revestían cualidades muy diferentes a las actuales, aspecto solucionado con el Protocolo de la ronda de Uruguay (Gil, Caballero Sierra, Corral Strassman, 2002)). La tendencia a la bilateralidad con escasas uniones aduaneras es la regla: es interesante la tesis de Baldwin (2012) acerca

\footnotetext{
${ }^{30}$ No obstante, el principio de NMF no es absoluto, y contempla excepciones para equilibrar las externalidades negativas (Gil, Caballero Sierra, Corral Strassman, 2002). Ellas permiten articular al regionalismo con el multilateralismo en el reconocimiento de las uniones arancelarias y los acuerdos de libre comercio (art. XXIV, inc. 4 a 10 del GATT y art. V del GATS). Otras de las excepciones residen en la 'Decisión sobre Tratamiento Más Favorable, Reciprocidad y Plena Participación de los Países en Desarrollo (Ronda Tokio, GATT 1979)' o la CH del GATT 79, que favorecen -o compensan- a los países en desarrollo con el SGP -trato preferencial sin reciprocidad a originarios- y el SGPC -para intercambio de concesiones comerciales-. La CH permite períodos más largos para ciertos compromisos, medidas que aumentan las oportunidades comerciales, asistencia para crear capacidades comerciales, diferencias y normas técnicas, junto a otros mecanismos (igualmente sometidos al principio de transparencia (WT/COMTD/W/196, 2013)). El mecanismo institucional que permite la coherencia final y concreta del sistema es la notificación de los ARC ante el CARC, donde la OMC coteja la coherencia del acuerdo con las reglas del artículo XXIV del GATT, $\mathrm{V}$ del GATS y la $\mathrm{CH}$.
} 
de la causa de este fenómeno en América y Europa, como un 'evento idiosincrático'. El detonador es el TLC México-Estados Unidos, que rompió la dinámica tradicional de relacionamiento interamericano, y así precipitó la formación de acuerdos bilaterales). Además, tienen también mayor amplitud e involucran a países de diferentes regiones, fenómeno señalado peyorativamente como 'maraña de acuerdos' o spaghetti bowl (expresión es atribuida a Jagdish Bhagwati, denunciando una atomización que compromete la fluidez del comercio internacional y la competitividad de la producción de transables (Halperin, 2011)).

Aun así, ya inicios del milenio, evidencia empírica mostraba que el 55\% del comercio mundial acontece al interior de bloques económicos (Gilpin, 2001; citado en BernalMeza y Masera, 2008) y a quince años del tercer milenio ampara más de la mitad del duplica la actividad registrada en la esfera del GATT (De la Reza, 2015).

Si bien regionalismo abierto y multilateralismo son términos que aquí consideramos relacionados, no quisiéramos que se interpreten como identificados: los $A C R$ son importantes para el sistema multilateral de comercio, pero no pueden sustituirlo (Acevedo, 2014). La OMC considera que la liberalización del comercio a nivel bilateral o regional es importante para el sistema multilateral, no obstante, cree que algunas cuestiones sólo se pueden abordar eficientemente en su seno: materias como la reglamentación de servicios financieros o telecomunicaciones, agricultura o pesca, como las medidas correctivas -derechos antidumping y compensatorios-, resulta óptimo negociarlas para todos los países incorporados en la Organización. Azevedo 
(2014) lo sintetiza afirmando que la fragmentación del sistema comercial (es decir, los ACR) no puede sustituir los beneficios de negociar un conjunto de normas para todos.

En esta precisión de lo que constituyen los ACR por un lado y la negociación multilateral por el otro, también debemos tener en cuenta que ambos avanzan en sus propios ámbitos de manera desigual, lo que genera 'ruidos' en el avance conjunto hacia una mayor fluidez del intercambio mundial. Así, algunos ACR dan mayor acceso a mercados que el existente en el marco de la OMC, pero en normas antidumping avanzaron por igual a la OMC, y también contamos con el caso de la inversión -a la que refieren algunos ACR-, no existen normas de la OMC (Azevêdo, 2014).

Este regionalismo, compatible, complementario y dependiente del avance del multilateralismo por vía de la preferencia regional conjugada con liberalización multilateral (Ibáñez, 2000), avanza en dos vectores: 1) amplitud de la integración -que comparte con la OMC-, en una agenda que excede lo comercial (Bernal-Meza y Masera, 2005); y 2) rol de las regiones con márgenes de acción intrínsecos como actores del tablero global (ejemplos de esto pueden ser la proyección de un 
multilateralismo regional (Hettne, 2002) ${ }^{31}$, el interregionalismo y transregionales

(Briceño Ruiz, 2007) ${ }^{32}$ ).

En tercero lugar, tenemos lo que se podría incluir en una tercera oleada de regionalismo de corte estratégico ${ }^{33}$, orientada a objetivos político-sociales y productivos (Briceño Ruiz, 2013) y de notable heterogeneidad: Briceño Ruiz (2013) destaca, de hecho, tres ejes a su interior. El primero es el eje de integración abierta (representado en la Alianza del Pacífico y los TLC), luego el revisionista (con el 'nuevo Mercosur' dirigido a políticas de regionalismo social y productivo), y por último el anti sistémico (con un ALBA basado en la solidaridad y cooperación y opuesto a toda

${ }^{31}$ Como lo denomina Giacalone (2006: 5), el interregionalismo de Hettne (2002) resulta en un nuevo modelo de gobernabilidad [global], donde un proceso de regionalización en cualquier parte del mundo tiene repercusiones sistémicas en otras regiones, afectando la forma en que se organiza el orden mundial (Hettne, 1996). Incluso, bajo esta dinámica de nuevas formas de articulación para la liberalización del comercio deben verse los acuerdos mega regionales, que consolidan a una mayor escala relaciones preferenciales.

32 Briceño Ruiz (2007) señala al regionalismo abierto desenvuelto en dos niveles: el intrarregional y el interregional (Hettne y Söderbaum, 1998; citado en Briceño Ruiz, 2007). El primero refiere a bloques económicos basados en la cercanía geográfica (aunque menciona a Gilson (2000) que simplemente lo define como la interacción entre regiones), con diálogos región-región sin institucionalización común (el diálogo UE-Mercosur es un caso). El segundo es aquel que existe entre esquemas de integración y países que no presentan contigüidad geográfica, usualmente en foros, y que también incluyen Estados miembros o no de un bloque- que actúan por cuenta propia (como la APEC).

${ }^{33}$ La cualidad estratégica refiere a la capacidad conjunta de convertir a América Latina en un actor político (Briceño Ruiz, 2007). Por lo que el adjetivo referiría a un fin, no necesariamente a una definición. Otros autores lo denominan regionalismo post-liberal (Da Motta Veiga y Ríos: 2007; Sanahuja, 2010; Serbin, 2010) para hacer hincapié en el pasaje de una agenda centrada en la liberación del comercio y la IED a la conformación de objetivos político-sociales y productivos. Para Rigirozzi (2010) será regionalismo post-hegemónico, donde se rompe la posición defensiva del regionalismo ante la globalización y el discurso de corte neoliberal para devenir en posición de resistencia a la hegemonía estadounidense. En este punto podemos encontrar un criterio unificador gracias a Serbin (2010), quien menciona que, allende las notas que resalte cada autor, todas confluyen en un denominador común: la creación de un espacio sudamericano con la exclusión de Estados Unidos. De hecho, la CSN es la respuesta brasileña al ALCA (Briceño Ruiz, 2007), con aspiraciones productivas, infraestructurales y de cooperación que superan la integración profunda norteamericana. 
integración basada en libre comercio -como los ejes anteriores-, lo que echa por tierra la aspiración prebischereana de un mercado regional latinoamericano).

De este modo, con continuidades y rupturas con el regionalismo abierto, no se puede señalar un comienzo taxativo, pero sí podemos afirmar que el 2003 (Briceño Ruiz, 2013) comienzan a acontecer unos hitos que forjan un perfil:

No es fácil indicar cuándo se inicia esta nueva fase, pero sí pueden señalarse algunos momentos críticos, como la firma del Consenso de Buenos Aires en octubre de 2003 por Luiz Inácio Lula da Silva y Néstor Kirchner, el colapso de la negociación del Área de Libre Comercio de las Américas (ALCA) en la Cumbre de la América realizada en Mar del Plata en noviembre de 2005 o la reunión Cumbre de la Comunidad Sudamericana de Naciones (CASA), realizada en Cochabamba, realizada en diciembre de 2006, en la cual se planteó un amplio debate sobre el modelo de integración que condujo a la transformación de esa iniciativa de integración en la Unión de Naciones Suramericanas (UNASUR) (Briceño Ruiz, 2013: 11)

Este regionalismo se caracteriza por un énfasis en algunos aspectos diferenciales: en primero lugar, el desarrollo de infraestructura vial y comunicacional (incluyendo al IIRSA) ${ }^{34}$, la cooperación financiera (aquí el Banco del Sur despertó grandes

\footnotetext{
${ }^{34}$ La IIRSA es una iniciativa surgida en el año 2000 (pero que incluye proyectos financiados por el BID y CAF con anterioridad a esa fecha), que implica la creación de una infraestructura regional financiada los organismos mencionados junto con el FONAPLA y el BNDES (y por vía de éste involucra empresas constructoras brasileñas). Desde 2009 funciona conjunto al COSIPLAN, que lo incorpora como foro técnico de infraestructura. En el plano político Brasil es el país que pone más esfuerzos en el desarrollo del IIRSA y el destinatario de las principales obras en ejecución y posee un tercio de la inversión en su territorio (Serbin, 2010). Con el problema de costos (subestimados) ha sido también muy criticado por su objetivo meramente mercantil -sin dar cuenta de cuestiones ambientales y sostenibles-, y por ser favorable a la economía regional de los TLC y permitir la mayor injerencia brasileña en la región (Geus, 2011)
} 
expectativas, no sin tensiones: se lo podría haber sumado al trabajo del BID y la CAF, pero Venezuela se negaba a tomar contacto con BM y el FMI), la cooperación en energía (enfrentando el dilema de una integración energética a través de una estructura ofensiva símil OPEP o un régimen de complementación y beneficios mutuos $^{35}$ ), medio ambiente (no sólo en problemas globales como el cambio climático, sino también en industrias extractivas, y la gestión de recursos naturales y energéticos), seguridad y defensa ${ }^{36}$, cooperación sur-sur, entre otras (Llenderrozas, 2009; Serbin, 2010).

A diferencia de los otros dos regionalismos, aquí no podemos separar los perfiles de los casos prácticos, dado que los precisamos metodológicamente para anclar las particularidades (siguiendo el esquema de Sanahuja, 2012). En este sentido, los dos bloques señalados en la literatura como estrictamente post-liberales alcanzan a la ALBA-TCP y la UNASUR. A diferencia de otros, Giacalone (2006) también propone comenzar este período a partir de la constitución de la CSN procede no sólo por razones de linaje, sino porque este regionalismo presenta una doble dinámica que combina la decisión de dos países preeminentes -Brasil y México- que sobre la base de sus intereses nacionales, y según factores endógenos -la coincidencia ideológica-,

${ }^{35}$ Cf. CARDOSO, Elsa (2006). Integración energética y gobernabilidad en la región andina, Ildis, Caracas, p. 13.

${ }^{36}$ Serbin (2010) señala la propuesta de Da Silva del CSD en 2008, de convertir a América del Sur en una zona de paz -con integración de industrias de defensa e intercambio técnico-. Pero, y esto es de especial interés para estas líneas, la propuesta no puede desvincularse de la estrategia regional brasileña: permite recortar un espacio sin Estados Unidos afirmando la hegemónica regional y contribuyendo así a su estrategia global. EI CSD podría subordinar el poder militar a la autoridad civil y sudamericanizar (una expresión que Serbin toma de Sanahuja) la propuesta venezolana de la alianza militar gestada en el ALBA. Incluso acercaba a Colombia -reticente a Chávez- al reconocer otras amenazas a la seguridad y rechazar la acción de grupos armados fuera de la ley). 
combinados con aspectos externos -el proyecto europeo que incluye a Brasil y otras potencias emergentes junto con la necesidad de enfrentarse al TLCAN-, se lanzan a por la Comunidad Sudamericana de Naciones.

Este análisis hilvana a un tiempo varias dimensiones del quehacer internacional, el cual opera exactamente en esta dinámica multidimensional donde factores distintos y dispares se combinan en decisiones que reconfiguran los propios escenarios iniciales.

Estos últimos, no adoptan la morfología usual en las integraciones regionales (nos referimos a los diseños 'clásicos', por así decirlo, de Bela Balassa ${ }^{37}$ ), y presentan como factor común una serie de características concretas: mayor peso del componente político que comercial (cambiando liberalización por desarrollo con igualdad, y a ello subordinan la integración, por vía de intensificar la cooperación en cuestiones extracomerciales), atados a un discurso progresista y de predominio regional por Brasil y Venezuela. También presentan un retorna al Estado el desarrollo económico-social, y desde él reclaman autonomía frente al mercado -condensado en Estados Unidos y por extensión, con los organismos financieros internacionales-. Por nuestra cuenta, podríamos sintetizar el escenario a contrapesar en la tríada neoliberalismo (es decir, apertura], globalización (en este caso, entendida como regionalismo defensivo) y pérdida de autonomía (por vía del endeudamiento externo).

\footnotetext{
${ }^{37}$ Cf. BALASSA, Bela (1964): Teoría de la Integración Económica, Biblioteca Uteha de Economía, México DF.
} 
Este último aspecto nos lleva a plantear una dimensión que nos resulta determinante, al girar ciento ochenta grados el perfil del regionalismo abierto: en este modelo, no hay contradicción entre nacionalismo y regionalismo. El neo-nacionalismo -producto de la posición discursiva y de la reevaluación de los principios de soberanía nacional (Serbin 2010)-, rechaza la visión de los grupos regionales y organizaciones multilaterales como instrumentos para gestionar la globalización (típica del regionalismo abierto), y coloca al Estado como agente de esa defensa (lo que por supuesto tiene el coste de quedar tensionado a la hora de construir marcos regulatorios e instituciones multilaterales efectivos supranacionales):

Sin embargo, el neo-nacionalismo que está caracterizando este nuevo ciclo político presenta un dilema en ocasiones inevitable, cuando se trata de construir marcos regulatorios e instituciones regionales y multilaterales efectivas. Adicionalmente, este enfoque neo-nacionalista al regionalismo, también implica un rechazo a otras visiones "cosmopolitas" de regionalismo que ve los grupos regionales y organizaciones multilaterales como instrumentos para manejar la globalización y mejorar su gobernabilidad (Sanahuja, 2012: 33-34)

Creemos que un factor más distingue este regionalismo de los casos anteriores (y no del todo intrínseco a su perfil, sino más bien producto de los condicionamientos exógenos): la pervivencia y convivencia con esquemas vigentes de regionalismo pasados. Mientras en los albores del regionalismo abierto las configuraciones anteriores (ALALC, ALADI, PA) habían cursado los años ochenta en claro avance a una crisis casi letal, coyuntura en la que el arribo del nuevo regionalismo reimpulsa la lógica de la integración regional y monopoliza las iniciativas de la etapa post- 
prebischereanas-; la tercera oleada regionalizadora convive con bloques planteados en términos del regionalismo anteriores, y posee un linaje concreto con ellos (Mercosur y la CAN dan origen a la CSN).

Esto generó dilemas y nuevas complejidades, sobre todo, en los bloques más condicionados por su espíritu ideológico ${ }^{38}$, como es el caso del ALBA-TCP. En pocas palabras, ahora el fenómeno de la integración regional latinoamericana comienza a crear tensiones a su interior que hilvanan su historia y la hacen convivir con modelos de regionalización completamente diferentes.

Este regionalismo, centrado en la búsqueda de grados de autonomía política gracias a la exclusión de Estados Unidos y los organismos internacionales de crédito (Serbin, 2012), depositó en el Estado su agenda neo-desarrollista, para lo que debió forjar con mayor completitud una estrategia que superasen los intereses nacionales y avanzar a una plataforma colectiva para alcanzar objetivos comunes (Granato, Odonne, Battaglia, 2016)

\footnotetext{
${ }^{38}$ Esta tensión no es sólo de interés analítico. Serbin (2012) asegura que el destino de la UNASUR está atado a la pugna Mercosur - ALBA, dos modelos diferentes que procuran cuestiones distintas: producción industrial, inserción internacional, asuntos financieros son determinantes para el primero, pero están ausentes en el segundo (no así los temas energéticos, de infraestructura y de cooperación Sur-Sur que se presentan en ambos).
} 
Recorrer, historiar e indagar el perfil de la integración suramericana nos coloca de frente su decurso, y nos muestra sus cambios, contingencias, influencias coyunturales, logros, desafíos y claros fracasos. Vimos tres perfiles concretos, modelados por motivaciones $\mathrm{y}$ orientados a unos fines (independientemente de si fueron o no alcanzadas con completitud). De entre estos tres regionalismos, encontramos uno, el tercero, orientado a una acción estratégica de alto perfil (que aúna el espectro de proyectos y acciones contra hegemónicos como también la construcción de sinergias con el fin de ganar poder en la negociación multilateral). En este caso, la integración regional sirve para otros fines que exceden el desarrollo el crecimiento de mercados o incluso la ingeniería institucional para controversias principalmente comerciales, y adquiere así, un componente político, auto afirmativo, y deviene un actor al servicio de sus miembros Cualquiera fuese la dirección en que se considere, el titular de las ventajas obtenidas era un sujeto colectivo: una región, constituida por diferentes -y diversos- miembros.

Lo que estos regionalismos no contemplaron fue que uno de sus miembros se sobrepusiese a los fines colectivos del bloque, para nacionalizarlos por vía de su interés nacional. Colocar la región a ese servicio fue una de las caras de esta decisión. La otra implicó ampliarla a otros esquemas integradores más ambiciosos -ya bajo el esquema que proyectaba el interés nacional por sobre el beneficio colectivo-. Por supuesto, esto constituye un fin no contemplado en ninguno de los tres regionalismos (ni siquiera en el tercero que, si bien auto afirmativo, de suyo reafirma los fines colectivos). A 
deslindar y hacer foco en esta primacía que establece uno de sus miembros por sobre la región, dedicamos las líneas que siguen. 


\title{
Primera Parte
}

\author{
Insumos Conceptuales
}


Sección Primera

Perspectivas analíticas 
Capítulo I. Realismo y Régimen internacional

Sumario. En este capítulo comenzaremos con una caracterización del realismo, componente del paradigma tradicional en la sociedad internacional. Paso seguido, ahondaremos en uno de sus componentes normativo-teóricos determinante, como es el interés nacional (la categoría más importante de este capítulo para nuestro análisis), continuaremos con unas precisiones acerca del neorrealismo y la política de poder para finalizar abordando aspectos de la anarquía internacional y regímenes internacionales, que permitirá introducir la noción de régimen de integración regional. 
《Una "ciencia" sin una teoría aún puede ser una ciencia con un paradigma; $y$, hasta hace poco tiempo, el paradigma ha sido el del conflicto permanente entre estados actores --el paradigma realista》》 Stanley Hoffmann, 1991

Las relaciones internacionales ${ }^{39}$ son, sin duda, una de las áreas de más reciente conformación dentro de la ciencia social: si bien enraíza con disciplinas afines centenarias -el derecho internacional, la historia diplomática (Del Arenal, 1994), la misma teoría política (Wilhelmy, 1988)-, no es hasta un siglo atrás que encuentra suficiente sistematicidad $^{40}$. Portadora de unas tradiciones a su interior, aquí atenderemos la realista y la grociana o internacionalista:

Hedley Bull [1976] $]^{41}$, siguiendo los pasos de Wight [1966] ${ }^{42}$ considera que a lo largo de la historia del moderno sistema de Estados pueden distinguirse tres

\footnotetext{
${ }^{39}$ Así, en estas líneas tomaremos el término 'relaciones internacionales' en el sentido más amplio posible, mentando al conjunto de diversas relaciones sociales -lo suficientemente intensas y frecuentesde índole económica, social, tecnológica u otra (Wilhelmy, 1988), entre diferentes agentes (estatales y no estatales, transnacionales e internacionales (Dougherty y Pfaltzgraff, 1990)) que configuran la sociedad internacional en una coordenada geográfica y un momento histórico determinado. No se la debe confundir con el sistema internacional dado que determina sólo relaciones interestatales.

${ }^{40}$ Los estudiosos destacados asumen que entre los albores del siglo XX (Thompson, 1952; Deutsch, 1968) con una fuerte impronta del derecho internacional, o bien hacia el fin de la primera Gran Conflagración (Dougherty y Pfaltzgraff, 1990; Del Arenal, 1994). Otros como Hoffmann (1991), sostienen que fue parida por obras lo suficientemente científicas, aun cuando normativo-históricas: por un lado, Veinte Años de Crisis de Edward Carr (1939) y por el otro, Política entre Naciones de Hans Morgenthau en 1948 (a quien, a la sazón, también señala como el padre de la disciplina).

${ }^{41}$ Se refiere a su obra La Sociedad Anárquica. Un Estudio sobre el Orden en la Política Mundial (Madrid; Catarata, 2005), publicado originalmente en inglés, en 1976.

${ }^{42}$ Se refiere a su artículo The Balance of Power, compilado en 1966 por Butterfield, Herbert y Wight, Martin (eds.) en "Diplomatic Investigations. Essays in the Theory of International Politics", Cambridge, Harvard.
} 
tradiciones o líneas de pensamiento en constante competición entre sí, aunque dentro de cada una de ellas existen importantes diferencias de énfasis y argumentos entre unos autores y otros. Por un lado, la tradición realista y hobbesiana que considera la política internacional como un estado de guerra [...] Por otro, la tradición universalista o kantiana, que ve el mundo internacional como una potencial comunidad de la humanidad [...] Finalmente, una internacionalista o grociana que se desarrolla entre las dos tradiciones anteriores (...) describe las relaciones internacionales en términos de sociedad de Estados (Del Arenal, 1994: 97).

Las relaciones internacionales (Bull, 1966; Del Arenal 1989, 1994) condensan esta etapa inicial en la noción de paradigma tradicional. Esta denominación alude a una perspectiva y dinámica del medio internacional capturada por dos posturas que, con perspectivas antagónicas, también presentan rasgos comunes: el realismo y el utopismo o idealismo ${ }^{43}$. Sumariamente, este paradigma presenta el medio internacional sobre la base de unas notas particulares: una separación contundente entre la política interna y la internacional (en la que prima el poder como sobreposición a la inseguridad, por lo que los valores no tienen efecto y el progreso no

\footnotetext{
${ }^{43}$ No podemos eludir una caracterización breve del idealismo -o utopismo (Dougherty y Pfaltzgraff, 1990)-. Impera comenzar situando históricamente: hijo de la Primera Guerra Mundial (su estallido mostró los costes de la guerra como instrumento para asegurar la paz) y ahijado de Woodrow Wilson, quien asumió que Estados Unidos ingresa a la Conflagración para defender la moralidad internacional que Europa había perdido (Del Arenal, 1994). Su propuesta residió en un sistema de seguridad colectiva internacional que reduzca la capacidad militar individual para hacerla conjunta, y respalde ante una posible agresión de cualquiera de sus miembros (Wilhelmy, 1988). La paz y los conflictos debían ser administrados y el mecanismo multilateral residía en la Sociedad de Naciones (Wilhelmy, 1988). El idealismo acuña fe en el progreso y en la posibilidad de efectiva racionalidad de la conducta estatal (Del Arenal, 1994), junto a la construcción de escenarios donde exista armonía de intereses -la coexistencia estatal no debe ser necesariamente un juego de suma cero-. El utopismo tuvo dos auges más: en 1945 con la revolución nuclear, y en el movimiento del 'humanismo planetario' de los años setentas (Falk, 1971). Este último resurgimiento dio lugar en los ochentas al debate realistas - globalistas (escuela centrada en los fenómenos transnacionales -con menor importancia relativa de los Estados- y transgubernamentales -atienden a las capacidades intra-burocráticas y la toma de decisiones domésticas-). Los globalistas relegan, por supuesto, la importancia de la fuerza militar. Para mayor detalle, cf. Ray MAGHROORI y Bennett RAMBERG: Globalism versus Realism. International Relations Third Debate, Westview Boulder, 1982).
} 
es posible); en segundo lugar, los actores por antonomasia de las relaciones internacionales son los Estados y estadistas (ergo, resultan relaciones interestatales); y por último, esas relaciones son esencialmente conflictivas a causa de la anarquía, por lo que devienen una lucha por la seguridad nacional -el nombre que asume la supervivencia individual en la dimensión estatal- (Del Arenal, 1989, 1994).

A partir de aquí las estrategias de resolución se divorcian: Mientras el realismo genera el mecanismo derivado -la dinámica del equilibrio de poder-, el idealismo lo hace proponiendo mecanismos superadores por fuera de la lógica del poder. El realismo se inunda, así, de pragmatismo y sólo reconoce límites en la prudencia: la única decisión inaceptable es la que arriesgue la propia viabilidad. En cuanto a los motivos, pues la mera oportunidad justifica las acciones, y circunscribe sus motivos a la mera oportunidad. Este divorcio entre ambas dimensiones tiene, también, una consecuencia moral: la razón de Estado permite al estadista no estar restringido por normas domésticas (incluyendo las normas morales y consuetudinarias que alcanzan a los individuos). Pero esto no termina aquí, por lo que, en términos del pensamiento realista, no es conveniente llevar la escisión del orden interno / externo al extremo, aunque usualmente se lo haga. Veamos, por un lado, una consideración teórico epistemológica de uno de los padres del realismo, Morgenthau, quien afirma la diferencia entre la política interna y la internacional no es más que una diferencia de grado, y no de naturaleza (1948). Por el otro, una consideración analítica de una dimensión menos general de la política internacional, en palabras de Kissinger: la estabilidad del sistema internacional depende en gran medida de la estructura interna 
de los Estados. Así, un sistema estable requiere una compatibilidad sobre los medios y fines de la política exterior (es decir, es preciso un consenso en ciertos puntos con los demás países, lo que permite evitar una política exterior aventurera para lograr la cohesión interior (Kissinger, 1973)).

Aproximarnos al realismo implica, sin excepción, detenernos sumariamente en su genealogía: de raíces atávicas que se nutren en ideas, juicios y conductas ejercidas varios siglos antes de convertirse en un patrón para el ejercicio de las relaciones internacionales en el Renacimiento (Del Arenal, 1989). Podríamos ver eso como su linaje antiguo -no del todo uniforme-, dado que incluye los relatos de Tucídides sobre sus intuiciones de la acumulación de poder ateniense, los legalistas chinos, Mencio y Kautilya -tratadista indio al que Max Weber ponderó por encima de Maquiavelo ${ }^{44}$ (Pearson y Rochester, 2004). El linaje histórico más reciente -entre 1648 a 1914hilvana a pensadores que retrospectivamente podría colocarse en el realismo, como Thomas Hobbes (sin un soberano fuerte, es decir, en anarquía, las personas comienzan a usar la propia fuerza para defenderse de los demás hombres) y por supuesto, Maquiavelo (por la adopción de patrones morales diferentes que los particulares a la hora de gobernar ${ }^{45}$ y por el hecho de que la política se caracteriza por una coalición de intereses (Dougherty y Pfaltzgraff, 1990)).

\footnotetext{
${ }^{44}$ Weber señaló que Arthasastra hace que 'El Príncipe' de Maquiavelo resulte inocente (Cf. WEBER, Max (1977). La política como vocación en “El Político y el Científico", Alianza, Madrid. p. 169). De hecho, Dougherty y Pfaltzgraff (1990) reconocen en Max Weber uno de los antecedentes del realismo, sobre todo, por la centralidad que tiene el poder en su análisis y el componente agonista de su teoría política.

45 Esta afirmación puede llevar a apreciaciones imperfectas: no referimos exactamente a un ejercicio amoral de la política (en el sentido 'maquiavélico' del término) sino a que, para los realistas, el
} 
Pero no sólo autores asociables al realismo, sino también algunos que pensaban en organizaciones internacionales que condujeran u organizan la paz, como Dante -uno de los primeros en demandar una organización internacional capaz de hacer cumplir la paz- y otros que abogaban por una liga de naciones-estado como Jean-Jacques Rousseau, Jeremy Bentham (junto con los liberales británicos decimonónicos que ponderaban un mundo de naciones vinculadas por el comercio, para lo que la paz es un requisito), Immanuel Kant, con su plan de paz perpetua conformada por gobiernos representativos confederados. Y por supuesto, Max Weber, quien no sólo es determinante por el peso del poder que da a su (para cotejar el componente weberiano en el realismo recomendamos el valioso estudio de Raymond Aron, Max Weber y la política de poder, Revista de Sociología 15, 1981). sistema teórico, sino también por el aspecto normativo: Para Smith (1986), el realismo presupone la ética de la responsabilidad weberiana. Aun cuando no presenta categorías para juzgar la conducta, no elimina la moral de las relaciones internacionales. Y de hecho, presenta una propia. ${ }^{46}$ El mismo Aron reconoce este problema recurrente entre los autores realistas:

Cuando el realista (...) pretende ofrecer, no una imagen en bruto, sino un retrato retocado (...) surge la necesidad de nociones rigurosamente definidas (1962: 692).

fenómeno político no parte de alguna filosofía ética, sino que la misma teoría política se deriva de la práctica y la historia.

${ }^{46}$ Para cotejar el componente weberiano en el realismo recomendamos el valioso estudio de Raymond Aron, Max Weber y la política de poder, Revista de Sociología 15, 1981. 
Wight (1960) afirma que la tradición clásica -o como lo denominamos siguiendo a Del Arenal, paradigma clásico- está disperso, no es sistemática, se encontraba dispersa en escritos de filósofos y tratadistas muy diferentes y además resultaba inaccesible al lego. Frente a esto, existía una teoría muy interesante para los diplomáticos y algunos intelectuales: la del equilibrio del poder. Era efectiva, podía vérsela en funcionamiento y se la encontraba en las conversaciones de los conciliábulos diplomáticos. Creemos que, a este componente, es preciso agregarle otro más: el del interés nacional. Al igual que el equilibrio de poder, no es acuñada por el realismo, sino que estuvo vigente desde el absolutismo bajo el nombre de honra nacional o interés dinástico (Escorel de Moraes, 1986), incluso como voluntad del Príncipe, o bien confundida en la justificación de razón de Estado. Algunos siglos después, los gobiernos representativos modernos la malearían hacia la voluntad general o el interés público, hasta que el siglo XX la convirtiera en interés nacional propiamente dicho (Tomassini, 1991)

Aun cuando el realismo proclame su cientificidad en el desprecio de principios reificados (como le achaca al idealismo) y en sus generalizaciones basadas en observaciones históricas, no carece de componentes normativos en su genealogía. Podemos encontrarlos en la dimensión filosófica (pesimismo antropológico, conflicto natural), como en la dimensión de la teoría política (prioridad absoluta, ética y práctica de la seguridad, y el sujeto que la garantiza: el Estado nacional). Desde ya, todo ello posee consecuencias epistemológicas y teóricas de diferentes niveles: una especial 
importancia acerca de la soberanía territorial, los atributos de legitimidad y legalidad que ésta conlleva, etc. (Peñas, 2005). Dougherty y Pfaltzgraff agregan:

Al pedirles a los hombres de Estado que alteren su comportamiento, el realista se vuelve normativo en su orientación teórica y fracasa en suministrar una explicación adecuada acerca de por qué los líderes políticos a veces no adhieren a los dogmas realistas en la política exterior (1990: 137)

El realismo no sólo implica un sistema de pensamiento o ideas, es un desarrollo histórico, centrado en procesos estructurales sin los que no podría existir: el primero factor reside en la consagración formal al Estado como forma de organización políticosocial. Un largo proceso de secularización que, a un mismo tiempo, produce concentración y descentralización: el poder disperso en organizaciones territorialmente más acotadas (feudos aún persistentes, ducados, principados), se concentran en una institución soberana y comienzan a formar parte de un conjunto de pares idénticos, sin árbitro que los ordene. Esta bivalencia configura la realidad entre el interior de los Estados (bajo un pacto de sujeción hobbesiano -donde reina el orden y gracias a él, la paz-), y la descentralización frontera afuera (en estado de anarquía donde el orden es temporario y frágil, sólo sostenible por la fuerza-). Esa organización se dispone de una manera determinada: el sistema europeo de Estados en el siglo XVII. Este modelo de organización westfaliano (iniciado en los siglos XVII y XVII bajo el mando de los príncipes absolutistas, extendido hasta la Segunda Guerra Mundial), está regido por la anarquía entre pares -no existe árbitro para los Estados- y el estado de natura hobbesiano. Eso implica la carencia de convenant -pacto social- y de algún tipo 
de consensus iuris de Cicerón (García Picazo, 2010). En la práctica, esto funciona gracias al mecanismo del equilibrio de poder, el interés fundado en la raison d'état, y, como última ratio, el recurso de la fuerza armada (Hoffmann, 1991) ${ }^{47}$.

Y el segundo factor, residen en el reemplazo del derecho -característico de la convivencia interestatal medieval- por el poder en la Modernidad (Wight, 1951). Esto encuentra consistencia definitiva en la crítica de los años treinta al fracaso del idealismo wilsoniano (Del Arenal, 1989, 1994) y conforma la primera versión de lo que hoy llamamos realismo, un patrón político (pero también epistemológico y teórico ${ }^{48}$ ) que se nutriría a partir de esa época con diferente grado de intensidad según los debates $^{49}$ que tomarán mayor preponderancia en la teoría:

\footnotetext{
${ }^{47}$ A su vez, cada componente derivado -como efectivamente lo es apelación a la fuerza- genera consecuencias en otros componentes de menor agregación teórica. Pongamos sólo un ejemplo sobre el que luego volveremos: la hegemonía. Si la pensamos de la manera más acotada, casi idéntica a su etimología (del griego hegemonia, y del antiguo egemoni, guía), debemos asociarla a la idea de dominio, y éste apoyado con las armas como última ratio. Así era pensada por los teóricos ligados a la Doctrina de la razón de estado como Ranke y Dehio (Matteucci, Aricó, Soler, Tula, 2000)].

${ }^{48}$ El realismo implica, no sólo una cosmovisión y una posición antropológica determinada, sino también una perspectiva acerca de lo que es el medio internacional en particular y la política en general. No hay mejor lugar para cotejarlo que en los famosos seis principios de Morgenthau (1948): 1- Las relaciones políticas responden a reglas objetivas derivadas de la natura humana (racionalismo fundado en la separación de verdad de la opinión), 2- Los estadistas actúan en términos de la esencia de la política: interés definido como poder, 3- (dado el segundo principio) es preciso asegurar la propia integridad según el contenido del interés nacional dado por el contexto, 4- Existe una tensión entre moral y acción política eficaz. El contenido de la política no es la primera, 5 - El interés definido como poder previene de los excesos morales y la inoperancia política, y 6 - Las acciones políticas deben ser evaluadas con criterios políticos, es decir, preguntarse cómo ella afecta el poder de una nación (Morgenthau, 1948).

${ }^{49}$ Las relaciones internacionales se desarrollan a lo largo del siglo pasado en una serie de debates que condensan algunos análisis clave (Pearson y Rochester, 2004) como pueden ser los de Morgenthau, Deutsch, Easton, Waltz. Esos debates son principalmente cuatro: el primero normativo-idealista (1918 a 1930), el segundo empírico-normativo realista (1930 a aproximadamente 1945), el tercero conductista cuantitativo (1950 a aproximadamente 1960), y el cuarto, el post-conductista (desde 1965 a 1970) (Olson y Onuf, 1985).
} 
De acuerdo con Dougherty y Pfaltzgraff [1991] podemos decir que desde la Primera Guerra Mundial el estudio de las relaciones internacionales ha pasado a través de cuatro etapas. La primera, idealista y normativa, llega hasta la década de los treinta; la segunda, realista y empírico-normativa, alcanza la década de los cincuenta; la tercera, behaviorista-cuantitativa, caracteriza las décadas de los cincuenta y sesenta, y finalmente, una cuarta, post behaviorista, se inicia a fines de los sesenta llegando hasta finales de los años setenta (Del Arenal, 1994: 100)

El realismo tiene, ante todo, pocas esperanzas. Asume que la conducta de los Estados no puede ser reformada, y sólo podrá -como máximo- ser controlada. Rechaza la posibilidad de armonía, de convivencia pacífica, desde que sostiene que los conflictos de intereses son inherentes a la coexistencia estatal, por lo que la norma es el conflicto (no obstante, existe la cooperación, pero sólo cuando ella es síntoma del interés nacional de un Estado (Del Arenal, 1994)). El estado de naturaleza se encuentra vigente, pero no ya en los términos formales del hobbesianismo puro. Creemos que Aron (1979) explica con pericia esta fina diferencia:

Las relaciones entre los Estados no son por ello comparables a las de los animales de la jungla. La historia política no es auténticamente natural. La conducta diplomático-estratégica tiende a justificarse por ideas, pretende obedecer a normas y someterse a principios. Llamamos cínicos a aquellos que no ven en las ideas, en las normas, en los principios más que disfraces de la voluntad de poder, sin eficacia real. Acusamos de ilusos idealistas a aquellos que desconocen el hecho de que todo orden internacional debe mantenerse por la fuerza. La ilusión idealista adopta distintas formas, según sea el carácter de los imperativos o de los valores invocados. El idealismo ideológico consiste en considerar una idea histórica como el criterio, exclusivo y suficiente, de lo justo y lo injusto. Por ejemplo, el derecho de los pueblos a disponer de ellos mismos o la idea de las nacionalidades (Aron, 1979: 705 [traducción propia ${ }^{50}$, destacados en el original])

\footnotetext{
${ }^{50}$ Del original: Mas nem por isto se poderia comparar tal relacionamento com o dos animais na selva. A história política não é puramente natural. A conduta diplomático-estratégica tende a se justificar por
} 
Y en el mismo párrafo, alude a una de las características fundamentales del realismo para el manejo de los asuntos públicos: la prudencia. En un medio donde el poder es la moneda de cambio, la única manera de escapar a la ilusión idealista -que lleva al fanatismo-, es teniendo en cuenta que los Estados no son siempre culpables o puros. Esto lleva a Aron (ibídem) a considerar un deber político (pragmático) y moral, entender que cada Estado está legítimamente preocupado por sus intereses y no debe quedarse ciego frente a los intereses de los demás. Será la prudencia, la que permitirá seguir un curso de acción basado en una coyuntura singular con datos concretos:

\begin{abstract}
No por espíritu de sistema ni por obediencia pasiva a una norma o a una pseudo-norma; es también preferir la limitación de la violencia al castigo del pretendido culpable o a una supuesta justicia absoluta; es plantearse objetivos concretos, accesibles, conformes con la ley secular de las relaciones internacionales y no objetivos ilimitados y quizá desprovistos de significado, tales como "un mundo en el que la democracia estaría segura" o "un mundo en el que hubiera desaparecido la política de poder" (Aron, 1979: 709 y 710 [traducción propia ${ }^{51}$ ])
\end{abstract}

médio de certas ideias, pretende obedecer às normas e submeter-se a princípios. Chamamos de cínicos os que consideram que as ideias, as normas e os princípios não passam de disfarces da vontade de poder, sem eficácia real. Por outro lado, dizemos que sofrem uma ilusão idealista os que não levam em conta o fato de que a ordem internacional requer a força para sustentar-se. A ilusão idealista assume formas diversas, de acordo com os imperativos ou valores invocados. $O$ idealismo ideológico consiste em considerar uma ideia histórica como o critério exclusivo e suficiente do justo e do injusto; por exemplo. $O$ direito dos povos a dispor de si próprios, ou a ideia das nacionalidades.

${ }^{51}$ Del original: não por espírito de sistema ou por obediência passiva a uma norma ou pseudonorma; é preferir a limitação da violência ao castigo do suposto culpado ou a uma justiça absoluta; é adotar objetivos concretos, acessíveis, de conformidade com a lei secular que rege as relações internacionais. $E$ não objetivos ilimitados, possivelmente sem significação, tais como "um mundo seguro para a democracia", ou "um mundo onde não haja política de poder. 
Ese medio conflictivo, sumado a la anarquía entre pares, sólo ofrece un arma de protección: el poder. Lo que los Estados puedan lograr y lo que los neutraliza -hasta cierto punto- de ser una amenaza mutua, es el poder (Hoffman, 1991). Por eso, allende su ideología, perfil de cualquier índole, posición en el sistema internacional ${ }^{52}$, cualquier Estado debe procurarse este activo valioso. $\mathrm{Y}$ no existe manera de sublimarlo: los valores, las convenciones internacionales, los pactos, las intenciones e incluso las presiones de la opinión pública, no logran disuadir con la misma eficacia que la posibilidad de un conflicto armado o mutuas represalias pueden brindar (ergo, son elementos presentes, pero subordinados (Schwarzenberger, 1951). Por eso el poder comienza a ser una búsqueda en sí misma (Schwarzenberger, 1941). Y es eso lo que nos permite plantear la dinámica jerárquica del poder, por así decirlo: Wight (1951) señala que las consideraciones de bienestar no destruyen la política de poder, porque cada poder tiene un interés mayor que el bienestar (del cual éste depende) y por el cual en última instancia debe sacrificarse. Eso no es otra cosa que el mantenimiento del poder mismo.

\footnotetext{
${ }^{52}$ Las interacciones entre diferentes actores en el medio internacional presentan ciertas regularidades. La estabilidad de esas regularidades configura lo que los especialistas llaman sistemas políticos internacionales. Para Wilhelmy (1985), el sistema político internacional es producto de la interacción de unos actores -y especialmente los de mayor gravitación-, pero al mismo tiempo, estas interacciones influyen [permiten/limitan cursos de acción en] la conducta de los actores. De este modo, poseen tres componentes (Gilpin, 1981): miembros (agentes dotados de voluntad autónoma para relacionarse con otros actores, fueren o no Estados), interacciones (relacionamientos recíprocos, conflictivos o cooperativos), y control (principios de regulación del comportamiento internacional). Este último componente distingue la anarquía del caos (algo que retomaremos más adelante en el apartado de régimen internacional).
} 
Al poder se lo encuentra en sus atributos, y es ahí donde no debemos caer en el reduccionismo de concebirlo de manera meramente militar (Burton, 1965; Wilhelmy, 1988):

\begin{abstract}
Muchos análisis subrayan la importancia de la situación de un país determinado, de su capacidad económica medida en términos de su producto nacional o de sus exportaciones, de su prestigio o de la solidez de sus instituciones. Se ha dicho que la fuerza consiste en la utilización de medios físicos para obligar a tomar ciertas decisiones que la influencia es la capacidad de lograr el mismo objetivo por medios diferentes, y que el prestigio es el respeto debido a los que detentan el poder, digiriendo que este último concepto está integrado por todos estos elementos. También se ha distinguido entre la fuerza de una nación y su capacidad de utilizarla eficientemente ${ }^{53}$. Por otra parte, el poder es la capacidad de lograr ciertos resultados, y el control de una cuota de recursos que permite influir sobre ellos y que da preponderancia a un actor sobre otros ${ }^{54}$ (Wilhelmy, 1988: 60, destacado nuestro)
\end{abstract}

Los realistas afirman que el poder es un fenómeno cuali-cuantitativo multidimensional (Dougherty y Pfaltzgraff, 1990), que incluye la población, la tecnología y hasta algunos elementos domésticos como la forma de gobierno. También se incluyen factores menos dinámicos como los recursos naturales disponibles, y uno carísimo para el realismo -el más estático de todos-: la condición geopolítica. La ubicación de un Estado condiciona la orientación de su política exterior (que impacta en su vulnerabilidad a la conquista, pasando por el acceso a recursos naturales, hasta el impacto del clima y su capacidad productiva). Aron, a quien no podríamos tildar de idealista, refuerza esta

\footnotetext{
53 Referencia en el original: KINDLEBERGER, Charles (1970). Power and money: the politics of international economics and the economics of international politics, Basic Books, New York.

${ }^{54}$ Referencia en el original: HART, Jeffrey (1976). Three approaches to the measurement of power in international relations, en International Organization, vol 30.
} 
cuestión a través de su noción de poder: el poderío relativo de un estado se modifica de acuerdo con el cambio de circunstancias económicas, las innovaciones tecnológicas y la transformación de las instituciones y las ideologías. De este modo, las relaciones con otros estados no solo son el reflejo de su poder relativo, sino de sus ideas, valores y emociones de sus sociedades y líderes (Aron, 1979).

Es en este momento es donde debemos desplazarnos de la lógica de acumulación ordenada a la exterioridad del Estado -el medio internacional- y comenzar a ver la dinámica que todos ellos conforman y la manera en que ella deviene. El mecanismo que determina esa lógica, en el realismo clásico, no es otra que la del equilibrio de poder. El que, curiosamente, presenta una suerte de tensión interna en su denominación, bien señalada por Spykman: debemos llamarlo, en realidad, desequilibrio de poder (los Estados están interesados en que exista un margen de diferencia de poder a su favor, y la razón es evidente: no es seguro tener el mismo poder que un par, sólo es seguro tener más que él) ${ }^{55}$. A lo que debemos sumar que además del margen que los Estados desean para adquirir grados de libertad, se suma un desequilibrio de hecho: el reconocimiento de la soberanía estatal en el escenario internacional otorga igualdad de jerarquía entre Estados en lo formal, pero en los hechos, cada Estado posee una 'cantidad' relativa distinta de poder de influencia en un equilibrio dado (Kaplan, 1964).

\footnotetext{
${ }^{55}$ Cf. Spykman, Nicholas (1942): American Strategy and World Politics, Nueva York. Harcourt Brace Jovanovich. pp. 21-22.
} 
El equilibrio de poder es la única vía de moralidad que admite el realismo -por la que correrá la prudencia- ${ }^{56}$, y la manera más simple de definirlo resulta la de señalar que un Estado no debe poseer nunca fuerzas tales que los Estados vecinos se vean incapaces de defender sus derechos contra él (Aron, 1979). Y manera más precisa -y en el máximo nivel de abstracción-, refiere a la maniobra por la cual se impide a un Estado a la acumulación de fuerzas superiores a las de sus rivales $y / o$ aliados. $Y$ todo su sentido de ser se reduce a esto. Lo que acarrea una consecuencia lógica y teórica, que Raymond Aron (ibídem) pone en boca de Hume ${ }^{57}$ : el equilibrio de poder reviste una lógica opuesta a todo idealismo, dado que no podría funcionar en algún tipo de conformación de poder global (para Hume eso era una monarquía universal). Por eso Aron destaca que:

La política de equilibrio obedece a una regla de sentido común y se deriva de la prudencia necesaria para aquellos Estados que se preocupan de preservar su independencia y de no quedar a merced de un Estado que disponga de medios irresistibles. Parece condenable, a los ojos de los hombres de Estado o de los doctrinarios que ven en el uso abierto o clandestino de la fuerza, que explota a veces en violencia, la marca y expresión de la maldad humana. Además, estos censores deberían imaginar un sustituto, jurídico o espiritual para el equilibrio de voluntades autónomas. La misma política del equilibrio será juzgada como moral o, al menos como históricamente justificada ${ }^{58}$, por

\footnotetext{
56 Es interesante ver la postura de uno de los realistas más particulares, Reinhold Niebuhr, en esta cuestión: él se oponía a ver al hombre como un ser sin viso de bien (eso barría su sistema de creencias, pues era pastor protestante). Y por eso sugiere un realismo amenizado con una moralidad que abarcase a hombres como naciones, los que deben emplear su poder para hacerlo instrumento de justicia al servicio de intereses ajenos y no de sus propósitos particulares. Curiosamente, el mecanismo para lograr la justicia internacional era, simplemente, el equilibrio de poder (Cf. NIEBUHR, Reinhold (1949) Christianity and power politics, New York, MacMillan)

${ }^{57}$ En el clásico ensayo sobre el tema On the balance of power de 1752.

58 Más adelante afirma (página 201) algo que resulta importante para nuestro interés de presentar el realismo como una explicación compleja, densa y en lo absoluto unidimensional de la 'perenne mezquindad humana'. De este modo, en plena Belle Époque, el equilibrio de poder resultaba un compromiso histórico entre el estado de naturaleza (donde el más fuerte es el enemigo, y éste es quien
} 
todos aquellos que temen una monarquía universal y que desean la supervivencia de los Estados independientes. (Aron, 1979: 195 [traducción propia $^{59}$ )

El balance de poder como dinámica entre Estados no escapa a cierta ambigüedad conceptual, siempre solapada en los análisis que refieren a él. Por un lado, la manera en que se distribuye el poder entre los Estados en un momento de la historia (Wilhelmy, 1988), lo que creemos es su dimensión estática, referida a las posiciones relativas. Por otro, lo que vemos como aspecto dinámico, que Dougherty y Pfaltzgraff (1990) denominan 'alteración' del equilibrio: por ejemplo, un Estado adquiere primacía en el tablero mundial, lo que es respondido por los otros con una coalición contra él. Esto no es más que una manera de re-acomodar las cantidades de poder distribuidas, por así decirlo, ya sea por vía de la restauración o por la simple constitución de un estado nuevo.

Claro que, como señaló Morgenthau (2003), corregir el balance de poder lleva con él los elementos de nuevas perturbaciones ${ }^{60}$ : por eso creemos interesante enfatizar lo

escoge entre la guerra o la paz) y el imperio de la ley. Pero ese estado de natura no es la guerra de todos contra todos sin límites: los Estados reconocen el derecho a la existencia y quieren preservar un equilibrio y hasta cierta solidaridad frente al mundo exterior (Aron, 1979: 201)

${ }^{59}$ Del original: A política de equilibrio obedece a uma regra de bom-senso e deriva da prudência necessária aos Estados desejosos de preservar sua independência, de não estar à mercê de outro Estado que disponha dum meio incontrastável. Parece condenável aos olhos dos estadistas ou dos políticos doutrinários que interpretam o uso da força, aberto ou clandestino, como a marca e a expressão da maldade humana. Esses sensores devem assim conceber um substituto, jurídico ou espiritual, para o equilibrio de vontades autônomas. A mesma política de equilíbrio será considerada moral, ou será pelo menos justificada historicamente, pelos que temem uma monarquia universal e almejam a sobrevivência dos Estados independentes; será considerada senão imoral, pelo menos anárquica, pelos que, ao contrário, num espaço dado e num momento determinado, preferem a unidade de um império à manutenção de soberanias múltiplas 
que Wilhelmy (1988) señala como 'control'. Esto no es otra cosa que la consecuencia del significado anterior sólo que virando el énfasis al actor que controla el equilibrio del poder (un incremento decisivo de poder resulta en su capacidad de alterar una vez más el estado de cosas con cualquiera de sus movimientos). En menos palabras, aquello a lo que Haas señala como situación de hegemonía: el equilibrio -o desequilibrio- en favor de uno o unos actores).

Vale decir que ha habido también quienes se han revelado con estas críticas, como es el caso de Kenneth Waltz (1979a), bajo el señalamiento de una masiva mala interpretación del mecanismo por parte de los teóricos (sobre todo, en lo que hace a la objeción de sus supuestos 'irreales'): los presupuestos no son verdaderos ni falsos, sino que resultan esenciales a la construcción de una teoría explicativa. A diferencia de $\operatorname{otros}^{61}$, Waltz cree que el equilibrio es un mecanismo automático, inevitable, a causa de que los Estados procuran objetivos por esfuerzos internos (aumentando sus capacidades) y externos (reforzando sus alianzas y debilitando las ajenas) ${ }^{62}$, y así desarrollan una configuración del medio internacional al margen de las conductas de cada actor.

\footnotetext{
${ }^{60}$ Morgenthau es uno de los casos de críticos del equilibrio de poder que no podríamos sospechar de antemano: uno de los padres más renombrados del realismo, señala que aquél ha fallado efectivamente en varias ocasiones desde 1648 a 1914 -lograr que un Estado no prevalezca fue logrado a un precio bélico alto (Dougherty y Pfaltzgraff, 1990)-, por eso lo cree irreal. Después de todo, los estadistas compensan la incertidumbre buscando a la superioridad. Y también lo ve incierto, porque es imposible de mensurar (Morgenthau, 2003). Esta última cuestión la canceló Raymond Aron (1979) Ilamando al equilibrio de poder como 'equilibrio de fuerzas', las que son efectivamente mensurables.

${ }^{61}$ Es decir, a otros teóricos clásicos del equilibrio de poder como Churchill, Aron y hasta contemporáneos como Kissinger, los que -allende las diferencias- creían que el equilibrio debía ser un mecanismo de funcionamiento voluntario al que se seguía por prudencia.

${ }^{62}$ En el acápite específico volveremos sobre estas cuestiones, huelga desarrollarlas aquí.
} 
Para terminar, vale mencionar los significados que posee la expresión equilibrio de poder. Como tantos otros términos en relaciones internacionales y otras disciplinas sociales, sus significados aparecen desplazados en muchas ocasiones. Barbé (1987) expone esta diferencia en tres sentidos principales: el equilibrio del poder como situación, lo que implica una distribución determinada del poder en la escena internacional (el que podrá concebirse como una situación de equilibrio propiamente dicha -denominada equilibrium-, o bien, una alteración donde existen actores con preponderancia de poder que signan un determinado desequilibrio). El equilibrio de poder como política, es decir, como principio conductor, especialmente interesado en el impedimento de la preponderancia de algún Estado para mantener en equilibrio a los principales rivales (para esto, la prudencia a la Morgenthau es determinante). Esta lógica es similar a la de holder of the balance típicamente británica durante los siglos XVIII y $X X^{63}$. Y por último, el equilibrio de poder como sistema, donde el interés colectivo reside en mantener reglas de funcionamiento que sostengan el equilibrio -o sea, que contengan las ambiciones de uno o algunos de los otros Estados- ${ }^{64}$. Para esta dimensión es determinante la cantidad de centros de poder que presente el sistema

\footnotetext{
${ }^{63}$ La particularidad de esta dinámica reside en que Inglaterra ejercía la supremacía en Europa, pero no atenta contra el equilibrio sistémico porque su expansionismo se encauzaba en colonias fuera del continente (CF. KREIBOHM, Patricia (2015) La Primera Guerra Mundial. Una contienda de transición entre la Guerra Institucionalizada y la Guerra Total, en Relaciones Internacionales - № 49, distinguido con el Premio Intercultural 2014 de Ciencias Históricas)

${ }^{64}$ La vuelta al equilibrio puede ser vista de dos maneras principales: como un proceso automático (Barbé cita los casos de la propuesta de Jean Jacques Rousseau en su Extrait du Projet de Paix Perpétuelle de M. L'Abbé de Saint Pierre (1823); similar a la que Quincy Wright refirió como equilibrio mecánico -de lógica parecida a lo que Morton Kaplan asimilaba a la mano invisible de Adam Smith-. La otra manera reside en el equilibrio alcanzado de manera dirigida, de la cual el Congreso de Viena de 1815 resulta un ejemplo claro.
} 
(multipolar, bipolar o unipolar) y la estabilidad del sistema, en su carácter moderador de las conductas de los Estados (lo que no implica la eliminación del conflicto). 


\begin{abstract}
«Nuestra política exterior no sólo tiene un patrón doble con respecto a lo que ha dado en llamarse "derechos humanos", sino que también tenemos un patrón triple y uno cuádruple. En realidad, tenemos tantos patrones como las circunstancias lo requieren, que es como debería ser (...) Somos libres de empeñarnos en la silenciosa diplomacia de la persuasión, la abierta diplomacia de la intimidación, una política exterior que puede incluir o no la intervención militar, siempre dependiendo de las circunstancias》 Irving Kristol, 1993

"Inglaterra no tiene aliados eternos ni enemigos perpetuos; sólo sus intereses son eternos y perpetuos, y nuestra obligación es vigilarlos» Lord Palmeston, s/d
\end{abstract}

El realismo nos provee de unas características de la dinámica del medio internacional, de su lógica interna de funcionamiento -la mayoría de ellas pasibles de ser rastreadas históricamente- y ofrece el mecanismo teórico-práctico que logra sobreponerse a esa inseguridad impertérrita: el poder. Sobrevivir en la anarquía que determina relaciones preeminentemente conflictivas, arroja a los Estados a procurar su seguridad por sobre todas las cosas. Una dinámica planteada en estos términos, conlleva una posición de desconfianza preventiva, donde los Estados racionales-egoístas (Glaser, 1997) se ven obligados a velar por sí mismos (self-help) para asegurarse la supervivencia (security seekers) y así caen en el dilema de la seguridad: se arman para reasegurarse, y por esto mismo resultan una amenaza a terceros, lo que volverá a arrojarlo en estado de inseguridad, con el agregado, ahora, que los pares estará más armados (Waltz, $1979 a)^{65}$

\footnotetext{
${ }^{65}$ A la sazón, este dilema partió la escuela neorrealista en dos corrientes: los realistas ofensivos (como John Mearsheimer) y defensivos (como Kenneth Waltz o Stephen Walt). Los primeros sostienen que los
} 
Así entra en escena el interés nacional, aspecto insoslayable salvo que el Estado esté dispuesto a extinguirse (Morgenthau, 1948). Enarbolado en la política exterior, resulta en algo así como la interfaz del Estado con el sistema internacional, dentro de lo que se llamaría la alta política ${ }^{66}$. Su genealogía está imbricada con el realismo, por lo que los autores señalados como sus padres en el siglo XX (Carr, Morgenthau, etc.) no fueron los primeros en rescatarla de la historia moderna: En 1934, Charles Beard analizó la facetas del interés nacional norteamericano de fines de los '20s relacionando las potencialidades diplomáticas en relación con la política doméstica, en especial la económica ${ }^{67}$. Su determinante $-y$ tal vez la fuente de la vaguedad teórica que se le reprocha- reside, sin duda, en el pragmatismo. En concreto, en la imposibilidad de divorciarse de las circunstancias:

Sin embargo, el tipo de interés que determina la acción política en un determinado período de la historia depende del contexto político y cultural dentro del cual es formulada una política exterior [traducción propia] (Morgenthau, 2013: 18) ${ }^{68}$

La perspectiva morgenthauniana no es sólo materialista, de hecho, recupera a Max Weber para justificar esta definición acerca de la importancia del contexto:

\footnotetext{
Estados maximizan su interés en la acumulación denodada de poder militar, mientras los segundos sostienen que buscan preservar el statu quo a través del equilibrio de poder (Clulow, 2013).

66 La distinción entre alta y baja política es típica del realismo: mientras la primera alude a cuestiones de seguridad militar, la segunda alude a las dimensiones económicas, sociales y culturales (Nielsen y Pires, 1992)

${ }^{67} \mathrm{Cf}$. The Idea of National Interest, Macmillan Company, New York.

${ }^{68}$ Del original: Contudo, o tipo de interesse que determina a ação política em um determinado período da história depende do contexto político e cultural dentro do qual é formulada a política externa
} 
Son los intereses (materiales e ideales), y no las ideas, que dominan de manera directa las acciones de los hombres. Sin embargo, son las 'imágenes del mundo' creadas por esas mismas ideas que funcionará como cambio de agujas al determinar sobre cuáles rieles correrán los intereses que mantienen el movimiento de las acciones (traducción propia de Morgenthau, 2013: $18)^{69}$.

Centrado de manera genérica en la preservación de la integridad territorial, la independencia política y la identidad cultural (Clulow, 2013), el interés nacional subordina todo principio de corte moral o ideológico a sus determinaciones (Tucker, 1952). Para el realismo, la dinámica última sería la de oponer poder a poder

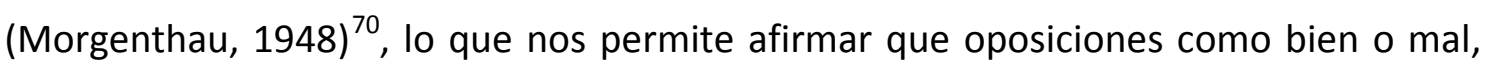
moral o inmoral, izquierdas o derechas, progresismo o conservadurismo, no aplican a la esfera del interés nacional. ${ }^{71}$ Es por eso que es atinado lo que señala Caughey (1967), refiriéndose a Morgenthau: la política es la ética (y no de otro modo). Con esto no afirmamos la amoralidad como algo necesario en la economía del interés nacional: puede, efectivamente, estar basado en principios morales de alguna índole, lo que resulta inaceptable es que lo informen principios morales divorciados de la realidad política. Y esta situación puede, incluso, llevar a un resultado moralmente condenable,

\footnotetext{
${ }^{69}$ Del original: são os interesses (materiais e ideais), e não as ideias, que dominam de modo direto as ações dos homens. Contudo, foram as 'imagens do mundo', criadas por essas mesmas ideias, que frequentemente serviram como chaves de desvio, ao determinar sobre que trilhos o dinamismo dos interesses manteve as ações em movimento.

${ }^{70}$ Recordemos el principio predicado por Baruch Spinoza unusquisque tantum iuris habet, quantum potentia valet, es decir, cada uno tiene tanto derecho como su poder le permite.

${ }^{71}$ Allende que en el discurso ante la opinión pública puedan alegarse razones políticas para justificar, explicar o proyectar acciones determinadas en la política exterior.
} 
desde que coloca a un Estado al borde del suicidio y a una sociedad a su destrucción. Con esto podemos concluir que el interés nacional es, en sí mismo, un valor moral.

El interés nacional es, por definición, irreductible a los intereses privados (Aron, 1962). Se lo supone el interés del Estado, y por ello es un hecho legítimo -sin necesidad del consenso que requieren los asuntos la política doméstica- ${ }^{72}$ sobre los objetivos externos estatales. Y lo cierto es que, aun cuando el concepto padece una alta vaguedad y en la práctica funciona no sólo informado por cuestiones de alta política también está cargado de justificaciones no siempre tan racionales como alega- ha orientado y sigue orientando la política exterior (Tomassini, 1991).

Por supuesto que esto conlleva consecuencias analíticas: se utiliza un concepto al que se le reprocha su vaguedad para desentrañar motivaciones y objetivos de la política exterior y así acercarlo a los intereses reales de la agenda internacional de un país en un momento dado. En el plano conceptual, esto podría entenderse como la carencia de operacionalización, ante la falta de categorías de juicio para definir, jerarquizar, comparar y relacionar intereses específicos y desagregarse en un análisis (ibídem). De hecho y ante esto, Tomassini propone la noción de agenda internacional, reflejo de un

\footnotetext{
${ }^{72}$ Recordemos la diferencia axiológica entre la política doméstica y la exterior recuperando a George Kennan quien aporta a esa distinción una explicación certera en la práctica política. En un famoso pasaje de su obra Realities of American Foreign Policy ([1954] citado en Dougherty y Pfaltzgraff (1991) afirma: cuando el comportamiento de un individuo pasa por la maquinaria de la organización política (...) para encontrar su expresión en las acciones de gobierno, entonces sufre una transformación general y los mismos conceptos morales ya no son importantes para él. Esto tiene una consecuencia técnica al interior de la hechura de: ella no expresa la aspiración de un pueblo. Es responsabilidad de una fracción política nacional, y aun cuando pudiere ser un gobierno democrático, ella no es consensuada: la opinión pública no interviene aquí, desde que 'los asuntos internacionales son asuntos de relaciones entre gobiernos y no entre pueblos' (ibídem)
} 
mundo más complejo, transnacional e interdependiente, de carácter más diversificado, menos jerarquizado y más entrelazado que el del realismo clásico. Por esto es determinante atender que la existencia del interés nacional implica, de suyo, multiplicidad de ellos y, por vía del supuesto de conflictividad en el medio internacional, la falta de armonía entre ellos:

Debemos, por lo tanto, rechazar por inadecuado y errado el intento de basar la moralidad en el espacio internacional sobre una supuesta armonía de intereses los que se identifican con el interés de la comunidad de naciones con el interés de cada uno de sus miembros individuales (Carr, 2001: 124 [traducción propia] $^{73}$ ).

\section{Completado por Kennan:}

Tanto como no hay ninguna relación personal sin complicaciones entre individuos (...) no hay relación internacional entre estados soberanos que no carezca de elementos de antagonismo, sus aspectos competitivos (Kennan, 1958: 367, en Dougherty y Pfaltzgraff, 1990 $)^{74}$.

Aun cuando la política exterior constituye una dimensión más de todas las del quehacer político (al igual la política doméstica en salud, por ejemplo), el interés nacional le imprime una suerte de dinámica diferente en dos sentidos: por un lado, su continuidad en el tiempo y por el otro, su discontinuidad con la política interna. Morgenthau (2003) explicó con precisión esta cuestión: los sucesivos cambios de

\footnotetext{
${ }^{73}$ Del original: We must therefore reject as inadequate and misleading the attempt to base international morality on an alleged harmony of interests which identifies the interest of the whole community of nations with the interest of each individual member of it (Carr, 2001: 124).

74 De KENNAN, George: Russian and the West under Lenin and Stalin, Harper \& Row, New York, 1958.
} 
gobierno y las preferencias personales de cada uno de ellos -o incluso de su titular, como en los países presidencialistas- no deberían impactar en el interés definido como poder, por la sencilla razón que la política externa queda determinada por un orden racional que la hace consistente consigo misma, inteligible y de un perfil con determinadas notas esperables (dicho de manera algo coloquial, lo que hace que la política exterior británica, estadounidense, brasileña o uruguaya sean similares a sí mismas a lo largo del tiempo -más allá de variaciones de cada gestión nacional-). Morgenthau sostenía que ese orden racional se ponía en juego en tres patrones de acción estatal para la lucha por el poder: la mantención del poder ya adquirido, junto con la distribución del poder en los demás actores. Se la conoce como estrategia de status quo y es típica de situaciones de posguerra. La segunda, conocida como imperialista, implica el incremento del poder (de suyo rompe el status quo, y puede tener una plétora de opciones a su interior: desde la hegemonía regional, hemisférica o mundial, hasta el cambio de correlación de fuerza con un sólo actor en el sistema internacional). Y el tercero, el recurso de la ostentación del poder-como por ejemplo ceremonias diplomáticas, o la ostentación de fuerza militar- conocida como estrategia de prestigio. Toda política exterior responde a uno o a una combinación de estos patrones.

De este modo, sobre un valor basal en constante funcionamiento (Lerche, 1956) ${ }^{75}$ se deposita el elemento variable, es decir, aquello 'determinado por las circunstancias'

\footnotetext{
75 Es decir, a pesar de los cambios circunstanciales de la política exterior (incluidas las conductas de otros Estados con respecto a la política exterior propia) y, desde ya, de la lucha política interna (Rubio García, 1976).
} 
(Rubio García, 1974). Es por ello que puede ser visto como un factor estabilizador del devenir del sistema internacional, siempre y cuando contemplemos que su permanencia no es perenne sino relativa: está también influenciado por aspectos de orden cultural, política, económica y hasta militar. De este modo, todo cambio en estos dominios podrá afectar (Lerche, 1956; Padelford y Lincoln, 1969) y eventualmente vencer la inercia de persistencia ${ }^{76} \tan _{\text {típica del interés nacional }}{ }^{77}$. Es necesario mencionar que existen análisis que no consideran la estabilidad del interés nacional como una nota distintiva. Aquí el interés nacional no supera más que las pretensiones de un Estado sobre otros Estados, y expresa, simplemente, los objetivos específicos del sector que gobierna. Esto implica que el interés nacional se desplaza a las elites, y entonces debemos reemplazar el primer adjetivo (nacional) por el segundo (gobernante) $)^{78}$.

Lo cierto es que creemos que no es conveniente detenerse en la supuesta vaguedad del término (esa objeción es sólo un pedido por el contenido del interés nacional, y su cualidad principal es, justamente, la de no versar sobre ellos). Por eso y esbozar una caracterización operativa a manos de Frederick Hartmann, quien considera al interés nacional en plural y lo define como:

\footnotetext{
${ }^{76}$ Este puede ser el caso de la dimensión identitaria, un componente aportado, principalmente, por los abordajes constructivistas, quienes proponen una noción del interés nacional resultado de ideas compartidas, identidad nacional y prácticas normativas, por lo que el contexto cultural -resultado de la interacción social- se torna en un componente determinante (para mayor caracterización, cf. LINKLATER, Andrew (2000) International Relations: Critical Concepts in Political Science, Routledge) 77

${ }^{78}$ Cf. Ernst HASS y Alien WHITING, Dynamics of International Relations, IAED, Nueva York, 1956. pp. 4445
} 
Las cosas que los estados tratan de proteger o conseguir frente a otros estados (Hartmann, 1994: 43)

Hartmann agrega, además, que los aspectos vitales son aquéllos por los cuales el Estado está dispuesto a armarse, y los secundarios aquéllos para los cuales no involucran violencia y apelará a la diplomacia, organismos internacionales, etc. Esos aspectos vitales o innegociables ante los pares, están, por supuesto, ordenados: una vez salvada la supervivencia del Estado, siguen en orden de importancia las preferencias de las elites y percepciones del ambiente externo, la autopercepción de las elites sobre su rol en la formulación de la política exterior, los riesgos en términos de política doméstica a los que la somete un determinado curso de acción (y su propensión o aversión a tomar riesgos) (Schweller, 2004). Podemos representar ese orden de importancia en algunos elementos meramente indicativos (De Almeida y Poli Navega, s/d): independencia nacional (y preservación de la integridad territorial), soberanía en la toma de decisiones estratégicas, garantía de recursos para la economía nacional (energía, bienes primarios y seguridad alimentaria -bajo una restricción dada por escasez o proteccionismo de cualquier tipo-). Los autores agregan una serie de objetivos de la política exterior que enriquecen por demás el interés nacional, y que no implican al país de origen solamente, como son la cooperación con los demás miembros de la comunidad internacional en la mantención de la paz, seguridad y estabilidad orientada al desarrollo económico-social, junto con la preservación de los derechos humanos y del sistema democrático a nivel regional y global (aun cuando esto último aún sea objeto de disenso en cuanto a su aceptación en el segundo nivel). 
Esto implica, por un lado, el involucramiento del ambiente internacional (democrático, estable, seguro) en el interés nacional, un componente solidario de los Estados en pos del sistema, que aleja de la noción de anarquía por doquier predicada por el realismo más estricto; y por el otro, aun cuando los primeros objetivos puedan parecer estrictamente nacionales, tienen que ser evaluados a la luz de las dinámicas creadas por la interdependencia económica -global o regional- (De Almeida y Poli Navega, s/d).

La importancia de estos aspectos nos deja enfrentados a una característica, un punto de fuga tal vez, que no necesariamente se desprende de diferentes concepciones técnicas, sino políticas: concebir el interés nacional requiere evaluar riesgos, oportunidades y escenarios estratégicos -principalmente de largo plazo (De Almeida, 2016)-. Una lectura inadecuada del ambiente externo, el sobredimensionamiento de algunos factores y la subestimación de otros, como una lista de objetivos demasiado extensa o con inconsistencias internas, hacen de la política exterior un camino errático. El criterio debe orientarse por prioridades eficientes (mayor grado de acción con mayor retorno). Así, al contrario del juicio de Kennan, acabaríamos por someter el diseño de la política exterior a diferentes grupos políticos en el ejercicio de la representación, los que manifiestan concepciones diversas del interés nacional basados en la supuesta legitimidad de las urnas. Una proposición falaz, dado que los electores no podrían poseer ni siquiera la información mínima para evaluarlo. Por eso De Almeida (ibídem) propone otra estrategia: si es imposible avanzar por la vía 
esencialista (qué constituye el interés nacional), podríamos tomar la vía negativa (qué

no es el interés nacional). Aún en ese caso, es preciso tener señales de contención ${ }^{79}$.

Pero evitaremos ahondar en estos aspectos -los retomaremos más adelante- para poder mencionar las implicancias teóricas del concepto de interés nacional para el realismo, que según los autores aparece articulada a otras variables de la dinámica internacional: en Carr, a la manutención del orden internacional ${ }^{80}$; en Morgenthau, a la paz internacional (por eso considera que las justificaciones ideológicas y toda consideración no esencial para la supervivencia del Estado contribuye al conflicto internacional ${ }^{81}$. En Kennan, a la limitación de capacidades y metas ${ }^{82}$; en Kissinger, la

${ }^{79}$ Es interesante señalar algo que menciona el autor (2016) acerca del contexto en que se define el interés nacional: citando a Rubens Antônio Barbosa, diplomático director de la Revista Interesse Nacional (año 1, número 1, abril-junio), quien definía, para 2008, el interés nacional brasileño en la intersección de la democracia como valor y la inserción internacional como objetivo (entendido como condición del desarrollo). Pero estas decisiones no se toman en vacío: Almeida toma por ejemplo la toma de posición valorativa en la democracia representativa mientras un parceiro firma el decreto bolivariano 39.355 (28/12/2009) de los Consejos Populares para el diseño de políticas (el que, por supuesto, no se condice con el criterio representativo del ejercicio democrático). En este sentido, los compromisos de las naciones en una parte del espectro del interés nacional pueden impactar en otra parte del espectro del mismo (sin olvidar que impactan también sobre alejar consensos construidos a lo largo de muchos años de negociaciones del cuerpo diplomático, una herramienta determinante de la política exterior). De este modo, las prioridades deben ser establecidas en una alianza basada en la evaluación de la complementariedad recíproca antes que en el impulso subjetivo basado en la afinidad de intereses (De Almeida y Poli Navega, s/d)

${ }^{80}$ Carr (2001) señala que poco importa cuál fuere el principio en que creyese el utopismo: lo determinante es que esos principios -aparentemente universales- estaban basados en una concepción de interés nacional determinado reflejo de la política doméstica. Al aplicarlos, trasparece los intereses egoístas de esa política doméstica, y ello nos muestra que la falencia del idealismo no reside sólo en no vivir según lo que predica, sino en su incapacidad de crear un patrón realmente desinteresado para gestionar los problemas internacionales.

${ }^{81}$ Por ejemplo, el nacionalismo impertérrito del siglo XX condenó a varias naciones a embarcarse en búsquedas de supuestos intereses nacionales que no son esenciales para su supervivencia. Por eso afirmó que el nacionalismo moderno se asemeja con el mesianismo nacionalista, y así oscureció por completo la noción de interés nacional en la práctica (esto incluye a Estados Unidos, quien a juicio de Morgenthau se embarcó en la intervención de Vietnam, conflicto situado más allá de sus intereses vitales (Dougherty y Pfaltzgraff, 1990)) 
estabilidad del sistema internacional (Dougherty y Pfaltzgraff, 1990). Incluso en Waltz, ya en las áreas del neorrealismo, el interés nacional es una herramienta al servicio de la estabilidad internacional y de la posibilidad de protección de Estados menores unidos a un hegemón. De hecho, los Estados menores pueden unirse al hegemón precisamente para asegurar su propio interés nacional. Lo que Waltz (1979a) Ilama comportamiento de grupo (bandwagon) funciona también como una suerte de garantía del interés nacional para los Estados que rodean al poderoso. El incentivo de la garantía no es ideológico ni estratégico, digamos que resulta un poco más imprescindible: en un medio donde la polaridad (es decir, la disposición de actores poderosos) diseña la estructura del tablero mundial, los Estados con menor jerarquía en la estructura deberán acomodarse a los centros de poder para preservar su integridad territorial.

Vemos con esto que, si bien el interés nacional no es previamente definible por algún contenido que no sea estrictamente pragmático, situado en tiempo y espacio, tiene un rol teórico y práctico en los análisis realistas. En otras palabras, es un elemento irremplazable para analizar y prever la conducta de un país y en la evaluación del funcionamiento del sistema internacional. Es, creemos, un elemento que ayuda a dar un perfil de consistencia en el tiempo, una racionalidad en determinado sentido en el devenir de los Estados en la escena internacional, por lo que brinda un parámetro del decurso del sistema internacional a partir de las conductas de sus actores (por

\footnotetext{
82 Kennan rechazaba de plano los valores absolutos y la moralidad inserta en el interés nacional (esto sólo tenía un destino: los objetivos ilimitados, es decir, la dominación total a través de la guerra total y leyes de rendición incondicional). Por ello los objetivos de política exterior deben ser esencialmente limitados (Kennan, 1967)
} 
supuesto, con las salvedades del caso, que remiten a las interpretaciones que los estadistas hacen de ese interés, a las contingencias del medio internacional, etc.). No obstante, esto, la categoría de interés nacional sigue presentando algunos problemas. La primera es el grado de consistencia con la realidad: Estados pequeños o incluso medianos no diseñan sus políticas exteriores en clave de poder (Clulow, 2013). También existe la posibilidad que quieran incrementar su poder, pero no pensándolo en términos de seguridad -por la existencia de una amenaza militar concreta-. Luego están los problemas operativos del interés nacional: los estadistas no deciden en vacío, interpretan según múltiples constricciones (políticas, culturales, la información que les acercan y, muchas veces, no pueden emigrar por completo de las decisiones de sus predecesores (Dougherty y Pfaltzgraff, 1990)). Y, si atendemos que el interés nacional está formulado por un grupo determinado -siguiendo a Kennan-, pues las interpretaciones resultan diferentes según quienes lo presenten (Lerche, 1956).

Tal vez la objeción más lapidaria venga de entre sus filas: existe una imposibilidad de definir el interés nacional en términos realistas, juicio que Rubio García (1976) coloca en Raymond Aron. Si el interés nacional implica la prioridad de la seguridad, de los fines limitados, de la consciencia de los recursos disponibles y de que la diplomacia no se 'contamine' de idealismo, debemos, también, contemplar que una gran potencia no sólo se reduce a preservar su seguridad y de suyo quiere tener más influencia (es decir, el mayor número de aliados y el menor de enemigos). La influencia no sólo implica 
fuerza, sino también un estilo de vida en el sentido más amplio del término. $Y$ eso, curiosamente, deviene en el espíritu de cruzada ${ }^{83}$, siempre aborrecido por el realismo.

\footnotetext{
83 Morgenthau define el 'espíritu de cruzado' con eficiencia: así como los cruzados querían liberar los sitios sagrados de la dominación de los infieles, Woodrow Wilson deseaba cambiar al mundo en un lugar seguro para la democracia; los nazis insistían en abrir Europa Oriental a la colonización alemana, dominar a Europa e conquistar o mundo (Morgenthau, 2003: 49 y 50). En menos palabras, las políticas exteriores oficiaban misiones sagradas por llevar la religión política verdadera. La realidad, la visión pragmática, el interés despojado de 'deber ser', queda descartado en esta concepción de política externa. Kissinger (1986) señala que Wilson transformó la neutralidad norteamericana previa 1917 en una cruzada planetaria, reinterpretando a Washington al asumir que no había una diferencia entre libertad nacional y ajena. Kissinger explica esta interpretación polémica según Terencio: 'nada que concierna a la humanidad puede sernos ajeno'-, por lo que intervenir está justificado.
} 
《Si el adversario considera que usted es imprescindible o temerario, estará desalentado a presionarlo mucho》》 Richard Nixon, 1980

《Los pensadores más sensitivos del Occidente han reconocido que el excesivo empirismo puede conducir al estancamientol》 Henry Kissinger, 1966

El neorrealismo -o realismo estructural ${ }^{84}$ - nace a finales de los setentas incorporando nuevos elementos teóricos y metodológicos (Hoffman, 1991) que incorporan elementos más allá de los actores individuales. Observar la dinámica de conjunto no era una novedad: En 1962 [1979] Aron ya consideraba, casi como un precursor del neorrealismo -esta consideración es exclusivamente nuestra-, al sistema internacional como una variable determinante del análisis de las relaciones internacionales. Lo que sí fue novedosos su sistematización analítica: El factor teórico determinante reside en la estructura del sistema internacional -sus influencias sobre la política internacional de los Estados (Del Arenal, 1994)-, y el factor metodológico saliente implica un interés en la rigurosidad científica con la incorporación de métodos cuantitativos. Estos permiten sobreponerse a lo que se señalaban limitado en el realismo: la carga de

\footnotetext{
${ }^{84}$ Esta identidad podría ser objetable. A los fines de estas hojas no reviste mayores consecuencias, pero lo que denominamos neorrealismo se circunscribe a la formulación de Waltz en Theory of International Politics mientras existen otras que son denominadas propiamente realismo estructural como el de Buzan, Jones y Little (1993) quienes comparten con los institucionalistas y los teóricos de la sociedad internacional, la posibilidad de cooperación sostenida en un clima de anarquía; también encontramos otros trabajos de Snyder y Diesing en teoría de los juegos (1977) y los desarrollos de Robert Gilpin sobre las causas de declive de los Estados hegemónicos.
} 
supuestos antropológicos que da lugar a enfoques intuitivos atados a la perspectiva del analista. Así, se pretende superar la validación sólo apoyada en el análisis histórico sin basamento en la teoría social (Nielsen y Pires, 1992), junto con el sesgo de autonomía absoluta de la política -ella se decide, en última instancia, en la fuerza militar (ibídem)-, y la dinámica de actores más similares a mónadas que a un sistema con cierto grado de organización.

Esto muestra algo que creemos alentador: las relaciones internacionales se organizan entre diferentes debates que no son simples de hilvanar en un mismo corpus (sus supuestos resultan lo suficientemente diferentes como para no poder hacer una sutura prolija, y a la vez, no todos tienen el mismo grado de generalidad (Palomares Linares, 1991)). Pero, en el nivel estrictamente metodológico, podemos encontrar una cierta integración, en este caso. Así el anhelo por la rigurosidad científica caracteriza al paradigma conductista (behaviorista), en auge en los cincuentas y sesentas del siglo veinte, centrado en herramientas experimentales cuantitativas alejados del análisis intuitivo y cualitativo del paradigma tradicional. Podríamos verlo inervado en el neorrealismo y así encontrar su aporte duradero al corpus disciplinal. Reformulando a Vásquez (1983), Banks afirma:

Al igual que el idealismo anteriormente, el behaviorismo nunca cuestionó los presupuestos fundamentales respecto al objeto en el enfoque realista subyacente, se centró en los métodos de investigación, así como el idealismo se había centrado en los valores y las prescripciones de política. Ambos dejaron al realismo el control de las cruciales suposiciones estadocéntricas (Banks, 1985:11). 
En esencia, el neorrealismo se constituye a la luz de las insuficiencias de los globalistas $^{85}$, el realismo tradicional, influidos por las teorías del rational choice contemporáneas (Peñas Esteban, 2005) y la presión por obtener conclusiones más positivas, es decir, relaciones causales y conocimientos que permitan predecir e intervenir sobre la conducta entre Estados. Tanto en el neorrealismo como en el paradigma alternativo (globalismo) la influencia de metodologías racionalistas que incorporan la maximización de objetivos son la regla (por ejemplo, la teoría de los juegos para conceptualizar las situaciones de anarquía-cooperación).

Este tipo de formalizaciones se aleja del método histórico clásico, y se pierde gran parte del contenido filosófico -e incluso primitivamente psicológico- de antaño. Waltz (1979) pretendía una teoría lo suficientemente positiva de la política internacional que debía explicar por qué acontece la guerra e indicar algunas de las condiciones que la harían menos probable (pero no predeciría el desencadenamiento de alguna en particular). La razón reside en el que la teoría explica continuidades (qué esperar y por qué esperarlo), y, dentro de una configuración teórica sistemática explicará

\footnotetext{
${ }^{85}$ El debate neorrealismo-globalismo, enmarcado en la coyuntura de la crisis del sistema de BrettonWoods y el petróleo, involucró a Joseph Nye y Robert Keohane (aunque la posición del primero cambió a lo largo del tiempo). Los autores cuestionaron el estatocentrismo en un mundo cada vez más interdependiente gracias a los efectos de las instituciones internacionales (Salomón González, 2001). Baldwin (1993) sintetizó el debate en media docena de ideas, donde el neorrealismo afirma: 1) la anarquía constriñe el comportamiento estatal; 2) la cooperación internacional es difícil de lograr y mantener; 3) a los estados pretenden una posición de superioridad (por eso desestima la cooperación); 4) La seguridad supera toda prioridad económica; 5) la distribución de recursos (capacidades) explica su comportamiento (aun cuando decidan cooperar). 6) Los efectos constrictores de los regímenes e instituciones internacionales en la anarquía que señalan los neoliberales la anarquía, resulta exagerada en efectividad. Salomón González (2001) señala que, en la actualidad, la controversia se desplaza a la capacidad de afectar de instituciones internacionales las negociaciones multilaterales de los estados.
} 
recurrencias y repeticiones, pero no explicará el cambio. Curiosamente, señaló esto como una cuestión de elegancia:

Elegancia en la teoría social significa generalización a partir de explicaciones y predicciones (Waltz, 1979a: 102)

En el neorrealismo se mantienen intactas las consideraciones acerca de la centralidad del Estado y la moral escindida entre el orden interno y el exterior. La cualidad black box del Estado en el realismo (es decir, la de ser un actor unificado, coherente y racional, donde esas dos últimas cualidades se las otorga el interés nacional) se sostiene en el neorrealismo, sólo que el énfasis se traslada al plano sistémico (Actis y Schenoni, 2014) ${ }^{86}$. Existen quienes discuten el verdadero peso de la 'novedad' del neorrealismo, sobre todo, en la dimensión estructural (Maghroori y Ramberg, 1984; Ashley, 1984; Del Arenal, 1994): en la versión clásica, muchos analistas se detenían en sus análisis acerca del sistema internacional (como es el caso del sesudo análisis de Aron de 1962 (aquí, en edición de 1979)). Pero también, como el realismo ha analizado la política internacional desde el equilibrio de poder, implica cierta intuición estructural acerca de la dinámica de un grupo de Estados (cuestión en la que se detuvieron todos los realistas clásicos, obligados por su propia concepción de la dinámica interestatal).

\footnotetext{
${ }^{86}$ Aspecto opuesto al liberalismo, interesado en la apertura de esa caja negra con el fin de analizar los condicionantes de la proyección externa, fuere atendiendo el régimen político o las fuentes y tipos de poder (ibídem)
} 
Una diferencia -algo tibia- reside en reconocer la existencia -no necesariamente su impacto- de actores no estatales, que actúan a nivel de procesos. Una diferencia central reside en el poder, el cual resulta ineludible pero no un fin en sí mismo, por eso es recolocado en otro nivel de generalidad, es decir, en el de medio, en el de componente ineludible de la relación política:

Tanto como el instrumento de poder y de sanciones no agota la natura de la ley, la natura de la política no se agota refiriéndose primordialmente al poder como su herramienta más importante (...) El neorrealismo, en otras palabras, procede desde el presupuesto de que un grado mucho más alto de cooperación concreta y cuasi institucionalizada entre diferentes disciplinas es necesario antes de que se pueda hacer un avance esencial en nuestra capacidad de analizar y, si es posible, predecir procesos de acción política de los sistemas tan complejos como, por ejemplo, el estado-nación y sus subsistemas estructuralmente esenciales (Kindermann, 1985: 10-12 ${ }^{87}$; citado en Dougherty y Pfaltzgraff, 1990)

La dimensión estructural está, así, a la misma altura epistemológico-teórica que los Estados en el realismo clásico, pero, si bien los reconoce como las unidades por antonomasia del sistema internacional, es la segunda la que toma el lugar explicativo principal (si el neorrealismo se estableciera en las unidades, resultaría reduccionista, al meramente explicar las partes). Uno de sus padres, Kenneth Waltz, lo sintetiza con claridad:

La realpolitik señala los métodos por los cuales es conducida la política exterior y proporciona una racionalidad para ellos. Los constreñimientos

\footnotetext{
${ }^{87}$ De KINDERMANN, Gottfned-Karl The Munich School of Neorealism in International Politics, manuscrito inédito, Universidad de Munich, 1985.
} 
estructurales explican por qué son usados repetidamente esos métodos a pesar de las diferencias entre las personas y los Estados que los usan (Waltz, 1979a: 117).

El supuesto epistemológico detrás de esto es simple: la política internacional es más que la suma de las políticas exteriores de cada uno de los actores del sistema internacional, por lo que la estructura, es decir, la manera en que se disponen las partes especificadas por funciones, las que, si bien en apariencia están en pie de igualdad -todos los Estados son soberanos de manera equivalente-, ellas pueden presentar la forma jerárquica ${ }^{88}$ o anárquica (a mayor jerarquía, mayor diferenciación de funciones -y mayores medios, por ende, mayores capacidades-, a mayor anarquía, mayor similitud de ellas). De este modo, las unidades yuxtapuestas (los Estados) presentan diferentes formas y se comportan de manera distinta, al interactuar, pero también producen resultados diferentes (Waltz, 1979; comentado en Dougherty y Pfaltzgraff, 1990).

La variabilidad condiciona la estructura, por lo que los Estados se enfrentan a potenciar sus capacidades (políticas, militares y económicas) orientadas a su seguridad -lo que a su vez les dará un determinado lugar en la estructura-, y también, a (re)alinearse con otros agentes (decisión que retoza en la evaluación que hagan del

\footnotetext{
${ }^{88}$ Esta complejidad ya había sido expuesta por Raymond Aron (1962) en su estudio de los sistemas internacionales: la soberanía, formalmente idéntica en el tablero mundial, resultaba jerarquizada en el sistema internacional. Habría, por así decirlo, naciones con soberanías más efectivas que otras (Bertoglio Cardoso, 2008), algo muy simple de cotejar si pensamos en las décadas de bipolaridad del sistema internacional: el duopolio nuclear determinó una jerarquía determinada, donde dos potencias eran las únicas capaces de escoger soberanamente entre la guerra y la paz (Aron, 1962). Esta noción de limitación soberana adquiere otras formas, podemos también pensar en limitaciones soberanas para América Central con respecto a los Estados Unidos post Guerra Fría (Bertoglio Cardoso, 2008)
} 
equilibrio de poder). En esencia, la estructura, mientras los constriñe también los habilita a diferentes cursos de acción (y esta es la característica teóricamente efectiva de incluir la dimensión estructural: permite explicar y predecir continuidad dentro de ella $\left.{ }^{89}\right)$. Cambios al nivel de unidades producen menos cambios en los resultados del sistema que los que se esperarían de cambios en una estructura (por la tendencia contrición de ésta), y eso permitirá ver tendencias en el curso del devenir internacional (Waltz, 1979a) ${ }^{90}$.

En un medio tan dinámico, la categoría cambio (en la distribución de capacidades de las unidades) determina las sucesivas estructuras (Waltz, 1979), y resulta el concepto dinamizador que compensa el enfoque preponderantemente estático o estructural. Esto nos permite incorporar a Gilpin (1986) en sus aportes acerca de los cambios que sufre el sistema internacional: el primero cambio del sistema sucede por alteración en los agentes (desde las ciudades-estado griegas, el sistema europeo medieval y los estados nacionales modernos). El segundo, en los agentes que se erigen hegemónicos los que ascienden a expensas de los que están en decadencia ${ }^{91}$ - y por lo tanto establecen las reglas por las cuales el sistema opera. Y, por último, en las interacciones

\footnotetext{
${ }^{89}$ Este afán explicativo del neorrealismo fue, también, ampliamente criticado: la interpretación bajo un esquema de índole racional (agencia) se pone en tensión con las restricciones estructurales (Dougherty y Pfaltzgraff, 1990).

${ }^{90}$ El devenir analítico y epistemológico del (neo)realismo no termina aquí: Al final del siglo pasado, final también del orden bipolar sostenido casi cincuenta años de él, se dividen las aguas en el optimismo de Fukuyama del fin de la historia, mientras Huntington señalará que las civilizaciones colisionan. El core del realismo sigue tan pesimista como siempre, y a partir de aquí su vertiente ofensiva con Mearsheimer a la cabeza, mostrará la lógica epistémica y la potencia de los ciclos hegemónicos (Actis y Schenoni, 2014)

${ }^{91}$ La que ha dejado de aumentar sus capacidades y/o se embarcó en compromisos desfavorables. No obstante, Gilpin (1981) asegura que el mecanismo no resulta 'tan racional' en la práctica: a lo largo de la historia, fue la guerra la que más usualmente ha redistribuido poder entre los vencedores y los vencidos.
} 
políticas, económicas o socioculturales de sus miembros (estos cambios ocurren guiados por la inevitable propensión de los estados y otros agentes a buscar extender su control territorial, influencia política y dominación económica, hasta que los costos marginales de un cambio mayor exceden los beneficios marginales (Gilpin, 1981).

Lo mismo acontece con el equilibrio, buscado hasta el punto marginal en que las unidades encuentran beneficios en el incremento de sus capacidades en el sistema existente. Esto tiene consecuencias analíticas de gran generalidad, y, aunque lo parezcan menos, son tan realistas como siempre: la política internacional no es más que fuerzas que conducen al conflicto y la consabida acomodación a través de diferentes sistemas internacionales (Gilpin, 1986). Una terminología que pudiere parecer funcionalista, pero que expresa, no obstante, una forma sistémica de equilibrio de poder. $Y$ en cuanto a las discusiones de entonces, bien lo señala Dougherty y Pfaltzgraff (1990): la interdependencia económica blandida por entonces, no garantiza, a juicio de Gilpin, que la cooperación triunfe sobre el conflicto. La comunidad internacional no es eficaz para neutralizar la anarquía internacional. 
《/Cuando un Estado es borrado del mapa del mundo, se convierte en víctima de una violación del derecho internacional. Si nadie viene en socorro suyo, será bien pronto olvidado y el Estado que le ha dado el golpe de gracia no dejará por ello de ser acogido en las asambleas de las naciones supuestamente pacíficas》)

Raymond Aron, 1960

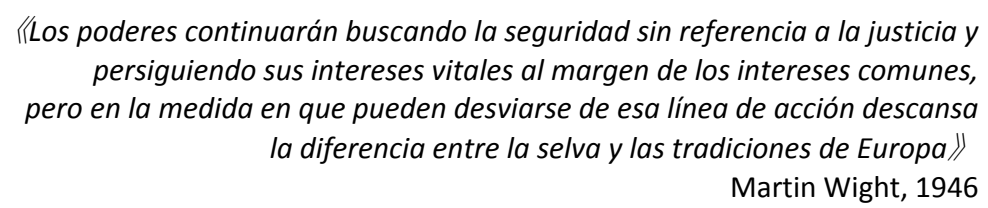

La anarquía en el medio internacional es una de las categorías con mayor potencia explicativa para todo el linaje realista (clásico o neoclásico): en ella se abona la perennidad del conflicto entre Estados (con lo que no necesariamente negamos las islas de conducta cooperativa, justificadas en las ventajas que presentan). $Y$ de esta dinámica se desprende una herramienta derivada, que más adelante señalaremos en mayor detalle: el equilibrio de poder. La anarquía es, también, el factor distintivo del medio internacional (Wight, 1951) divisoria de aguas entre la política fronteras afuera y la doméstica:

La característica que distingue la política internacional de la política común es la anarquía. El estudio de la política internacional presupone la ausencia de un gobierno, tal como el estudio de la política interna presupone la existencia de uno (Wight, 1951: 102). 
No todo concluye en los límites de la anarquía: debemos sumar el principio de horizontalidad entre pares (si los Estados no reconocen un hegemón que ordene el escenario internacional), junto con el principio de conservación del sistema internacional (los Estados tienen incentivos a que un actor no domine el sistema, precisan del poder distribuido), y el principio violencia tolerable (los conflictos no deben sobrepasar los niveles de violencia que destrocen el sistema internacional más allá de un límite dado) (Wilhelmy, 1988).

No obstante, esto, es determinante no llevar el supuesto de la anarquía hacia consecuencias prácticas que no posee: como menciona Wilhelmy (1988), se debe separar la anarquía internacional (es decir, la dinámica conflictiva resultado de la ausencia de un superior jerárquico formal) del caos (un orden errático que sólo cesaría si el actor más fuerte impone su imperio universal). Con esto no negamos la utilidad explicativa que el supuesto de la anarquía pudiese tener, sólo pretendemos pensarlo sin reduccionismos (heredado de aquéllos que pueda padecer el realismo ${ }^{92}$ ) y así poder dar cuenta de las instituciones de diferente tipo y alcance que efectivamente tienen un rol en el sistema internacional. Por eso Wilhelmy afirma que allende la efectividad teórico-explicativa que pudiere tener, existe efectivamente cierto grado de

92 Existen numerosas críticas al realismo de diferente grado de generalidad teórica (Dougherty y Pfaltzgraff, 1990). Creemos que la determinante siempre es, por una cuestión lógica, la de mayor generalidad (a partir de ella se ponen en interdicción todas las de menor nivel). Y ella reside en las dificultades operativas del concepto de poder: Hoffman (1991) lo señala con precisión al afirmar es imposible subsumir bajo una palabra variables tan diferentes como: poder como una condición de la política y poder como criterio de la política; poder como potencial y poder en uso; poder como suma de recursos y poder como conjunto de procesos. No obstante, no por ello podemos desecharlo como herramienta explicativa: en el mismo desarrollo, Dougherty y Pfaltzgraff afirman que el realismo es, sin duda, el intento más importante por aislar una variable clave del comportamiento político -el poder- y conformar así, una teoría de las relaciones internacionales. 
sociabilidad internacional que puede fundar algunas relaciones de cooperación (ibídem). Esta posición es común a los neorrealistas, quienes recelan la utilidad del supuesto de anarquía como divisor de aguas: Waltz (1979b) sostiene que la estructura se sobrepone a la violencia que produce la anarquía. Así, el nivel de conflictividad es variable, asentado en factores estructurales como en circunstancias coyunturales donde está ausente en el medio externo, mientras a nivel doméstico la violencia puede ser alta. Por lo tanto, dado que no existe orden humano en el que no haya violencia, la anarquía no podría tener tanto poder explicativo como para definir el orden internacional:

Para descubrir la diferencia cualitativa entre los asuntos internos y externos uno debe cotejar un criterio diferente de la existencia de violencia. La distinción entre la esfera política nacional de la internacional no se basa en el uso o no uso de la fuerza, sino en sus diferentes estructuras (Waltz, 1979: 103 [traducción propia] ${ }^{93}$

No obstante:

Aún en las áreas en que la cooperación ha alcanzado cierta importancia -por ejemplo, los acuerdos de integración económica y algunas organizaciones internacionales- el modelo de "la sociedad anárquica' (Hedley Bull) ${ }^{94}$ insiste en que se mantenga permanentemente, en forma más o menos visible, la competencia de diversas voluntades nacionales (Wilhelmy, 1988: 20).

\footnotetext{
93 Del original: to discover qualitative differences between internal and external affairs one must look for a criterion other than the occurrence of violence. The distinction between international and national realms of politics is not found in the use or the nonuse of force but in their different structures)

${ }^{94}$ Se refiere al trabajo La sociedad anárquica: un estudio sobre el orden en la política mundial (2005 [1977]), Madrid, Los Libros de la Catarata, pp. 78-79.
} 
No se requiere mucha perspicacia teórica para cotejar que, si bien los Estados son la entidad más perenne en el sistema internacional, ellos están profundamente influenciados por su líder individual o por la estructura del sistema internacional (Dougherty y Pfaltzgraff, 1990). Como esta consideración nos llevaría a una innumerable cantidad de consecuencias teóricas, rescatemos el ancla teórica la anarquía, no ya como estado de guerra masiva a la Hobbes, o como principio de funcionamiento práctico a la Aron, sino como sistema de autoayuda a la Waltz ${ }^{95}$. De este modo, contaremos con un aspecto que nos permita llegar a un concepto que, aún dentro de un marco neorrealista, describa de manera más apegada al funcionamiento concreto del sistema internacional. Mayer, Rittberger y Zürn (1997), creen que existe un fenómeno particular, donde la anarquía no conlleva necesariamente la autoayuda neorrealista, sino que existe una suerte de gobernabilidad sin gobierno: Las instituciones normativas regulan interacciones sociales sin una autoridad central como pre-requisito.

Desde una perspectiva donde importa la búsqueda de ganancias relativas entre agentes, donde es preciso no caer en subordinación o dependencia -lo que derribará la idea de sociedad internacional-, existe una manera de articular intereses comunes: Tal es el caso de los regímenes internacionales. Si la anarquía alcanza un tipo de relacionamientos -procesos de competencia político-diplomática y militar (ibídem)- no

\footnotetext{
95 Con esto queremos señalar que la anarquía no indica, necesariamente, un estado constante y generalizado de guerra -ni la naturalidad de ser la política por otros medios a la Clausewitz- sino que la noción de anarquía inspira la necesidad de autorregulación de los Estados y el velo por su seguridad (recomendamos una interesante crítica de la noción de anarquía en FERNANDES, António Horta (2012). A anarquia internacional: Crítica de um mito realista en Relações Internacionais, nro. 36. pp.87-109).
} 
por ello podemos afirmar que absorbe las interacciones de la esfera internacional: es necesario reconocer áreas de cooperación a diferente nivel ${ }^{96}$, expectativas, convenciones (Keohane, 1989), principios compartidos por algunos miembros del sistema internacional, como también normas acordadas por los gobiernos respetadas en mayor o menor proporción (Ruggie, 2009) y plasmadas en algún grado de institucionalización. Éstas cumplen un rol nada menor: configurar las expectativas de los actores (Keohane, 1989) en un espacio sujeto a la mayor variabilidad imaginable, como es el medio internacional.

La categoría régimen internacional es el vector que nos permite pensar el medio internacional con el suficiente realismo -no por alusión al paradigma, sino por el acercamiento al funcionamiento concreto de él-, e incorporar un fenómeno tan innegable como la existencia del poder: la integración regional. Por eso antes, ahondemos un poco más en esta categoría bisagra:

Los regímenes internacionales son un fenómeno actitudinal -existen como entendimientos- acerca de lo que sería una conducta y procedimientos apropiados (Puchala y Hopkins, 1982) para la toma de decisiones (ibídem), a manos de actores principales (estatales y no estatales), con una característica determinante ante el fatalismo neorrealista: cuando versan sobre un aspecto de la realidad acotado -la política monetaria, legislación marítima, etcétera- se permiten moldear conductas.

\footnotetext{
96 Estos factores de no-poder fueron demostrados por Robert Axelrod en los ochentas, al mostrar mecanismos de cooperación egoísta en condiciones de interdependencia estratégica a futuro (dilema del prisionero). Keohane (1984) asegura que esto puede comprobarse en la práctica diplomática y el control de armas a futuro.
} 
Esta suerte de consenso mínimo y dinámico (Haas, 1975; Barbé, 1989) ${ }^{97}$ permite explorar los límites de la cooperación en un mundo inherentemente conflictivo (Rochester, 1986), donde la coordinación del comportamiento se ordena al alcance de resultados deseados en alguna área (Krasner, 1983). Ésa es la función de los regímenes internacionales: facilitar la coordinación de acciones políticas, permitir conductas cooperativas, reducir la incertidumbre (Murillo Zamora, 2004).

Así, podemos apelar a la caracterización canónica de régimen internacional -producto del diálogo entre neorrealistas y neoliberales de principios de la década de los ochentas (previamente editada por Steven Krasner en 1982)- y afirmar que los regímenes internacionales revisten principios -de hecho, causalidad o valores-, normas -derechos y obligaciones predefinidos-, reglas -pre y proscripciones de acción- y procedimientos de toma de decisiones -prácticas colectivas- que permiten a las expectativas de los actores converger en un área determinada de las relaciones internacionales (Krasner, 1982) ${ }^{98}$.

\footnotetext{
${ }^{97}$ Al recuperar la noción de régimen internacional impera referir a su aparición -a mediados de los años setenta- y de la mano de la aproximación sistémica (Haas, 1975), con el surgimiento de la idea de organización internacional (el singular no es casual). Su advenimiento se explica por reflejo de la distensión EEUU-URSS por la paridad nuclear, la capacidad comercial de Europa y Japón, el retroceso de la hegemonía norteamericana y la derrota en Vietnam, la crisis del sistema monetario, el embargo de la OPEP, y el Informe del Club de Roma sobre los límites del crecimiento (1972) que señala problemáticas globales (contaminación, expansión demográfica y subalimentación) (Kratochwil y Ruggie, 1986; en Barbe, 1989).

98 Tal vez la cualidad de canónica obligue a extractar: así, los regímenes pueden ser definidos como estructuras de principios, normas, reglas y procedimientos decisorios implícitos o explícitos, a partir de los cuales las expectativas de los actores convergen en un área de las relaciones internacionales. Los principios refieren a creencias de hechos, causalidades y patrones de conducta. Las normas son patrones de conducta definidos en términos de derechos y obligaciones. Las reglas son prescripciones o proscripciones específicas de conducta. Los procedimientos decisorios son prácticas predominantes para la hechura e implementación de acciones colectivas [del original: Regimes can be defined as sets of
} 
Aceptar la institucionalidad internacional -aunque no sin cierto resquemor para los realistas- implicó, no llegar a abandonar por completo a anarquía, pero sí encontrar zonas de comportamiento donde el poder no resultaba patrón último. Aceptaban así, la existencia de reglas (formales e informales) estables e interconectadas que prescriben comportamientos, constriñen actividades y configuran expectativas (Keohane, 1982). Los regímenes encarnan reglas explícitas acordadas por los Estados, sólo que con un nivel menor de institucionalidad. En estas líneas, la noción de régimen internacional implica admitir la existencia del orden (es decir, escenarios donde se producen efectos recíprocos entre actores diversos y los Estados (Keohane y Nye, 1989)). El adjetivo refiere a relaciones donde la multiplicidad de canales conecta a las élites gubernamentales y las no gubernamentales, corporaciones, y demás; en relaciones que no serán resueltas por la fuerza, con unas agendas múltiples -economía, ecología, cultura, etcétera- y sin jerarquías (es decir, no predichas por la seguridad) internacional que opera bajo categorías estrictamente (neo)realistas ${ }^{99}$ (ibídem) pero deviene en un marco de interdependencia compleja ${ }^{100}$ :

implicit or explicit principles, norms, rules, and decision making procedures around which actors' expectations converge in a given area of international relations. Principles are beliefs of fact, causation, and rectitude. Norms are standards of behavior defined in terms of rights and obligations. Rules are specific prescriptions or proscriptions for action. Decision-making procedures are prevailing practices for making and implementing collective choice (Krasner, 1982: 186)]

${ }^{99}$ Con la expresión '(neo)realismo' pretendemos establecer, para esta tesis, una caracterización general que condensa ambas evoluciones de la corriente, con tres fines: 1) denominar al paradigma de las relaciones internacionales, en su versión original junto con los aspectos que agregan los desarrollos de Waltz y otros; 2) a nuestro esquema analítico aquí, que podríamos juzgar como atenuado dado que concebimos la integración regional mediada por la noción de regímenes internacionales (aun así, se podría prescindir de ese juicio, dado que los regímenes son concebidos aquí en un enfoque realista. No obstante, preferimos tomar ese reparo, porque puede tener consecuencias analíticas para nuestro caso). 3) a la conducta de Brasil en nuestro período, hasta tanto no hayamos planteado lo que aquí 
Dado que la fuerza militar se ha devaluado, los Estados militarmente fuertes encontrarán más difícil utilizar su dominio para controlar los resultados en temas donde son débiles (Keohane y Nye, 1989: 31).

Se ha señalado a los regímenes como una sutura entre el realismo y el utopismo (Barbé, 1989). La razón de ello reside en que supone al Estado influido por normas donde se insertan diferentes configuraciones internacionales articuladas con el interés nacional y dinámicas del neorrealismo -por la vía de la racionalidad propia de estos estudios-. No obstante, en su potencialidad teórico-metodológica, alcanza análisis más acotados que las pretensiones de generalidad que han revestido el realismo, el neorrealismo o la interdependencia compleja, quienes procuraron una explicación totalizadora del funcionamiento de la sociedad internacional. En cambio, ha sido utilizada para temas como el comercio, el fenómeno del colonialismo, la disuasión nuclear, el petróleo o el estudio del mar (Barbé, 1989).

Entre esas configuraciones internacionales está, por supuesto, la integración regional, en la que tenemos que atender cómo se forman las lealtades entre actores involucrados (Wilhelmy, 1988). De hecho, el diálogo neorrealismo-neoliberalismo anida en la re-conceptualización de las teorías de la integración europea posterior al

denominaremos la Estrategia de Poder Global Brasileña, constructo analítico que nos permitirá indagar el rol del Mercosur al servicio de la estrategia de acumulación de poder brasileña

100 La interdependencia compleja implica escenarios donde se producen efectos recíprocos entre actores diversos y los Estados (Keohane y Nye, 1989)). El adjetivo refiere a relaciones donde la multiplicidad de canales conecta a las élites gubernamentales y las no gubernamentales, corporaciones, y demás; en relaciones que no serán resueltas por la fuerza, con unas agendas múltiples -economía, ecología, cultura, etcétera- y sin jerarquías (es decir, no predichas por la seguridad) 
neofuncionalismo y que tomó por mentores a la concepción reticular del ecosistema comunitario en Robert Keohane, y a la explícita denominación de régimen internacional -basada en la convergencia de intereses- que Stanley Hoffmann (1991) ${ }^{101}$ utiliza para la integración (por cierto, Hoffmann produjo una de las más prolíficas críticas a las teorías neofuncionalistas de la integración desde mediados de los años sesentas $\left.^{102}\right)$.

Volviendo a nuestra estructura expositiva, remarquemos que, en una progresión teórica donde ya adicionamos al realismo clásico el aporte de la dimensión estructural del neorrealismo, la noción de régimen internacional nos permitirá cotejar la dimensión en que el comportamiento internacional procura la cooperación (Barbé, 1989) concomitantemente a la existencia del equilibrio de poder -por lo que es preciso atender la posición relativa en el sistema internacional- y la constante persecución/expresión de intereses nacionales ${ }^{103}$.

\footnotetext{
101 En esta tesis tomaremos los desarrollos neo-funcionalistas como basamento teórico para la integración regional bajo la decisión metodológica del pragmatismo que presenta esta escuela (allende sus diferentes exponentes), por lo que esta referencia teórica no será contemplada. No obstante, era imposible eludir en un pasaje donde recuperemos la noción de régimen internacional.

${ }^{102}$ Para no pecar de un exceso de reduccionismo agreguemos que estos autores ven la integración como proceso intergubernamental (recordemos: escriben un año antes de la firma del Tratado de Maastricht), dado que la autoridad sigue siendo ejercida por los gobiernos en la Comunidad Europea, pero también señalan la existencia efectiva de una supranacionalidad, anclada también en la toma de decisiones (con la mayoría cualificada acorde el derecho comunitarios y controlada por el Tribunal de Justicia)..

${ }^{103}$ Esta no es una posición aceptada entre todos los especialistas: sólo por nombrar algunos, Waltz (1979a) y Strange (1986), quienes aseguran que la presencia de esos dos componentes, implica que no ha lugar para régimen internacional alguno. Por cierto, la corriente waltziana ha mirado con el previsible soslayo la incidencia de las instituciones internacionales (Hasenclever; Mayer y Rittberger, 1999)
} 
El régimen internacional es un reflejo de las relaciones de poder -por tanto, la hegemonía es una categoría determinante para desentrañarlo-, lo que nos permitirá encontrar la cooperación (es decir, el relacionamiento cooperativo que implica diferentes configuraciones como la integración regional, no lo que denominamos cooperación internacional) como un patrón sostenido en el tiempo (Buzan, Jones y Little, 1993). Admitir la cooperación entre Estados justifica la existencia de regímenes internacionales, pero ello no implica renunciar a la lógica del poder (de hecho, Gilpin y Krasner sostienen que el poder es determinante para lograr cooperación (Gilpin, 1981 y Krasner, 1991; citados en Hasenclever; Mayer y Rittberger, 1999) y que en un ecosistema de cooperación los Estados siguen compitiendo por el poder y la riqueza. Sólo que en este caso, deberán atender las ganancias absolutas de cooperar -es decir, aquello que obtienen para sí de manera neta-, como las relativas -aquellas ganancias ajenas, que a futuro puedan volver a los no tan aventajados como posiciones de poder- ${ }^{104}$.

Esto también implica que no se renuncie a la racionalidad propia del neorrealismo: incluso Keohane -quien ha tenido una posición que viró hacia el realismo, pero originariamente no estaba en sus huestes- sostuvo que los regímenes serían abandonados si los gobiernos sopesaran costos de oportunidad más altos que cualquier otro curso de acción alternativo y factible (1984). Sólo que no siempre razonan de manera racional, sino que desembocan por la vía estratégica adaptándose

\footnotetext{
104 Esto que puede sonar críptico y digno de negociaciones de alta política, es muy conocido para cualquier estudioso del comercio internacional: EI SGP del GATT es una manera estandarizada de trato especial para socios que pueden 'aprovechar menos' un esquema cooperativo dado.
} 
a sus intereses o circunstancias (Murillo Zamora, 2004), lo que también es un tipo de racionalidad basada en el poder y no ya en la utilidad.

La posibilidad de una conducta cooperativa entre los Estados nos permitirá ingresar a la integración regional como fenómeno de configuración de objetivos comunes (Del Arenal, 1994$)^{105}$, y es la existencia de regímenes internacionales en clave realista la que nos parece la mejor vía de explicación para abordar el regionalismo, desde el sistema internacional (para hacer foco sobre el regionalismo a su interior, apelaremos más adelante al neofuncionalismo).

${ }^{105}$ Ahondaremos la cualidad cooperativa y no coercitiva en la próxima parte. 


\section{Regímenes de integración regional}

Lo cierto es que el realismo tiene otras vías de explicación para la integración regional. Pero consideramos que resultan meramente aproximativas, parecen no llegar a tocar la integración para asirla en un sistema de análisis lo suficientemente sólido. Es innegable que el neorrealismo tiene, de suyo, limitaciones epistemológicas para concebir la integración regional más allá de un medio para satisfacer intereses nacionales (Hurrell, 1995), mientras el comportamiento racional de los estadistas (sólo) permite alcanzar acuerdos puntuales según intereses respectivos y cotejando ganancias relativas vis a vis sus capacidades (Waltz, 1979; Hurrell y Fawcett, 1995). Pero es necesario aclarar: las limitaciones del realismo no significan imposibilidad perenne: el realismo contempla la posibilidad de construcción de lealtades colectivas (Wilhelmy, 1988). El rasgo distintivo radica en que existe empleo o amenaza de la fuerza de por medio por una coalición de Estados (no debemos pensar en una situación bélica, la ostentación de poder en épocas de paz aplica a esta concepción). De este modo, en términos analíticos la diferencia no reside en la posibilidad o no de agruparse bajo una estructura (aquí el realismo y cualquier perspectiva idealista considera la posibilidad), sino en los fines y la metodología: la ostentación de poder y los efectos que esa ostentación -o ejercicio eventual- tiene para los agrupados. 
Claro que existen a su interior, otros caminos teóricos de menor alcance como la teoría de la estabilidad hegemónica, que vincula la seguridad y el poder de un Estado dominante con la cooperación propia de los regímenes internacionales, en la búsqueda de las razones de su emergencia y efectividad (Hasenclever, Mayer y Rittberger, 1997). El hegemón resulta motor y garante de la cooperación intergubernamental, y resulta efectiva cuando las políticas realmente seguidas por un gobierno son percibidas por sus contrapartes como estimuladores para la realización de sus propios objetivos (Keohane, 1986). En un mundo donde prima el desorden (Tokatlian y Pardo, 1990) la hegemonía, es decir, la cualidad de un Estado de absorber voluntariamente en sus reglas a las relaciones interestatales de terceros (Keohane, 1986), es necesaria para imprimir un orden internacional determinado y la permanencia de regímenes internacionales.

Por eso escogemos la noción de regímenes internacionales de corte realista como vía para avanzar hacia la de regímenes de integración regionales de Murillo Zamora (2004) que sutura ambos conceptos considerando a la integración como un régimen internacional (más acotado y formalizado gracias a la voluntad política). Si bien más adelante volveremos sobre la noción de integración regional in extenso, para poder alcanzar una progresión teórica entre realismo, regímenes internacionales e integración regional, detengámonos en lo que Murillo Zamora destaca acerca de la integración: un proceso de construcción progresiva, diferente de cada uno de sus miembros, asentado en una realidad territorial específica donde alcanzará sus intereses: 
Esto se explica por el interés de los agentes para facilitar la consecución de sus intereses y reducir los riesgos en la toma de decisiones. Por lo tanto, se trata de un proceso gradual en el que hay avances y retrocesos y no una evolución lineal con pendiente positiva, porque no es un mecanismo coercitivo, sino un proceso de construcción social dinámico, condicionado por factores endógenos y exógenos. (Murillo Zamora, 2004: 19)

Encontramos que los bloques posibilitan integraciones regionales intergubernamentales que, sin que mucha demostración sea necesaria, son una construcción de nuevos agentes internacionales. De una estructura dada, se derivan unas interacciones entre Estados y actores subnacionales en el sistema internacional, por lo que cualquier bloque puede ser visto como un régimen internacional que, como menciona Schelke (2000), reduce la inconsistencia dinámica de la política (es decir, alivia los costes individuales de los agentes estatales en la persecución de objetivos y maximiza beneficios mientras de suyo se reconoce vigencia de principios, normas y procedimientos aplicados (Murillo Zamora, 2004)). De hecho, podemos encontrar caracterizaciones del regionalismo que poco se diferencian con los criterios que definen los regímenes internacionales:

[el regionalismo constituye] la cooperación entre gobiernos $u$ organizaciones no gubernamentales de tres o más países geográficamente próximos e interdependientes para procurar ganancias mutuas en una $o$ más áreas temáticas (Alagappa, 1995: 362)

A la hora de concebir la integración regional como un régimen internacional, la frecuencia entre miembros como la cercanía de las elites -gubernamentales y 
empresariales-, se torna determinante para el acercamiento de sus respectivos intereses en un marco de principios y normas asumidos que condicionan la conducta y la convergencia de esos intereses comunes. Esto permitirá avanzar con la decisión de integrarse de cara a obtener beneficios nacionales del armado conjunto ( $y$ no es diferente del surgimiento de los regímenes internacionales acotados a un tópico o problema: se reconoce la necesidad de modificar o adaptar normas y reglas existentes a las nuevas condiciones que se requieren). Un acuerdo, un contrato formal -y claro que voluntario-, permite el establecimiento de expectativas mutuas en un marco de cooperación más estable y permanente que la colaboración interestatal (Keohane, 1984). Las expectativas mutuas facilitan la interacción continua y la responsabilidad entre pares, lo que organiza las relaciones interestatales (Bernal-Meza, 2006). De este modo, los regímenes de integración regional:

Se trata de un conjunto de normas, reglas y procedimientos, que tienen sentido en el espacio de convergencia de intereses y expectativas, de negociación y toma de decisiones, que permite el desarrollo de organizaciones y mecanismos comunes en una o varias áreas temáticas y en una dimensión espacial determinada. La estructura adoptada responde a niveles de legalización, según los intereses de los agentes estatales miembros y a las presiones de grupos no gubernamentales y de la opinión pública (Murillo Zamora, 2004: 26).

Este escenario de interacción de agentes gubernamentales (aunque no exclusivamente tales) permite coordinar dimensiones de gestión (seguramente en el inicio partirán de la esfera comercial, la que convivirá con otros regímenes internacionales como los comerciales bilaterales y multilaterales integrados por uno, algunos o todos sus miembros). Un régimen de integración regional sirve a los intereses de los Estados en 
tanto que provee provechos tangibles -en clave de costo/beneficio-, lo que, incluso, conducirá al aumento de los niveles de institucionalización (Puchala, 1971). En este sentido, será abandonado -o padecerá una crisis de diferente intensidad- cuando sus miembros vean qué expectativas e intereses no son satisfechos, y así evaluarán el costo de oportunidad de salir de él y/o integrar otros regímenes de integración regional.

Dado que los intereses concretos resultan la variable crítica -motorizan la constitución, resulta clave atender a las expectativas que se depositen en ellos, junto con el decurso de las interacciones entre factores endógenos y exógenos que permitan avanzar (o no) a la institucionalización. Ella será emergente y función -a un tiempo- de la velocidad de construcción del régimen y su duración en el tiempo. Puchala (ibídem) destaca que resultan determinantes algunos condicionantes como los canales de comunicación entre los (futuros) miembros, el tipo y alcance de las transacciones políticas que sucedan en las instituciones del régimen, como la densidad (cantidad y calidad) de la interacción de actores no gubernamentales.

A su vez, este entramado oficiará como un insumo del régimen e impactará sobre él como sobre las conductas de los miembros, a las que habrá que sumar factores exógenos al régimen (lo que incluye desde la importancia de transacciones comerciales extra-bloque previas de algún miembro, hasta la presencia de un hegemón interesado en la región (Murillo Zamora, 2004)). Por eso la historia de las relaciones externas de 
cada miembro participa de manera mediata de la conformación del régimen ( $y$ a la vez es un dato relevante para su devenir).

Los regímenes de integración regional no están cerrados en sí mismos, por lo que no se constituyen en un ambiente vacío o fuera de la historia ${ }^{106}$ : se desenvuelven en interacción con la estructura sistémica -doméstica, regional e internacional-, poniéndolo en relación con un entorno que interviene en la consolidación, adaptación o transformación (ibídem). Dado el pragmatismo que reviste la motivación de la constitución -los resultados que obtengan de ella-, es determinante tener en cuenta las características de cada miembro ${ }^{107}$, y así lograr que la maximización del bienestar nacional esté asegurado: Schmitter asegura que los regímenes de integración pueden intervenir en la brecha entre las consecuencias reales y deseables entre los actores estatales y otros actores en la integración regional ${ }^{108}$.

\footnotetext{
${ }^{106}$ Esta afirmación nos obliga a relacionar el abordaje de los regímenes de integración regional con lo que Bernal-Meza (2009) presenta en su triple dimensión del regionalismo: en este caso, la del concepto. Allende la forma de regionalismo del que hablemos (económico, político, cultural o cualquiera fuere), podemos pensarlo como un actor del sistema internacional que se erige como subsistema. Para lo que debe adquirir una identidad propia -expresar esa distinción a través de sus instituciones- y así erigirse bien público.

${ }^{107}$ Murillo Zamora establece aquí una relación con el neofuncionalismo en cuestión de teorías de la integración regional: menciona que los regímenes de integración son sensibles al tamaño y características de los miembros, el proceso de sus respectivas tomas de decisiones, el volumen e intensidad de transacciones entre ellos antes de la conformación del bloque, la potenciar articulación institucional (y las características nacionales de ella), la dependencia extra regional, entre otras (Cf. HAAS, Ernst y Philippe SCHMITTER (1964). Economics and Differential Patterns of Political Integration: Projections about Unity of Latin America, en International Organization, vol. 18, núm. 4).

${ }^{108}$ Cf. Philippe SCHMITTER (1971). A Revised Theory of Regional Integration. En Leon LINDBERG y S. SCHEINGOLD (eds) Regional Integration Theory and Research, Harvard University Press, Cambridge. pp. 246-48.
} 
Si bien aquí sólo mencionamos cuestiones que hacen a la integración y la cooperación, precisamos aún de los insumos que presentaremos en lo tocante y en la segunda parte, por lo que permanecemos, por ahora, con una dinámica internacional donde las evaluaciones de ventajas mutuas no impiden la cooperación, aunque condicionen su intensidad y perfil (Hasenclever; Mayer y Rittberger, 1999).

Este acápite cumple, también, una función lógica en la estructura de esta tesis: aquí articulamos el (neo)realismo con los regímenes internacionales, con el fin de concebir la integración regional en clave del paradigma tradicional. Aún nos resta plantear dos conceptos al interior de éste -una consideración acerca del poder y la noción de power politics-, que decidimos incluirlos con posterioridad a este desarrollo por el menor grado de generalidad que alcanzan. Así, esta generalidad descendiente nos llevará desde la noción operativa de integración regional hacia la focalización de algunas consideraciones históricas y particulares de nuestro caso de estudio. 
Capítulo II. Política de Poder

Sumario. En este capítulo construiremos una noción dinámica de política de poder, para lo que precisaremos previamente de una noción operativa de poder. Concluimos con este capítulo, una primera parte que recorre en grado de generalidad descendente el paradigma tradicional, la evolución del realismo y la importancia del concepto de interés nacional, para pasar a la noción dinámica de equilibrio de poder y así construir una categoría operativa de poder que retomaremos en la tercera parte. 


\begin{abstract}
《La prudencia es la virtud suprema del hombre de Estado (...) el verdadero realismo es el que tiene en cuenta toda la realidad, el que dicta una conducta diplomático-estratégica adaptada, no a la imagen retocada de lo que sería la política internacional si los estadistas fuesen prudentes en su egoísmo, sino a la que es, con las pasiones, las locuras, las ideas y la violencia del siglo》"

Raymond Aron, 1962

〈[El poder, como el amor, es más fácil de experimentar que definir o medirlo》 Joseph Nye, 2004
\end{abstract}

Esta primera parte y la segunda encontrarán sentido en la elaboración de lo que denominaremos postreramente estrategia de poder global brasileña (EPGB). De este modo, la caracterización acerca del poder será planteada a la luz de este caso suramericano. Pero no podemos avanzar sin precisar dos cuestiones muy generales mas no por ello accesorias: por un lado, plantear una caracterización general realista acerca del poder, y por el otro, precisar lo que entenderemos por política de poder en esa estrategia brasileña (y que es el objeto del próximo apartado). Cuando nos referimos a una caracterización 'realista' acerca del poder no estamos refiriendo exactamente al paradigma, sino que, jugando con las palabras, nos referimos a realista por oposición a imaginaria, a irreal. Buscamos un contrapunto con un aspecto presente y problemático que aquí no quisiéramos cometer: que el paradigma tradicional acabe por representar una visión mecánica, simplista de la política internacional. El paradigma tradicional presenta una densidad teórico-explicativa considerable, pero la 
tendencia a reducirlo a sus notas mínimas -incluso las más extremas, como la voracidad, la inmediatez y la rapacidad por el poder -, puede ser un camino a veces muy usual. Sin extendernos en ello, aquí seremos más modestos: nos dedicaremos sumariamente a mostrar algunos trazos en que analistas realistas efectivamente han puesto en juego en sus análisis, y que suelen quedar relegados. Creemos que en ellos reside la complejidad -y por ende la utilidad-, del paradigma tradicional. Intentamos así, darle realismo al realismo.

Lo primero que creemos necesario afirmar: que ciertos componentes no resulten determinantes -o la última ratio- no significa por ello, que no estén presentes. Es decir, aquello que conforma la dinámica internacional entre actores estatales y que resulta más intangible que la fuerza militar, tiene una incidencia, y los análisis como los hacedores de política realistas lo leerán con interés. Decidirán seguramente en términos de alta política, pero no por ello ignoran el cordón de cuestiones que la rodean (y es posible que aspectos de la baja política -como lo económico-, están casi tan presentes como la primera). La razón de ello es sencilla: esos mecanismos expresan poder, y sobre ellos, como si fuesen lechos de un río, también corre el poder (volveremos sobre esta cuestión para la integración suramericana en el epílogo).

El rol de las ideas, de las dimensiones que exceden la fuerza, las normas -formales o no-, y hasta de la propia moral realista (reducida a la prudencia) están presentes aunque de manera subordinada- en el devenir analítico realista. $Y$, dado que ellas conforman su espectro hacen de él un enfoque asequible y plausible de la realidad. Lo 
tornan realista. Mientras lo simplificamos, el realismo resbala por el costado de sus vicios: el maquiavelismo vulgar, el hobbesianismo mecánico y el cálculo richelieano que ignora costos menores a la hora de estimar el interés nacional, y otras cuestiones más acotadas que también pueden ser nidos de reduccionismos como el mentado reproche wilsoniano acerca de la diplomacia secreta bismarkiana en las postrimerías del siglo XIX (aspecto que veremos más adelante, en palabras de Kissinger, como práctica nada recomendable en el ejercicio diplomático). Si bien la diplomacia secreta fue un hecho por entonces, asociar y reducir al realismo a estas prácticas -como algo intrínseco-, sólo nos lleva a un realismo irreal (valga la expresión) ${ }^{109}$.

Tanto el realismo iniciado por Carr, como los desarrollos del mundo bipolar y los componentes que aportó el neorrealismo, e incluso los aportes de principios de los ochentas, que interpelan e incluyen autores que fueron revisando sus posiciones como el caso de Keohane-, no pueden ser vistos como un planteo simplista sobre la persecución del poder. Este acápite pretende señalar esa densidad teórica a través de unas ideas indicativas. De este modo, no definiremos una noción estanca acerca del poder: aun cuando esto pueda ser visto como esperable en una tesis de maestría, queremos deliberadamente plantear que esto no es lo importante. Lo determinante aquí reside en cómo se lo conciba. Lo concebimos un fenómeno complejo y

\footnotetext{
${ }^{109}$ Y no solamente estas estrategias que acotan el poder explicativo del realismo por vía de la reducción: es usual leer muchos análisis, a veces por cuestiones tan menores como las limitaciones de espacio, optan por extractar las principales características del realismo en sus notas distintivas (y que resultan extremas), a la postre alejadas del ejercicio práctico del poder.
} 
multidimensional (Holsti, 1964, 1967) $)^{110}$ que puede ser pensado también en el orden de la influencia, incluso con determinantes de cuño simbólico y percepcional. Ninguno de estos componentes nos aleja del (neo)realismo, antes, por el contrario, otorgan realidad al paradigma tradicional: sólo por citar un ejemplo, un proto-realista como Reinhold Niebuhr creía que los conflictos entre los hombres suceden en un espacio de competencia de orgullo. Poseer poder es poseer prestigio, algo necesario de defender ante eventuales intrusiones. Incluso, lo sobrepone a la lucha de la supervivencia ${ }^{111}$. EI prestigio no es otra cosa que el poder otorgado por quien observa. Vive en el receptor, que no en el emisor. Morgenthau, como mencionamos más arriba, postulaba que la política de poder tenía tres vertientes: preservar el statu quo, expandirse o ganar en prestigio, donde esta última se centraba en demostrar poder, es decir, construirlo en la apreciación ajena hasta el punto en que la sombra política del uso concreto del poder se vuelve innecesario ${ }^{112}$.

Es por esto que creemos que este paradigma plantea la suficiente complejidad no sólo en su explicación del escenario internacional, sino en el tratamiento del insumo básico de aquélla (la unidad mínima de energía social, por así decirlo): el poder. Por supuesto, todo lo que atenga a él, se traslada a las categorías conceptuales en que resulta

\footnotetext{
${ }^{110}$ Su definición está anclada en capacidades de los Estados, las que concibe como cualquier cualidad u objeto físico o mental utilizable como instrumento para inducir, persuadir, recompensar, amenazar o castigar (1967).

${ }^{111}$ Cf. NIEBUHR, Reinhold (1947): Moral Man and Immoral Society, Nueva York, Scribner's

${ }^{112}$ Este tipo de cuestiones son muy bien graficadas en otros estudios pertenecientes a la teoría de la disuasión: Cf. también ALCOCK, Zed y Alan NEWCOMBE (1970). The Perception of National of Power, Journal of Conflict Resolution, XIV, $\mathrm{N}^{\circ} 3$ (septiembre).
} 
determinante (power politics ${ }^{113}$, por ejemplo, una noción de suma importancia para estas líneas.

Comencemos, pues. Morgenthau (2003) contemplaba factores materiales e inmateriales en la noción de poder, y curiosamente agregaba un tipo que otros autores -incluso de otros paradigmas- no han hecho hincapié: lo que denominó la moral nacional.

El poder puede consistir en cualquier cosa que establezca y mantenga el control del hombre sobre el hombre. El poder cubre, pues, todas las relaciones sociales que sirven a tal fin: desde la violencia física hasta los lazos psicológicos más sutiles por el que una mente humana controla a otra (Morgenthau, 1963: 21)

También las cualidades: la calidad del gobierno y la opinión pública, participa en la materia prima para confeccionar el poder de la nación. Pero también la diplomacia (un factor crítico, y con la complejidad de resultar de naturaleza inestable). Reforcemos esto con una idea muy precisa de Kissinger:

Todo estadista debe tratar de conciliar lo que considera justo con lo que considera posible (...) [la diplomacia] el arte de relacionar a los Estados entre sí por el consentimiento antes que, por el ejercicio de la fuerza, por la presentación de un campo de acción que concilie las aspiraciones particulares con un consenso general. Porque la diplomacia depende de la persuasión y no de la imposición, presupone un marco determinado ya sea mediante un acuerdo sobre un principio legitimador o, teóricamente, a través de una interpretación idéntica de las relaciones de poder (Kissinger, 1973: 16 y 414)

\footnotetext{
${ }^{113}$ En el siguiente acápite aclararemos por qué referimos a la política de poder en su denominación anglosajona.
} 
Esas dimensiones que Morgenthau destaca, dependen de factores externos al poder: pensemos en la idiosincrasia, la cultura nacional, los valores y prejuicios nacionales serán factores a tener en cuenta al conformar el interés nacional y la política externa (esto tiene un valor crítico para nosotros en la resolución de nuestra pregunta: la vía conceptual para lograrlo se asienta en la autopercepción). Asimismo, las que determinan un cuerpo diplomático óptimo (que abarcan desde la importancia de la carrera profesional hasta la incidencia que los funcionarios políticos le permitan), de la gestión de gobierno (condicionada por la gobernabilidad, variables múltiples del sistema político -y aquéllos factores que influyen sobre él-), a lo que se sumaría los factores culturales.

Aron (1979) también excede la dimensión material del poder ${ }^{114}$ y propone tomar en consideración además del escenario de acción y los recursos materiales, no desestimar la capacidad de acción colectiva como la legalidad de toda índole. Aron aseguraba que lo legal -y no la contundencia del uso de la fuerza-, es por lo común lo más eficaz y rentable porque inspira confianza a los demás Estados:

\footnotetext{
${ }^{114}$ La política refiere a relaciones entre hombres, por lo que los factores morales y psicológicos no son prescindibles: Fraga Ikibakní (1958) grafica esta idea de manera magistral, con un ejemplo histórico: La pregunta irónica de Stalin acerca de cuántas divisiones tiene el Papa, no resultaba del todo adecuada porque un pronunciamiento del Papa produce más efectos políticos que varias divisiones, mientras Inglaterra, con mayor poderío militar en el siglo XX que en XIX, no pudo conservar la India. La razón residía en una idea: había prendido la idea nacional.
} 
La mentira no es de ningún modo la cualidad típica ni el medio indispensable para la diplomacia. La exigencia de que la política se someta a la ley moral universalmente válida es también reconocida en la práctica. No hay, pues, lugar, en general, a sugerir una contradicción entre política y moral (Aron, 1979: 716 [traducción propia] ${ }^{115}$ )

Ambos autores combinan elementos cualitativos y cuantitativos (Creus, 2013), tal vez por eso para ellos el poder resulta tan complejo, de esquiva ponderación ${ }^{116}$ y se resolvía teóricamente por la observación y la intuición analítica, anclada en la historia. Aun cuando en Waltz (1979a, 2000) encontremos un positivismo mayor con el correlato de la mayor simplicidad, la medición -el gran problema de los clásicoscomienza a ser posible. Pero el neorrealismo también se ve alimentado por la efervescencia teórica de los setentas y ochentas al interior de la teoría de las relaciones internacionales. Si bien mencionamos que no nos dedicaríamos a definir al poder, no queremos prescindir de la caracterización que puede darnos el neorrealismo para encontrar ahí las facetas cooperativas que pueden ser articuladas en este paradigma. Es Klaus Knorr quien puede aportar la naturaleza relacional de las dinámicas que se inscriben en aquél:

Un efecto, antes que como la posesión de medios que pueden producir efectos relevantes (Knorr, 1970: 167)

\footnotetext{
${ }^{115}$ Del original: A mentira não é uma qualidade típica ou um instrumento indispensável da diplomacia. A exigência de que a política se submeta à lei moral, universalmente válida, é reconhecida também na política'. Por isto, não se pode invocar, de modo geral, uma contradição entre a política e a moral.

${ }^{116}$ Esto acontece en el caso de Morgenthau. En el de Aron el poder es efectivamente mensurable, a partir de la estimación de la fuerza material.
} 
Lo relacional es su instrumentación (Knorr, 1975): la resolución de esa dinámica es lo que divide la cooperación -es decir, el beneficio de la creación de valores materiales o inmateriales-, de la otra manera de resolución, el conflicto, en que se disputan valores a expensas mutuas (en el primero caso su dinámica será el poder y la influencia mientras que en el segundo será estrictamente el poder propiamente dicho (Dougherty y Pfaltzgraff, 1990)). De este modo, los Estados pueden construir influencia sin apelar al poder, afectando la conducta ajena sin recurrir a los últimos atributos del poder que provee la fuerza o las herramientas económicas (Knorr, 1981). Estas dos vías de resolución son relativas, que no absolutas (es decir, no definen la relación total). Por eso dos Estados pueden estar en estado de conflicto y cooperación concomitantemente ${ }^{117}$ :

La cooperación y el conflicto son modos de interacción que tienden a incrementar la interdependencia internacional. Las sociedades cooperan para aumentar la producción de valores disponibles para cada una. En ese caso están persiguiendo objetivos compatibles. Todas las sociedades participantes se benefician. El comercio internacional y el mantenimiento organizado de la paz son ejemplos de esa cooperación. Las sociedades luchan para obtener, o para evitar perder, productos o insumos de valores requeridos para la producción de valores. En este caso están persiguiendo objetivos incompatibles (Knorr, 1981: 61)

Sin ahondar en las características de la cooperación (que serán objeto de capítulos posteriores), pretendemos en estas líneas haber señalado con una sumarísima

\footnotetext{
${ }^{117}$ Esto tiene una consecuencia teórico-práctica: existe una mixtura de intereses, por lo que los juegos de poder equivalentes a suma cero dejan lugar a la competitividad (del lado del conflicto) y la solidaridad (del lado de la cooperación).
} 
muestra cómo debemos desencajar al realismo clásico y neoclásico de toda visión simplista o unidireccional del poder (no ya a partir de nuestras consideraciones, sino a partir de la propia producción y análisis del paradigma). Esta concepción compleja, en donde elementos que exceden los atributos clásicos del poder -o los que se podrían inferir del reduccionismo del paradigma tradicional-, es la que pretendemos trasparezca desde un inicio. Retomaremos esto al final de estas líneas, al abordar los efectos del poder efectos en el espacio cooperativo suramericano. 


\begin{abstract}
(Sin embargo, ello no supone la ausencia de toda moralidad en la esfera internacional (...) si es utopía el ignorar el elemento de poder, es irreal el realismo que ignora al elemento de moralidad en cualquier orden mundial. (...) un orden internacional no puede basarse sólo en poder, por la sencilla razón de que la humanidad a largo plazo, siempre se rebela contra el poder desnudo. Cualquier orden internacional presupone una sustancial dosis de consenso general》》

Edward Carr, 1939

《La filosofía política de la era moderna (...) se funda en la perplejidad que el racionalismo moderno es irreal y el realismo moderno es irracional》》

Hannah Arendt, 1958
\end{abstract}

El corazón mismo de lo que aquí definiremos como la Estrategia de Poder Global Brasileña reviste una política de acumulación de poder, la que concebimos como power politics (Aron, 1962). Es posible que resulte curioso tratar esta noción por separado del realismo como tal. Las razones de hacerlo son dos. Por un lado, una intrínseca: el término tiene especial valor analítico en estas líneas, y eso amerita una presentación detallada. Por otro lado, la extrínseca: éste término suele enumerarse como característica distintiva -muchas veces para acentuar sus diferencias con el utopismo-. En este sentido, cada concepto derivado de un sistema teórico tiene una función específica que iluminará una porción de la realidad a analizar. En función de ello, aquí separamos lo que consideramos la caracterización del medio y sus actores, de la manera de operar en ese medio por esos mismos actores. Una cuestión es el componente estático, y otra muy distinta el dinámico: es decir, por un lado, debemos plantear el medio anárquico (Aron, 1979) pasible de presentar regímenes 
internacionales donde interactúan unidades similares (alike units para Waltz, 1979) en condiciones de inseguridad; y por otro la dinámica que lo anterior asume para hacer viable la existencia. Esto último es, por supuesto, el equilibrio de poder.

En el espacio de los actores, encontramos el correlato de la conducta egoísta y el animus dominando o deseo de dominio (Muñoz Sánchez y Frasson-Quenoz, 2011), contrapesado con el principio moral por antonomasia del realismo (la prudencia). Para vehiculizar el sistema de autoayuda (self-help para Waltz, 1979) tenemos que adentrarnos en el medio: el poder. Y en una necesidad derivada: su acumulación. Esto no es otra cosa que la política de poder. El medio estará orientado a una serie de objetivos inervados por el interés nacional (el que incluirá desde la fundamental seguridad nacional hasta los objetivos subordinados que el Estado en cuestión determine).

Georg Schwarzenberger, quien descontaba al poder como el principal elemento de la política de la sociedad internacional ${ }^{118}$, caracterizaba la política del poder como un tipo de relacionamiento entre Estados en el que predominan algunas reglas de conducta: armamentos, aislacionismo, diplomacia de poder y de la guerra. De este modo:

\footnotetext{
118 El ejercicio de la política en la sociedad internacional no es otra cosa que lo que usualmente se denomina relaciones internacionales. Utilizamos aquella expresión para aclarar que, a pesar de referirnos aquí en términos de la segunda, no por ello es la más precisa: Siguiendo a Del Arenal (1994) el verdadero objeto al que debemos atender en el espacio político fronteras afuera no son las múltiples interacciones entre diversos actores, sino su resultado, es decir, la sociedad internacional (particularmente, creemos más adecuada la denominación 'sociedad global', dada la interpretación acotada que implican las 'relaciones entre Estados').
} 
Puede definirse la política de poder como un sistema de relaciones internacionales en que los grupos se consideran a sí mismos como los fines últimos; emplean, al menos con propósitos vitales, los medios más efectivos a su disposición y son medios de acuerdo con su peso en caso de conflicto (Schwarzenberger, 1951: 12)

En un medio donde predomina la lógica hobbesiana (recordemos el principio que rezaba 'donde no hay poder común no hay ley, y por tanto, no existe la injusticia'), el poder es determinante, pero no lo único: los Estados eligen otros grupos con los que relacionarse ${ }^{119}, \mathrm{y}$, si bien el derecho y la moral existen y regulan algunas relaciones interestatales (Aron, 1979) están limitados por su posición subordinada ${ }^{120}$. Como hemos mencionado en el apartado anterior, procederá según su imperio: o bien los ignorará, o bien los usará a su favor.

No podemos avanzar más sin aclarar el título de este acápite, dado que implica una posición acerca de la concepción de política de poder que aquí tendremos. Hemos decidido colocarlo en su denominación anglosajona siguiendo la distinción que establece Raymond Aron (1979) y que especificaremos en lo tocante. Además, permite distinguir con precisión términos que se usan descuidadamente como sinónimo, intercambiando power politics, por machtpolitik y realpolitik. En este sentido, es necesario comenzar con una distinción fundamental entre las primeras dos: es provechosa la que establece Aron (1979) entre machtpolitik y power politics. Mientras

\footnotetext{
${ }^{119}$ Recordemos que Schwarzenberger es un ávido defensor de la teoría de la sociedad internacional, por lo que las relaciones internacionales son, en esencia, relaciones entre grupos de diferente nivel y agregación -grupos y grupos, grupos e individuos, individuos e individuos- que impactan y dinamizan el escenario internacional.

120 Es necesario mencionar la línea de razonamiento del autor: quien ve esta condición como temporaria, o, al menos, pasible de modificarse: de este modo, la primacía -o una mayor preeminenciapuede construirse a futuro (Schwarzenberger, 1951)
} 
la primera es un valor (el autor toma al germano Treitschke, señalando que el Estado es poder y su pecado la debilidad, por lo que una política de la fuerza es virtud), la segunda es un hecho (apegada a la limitación de objetivos, sopesando las diferentes alternativas antes de decidir):

Ambos enseñan la prudencia, pero uno a partir de una política de poder, exaltada como conforme con la vocación de los hombres y de los Estados, y el otro partiendo de una política de poder, aceptada con resignación para evitar males mayores (Aron, 1979: 716 [traducción propia] ${ }^{121}$ )

De este modo, la power politics acepta que los Estados alentados por su voluntad de poder se ven en rivalidad continua, pero no se enorgullecen de ello ni ven en ello algún principio que lo justifique (moral, jurídico, consuetudinario, o incluso divino). Aron recupera a Weber para graficar la lógica de su razonamiento cuando mostraba los orígenes del capitalismo vis à vis el hombre contemporáneo: 'los puritanos querían ser profesionales, nosotros estamos obligados a serlo'. Del mismo modo con la power politics: mientras la machtpolitik está asociada a la esencia del Estado -la fuerza-, por lo que es una virtud poseerla; la power politics es, un mal inevitable, un trago amargo ineludible. Omitirla, es un lujo que los Estados no pueden darse, so pena de perecer.

Pero esta no es la única conversión de la posición europea frente al re significación norteamericana: de este lado del Atlántico, la primacía de la política exterior se pierde.

\footnotetext{
${ }^{121}$ Del original: Os dois recomendam prudência: um deles a partir de uma política de potência exaltada, que considera consentânea com a vocação dos homens e dos Estados; o outro, a partir de uma política de potência aceita com resignação, para evitar males maiores.
} 
En Europa, Treitschke señalaba al Estado como la unión de la justicia y la (capacidad de la) guerra, pero ésta prima porque no podrá imponer la primera sin ella. Entre los norteamericanos, la polémica contra los idealistas prima, impregnada de pragmatismo e individualismo. Eso los lleva a ver al hombre, interesado y violento, y a la política, pues en funcionamiento gracias a su medio: el poder.

Aron enfatiza que esto no es meramente una impronta, sino una perspectiva que reviste consecuencias teóricas: en la obsesión de refutar el contractualismo liberal -el que se conforma con el respeto por la ley-, los realistas oponen potencia contra ley o moralidad, y definen a la política por el poder y no al orden internacional por la anarquía. Esta concepción se daría de bruces con otros analistas, especialmente con Wendt (1992), quien sostiene que la power politics y el sistema de auto-ayuda de la estructura internacional no se deriva de la anarquía, sino del patrón de interacciones entre Estados -si deciden tratarse como enemigos o no- y a partir de aquí podremos definir si la anarquía puede ser asociada (y de qué modo) a la power politics, a la indiferencia o bien a la seguridad cooperativa ${ }^{122}$.

Por último, la realpolitik, en manos de los especialistas anglo-norteamericanos (Kennan y Kissinger, por ejemplo) resulta una corriente de pensamiento y una práctica relacionada al cinismo, oportunismo y maquiavelismo (en tanto que política sin escrúpulos y al servicio del aumento del poder (Rubio García, 1974; Bew, 2016)). Por eso se denomina a la tradición norteamericana como anti-realpolitik (Bew, 2016). Esta

\footnotetext{
${ }^{122}$ Cf. WENDT, Alexander (1992) Anarchy is what States makes of it. The social construction of power politics, International Organization Vol. 46, No. 2. pp. 391-425.
} 
nominación es la que tal vez propenda a hacerla intercambiable con la persecución del interés nacional o incluso con la raison d'état. Lo errático aquí reside en que la realpolitik es, definitivamente, mucho más nueva que la machtpolitik: el término fue acuñado por un activista liberal del siglo XIX -August Ludwig von Rochau- en 1853 (en su tratado Fundamentos de la Realpolitik), para referirse a la evaluación de una política como provechosa en tanto que se coteje concomitantemente las circunstancias en las cuales el estadista opera. Las ideas no son necesariamente prescindibles, pero la variable de ajuste será la fuerza política antes que la pureza o elegancia de ellas ${ }^{123}$. Claramente, el casi olvido de von Rochau como mentor y la reconfiguración del término fue el destino de esta mentada palabra para el siglo siguiente.

No obstante, y más cerca en la historia, Kristol reconoce a la realpolitik como una herramienta disponible -aunque excepcional-, dado que las políticas exteriores sólo subsisten a largo plazo si se condicen con valores nacionales en lo social, político, económico, etcétera. Claro que ello no obsta períodos -o acontecimientos- que justifiquen eludirlos (también, por un tiempo limitado (Bew, 2016)). Rubio García (1974) señala que Talleyrand y Metternich -encarnación de la realpolitik- tenían ideales políticos y sus políticas estaban al servicio de ellos, por lo que la mentada realpolitik no significa carencia de ideales o fines, sino que reviste algo de corte instrumental: es decir, una política exterior basada en cálculos fríos (sin principios idealistas) ante los intereses nacionales, sopesando los costos y beneficios que implica el uso del poder (militar).

\footnotetext{
${ }^{123}$ Bew afirma en el original: rather than their purity or elegance (página 6)
} 
Podríamos sintetizar la diferenciación en una simple regla: el valor inscrito en un Estado germánico -que es poder y por tanto prestigio (Aron, 1979)- erige la machtpolitik, la lucha basada en la fuerza. Cuando atraviesa el Atlántico, su inevitabilidad la transforma en power politics. La realpolitik permanece en una suerte de limbo, del que es mudada alternativamente al infierno (en administraciones tan diferentes como la de Nixon-Johnson y la de Carter). Y luego resulta tolerada -que no ponderada- como en el caso de Kristol. Resulta curiosa la manera en que Bew caracteriza esa incomodidad, ese decurso sinuoso:

\begin{abstract}
De este modo, aun cuando la realpolitik había sido usado de manera positiva en el Reino Unido y en Estados Unidos, también causaba incomodidad. En la década del treinta en Inglaterra y los setentas en Norteamérica, en dos contextos tan diferentes, los analistas de política exterior reclamaron la inclusión de la realpolitik por sus propios estadistas y diplomáticos. Un brutal neologismo teutónico para atragantarse. Como Peter Viereck, un analista germano-americano de la realpolitik escribió en 1942, se 'pronunciaba con una larga, gutural, truculenta ' $r$ ', y connotaba rruthless ([despiadado], el adjetivo favorito de Hitler) y 'rrrealista'. Uno podría contrastarlo con las suaves inflexiones del francés -la lengua tradicional de la diplomacia- de la cual détente es un buen ejemplo (ibídem: 3 [traducción propia] $^{124}$ )
\end{abstract}

\footnotetext{
${ }^{124}$ Del original: consequently, even when Realpolitik has been used favourably in the United Kingdom or the United States, it has caused discomfort. In the 1930s in Britain and the 1970s in America, in very different contexts, the critics of foreign policy often cried foul about the ingestion of Realpolitik by their own statesmen and diplomats. A harsh Teutonic neologism, it has a tendency to get stuck in the craw. As Peter Viereck, a German American critic of Realpolitik wrote, in 1942, it was "pronounced with a long, throaty, truculent ' $r$ ', and connotes 'r-r-ruthless' ( $r$-r-rücksichtslos, Hitler's favourite adjective) and ' $r$-rrealistic' (r-r-realitsich)". One might well contrast it with the smoother inflexions of French --the traditional language of diplomacy-- of which détente provides a notable example'.
} 
Ya alcanzado el fin de la primera sección, comencemos ahora pues, a delinear teóricamente el espacio regional en sus aspectos más teóricos, y así poder avanzar al final de la sección a las notas propias del caso suramericano. 
Sección Segunda

Herramientas conceptuales 
Capítulo III. Regionalización e integración regional

Sumario. En este capítulo abordaremos el fenómeno de la región y regionalización, piedra de toque para comenzar a circunscribir nuestro desarrollo en la dimensión geográfica suramericana. Paso seguido, construiremos formalmente la integración regional tomando por eje el neofuncionalismo, guiados por su riqueza teórica y el componente fuertemente pragmático que presenta. Concluimos el capítulo con una nueva especificación en el caso suramericano con el fin de plantear características y algunos insumos teóricos que precisaremos en la construcción de la estrategia de poder global brasileña (EPGB). 

en la política internacional, depende de decisiones políticas 》)

Joseph Nye, 1996

«[las regiones son] difíciles de describir, pero las reconocemos cuando las vemos》 Eric Van Young, 1991

Las herramientas conceptuales que nos deparan en esta segunda sección guardan una estrechísima relación conceptual y alcance entre sí. Pero no divorciamos este tramo de las que abordamos en la primera sección. Nuestro interés es tejer conceptualmente ambas secciones: trabajamos aquí sobre la región y la regionalización -por la vía pragmática del neofuncionalismo-, la enfocaremos en el caso suramericano y concluimos en algunos insumos analíticos que precisamos para la segunda parte. No sin antes abordar la hegemonía como fenómeno (en el siguiente capítulo) y que nos permite volver a recuperar la lógica del poder, habiendo ya ingresado en el alcance regional.

En estas líneas compartiremos la denominación de Andrés Malamud (2011) para regionalización al referirnos al aumento de interacciones en una determinada región, y regionalismo para lo que entendemos como integración regional. Dentro de ella contemplaremos la cooperación internacional sólo como una herramienta, posibilitada por la característica intrínseca de la integración: la de ser un patrón de interacción no 
coercitivo cooperativo (Del Arenal, 1994) ${ }^{125}$. Partiremos, ahora, señalando la primera disquisición conceptual necesaria:

\begin{abstract}
La integración regional -a veces denominada regionalismo- consiste en un proceso formalizado y conducido desde el Estado. En contraste, la regionalización -o aumento de la interdependencia intrarregional- es un proceso informal por el cual se incrementan los flujos de intercambio entre un conjunto de países territorialmente contiguos. Este proceso puede promover la integración formal que, a su vez puede retroalimentar, pero su motor principal no reside en el Estado, sino en el mercado y, secundariamente, en la sociedad civil (Malamud, 2011: 220. Destacados en el original)
\end{abstract}

Vemos, en primero lugar, que regionalización y regionalismo se vinculan: el primero es el escenario, donde suceden las condiciones (macro)sociales del segundo (Murillo Zamora, 2004). La regionalización constituye un proceso en el tiempo también asentado en otra noción: la región. Concepto añoso -acuñada en el siglo XVIII y ligada al establecimiento de divisiones naturales del planeta-, en los hechos siempre ha referido predominantemente a cuestiones territoriales (Fawcett y Hurrell, 1995). No obstante, es un espacio social, producto de las interacciones humanas que tiene al interior de su delineado geográfico -incluso, estas mismas interacciones pueden ser la causa de ese delinead geográfico posterior- (Niemann, 2000) ${ }^{126}$. Mellado (2013)

\footnotetext{
${ }^{125}$ No obstante, en todo momento tendremos en cuenta que la cooperación internacional reviste una condición necesaria pero no suficiente para el regionalismo (Bernal-Meza, 2009). En otras palabras, la cooperación internacional no se agota en el regionalismo de cualquier nivel de desarrollo y características.

${ }^{126}$ Bernal-Meza (2006) recupera una idea de Smouts (1997), señalando que las regiones son, en primera instancia, comunidades más imaginadas que reales (y no al contrario). Creemos que esta idea, la que a primera vista podría ser interpretada en clave constructivista, es, en realidad, una definición procedente para equiparar las regiones a su dimensión territorial y social por igual (dónde 'social' es histórica, cultural y hasta étnica).
} 
menciona el redescubrimiento de la región como una categoría analítica, de interés político y económico (motivada por un considerable interés en las ciencias sociales, donde ha recibido diferentes perspectivas de análisis), en la que se configuran actividades productivas que reorganizan el espacio como producto social. Sus componentes son la configuración territorial -elementos naturales modificados o no por el accionar del hombre- y la dinámica social, es decir, las relaciones sociales situadas en tiempo y lugar. La región implica una ocupación y usos del territorio que devendrá en la búsqueda de un posicionamiento espacial competitivamente estratégico (Ceceña, 2008; citado en Mellado, 2013).

Este espacio, que contiene relaciones sociales, está atravesado e influido por divisiones formales político-jurídicas, por lo que se transforma en una distribución de poder equilibrada (Remiro, 1999) ${ }^{127}$. Las regiones constituyen una continuidad física dividida por la jurisdicción estatal y su política (ibídem), eso las hace especialmente complejas: relaciones sociales asentadas en un territorio, pero no conducidas por Estados, que a su vez tienen que adecuarse a cierta formalidad y pueden estar influenciadas mediatamente por la política.

No necesariamente son espacios armónicos, ni la creciente regionalización es beneficiosa per se: puede llevar a la integración de espacios como también a la

\footnotetext{
${ }^{127}$ Remiro sostiene que para que la región se proyecte de manera ventajosa frente a sus partes necesita, obligatoriamente, de una identidad de intereses comunes y de una distribución de poder equilibrada. Para graficarlo, asegura que podemos hablar de América Latina como región, pero no del continente americano como tal. La razón de ello reside en las consecuencias estratégicas: el panamericanismo derivado de la Doctrina Monroe- implicó subordinación política a un hegemón hemisférico, pero extra regional.
} 
concomitante marginación de otros (Bernal-Meza, 2008). Y, de hecho, también puede

estar atravesada por severas tensiones relacionadas con el poder, como:

La región necesita líderes, pero es manipulada por hegemones, que buscan hacer de ella su propia zona o esfera de influencia (...) la región defiende su identidad e intereses comunes en un medio universal cuyo cosmopolitismo refuerza (Remiro, 1999: 13. Destacados en el original)

Es preciso no ver el tándem región-regionalización (y posteriormente regionalismo) como compartimentos estancos. Los tres son un proceso en sí mismo ${ }^{128}$, que, a su vez, se influencia entre sí:

El regionalismo, como proyecto político, está en constante cambio y mutación, marchando desde una base geográfica compartida hacia la formación de una "comunidad imaginada". Este proceso pasa por cinco etapas: 1) la definición de la unidad geográfica; 2) la profundización de las relaciones entre los grupos que comparten esa base territorial (sistema social regional); 3) la creación de una sociedad regional, en forma espontánea o por medio de la cooperación en áreas específicas; 4) el desarrollo de un marco organizativo para la cooperación (comunidad regional); y 5) un sistema regional institucionalizado cuando la región actúa como un sujeto activo con identidad propia, capacidad, legitimidad y una estructura de toma de decisiones (Hettne, 2002: 957; citado en Giacalone, 2006. Los destacados son nuestros)

\footnotetext{
${ }^{128}$ La autora menciona, más adelante, algo que podemos destacar a los fines de esta idea de permanente reconfiguración -no sólo práctica, también conceptual-: en la actualidad, la noción de región privilegia aspectos no territoriales y se vuelca por el proyecto político. Y así la región atávica dá lugar al regionalismo, que se erige por encima de aquélla y la reconfigura conceptualmente y en la práctica: los regionalismos devienen actores (del sistema internacional) por lo que su rol político se sobrepone al meramente territorial.
} 
Existen maneras diferentes de concebir un proceso de regionalización vis à vis otros conceptos. Su generalidad, su cualidad procesual, implica que contengan otros fenómenos y se relaciones con otros de igual generalidad. Si pensamos que la regionalización puede resultar una antesala del regionalismo, no podemos ver a la región y el regionalismo por fuera de la nueva dinámica impuesta por la globalización. Lo que queremos destacar es muy concreto: cualquiera fuese la perspectiva, definición o incluso juicio de valor que se tenga acerca de ellos, traerá acarreado otra concepción acerca de la última ${ }^{129}$. La región aparecerá como un proceso donde el crecimiento de la interacción económica acaba por aumentar el intercambio social y cultural (Hurrell, 1995). Así se construirá la posterior 'nave regional' (Hurrell dixit), que no puede prescindir de la proximidad física de al menos tres miembros (junto con la cooperación para ganancias mutuas sin límite de agenda y su interdependencia).

Pero también se la puede ver como Remiro (1999), quien la considera un espacio de complejidades propias, por lo que su evolución hacia el regionalismo se propone como plataforma para expresar más eficazmente una posición sobre problemas universales (página 13). Heveem (2000) destaca la importancia de una identidad geográfica previa para la regionalización (y ella frente a la globalización): el camino es, para el autor, de las ideas hacia la identidad y de ahí a la institucionalidad regional para la posterior articulación con el orden mundial.

\footnotetext{
${ }^{129}$ No es sólo la concepción con relación a la globalización donde el término resulta tensionado. La dirección que atraviesa la regionalización y posterior regionalismo -centrípeta o centrífuga-, también se ve influenciado por la perspectiva analítica (Bernal-Meza, 2008). Así, podemos encontrar casos de mayor creación de comercio conviviendo con aumento de polarización global y desarrollo desigual regional. Por eso pensar el regionalismo no sólo refleja una postura acerca del orden mundial, sino que, por el contrario, obliga a comprenderlo y mantener las dimensiones globales/regional vinculadas (ibídem).
} 
La importancia de la relación entre regionalización/regionalismo y orden mundial aparece con importancia insoslayable en Bernal-Meza (2000, 2006, 2008; Bernal-Meza y Masera, 2008), y así es como reparar en el proceso en América Latina nos remite a verlo como uno de los procesos que caracteriza el devenir de la economía mundial (el otro, su correlato, es la mundialización/globalización (Bernal-Meza, 2006a) ${ }^{130}$ ). Relacionados de suyo, el primero debería oficiar como contrapeso a las tendencias del segundo, y no como un mecanismo adaptador de las dinámicas económicas globales, puesto al servicio de una estrategia que incorpore la sustitución regional -que no nacional- de importaciones, la articulación (especialización/complementación) económica intrarregional y una inserción competitiva (primero nacional).

De hecho, esto último nos obliga a afirmar que estos términos están tan imbricados que es imposible no referir, aunque sea brevemente, a su relación con la globalización. Si la regionalización es corolario de ella en términos de la economía mundial (Bernal-

\footnotetext{
${ }^{130}$ Es necesario aclarar el término, dado que no sólo es un cambio de denominación, sino que contiene consecuencias teórico-analíticas determinantes: Para Bernal-Meza, la mundialización es un factor que afecta la regionalización como tal e inerva una toma de posición histórico-estructural (esto lo liga a Wallerstein y Kippendorff, pero también a la connotación procesual de Tomassini (1984) y Sunkel (1987)). En pocas palabras, la mundialización reviste un proceso prioritariamente económico y tecnológico, mientras la globalización le otorga su carácter ideológico. Producto del ordenamiento mercantilista, es más añosa de lo que pensamos: de la internacionalización hacia la transnacionalización de las economías nacionales, articuladas en un sistema mundial con un modo de acumulación determinado, devino ideología desde la interdependencia entre actores desiguales. Estas dos caras del fenómeno -complejo y no consolidado- muestra el incremento de flujos, nuevas formas de pensar, producir -financiarizando la economía-, vincular y relacionarse. Todos aspectos que no son nuevos, pero sí se han intensificado). Tiene, también, otras facetas: resultar una vía de justificación ideológica para políticas internacionales y nacionales, promueve la homogenización y fragmentación. Para el autor es, también, un término profundamente normativo: provee una posición eidética, interpretativa y prescriptiva en dirección centro-periferia. Para más detalle, cf. Bernal-Meza (2000, 2006, 2008)
} 
Meza y Masera, 2008), la cooperación y el regionalismo podría representar una estrategia coadyuvante de las políticas del desarrollo ${ }^{131}$ : El vínculo globalizaciónregionalización permite comprender la estructura del sistema internacional desde una coyuntura dada de expansión del capitalismo global ${ }^{132}$. Un aspecto que no es estanco, sino profundamente dinámico: la regionalización institucionalizada -el regionalismo-, vinculado al ámbito multilateral y al orden mundial, repercute sistémicamente porque conlleva en sí mismo los (re)alineamientos estratégicos de cada uno de sus miembros (ibídem). Y cada alianza incide en las negociaciones multilaterales.

Cualquiera fuese la perspectiva para concebir una región, ella siempre es escenario espacial-social con entidad a partir de una serie de características propias, y diferentes de otras regiones. Es una estructura propia más allá del Estado, que se realiza exclusivamente en las prácticas sociales e intereses que le son propios (también, allende lo estatal). Podemos realizar una operación intelectual inversa para definir la región: el regionalismo -la integración regional- no es más que el proyecto políticoeconómico de la regionalización (Mittelman, 1996; Lerman, 2002) ${ }^{133}$; y ésta, es la

\footnotetext{
${ }^{131}$ Bernal Meza señala unos aspectos específicos: el avance de la cooperación en diversos planos y dimensiones del sistema social (científico-tecnológico, cultural, industrial, etc.), el diseño de la inserción competitiva internacional conjunta, la coordinación de estrategias en foros internacionales y el delineamiento de un espacio defensivo (no sólo en cuestiones de seguridad, sino también económicas, políticas y culturales).

${ }^{132}$ Esta idea suena lo bastante vacua si no tenemos en cuenta que la globalización/mundialización es un proceso unificador de asimetrías. Esto que parece una contradicción de términos, en realidad responde a las múltiples fuerzas centrífugas de dispersión y fragmentación con centrípetas de interdependencia (Bernal-Meza, 2006a)

${ }^{133}$ La arquitectura de este proceso nos indicará la concepción previa que rigió la integración: tanto como una vía de inserción a la dinámica globalizadora o bien como un contrapeso a sus efectos (Molina, 2007)
} 
conformación de interacciones sólidas y frecuentes en el tiempo que acontecen en una región (Murillo Zamora, 2004).

Esto las hace fenómenos ex post, por así decirlo, y nos lleva a relacionarlo con una afirmación de Giacalone (2006): dado no existe criterio único para definirlas, tampoco para identificarlas. Menos aún, es un error pretender dar con una región modelo o una agenda unívoca (cada una se desarrolla según sus propios intereses en relaciones a su interior y a su exterior -con pares o el medio internacional-). Es por esto que se hacen visibles a posteriori, una vez ha acontecido la interacción en una frontera que es geográfica, pero también histórica, cultural y político-económica.

Existe una cuestión particular, casi curiosa, de la dificultad de definición para la región y la regionalización: su mutua interacción como conceptos. Si bien suele plantearse a la primera como precedente de la segunda, lo cierto es que, al concebir la segunda, suelen alterarse las connotaciones de la primera. Así, al atender a la regionalización en la práctica -es decir, como proceso concreto- es preciso observar la articulación de una región o de varias regiones. Pero la manera en que deviene ese proceso -articulado a las fuerzas globalizadoras o como resistencia a ellas- se altera la noción de región de la que parte: en el caso que haya resistencia, serán más afectas a las lealtades preexistentes al orden global -las nacionales- o incluso pretenden ser su reemplazo, y así se erigirá como alternativa plural ante la homogeneización. De otro modo, si se ve la regionalización como el correlato fragmentario del orden global, es decir, articulado con las fuerzas globalizadoras, las regiones se anclan teóricamente en patrones 
históricos, y su función vira hacia la organización y regulación local del orden global (Molina, 2007). Las modificaciones del Estado-nación como lo conocimos alcanzados noventa años del siglo pasado, llevarían a una refuncionalización de ellas, por entonces un cuerpo de mayores dimensiones y complejidad con peso predominante en la dimensión económica (Pipitone, 1996: 127; citado en Molina, 2007) $)^{134}$.

Pero esto no termina aquí: Giacalone (2006), al explayarse sobre la importancia de las regiones en la primera década del milenio, nos permite agregar otra modificación retrospectiva -por así decirlo- desde la integración regional. Recuperando a Van Langenhove y Costea (2004) acerca de la importancia creciente de los bloques regionales (que alcanzaron la integración política y las regulaciones internas), afirma que éstos acaban por modificar la dinámica internacional, y progresivamente van erigiéndose en actores internacionales relevando la dinámica estatal westfaliana (territorial, soberana, autónoma y legal). Así, las regiones cobran solidez y visibilidad gracias a procesos de integración exitosos. Es por esto que es tan difícil capturar teóricamente a la regionalización, la que, de suyo, es un proceso (Ibañez, 2000) al interior de un espacio geográfico (región) y que sólo puede ser señalado por la intensificación de relaciones entre actores estatales y no estatales, pero sin la intervención de conducción estatal -o institucional de algún otro tipo-. La frecuencia y profundidad de las interacciones económicas permite nominar a la regionalización, que, no obstante, son políticas, económicas e ideológico-culturales (ibídem).

\footnotetext{
${ }^{134}$ Las razones de ello residirán en la incapacidad de mantener un sistema unipolar ante la sociedad riesgo, junto a los nuevos actores que agrietan circuitos productivos, financieros y comerciales; y la multiplicidad de problemas que no se acotan a las fronteras nacionales (ibídem).
} 
《La integración puede compararse con el poder, pues recordamos que el poder se concibe como una relación en la cual se hace que por lo menos un actor actúe en forma diferente de aquella en que actuaría de otra manera》

Karl Deutsch, 1968

《La política es lo que produce el 'sistema', si bien el sistema luego sigue restringiendo la futura política o dicta sus límites》

Ernst Haas, 1964

En este acápite desarrollaremos insumo teórico determinante a través de dos exposiciones: por un lado, la base teórica dura de la integración centrada en el neofuncionalismo, del que donde presentaremos dinámicamente -y seguramente con un exceso de síntesis- sus ideas fundamentales (reservándonos la licencia de hacer una breve referencia al trabajo de Joseph Nye de fines de los sesentas y comienzos de los setentas). Terminaremos este desarrollo con una referencia breve y obligada al neorrealismo. Por el otro lado, el siguiente acápite, saltaremos en tiempo y espacio para abocarnos a las referencias teóricas de analistas dedicados a la integración suramericana, con el fin de convertirla en un insumo determinante para nuestra EPGB.

Antes de comenzar, una simple aclaración más: somos conscientes que, entre el neofuncionalismo y la gestación del Mercosur, mucha teoría corrió en manos de especialistas en integración regional. La decisión de apelar a él está basada en su impronta pragmática para unas páginas en que este tipo de perspectiva resulta consistente, pero que a la vez establece un contrapunto por vía de la posibilidad de 
cooperación entre Estados. Podríamos haber escogido, por cercanía histórica con la integración suramericana, al intergubernamentalismo institucional (más adelante nos referimos a él) o el liberal (racionalista, basado en la teoría de la negociación y visibilizando el rol grupos internos en el proceso integrador ${ }^{135}$. Hubiese sido adecuado también el neoinstitucionalismo (Wiener y Diez, 2004; March \& Olsen, 1984), que incorpora el rol de las instituciones como estructuradoras del acceso de las fuerzas políticas al proceso político para el origen y evolución del cambio sistémico.

No obstante, el contrapunto (cooperación) y la continuidad (pragmatismo), nos pareció lo más provechoso analíticamente. El neofuncionalismo de los años sesentas y su revisión de los setentas -a manos de Nye $(1969,1970)$ - es el intento más sólido de producción analítica por primera vez desde el federalismo decimonónico ${ }^{136}$. Demuestra la posibilidad de articular objetivos nacionales sin apelar al uso de violencia (un factor divisor de agua para el mundo de posguerra), en un marco de concordancia práctica (Puchala, 1972) ${ }^{137}$, pero exige el frío cálculo de ventajas y/o desventajas.

\footnotetext{
135 Para mayor detalle Cf. MORAVCSIK, Andrew (1993). Preferences and power in the European Community: a liberal intergovernmentalist approach en "Journal of Common Market Studies" 31 (4). pp: 473-523).

${ }^{136}$ El federalismo es, sin duda, la más antigua de las teorías de la integración. Nos referimos aquí a la versión más moderna de ellas -la del federalismo norteamericano- y no ya a las esbozadas por pensadores griegos o incluso a las referencias kantianas. Los estadounidenses concibieron un esquema viable -e imitado por otras naciones- no sólo por las organizaciones constitucionales producto de las diferentes independencias decimonónicas, sino también por el propio integracionismo de posguerra. Consistía en dos vías verticales para alcanzar la federación: por un lado, la negociación constitucional intergubernamental, y por otro, la convocatoria a asamblea constituyente (Burgess, 2000). Malamud (2011) señala que este modelo inspiró a los impulsores de la integración europea como Jean Monnet y Robert Schuman, pero, hacia 1949, no alcanzó para sostener el Consejo de Europa y eso provocó que el incrementalismo fuese el camino a seguir.

${ }^{137}$ Cf. PUCHALA, Donald. Of Blind Men, Elephants and International Integration. En "Journal of Common Market Studies", año X, Nro. 3, marzo de 1972.
} 
Si existiera una manera precisa y adecuada de comenzar cualquier apartado para teorizar de la integración lo encontramos en Del Arenal (1994), al afirmar que no es otra cosa que un fenómeno complejo y multidimensional, de índole cooperativa -de suyo, no coercitiva-. La cualidad cooperativa y no coercitiva distingue de manera crítica el fenómeno de la integración regional, por lo que quisiéramos destacar especialmente.

El aspecto de la multidimensionalidad es caro a estas páginas. Los intentos de desarrollar categorías analíticas de esta índole fueron preeminentes en los sesentas (con el influjo de los cincuentas de corte cuantitativo). Esto no unificó posiciones. Dougherty y Pfaltzgraff (1990), señalan el caso de Nye (más adelante nos dedicaremos a él con más detalle), quien objetó la linealidad -y tal vez la simpleza- de los enfoques producidos en el marco del funcionalismo y su revisión, reclamando diferenciación sobre elementos económicos, políticos y legales pasibles de medición, diferenciar el entorno interno del ambiente, las continuidades y diferencias del proceso. Todo ello en aras de generalizaciones más acotadas y comparables (Nye, 1970). También León Lindbergh (1970) es un exponente de esta búsqueda en el sistema de toma de decisiones colectivo entre naciones -al que denominó proceso multidimensional interactivo (1963)-, pasible de identificarse, compararse, medirse y analizarse en el 
nivel de toma de decisiones colectivas (si bien de claro corte behaviorista, en Lindbergh es más fuerte la impronta de teoría de sistemas) ${ }^{138}$.

Dado que los estudios sobre integración regional suelen abocarse -con total pertinencia-, sobre la referencia a las teorías de la integración regional desde mediados del siglo pasado hasta el presente, en estas líneas, y desde la perspectiva de las relaciones internacionales, tenemos que dar cuenta de este tipo de características densamente teóricas, pero también procedentes a una visión asentada en la sociedad internacional. Por el desarrollo que dimos en la primera sección de esta tesis al realismo clásico y neoclásico, puede instituirse sin esfuerzo que el conflicto es una categoría determinante para el análisis internacional. Lo que resulta errado sería asociarlo al realismo como tal o concebirlo en términos exclusivamente hobbesianos, por así decirlo (Wilhelmy, 1988).

De manera muy sumaria, podemos encontrar algún tipo de conflicto entre dos o más actores en la persecución de objetivos idénticos sobre recursos escasos u objetivos similares, pero con compatibilidades en otros aspectos (por supuesto, estas diferencias condicionarán qué desencadenará: conflicto de baja intensidad o una crisis). Una situación de conflicto, no es más que un tipo de relación social que no sólo se expresa por su forma más grave, la bélica. El conflicto puede ser visto como una forma natural

\footnotetext{
${ }^{138}$ Plantea propiedades variables que muestran ese compromiso a la decisión conjunta (por medio del alcance funcional -número de áreas temáticas-, el estadio -sólo al principio de la decisión o en todo el proceso-, el nivel hasta el cual las demandas se articulan en la dimensión colectiva, el rol del liderazgo en la dimensión colectiva, el grado de cumplimiento individual y colectivos de las decisiones regionales, etcétera).
} 
del comportamiento político, no ya por una visión antropológica pesimista sino por una perspectiva más estratégica: resulta un instrumento de negociación (Nieburg, 1969) ${ }^{139}$. En todos los casos, es preciso tener en cuenta su intensidad como las crisis y los conflictos sociales:

Lo que caracteriza a la integración es la existencia de condiciones que permiten, sin el recurso a la guerra, avanzar en el camino de la superación de las diferencias, tensiones y conflictos entre las diversas unidades políticas. En este sentido, existe una indudable relación entre las teorías de la integración y el estudio de los conflictos (Del Arenal, 1994: 259)

A los fines de presentar la integración regional, es necesario destacar que cada sector de actores del escenario internacional puede establecer mecanismos de cooperación de diferente nivel e intensidad (Wilhelmy, 1988) para la persecución de objetivos comunes sobre la base de intereses respectivos, o bien, consensuar y concertar intereses divergentes. La manera de realizarlo es la dinámica cooperativa y la integración regional implica, desde ya, una forma de cooperación (Gasparini, 2014; AECI, 2015). Vale remarcar que estamos utilizando aquí la noción de cooperación por oposición a conflicto (es decir, en tanto que dos caminos posibles -con diferentes perfiles a su interior- para que dos o más actores interactúen). De este modo, no

\footnotetext{
${ }^{139}$ Nieburg creía que la modificación de la conducta ajena era determinante en el juego del poder. Por eso la violencia política reviste actos de desorganización, destrucción o daño cuya finalidad, elección de objetivos o víctimas, circunstancias, ejecución y/o efectos tengan significación política, es decir, que tiendan a modificar el comportamiento de otros en una situación de negociación que tenga consecuencias para el sistema social (1969: 13). Es un tipo de violencia anclado en diferentes actores dentro de un sistema político (nacional o internacional). La violencia de baja intensidad aparece asociada como recurso de negociación, pero, desde ya, es difícil gestionar la línea que divide la discrepancia y la demostración a través de algún tipo de coerción de los hechos de violencia que ya no tienen retorno.
} 
estamos aludiendo a lo que se denomina conceptualmente cooperación internacional $^{140}$.

Cooperar posee un requisito: el consenso en sus innumerables formas. La cohesión proviene del consenso logrado en acuerdos en valores políticos compartidos plasmados sobre una ingeniería legal que también permitirá resolverlos (Dougherty y Pfaltzgraff, 1990). En cuanto a la cualidad no coercitiva, resulta importante en términos teóricos porque es el aspecto que constituye la real línea divisoria de aguas entre el realismo (clásico) y las teorías de la integración (cualquiera fuere la perspectiva teórica de ellas).

Antes de cualquier referencia teórica, tenemos que mencionar algo evidente: la mayoría de los desarrollos han sido desarrollados para el caso de Europa occidental, en un momento dado (a partir de la Segunda Guerra Mundial), y a la luz de unos procesos determinados (las organizaciones internacionales regionales europeas). También existe una diferenciación lógico-analítica en términos de generalidad teórica: mientras los debates de la teoría de las relaciones internacionales (Del Arenal, 1989) versan sobre

${ }^{140}$ Es necesario diferenciar la vía cooperativa de interacción de la cooperación internacional propiamente dicha. A los fines de esta disquisición -más adelante avanzaremos por la precisión conceptual-, la integración regional como una especie de conducta cooperativa, mientras la cooperación internacional, alude a un fenómeno perfectamente compatible en países que poseen diferencias cuanti y cualitativas y sin avance alguno en cualquier forma de integración regional (Bernal-Meza, 2008), que se propone promover ventajas recíprocas a través de políticas públicas que las aseguran (Keohane, 1998; citado en Lanci, 2007). Un ejemplo podría señalarse en la coordinación de posturas en foros multilaterales y/o organizaciones internacionales (Hurrell, 1995). En pocas palabras, puede existir cooperación internacional sin integración regional, como puede pensarse a la primera como un preludio que conduce a la segunda (o incluso, una versión menos intensa de la integración, como menciona Silvana Insignares Cera en La UNASUR: ¿integración regional o cooperación política?: UNASUR: ¿Regional Integration or political cooperation? Revista Derecho, 2013, n.40. pp.167-198. 
cuestiones de largo alcance -pretenden explicar el funcionamiento del espacio internacional como un todo-, existen, dentro de ellos, las cuestiones de mediano alcance (Dougherty y Pfaltzgraff, 1990), es decir, con el objetivo de explicar una zona de fenómenos determinados (Wilhelmy, 1988). Entre tantos otros, el estudio de la integración regional constituye uno de ellos. Esto conlleva otras consecuencias epistemológicas, en lo atinente a cuál es el anclaje apropiado para centrarse en el análisis de la realidad internacional: como menciona Dougherty y Pfaltzgraff (1990), qué posición deberíamos adoptar entre la dimensión micro y macro nos lleva sin solución de continuidad a cuestionar cuáles son los agentes propiamente dichos del análisis internacional. Sin tomar una posición sobre esto, mencionemos unos actores determinantes para la concepción integracionista: los agrupamientos internacionales formados por Estados. Claro está, sería imposible avanzar en un análisis en esta dimensión sin tener en cuenta los otros anclajes posibles del análisis internacional como son los individuos, los grupos subnacionales, los grupos transnacionales, el propio sistema internacional y las combinaciones pertinentes entre ellos). No existe un argumento sólido para sostener la unidimensionalidad: En lo personal, es el recorte analíticamente útil -aquél que incluya la mayor riqueza de dimensiones y por esto imite la complejidad de la realidad en la mayor medida-, el norte a escoger.

Y si de aquello que señalamos al principio en boca de Del Arenal -la complejidad multidimensional de la integración- la podremos observar en cada una de las posiciones teóricas, allí se acaban los consensos. Las teorías de la integración se dividen entre aquellas que conciben la integración como un proceso (en donde lo 
determinante son las causas que desencadenan el bloque), o bien como un estado, es decir, un resultado final un hecho alcanzado que, a su vez, comienza a ser una condición para otros procesos subsiguientes (donde se atienden los alcances obtenidos en términos de características y configuraciones). En estas páginas tomaremos posición y atenderemos los desarrollos teóricos de quienes entienden la integración regional como un proceso ${ }^{141}$.

Dentro de quienes ven la integración como un proceso, encontramos la piedra de toque de la teoría de la integración regional: el aporte funcionalista (Del Arenal, 1994), por lo que la teorización de la integración regional se desembaraza de los supuestos principales del realismo -irreductibilidad del Estado y prevalencia del interés nacional-. Había aquí un componente meramente axiológico: las necesidades de la humanidad eran, por definición universales, mientras los Estados sólo podían atender necesidades acotadas a una jurisdicción. Y este supuesto avanza a una forma más prescriptiva: son los Estados los que encarnan esta suerte de 'falla' del sistema internacional, que no es otra que la guerra periódica. Con posterioridad a la Segunda Gran Guerra, los sistemas gubernamentales se complejizan técnicamente. La lógica del mero poder-después de los desmanes que había causado en la última década-, no parecía describir la realidad acabadamente. Los problemas comenzaban a verse sin fronteras de por medio, y la solución comenzó a concebirse también en conjunto (incluso, Dougherty y Pfaltzgraff

\footnotetext{
${ }^{141}$ Es el caso de Amitai Etzioni quien basa la ingeniería integracionista en el criterio weberiano que cimente la integración nacional: el monopolio del uso legítimo de la fuerza. El grado de control sobre esos medios indica el grado de integración política (Dougherty y Pfaltzgraff, 1990), que se refuerza por la capacidad de asignar y distribuir recursos gracias a su imperio. Esto opera como foco de identificación política para la gran mayoría de los ciudadanos. Ergo, allí podremos hablar de integración política.
} 
(1990) señalan este fenómeno como el comienzo de la cooperación técnica). Si las soluciones eran comunes y los Estados habían subsumido a la humanidad en el desastre ${ }^{142}$, pues había que pensar en algo mejor.

En la medida en que no se vire hacia una lógica donde las organizaciones internacionales atiendan las funciones necesarias para satisfacer las necesidades humanas, el conflicto estará al acecho (esto indica que la guerra no es algo inherente a la natura humana, sino que constituyen un problema transaccional). La ramificación de Mittrany suponía una colaboración por problemas a atender podría incluso, minar la competencia estatal en sí (y así la configuración del sistema internacional, deviniendo en una nueva sociedad internacional 'funcional' (Del Arenal, 1994: 263). En su máximo alcance, esta ramificación llevaría a la paz mundial por fuera de los belicosos Estados, pero deja pendiente la progresión lógica -y práctica- de la sociedad por funciones: no ofrecen mecanismo alguno por el cual la integración económica y social debía llevar a la integración política (Deutsch, 1990).

Tampoco por ello podemos desterrar su aporte: Lo cierto es que los gobiernos reconocen beneficios mutuos potenciales a partir de sus compromisos cooperativos y permiten su proliferación. Sólo debemos reconocer, claro, que esto no supone 'mundo

\footnotetext{
${ }^{142}$ Esto enlaza con algo que ya hemos tratado: el auge del realismo clásico de posguerra que es relevado, por así decirlo, luego de su aparente fracaso en la segunda posguerra por el funcionalismo y neofuncionalismo. Podemos rastrear ese 'clima de ideas', esta posición generalizada de la opinión pública ante el pasado reciente a través de la posición analítica de los autores. Por ejemplo, en Deutsch (1990) hasta en los autores de enfoque comunicacional como Deutsch. Al versar sobre cómo alcanzar y mantener la integración (recordemos que escribe originalmente en 1968): las organizaciones internacionales han sido consideradas, a menudo como el mejor camino para sacar a la humanidad de la era de los Estados nacionales (1990: 226; destacados nuestros)
} 
perfecto' (Viola, 2000: s/d). Esta omisión teórica no residió, claro está, en algún tipo de falta de perspectiva: moraba en asumir la necesidad de eliminación del sistema estatal como 'esqueleto' del sistema internacional. Eso los arrastraba a no reparar en la integración política. Pentland (1976) utiliza la imagen de la planta carnívora para exponer cómo fueron presa de sus propias concepciones: mientras los beneficios aparentes lo atraen al interior, una vez dentro de la planta, comprueba que todas las vías de salida fueron bloqueadas. Malamud (2001) asegura que cuando los técnicos no manejaron los problemas económicos y la teoría fue impotente para haber elegido ciertas opciones, se abrió paso un nuevo enfoque (el neofuncionalismo) y cita a Nelsen y Stubb, quienes aseguran que el funcionalismo ostenta su principal falla en la carencia de una teoría de la política.

Del funcionalismo inicial no creemos que haya que rescatar la función o la lógica de la ramificación, sino la noción (y posibilidad) de regionalización de los problemas, a lo que nosotros agregaremos una connotación: conlleva la posibilidad de apelar a una respuesta conjunta.

Aun cuando el cambio de paradigma era alentador, también era, pues, acotado. Por eso Schmitter en 1969 acuña el término neofuncionalismo, para conservar los avances pero mejorar las deficiencias (es decir, mantener la instrumentalidad a costa del componente no-racional de la política, la articulación de grupos de interés -en el 
neofuncionalismo da lugar a la dimensión conflictiva-, y la utilidad de la tecnocracia internacional) $^{143}$.

${ }^{143}$ El caso de mayor disparidad -y casi una curiosidad académica-, al interior de funcionalismo y neofuncionalismo reside en el trabajo de Ernst Haas, que nunca refiere a los términos de Mittrany para su exposición (Del Arenal, 1994). 


\section{El giro neofuncionalista}

El neofuncionalismo ${ }^{144}$ recupera la tradición federalista de unificación política típica del siglo XIX con la gradualidad del funcionalismo anclado en las necesidades concretas del actor (ibídem). El neofuncionalismo configura la ramificación funcionalista para presentar la noción de spill-over (término acuñado por Ernst Haas ${ }^{145}$ ), a lo que suma un perfil dinámico más político que ya no reposa en una reproducción 'natural' ante la progresiva obsolescencia estatal:

El proceso por el cual los miembros de un esquema de integración -de acuerdo sobre algunos fines colectivos en base a diferentes motivos, pero desigualmente satisfechos con el logro de los mismos- tratan de resolver su insatisfacción, ya recurriendo a la colaboración en otro sector relacionado (extendiendo el alcance de sus implicación mutua), ya intensificando su implicación en el sector original (incrementando el nivel de mutua implicación), o bien en ambos (Schmitter, 1969: 162 [destacados en el original])

\footnotetext{
${ }^{144}$ El neofuncionalismo no fue el único desarrollo de esta época: si bien el intergubernamentalismo se consolida en la academia en los ochentas, surge en los sesentas con la 'crisis de la silla vacía' y el Acuerdo de Luxemburgo (Lo Serrano, 2008), promoviendo una integración basada en ganancias relativas, sin apuntar a la supranacionalidad, perspectiva que se vio herida en 1986 con la firma del Acta Única Europea que re-impulsó la integración hacia el Mercado Único, ampliando competencias comunitarias. Esto llevó a que sus integrantes -Hoffman a la cabeza- revea su postura y acuñó una nueva variación intergubernamentalista: la institucional, consagrado en 1991 con Robert Keohane. No obstante, siguen reticentes a la cesión de soberanía (ibídem) pero lo compensan con las posibilidades de compartición y puesta en común de la soberanía, en áreas que no son claves para el interés nacional.

${ }^{145}$ Cf. HAAS, Ernst (1964). Beyond the Nation-State. Functionalism and International Organizations. Stanford University Press
} 
Si bien el trasvasamiento era inexorable para los inicios de la producción teórica de Haas (1958), el carácter conflictivo de la sociedad -grupos que compiten por intereses en conflicto- era también un hecho. Y haría que la integración no pudiese centrarse en el consenso por lo que, creemos, así ingresa un componente fuertemente pragmático a su perspectiva de la supranacionalidad:

En vez de tratar la integración como una condición en la cual el consenso político y los valores comunes están ya desarrollados, consideran la misma como un proceso en el que las élites políticamente significativas redefinen gradualmente sus intereses en términos de orientación regional en vez de nacional, y ello no por motivos altruistas sino porque perciben que las instituciones supranacionales son la mejor vía de satisfacer sus intereses egoístas (Del Arenal, 1994: 265)

Tanto el funcionalismo como su revisión acontecen en un clima determinado en la ciencias sociales: la influencia behaviorista -expresada en la indagación empírica cuantitativa- pero en el caso del neofuncionalismo ${ }^{146}$, la consecuencia en términos de la teoría de la integración regional reside en que su factor más alejado del funcionalismo -el proceso político y sus consecuencias-, está profundamente influenciado por la elaboración y verificación de hipótesis (y por la aspiración de elaborar una teoría de mediano alcance (Wilhelmy, 1988).

Para Pentland (1976) el neofuncionalismo encarna tres ideas rectoras: la región es un proceso político sui generis (destacamos la idea de proceso que para el

\footnotetext{
${ }^{146}$ Que continúa hasta la dimensión teórica con una fuertísima impronta sistémica (y no distingue entre quienes sostienen que la integración es un proceso como Deutsch y Haas, o una condición o estado como Amitai Etzioni (Dougherty y Pfaltzgraff, 1990)
} 
neofuncionalismo era una derivación de su concepción de la política ${ }^{147}$ ), con apoyatura en las instituciones -estatales- que gobiernan el proceso integrador, y por último, la noción de cambio político como desarrollo vertical y horizontal. Es por esto que el neofuncionalismo considera que los primeros pasos a la integración son económicos, pero tienen implicancias políticas (Del Arenal, 1994): la razón reside en que es necesario algún grado de delegación de autoridad, por lo que proponer una integración ciento por ciento económica de suyo acarrearía consecuencias políticas, resultando en una nueva comunidad política, sobreimpuesta a las nacionales que la conforman. De hecho, la politización es una suerte de consecuencia intrínseca: el rol técnico inicial más apolítico que imaginemos implica una consideración de medios-afines para lograr sus objetivos (es decir, escoger entre alternativas, entre cursos de acción) y eso conlleva valorizaciones, opciones, pues: política (Dougherty y Pfaltzgraff, 1990).

El éxito de esas decisiones consolidará un sector y a partir de esto, la vieja ramificación de Mitrany se convierte en Haas en el spillover gracias al involucramiento de actores inter-burocráticos con cada vez mayor peso y mayor alcance que progresivamente comienza a involucrar intereses mayores. Este escalamiento era el verdadero problema teórico de Haas (que resolvió a través de la teoría de sistemas): la actividad

\footnotetext{
${ }^{147}$ La política no reviste, para los neofuncionalistas, una dinámica teleológica: no persigue algún valor (bien común, igualdad, etc.) o un estado futuro de cosas (cambio del status quo en cualquier forma (Del Arenal, 1994). Tienen una considerable influencia sistémica, por lo que se interesan en la política como proceso por áreas específicas (defensa, política exterior, etc.). Los valores sólo disponen jerarquías de zonas a las que hay que atender dentro de un esquema autoritativo de actividades. Esto les permite ver una complejidad de funciones en la política -verticales y horizontales-, que permite entender tanto la dinámica de funcionamiento de una institución como de una nación entera.
} 
gubernamental relaciona agentes y también constituyen ingresos (inputs) en el sistema internacional. Del mismo modo, la actividad de las organizaciones internacionales y lo que Ilamamos régimen internacional, conforman la estructura del sistema internacional, y generan inputs dando lugar a resultados (outputs). Ellos pueden producir tendencias integradoras/desintegradoras en el entorno internacional: es decir, los agentes nacionales reforzarán/debilitarán la cooperación internacional. Cualquiera sea el camino que elijan, ambos implican nuevas funciones y traerán consecuencias no queridas por lo que fines y funciones pueden transformar el sistema internacional (por vía del aprendizaje que refuerza fines originales integradores o bien por el aprendizaje de la experiencia inmediata anterior que reevalúa sus fines (Haas, $1968)^{148}$ ). Este es el germen conceptual de la noción de supranacionalidad:

Tal vez la conclusión más destacable que podemos esbozar de los experimentos de comunitarización es el hecho que los grupos de interés más importantes como los políticos determinan su soporte u oposición a una institución central y nuevas políticas sobre la base de un cálculo de costobeneficio (Haas, 1958: 143 [traducción propia] ${ }^{149}$ )

Pero no debemos entenderlo bajo criterios actuales: para Haas, diferente pero no tan lejano a los funcionalistas, imperaba el mismo clima de ideas de posguerra (que para entonces no era sólo un clima de la opinión pública por así decirlo, sino que ya había

\footnotetext{
${ }^{148}$ Schmitter (1969) sugirió que el derrame debe ser repensado, las veces como el aumento en el alcance de las funciones de una organización (una suerte de expansión combinada con una complejización -la consideración es nuestra-) sin necesariamente un aumento de autoridad; pero también en la dimensión de la autonomía respecto de las autoridades centrales.

149 Del original: Perhaps the most salient condusion we can draw from the community-building experiment is the fact that major interest groups as well as politicians determine their support of, or opposition to, new central institutions and policies on the basis on a calculation of advantage.
} 
influenciado a la ciencia social como tal). Por eso la supranacionalidad era, en realidad, el triunfo de la economía (la 'técnica') por sobre la irracionalidad de la política de poder estatal que llevaba en sí misma la onerosísima institución bélica como método de resolución de conflictos. No era, así, lo que hoy podríamos ver como la imposibilidad de ver a la política fuera de un escenario público -fuere regional o de cualquier otra índole-. De hecho, el rol del conflicto también podría estar presente, aunque no como aglutinador principal de la integración -es decir, huir de la conflictividad internacional puede resultar un considerable motivo, pero no ofrece la suficiente envergadura para sostenerla en el tiempo y en los nuevos desafíos que ella genera). Para Haas la integración es un proceso que vincula un sistema internacional concreto con uno futuro oscuramente discernible. Si el sistema de Estados nacionales implica sus interacciones y respectivas interpenetraciones, la integración describió un aumento de la interacción -e interpenetración- haciendo gris la diferencia entre la interacción típica de organizaciones internacionales y las de los estado-nación (en palabras de Deutsch, la interdependencia comienza a ser mayor a su antigua independencia). Y serán razones estrictamente pragmáticas (expectativas de beneficio) las que permitirán iniciar este proceso, sin requerimiento de altruismo alguno (Haas, 1958).

Es preciso aclarar que Haas varió sus juicios de los primeros escritos de los años cincuenta: a partir de fines de los setentas, comenzó a considerar que lo existente era un clima de interdependencia más que de integración regional propiamente dicha: en su escrito de 1977, Scientist and World Order. The Uses of Technical Knowledge in 
International Organizations (editado por Berkeley), entrevistó a una serie de funcionarios de organismos internacionales, llegando a la conclusión que la integración no resulta un proceso inexorable sino un camino que depende de los actores que la constituyen (la razón que aduce es que los problemas para los cuales la integración se ponía a disposición ya no resultan más regionales, junto con la comprobación que el impacto de las organizaciones internacional no varió desde las primeras iniciativas).

Dougherty y Pfaltzgraff mencionan la ineficacia de las conferencias internacionales aquel si bien reconocían las complejidades de los problemas, acaban por convocar a iniciativas regionales tímidas o sencillamente nacionales para problemas puntuales. Esto fue lo que Haas llamó vinculación de temas fragmentaria y lo arrojó, directamente, al revisionismo de la teoría de la integración regional (Del Arenal, 1994), donde resulta más procedente que la integración puede estar relacionada a la interdependencia -pero no necesariamente es una función de ella- y puede ser pensada a la luz de las concepciones transnacionales.

Por eso, los desarrollos neofuncionalistas resultan determinantes para las teorías de la integración regional y para estas líneas: permiten divisar una solución por fuera de todo utopismo donde la fuerza está fuera de toda posibilidad y a la vez, no caía en el utopismo de reificar valores e imponerlos a múltiples realidades. Pero no por ello era sordo a cualquier consideración valorativa: Haas menciona (1964) que el sólo interés en expectativas de ganancia resulta poco viable a mediano plazo si no está reforzada por un compromiso ideológico profundo. La razón que esgrime es interesante: si se 
logran avances modestos con pragmatismo, no alcanzará con éste para avances más drásticos. En este sentido, creemos que el neofuncionalismo, sostiene la importancia del pragmatismo -al igual que el realismo-, pero lo resuelven bajo otros parámetros -la cooperación no coercitiva- lo que permite desencajar el pragmatismo de sus feroces consecuencias.

La articulación de expectativas, de previsibilidad por fuera de la fuerza y el conflicto de gran escala potencial, es sintetizada por Karl Deutsch bajo lo que denominó posibilidad de reaseguro de expectativas confiables, un factor comparable al poder en términos de efectividad, pero sin sus perjuicios extremos:

La integración es, por lo tanto, una relación entre unidades en la cual éstas son mutuamente interdependientes y juntas producen propiedades de sistema de las que carecen por separado. Sin embargo, a veces el término "integración" se utiliza también para describir el proceso integrativo mediante el cual se alcanza tal relación o estado de cosas entre unidades que antes se hallaban separadas (Deutsch, 1990: 189. Destacados en el original)

Karl Deutsch es el último neofuncionalista que no podemos ignorar. Su enfoque es vasto y avanza sobre cuestiones que su posición epistemológica behaviorista le permitía: la cuantificación, la comparación y ponderación. No vemos estos aspectos negativos en ningún sentido (como tampoco tenemos objeciones para con el perfil intuitivo del realismo clásico). Deutsch se basó en los flujos de transacción como uno de sus indicadores para evaluar el creciente nivel de la integración europea, detectando la meseta que alcanzó a fines de los cincuentas (Deutsch, 1990: 224). La causa residía en los flujos de transacción (y en las conclusiones que extrajo del estudio 
directo de las elites francesa y alemana, por lo que vemos que su perfil behaviorista puro es relativo, no descartó otras herramientas cualitativas).

Un factor que quisiéramos destacar de su trabajo es el que proyecta la integración a futuro: a medida que la década del sesenta avanzó, las organizaciones internacionales y las coordinaciones comunitarias avanzaron, se hacía necesario no sólo analizar las ventajas de la conformación de esfuerzos conjuntos sino sostenerlos en el tiempo y las ancla más en el pasado que en el futuro (porque son condiciones y no prescripciones de acción). En su Análisis de las relaciones internacionales (1990) señala cuatro: la pertinencia (es decir, el volumen relativo y el peso de las transacciones entre miembros en comunicaciones, comercio, intercambios turísticos, etcétera), las recompensas conjuntas (la covarianza de beneficios entre dos o más miembros: la ventaja que recibe uno está ligada a la ventaja que recibirá otro), la sensibilidad mutua (los recursos y capacidades de un miembro deben ser significativos para el otro), y la lealtad común generalizada (la percepción e importancia dada a la existencia de intereses conjuntos). Siempre es notable cómo Deutsch, desde una perspectiva metodológica ligada a la medición se ocupa de aspectos profundamente intangibles como la comunicación, las percepciones y las expectativas. 


\section{Las fisuras neofuncionalistas}

Por el hecho de seleccionarlo como patrón en estas líneas, no quisiéramos dejar al neofuncionalismo planteado como un bloque teórico acabado, ni menos aún mostrarlo canónico. También lo hacemos para cumplir con una manera de presentarlo: señalamos el surgimiento con el funcionalismo, planteamos la esencia del neofuncionalismo ${ }^{150}$, y ahora concluimos esta sección con un teórico que trabaja desde el neofuncionalismo hacia el futuro. Por eso nos permitimos hacer una brevísima referencia al trabajo de Joseph Nye, quien trabajando desde dentro del esquema neofuncionalista, se vuelve contra sus propios supuestos y los lleva a un nivel de mayor análisis a través de su posición crítica. Nye termina de descargar de la integración todo resabio axiológico -afirma que no debe vérsela como algo bueno en sí mismo, ni tampoco se le debe adosar la capacidad de solucionar problemas macro sociales como la paz o el desarrollo (Comparato, 2013). Creemos que refina, profundiza y amplía al neofuncionalismo con un análisis útil para procesos fuera de

\footnotetext{
${ }^{150}$ Sólo para señalar sin exponerlo, tenemos que decir que el neofuncionalismo ostentó vaguedades y problemas que no resueltos: Se comprobó que algunas áreas económico-sociales no ramifican a la política mientras en otros casos es difícil diferenciarlas (Dougherty y Pfaltzgraff, 1990). Así, la integración acaba descansando, en la práctica, sobre la voluntad política pero atrapada por la reticencia a ceder competencias soberanas en una estructura común (Pentland, 1976): un proceso que depende de la voluntad política se dá de bruces con la limitación que le coloca la propia política a la hora de ceder soberanía (o traspasarla, dado que la supranacionalidad resulta una soberanía consensuada, por así decirlo). Dougherty y Pfaltzgraff (1990) señalan algo muy atendible para nuestras latitudes: la integración puede no resultar el camino en una región con menor capacidad para abordar ciertos objetivos y problemas -nacionales y regionales-, a lo que se debe sumar el tendón de Aquiles de economías primarias, de alta orientación externa.
} 
Europa central (Nye, 1969; 1970)). Nye es el primero de los teóricos preocupado no ya por dar lugar a la integración, sino por garantizar su continuación a largo plazo (1970), un problema que enfrentamos hoy en día, incluso, en los procesos más desarrollados como los de la UE. Son cuatro factores los que intervienen en ello: 1) los medios conciliar los intereses en conflicto para asegurar la ampliación y profundización del apoyo político; 2) los cambios de condición, poder y beneficio económico entre los diferentes grupos dentro del bloque deben ser redistribuidos compensatoriamente entre sí para garantizar el apoyo al bloque (esto vale para los actores al interior de un país y para los miembros del bloque individualmente: las asimetrías erosionan cualquier integración); 3) atender las alternativas en el nivel de beneficio marginal (cuando la integración avanza, los decision makers deben aumentar el alcance de ella, pero también generan menos avances con cada decisión; y 4) la externalización con no miembros sobre temas en común (a mayor integración, los terceros reaccionan con mayor medida -amigable u hostilmente- a ella).

Recuperando algunos mecanismos neofuncionalistas, los reformula en dirección a mejorarlos: comenzando con el spill-over, menciona que la interdependencia funcional puede dar lugar a desequilibrios que presionan a los agentes políticos a redefinir su labor conjunta (esto puede ser positivo o destructivo: o bien existe derrame o bien existe retroceso), y, por otro lado, cada coalición específica -por labores- se articula por proyecciones político-ideológicas y no por consideraciones técnicas (la profundización -o no- de la integración depende en gran parte de la suerte del grupo 
político o coalición que la promueva) ${ }^{151}$. En cuanto al aspecto del aumento de transacciones -comerciales, comunicacionales, etcétera- señalado por Haas (1964), Nye cree que efectivamente pueden ser un factor de fortalecimiento de las instituciones supranacionales sólo si los dirigentes políticos no eligen absorberlas y tratarlas desde la dimensión nacional (de este modo, sólo intensifican el manejo central de una/s tarea/s). La misma distancia toma de la formación de grupos regionales no gubernamentales (asociaciones transnacionales), que ve débil no sólo por su entidad, sino porque los intereses determinantes continúan a manos de grupos de interés de nivel nacional (Nye, 1969). Un fenómeno para lamentar, dada la importancia del compromiso de los agentes externos en la conformación de bloques: gobiernos externos, organizaciones internacionales y agentes no gubernamentales son imprescindibles para la sinergia necesaria a la hora de integrarse. $Y$, por último, Nye recupera la dimensión identificatoria de la permanencia en el bloque ${ }^{152}$ anclada en lo simbólico, pero sin sobre-dimensionarla: ante la posible existencia de tendencias nacionalistas o corporativas del sector privado, es necesario concebir que la integración pueda comenzar con una pertenencia débil. Esto permite a los agentes tolerar pérdidas en el corto plazo por expectativas futuras, por lo que conviene que la

\footnotetext{
${ }^{151}$ Esto se relaciona con lo que denomina la socialización de la elite (Nye, 1970): el nivel de involucramiento de los burócratas nacionales en la integración regional determinará el nivel de su socialización -tienen incentivos a no apoyarla si a futuro perderán su preponderancia en la decisión en pos de la supranacionalidad-.

${ }^{152}$ No es sólo en esta dimensión que aparece la percepción: como señala en 1969, las percepciones de los decisores de sus dependencias externas (exportaciones, amenazas potenciales y cambios en la preponderancia internacional), también fisuran la integración si esta no es vista como la salida a esos u compensatoria a través de ser la solución a otros problemas.
} 
integración se perciba lo más libre de costos en su inicio (1968). Caso contrario, es uno de los factores que la perjudica de manera más directa ${ }^{153}$.

Como señalamos más arriba, la continuación de la teoría de la integración regional en la década de los ochentas y noventas siguió siendo prolífica, disputada y pudo probar(se) con procesos que iban tomando más forma a partir de mediados de la década (incluso tuvieron que someterse a revisiones que los pusieron en crisis como en el caso de intergubernamentalismo primigenio). Aquí dejaremos esas discusiones de lado por las razones que mencionamos al inicio del capítulo, y apelaremos a rescatar la integración ciento por ciento aplicada a nuestro caso, a través de unos desarrollos determinantes para construir nuestra EPGB. Después de todo, con este capítulo termina el desarrollo de las herramientas conceptuales, y en la próxima parte ya nos abocaremos al problema en esta tesis.

\footnotetext{
${ }^{153}$ En el desarrollo de Nye, es central el potencial integrador $(1968,1970)$, es decir, las condiciones integradoras estimuladas por el propio proceso. $Y$ funcionan en su esquema como condiciones (es decir, son imprescindibles): es precisa la simetría económica de los miembros (no ya entre el tamaño o la estructura económica, sino en la relación comercio-integración-desarrollo por ingreso per cápita. Y a menor ingreso, mayor necesidad de simetría, lo que aplica de manera determinante a las economías no industrializadas). Sigue con la complementariedad de la élite, es decir, la baja oposición entre los intereses de cada una, y en relación con esto la existencia de pluralismo, y, por último, la capacidad de adaptación y respuesta de los miembros (es decir, de garantía de estabilidad interna, lo que permitirá la posibilidad de tomar decisiones clave permite su integración en un nivel de gestión colectiva mayor como la región).
} 
《La integración económica europea podría haber sido mucho más lenta si los gobiernos se hubieran visto obligados a enfrentarse a la inversión, la moneda y cuestiones comerciales (...) dudaría en reclamar la validez de este criterio para el estudio de la integración política regional en América Latina, Oriente medio o el sudeste asiático》》 Ernst Haas, 1958

《El pasaje del intergubernamentalismo a la supranacionalidad [es] progresivo, sin embargo, progresivo no significa inevitable ni irreversible》)

Andrés Malamud, 2001

Hemos caracterizado a la integración regional en sus aspectos teóricos más basales, tal vez, también más abstractos. Precisamos ahora construir un anclaje denso teóricamente, pero orientado a la integración americana del sur.

El apartado anterior nos dio un buen punto de partida, relacionado con la primera sección: el pragmatismo neofuncionalista nos permite partir de la aseveración según la cual los países se plantean la posibilidad de integrarse si -y sólo sí- advierten que hacerlo redundará, en primero lugar, en beneficios político-económicos (Bernal-Meza, 2008). Comenzamos por esta característica -y no por un intento de definición-, por la sencilla razón que no existe una teoría de la integración para estos lares, un concepto uniforme o taxativo (Bernal-Meza, 2009) ${ }^{154}$. Y, además, es preciso reparar en el sentido, la dimensión, que se apunta al invocarlo: podrá ser en tanto que una posición

\footnotetext{
154 De manera contundente: No tenemos una teoría de los regionalismos que nos permita explicarlos en conjunto (Bernal-Meza, 2009: 5).
} 
de economía política -el grado de integración económico-comercial-, un instrumento de la política externa -una forma de inserción internacional que configurará un subsistema internacional-, o bien como proceso, donde se apunta a la conformación de algún tipo de nuevas lealtades supranacionales políticas. Estas dos últimas dimensiones han, al mismo tiempo, influido e instrumentalizado algunas políticas exteriores latinoamericana (ibídem).

Este costo de oportunidad a su favor tiene que redundar en mecanismos de cooperación y en la potencial implementación de responsabilidades compartidas en el logro de objetivos comunes en áreas previamente consensuadas: Esto avanzará a la regularidad de relaciones (es decir, la frecuencia de ellas), a una mayor dependencia mutua y algún grado de coordinación entre las unidades (Atkins, 1991; citado en Bernal Meza, 2009). Pero no puede quedarse en el mero voluntarismo o en las relaciones de hecho, debe efectivamente avanzar, pues, hacia la ingeniería jurídica que institucionalizará la iniciativa comunitaria en un acuerdo de integración regional de algún formato determinado (Giacalone, 2006). Es necesario pensar de manera pragmática el regionalismo no sólo a su interior (sus actores y respectivas voluntades), sino también al exterior de ellos: la interdependencia interna tiene como correlato la imposición de costos para quienes no integran el esquema (Hettne, 1993) ${ }^{155}$. Esto puede reflejarse en el impacto negativo en arreglos regionales preferenciales o

\footnotetext{
${ }^{155}$ Hurrell señaló tres perspectivas desde dónde ver el surgimiento del regionalismo latinoamericano: la presión sistémica de las fuerzas internacionales y la acumulación de poder externa, sobre todo, en relación a las reconfiguraciones económicas de la década de los ochentas. También puede verse como producto de la interdependencia (asimétrica y vertical Norte-Sur), en relación al tándem Estados Unidos y México. Y, por último, los factores internos relacionados con la identidad regional, buena base para coordinar acciones para alcanzar metas comunes.
} 
alterando la distribución del poder político en las opciones de decisión en materia de política exterior (ibídem). Y dadas estas posibilidades, Hettne afirma que la cohesión del bloque no se determina únicamente por la densidad institucional o por el liderazgo de un hegemón regional. Incluso, podemos relacionar este aspecto con la posibilidad del esquema de convertirse efectivamente en un actor internacional:

Debe adquirir una identidad propia, que le permite enfatizar sus aspectos propios y distintivos y se expresa a través de éstos. Es, además, esencial para que ese regionalismo pueda considerarse como un "bien público". Justamente de su identidad y elementos distintivos, propios y originales, obtiene el reconocimiento como tal (un bien público), el que se proyecta a través de sus instituciones. La idea de "bien público" hace que todos sus miembros puedan beneficiarse de él y debe partir del principio de la no exclusión (Bernal-Meza, 2009: 22$)^{156}$

Si pensamos en una óptica estrictamente económica -perfil que ha motivado el Mercosur en sus orígenes-, la integración regional supone, entonces, un proceso de acercamiento y coordinación de las economías con miras a un territorio económico común, relacionados con la creación de comercio, la competencia intra-bloque, el aumento del tamaño del mercado interno a partir del territorio integrado, aprovechar las ventajas de una producción de escala, cooperación intrarregional en innovación tecno-industrial, financiamiento regional de planes para paliar las asimetrías -y demás distorsiones de la región-, y, finalmente, sinergia en las negociaciones internacionales (Balassa, 1980 citado en Bernal-Meza, 2008), lo que da una especial dimensión política

\footnotetext{
${ }^{156}$ Alcanzará tal condición en la medida que consiga expresar una identidad propia que lo proyecte a través de instituciones con independencia de la naturaleza de sus contenidos -apertura comercial, defensa de la democracia, protección del medioambiente, u otro- (ibídem)
} 
y transforma al bloque en un actor internacional frente a terceros. A su vez, la integración puede darse en niveles diferentes, desde una tímida coordinación mínima con ajuste recíproco de las partes avanzando al máximo de integración que implica el descentramiento de la lealtad soberana nacional para progresivamente re-depositarla en la dimensión regional.

Lo anterior es, para decirlo en pocas palabras el punto de partida y llegada conceptual que pretendemos de la integración regional en estas líneas. Pero para poder utilizarlo, tenemos que desgranar y profundizarlo, como también ampliar algunas cuestiones (en el apartado anterior recorrimos una vía teórica, y, por ende, más esencialista -el qué del objeto-, en un momento histórico en que los desarrollos eran aún incipientes, pero hoy por hoy, no podemos negar -y tenemos obligación de destacar- la complejidad del fenómeno integrador es muy otra).

Algunos aspectos pendientes son evidentes: la especial atención del neofuncionalismo en la realidad europea, en donde validó sus enunciados teóricos, lo que poco puede hacer por darnos una visión fiel de nuestra integración. Y eso tiene otra consecuencia: la validación no es sólo 'un segundo momento' de los desarrollos teóricos (es decir, el analista no sólo teoriza y luego chequea sus enunciados, sino que los propios enunciados están ya permeados por la referencia histórica que los teóricos viven). De este modo, estamos obligados a consultar analistas que operen en las mismas condiciones: elaborando teoría en, y con referencia a, estas latitudes. 
El primero aspecto necesario en términos expositivos para anclar nuestro desarrollo es incluir una variable histórica el decurso de la integración, para lo que apelaremos a los trabajos de Bernal-Meza $(2004,2006,2008)$, por el especial rol y peso que tiene la historia en su devenir intelectual. El segundo aspecto pendiente es aquél que no podemos ignorar a la hora de hablar de integración regional: la cooperación internacional. A estas dos tareas nos dedicaremos en lo tocante. 


\section{Regionalismo sudamericano}

Traer la dimensión histórica a nuestro análisis nos permitirá anclar la integración mercosureña sobre bases lo suficientemente concretas como para hacer una transición efectiva acerca de la parte tercera, donde nos abocaremos a la estrategia de poder global brasileña. Pero antes, debemos hacer una mención obligatoria sobre la exposición:

En la introducción a estas páginas, con el fin de presentar el proceso que nos permitió construir el problema teórico de esta tesis, caracterizamos las tres oleadas de integración con una serie de notas históricas y cualidades (de las cuales, al Mercosur le corresponde la génesis en segunda y la convivencia con tercera generación). Con el fin de retomar la cuestión, pero a la vez no repetirnos, haremos una referencia general y sumaria del devenir del Mercosur destacando más la perspectiva de los autores que las características ya presentadas.

Nos interesa comenzar por una ruta de razonamiento que utiliza Bernal-Meza (2006a), al señalar el decurso del regionalismo sudamericano no sólo por su caracterización y coyuntura(s), sino por sus patrones de funcionamiento: el pensamiento estructuralista cepalino de la mitad del siglo pasado como mecanismo de mejora para la inserción 
internacional a través de una reestructuración económica ${ }^{157}$ en el marco de una industrialización que necesitaba de un mercado ampliado con producción de escala (y la integración contribuiría a ello). El autor señala que el interés principal de esta dinámica era recuperar el deterioro de los términos de intercambio ${ }^{158}$, aspecto que, por cierto, fue pobremente alcanzado. A esto podemos agregar el porte de Giacalone (2009), que agrega la desigualdad estructural del continente y las escasas comunicaciones a causa de una infraestructura deficiente, la inestabilidad institucional -unida a unas hipótesis de conflicto ${ }^{159}$ - y el interés dispar en la integración dada la diversidad de regímenes (Chaparro, 1989). Asimismo, creemos que existe también un factor que no es tenido en cuenta lo suficiente: la dimensión institucional teniendo en cuenta las interacciones entre actores, no sólo la ingeniería formal.

Una segunda etapa adviene en los ochentas, de reanudación democrática (no está divorciado de esto la posterior inclusión de una cláusula democrática en la estructura jurídico-política basal del Mercosur), y creciente presión empresaria para evitar el deterioro de su alcance en la economía mundial (Briceño Ruiz, 2006). El giro de la

\footnotetext{
${ }^{157}$ El autor reconoce, por supuesto, una etapa inicial en las décadas posteriores a la independencia articuladas en la promoción de la cláusula latinoamericana a la nación más favorecida, de corte sociocultural basada en los orígenes comunes (Bernal-Meza, 2006a), y que aquí dejamos de lado para rescatar las más determinantes en este apartado.

${ }^{158}$ Esto se podría alcanzar a través de una cooperación regional que promoviera un espacio integrado con una coordinación nacional y regional de políticas fiscales, de la inversión y precios, evitando así la concentración geográfica desigual (Furtado, 1972, 1983; citado en Bernal-Meza, 2008)

${ }^{159}$ Hettne (1993) señala que no es la similitud o la solidaridad democrática -como la que se podría suponer de Argentina y Brasil en los ochentas- la que provoca la integración: son requisitos de regímenes internacionales específicos los que desencadenan el proceso. Así, la consolidación de la cooperación suramericana que luego devendría en el Mercosur, fue también una reacción defensiva a la proyección de la creación del TLCAN y contrabalancear el poder de Estados Unidos a través de un eje subregional.
} 
política comercial absorbe los fines de la integración regional, a través de la imbricación empresariado-Estado (y así la dimensión económica es determinante en este regionalismo). Es esta alianza la que determina a este regionalismo, por lo que él constituye más una forma que un contenido ideológico determinado (Hettne, 1996 en Briceño Ruiz, 2006):

[este regionalismo es] toda forma de política económica internacional que tiene como objetivo, apoyándose en el regionalismo económico, establecer una relación de fuerza y desarrollar una ventaja comparativa sobre los mercados internacionales a favor de un grupo de países que forman una entente económica (Deblock y Brunelle, 1993: 596; citado en Briceño Ruiz, 2006) ${ }^{160}$

Bernal-Meza (2006) agrega lo que consideramos la primera tensión interna, estructural, para esta etapa: el perfil pragmático no suple otros problemas estructurales de falta de complementariedad, perfiles exportadores similares, falencias infraestructurales y comunicacionales ${ }^{161}$. No obstante, fue diseñado con el fin de lograr preservar la imagen de autonomía subregional a partir de dos economías líderes, con un diseño determinante a manos de Brasil:

\footnotetext{
${ }^{160} \mathrm{El}$ autor agrega otra cuestión de especial relevancia para esta tesis en relación con su planteo: este regionalismo da una importancia considerable a la competencia económica, y a un tipo de cooperación diplomática y política que procura una mejor posición en el sistema internacional. Pero no por esto se inscribe en un perfil intergubernamentalita donde la seguridad prima, mientras el impacto de los acuerdos cooperativos se pesa a la luz de sus capacidades relativas.

${ }^{161}$ En estas líneas la variable geopolítica no puede quedar ajena: el avance hacia la cooperación suramericana permitió el abandono de viejas hipótesis de conflicto al forjamiento de la 'Zona de paz' (Bernal-Meza, 2008) que fueron contundentes en los sesentas del siglo pasado, pero que no estuvieron nunca ajenas a conflictos bélicos decimonónicos y sucesivas actualizaciones en el decurso de la centuria.
} 
La construcción de esta "región" denominada Mercosur, descansó en elementos comunes que estos dos país y luego los otros dos países incorporados plenamente (Uruguay, Paraguay), así como los asociados (Chile, Bolivia), comparten: la proximidad (sobre la base de factores comunes previos como la cercanía geográfica; vínculos históricos y culturales, etc.); valores fundamentales (como la promoción y preservación de la democracia como sistema político; el desarrollo socioeconómico regional; la industrialización; el crecimiento económico redistributivo y la transformación productiva regional con equidad); estrategias comunes de gobernanza y accountability; ampliación de la participación social, económica y política de comunidades, agentes y actores económicos y sociales (Bernal-Meza, 2008: 156).

El Mercosur representa para Brasil, la estrategia de integración adecuada para amenizar el desequilibrio comercial con respecto a la región, con el paralelo incentivo al surgimiento de nuevas inversiones con ampliación de mercados. Esto podría sintetizarse en la materialización -o continuación- de un proyecto de desarrollo nacional con independencia del Consenso de Washington (Briceño Ruiz, 2006), a lo que -agregamos nosotros-, se debe señalar que la independencia de éste último implica en este escenario, una autonomía política que decanta y puede ser traducido en una posición de poder regional innegable.

A esto se suma una tercera etapa, abierta, signada por el auge del regionalismo ${ }^{162}$ en un marco de advenimiento del neoliberalismo global, regional y nacional, lo que dotó

\footnotetext{
162 El autor señala unos factores específicos para el resurgimiento estuvo signado por la firma del European Single Market Act (1986) con el posterior Tratado de Maastricht en 1992 (inescindible de los acuerdos de incorporación de ex países socialistas); la dilación de la ronda Uruguay del GATT que estimuló la vía regional, pero que la creación de la OMC en 1994 desalentó (Bernal-Meza asegura que lo mismo sucede con Doha, por lo que las crisis multilaterales impulsan la estrategia regional); la firma del NAFTA en 1994 -y la propuesta del ALCA en la Cumbre de Miami- ante una Europa unificada; y, en
} 
al proceso del énfasis en la inserción económica externa y la racionalidad del mercado frente a un Estado mínimo (Mellado, 2013). En ella se materializa el pasaje de una concepción industrialista propia del modelo de sustitución de importaciones al comercialista. Esta fase perfila cambios cuantitativos, de la envergadura de la regionalización: el pasaje de una centena de acuerdos (Artículo XXIV y $\mathrm{CH}$ ) en cuarenta años del GATT, a la misma cantidad de firmas en una década en el marco de la OMC junto con el mayor volumen de comercio e inversiones en Europa Occidental, América del Norte y Asia Oriental (Bernal-Meza, 2008), paralelamente a un aumento del comercio intrazona en el conjunto de los intercambios mundiales. Y también virajes cualitativos, en aspectos que antes quedaban fuera de la integración, como es el caso de aspectos relativos a inversiones, transferencia de tecnología, cooperación industrial, junto con la posibilidad de expansión allende las regiones:

\begin{abstract}
Aunque en sus comienzos el regionalismo estuvo dirigido a expandirse dentro de una misma región, desde mediados de los años noventa se extendió en un área mayor como corolario de las relaciones que se establecieron entre acuerdos del nuevo regionalismo (Hanggi, 2000, 2006), dando lugar al "interregionalismo". Esta expansión geográfica supera los límites estrictamente geográficos de la región y llega a tener una dimensión continental -ALCA- o interregional -acuerdos de la Unión Europea/UE con Centroamérica o Mercosur, entre otros- (Mellado, 2013: 145)
\end{abstract}

América Latina, la restauración democrática que desactiva antiguas hipótesis de conflicto, de lo que es emergente el PICEAB de 1986. 
Esta etapa está signada por un 'pragmatismo político' ${ }^{163}$ y por la falta de coordinación entre las respectivas políticas exteriores de los miembros (en el Chile de 1990 a 2004, la Argentina de 1990 a 2002, y el Brasil de 1994 a 2002), junto con políticas de apertura comercial diseñadas bajo un criterio de inserción global directa sin concertación regional o subregional (Bernal-Meza y Masera, 2005). Si a esto sumamos la falta de una estrategia de desarrollo, en un marco de debilidad institucional, de exclusivo interés comercial junto con otras debilidades ${ }^{164}$, esta etapa de regionalismo suramericano no se alcanzó la posibilidad de un macro proyecto estratégico (BernalMeza, 2005)

Con el cambio de milenio, las estructuras continentales se multiplican en el ánimo de hacer converger lo alcanzado: la otrora ALCSA resulta, en 2004, la Comunidad Sudamericana de Naciones. Esta amplia zona geoeconómica con Brasil como arquitecto puso al Mercosur como núcleo de una integración más amplia (Mellado, 2013), donde el regionalismo al servicio de fines estratégicos ${ }^{165}$ ya era un hecho. Aún

\footnotetext{
${ }^{163}$ Colocamos entre comillas esta expresión respetando la denominación del autor, la cual es necesario darle la connotación que tiene: políticas exteriores, que suponen con ello adecuarse a las realidades del poder mundial, que no comparte la idea de que existan bloques de poder mundial, que no comparte la idea de que existan bloques de poder que restrinjan la hegemonía hemisférica ni permitan escapar de la subordinación y la dependencia (Bernal-Meza y Masera, 2005: 111)

${ }^{164}$ Es decir, la falta de una sólida infraestructura de transporte y sistemas de comunicación, deficiente complementariedad económico-productiva junto a estructura de exportaciones similares, etcétera (ibídem)

165 Utilizamos este término con fines estrictamente adjetivos, para evitar la confusión entre la denominación 'regionalismo estratégico' con el periodo que se inicia en 2003. La razón reside en que esta denominación ha sido utilizada para el relanzamiento del ímpetu regionalizador de la década de los ochentas (Briceño-Ruiz, 2006) como también en algunos análisis acerca del denominado 'regionalismo abierto' (Hettne, 1996). Para evitar estas ambigüedades, nos referiremos al perfil que reviste la región a partir del nuevo milenio como 'postliberal', una denominación lo suficientemente general como para ser
} 
restaba llegar a 2008 para que la Comunidad Sudamericana de Naciones deviniera en la UNASUR, en un marco de nacionalismo económico (que no ahorró conflictos al bloque del Sur (ibídem)).

El posliberalismo en integración regional (Sanahuja, 2010), presenta una agenda diferente, centrada en aspectos sociopolíticos, energéticos, infraestructurales y de seguridad regional, junto con arquitecturas múltiples y sentadas en bases diferentes a las del regionalismo abierto (como el caso del ALBA y la propia UNASUR). Mellado señalada dos valencias de este regionalismo, donde encontramos una tensión interna infranqueable: por un lado, múltiples esquemas, con concertaciones políticas de diferente cuño y alcance, en un marco ideológico vuelto hacia los intereses nacionales y receloso de la formalización institucional. Por el otro lado, una ampliación de agendas internas en el marco de la integración hacia dimensiones sociales, pero -y esta es la falla ineludible que Mellado introduce para este perfil integrador-, se presentan magros resultados a pesar de la condición externa claramente favorable que permitieron altísimas tasas de crecimiento).

Este regionalismo no es sólo la coyuntura donde se desenvuelve la política de poder brasileña de la administración Da Silva: Brasil tiene, además, una labor de arquitectura (Bernal-Meza, 2009):

pasible de precisarse, pero lo suficientemente alejada del perfil abierto, con el fin de establecer un claro hiato entre ambos. 
Como señalamos, históricamente el regionalismo latinoamericano osciló entre dos grandes tendencias: aquella impulsada por Estados Unidos ${ }^{166} y$ otra, impulsada por los propios países latinoamericanos actuando en conjunto, fuera a nivel regional o subregional. Sin embargo, actualmente estaríamos en presencia de una tercera vía o línea de regionalismo que sería aquella impulsada por Brasil, de características netamente sudamericanas (Bernal-Meza, 2009: 23. Los destacados son nuestros)

Esto nos obliga a articular el regionalismo postliberal bajo una dimensión diferente: sus características revelan posiciones políticas del hegemón regional. De este modo, el regionalismo no es sólo una conformación coyuntural y una convergencia político económica colectiva, sino que reviste un rol específico en la política exterior de un de sus miembros.

$\mathrm{Si}$ atendemos el perfil del regionalismo brasileño, tenemos que reparar en su autonomía e independencia durante la gestión Da Silva anclada en la búsqueda de reconocimiento como potencia regional (a través de la construcción de alianzas estratégicas con potencias similares y el fortalecimiento de la cooperación y la integración suramericana (ibídem)). Un perfil que no se diferenció de una política exterior que con anterioridad se orientaba a objetivos vinculados al desarrollo y la expansión de mercados, junto con la búsqueda de poder con su respectiva zona de influencia suramericana y luego hemisférica frente a los Estados Unidos (Bernal-Meza, 2009). Esta posición intermedia -de política económica proteccionista sin oponerse a la

\footnotetext{
${ }^{166}$ En un trabajo anterior (2008), el autor aclara que el regionalismo en América Latina ha oscilado históricamente entre esquemas de integración intra-latinoamericanos sin presencia de los Estados Unidos de América, a otros donde se establecieron esquemas de cooperación bajo su influencia o intervención más o menos directa (bajo formatos tan diferentes como el Panamericanismo decimonónico monroista hasta el ALCA).
} 
coyuntura mundial pro apertura-, acentuó la línea divisoria a la que Brasil ya se había apegado con anterioridad a nuestro período: Dejó América Central y Caribe para la influencia norteamericana, y se reservó la porción sur para que el Mercosur sea el vector de influencia (como fuerza centrípeta de la CAN y la incorporación de Chile, Surinam y Guyana).

El regionalismo viró suramericano -que ya no latinoamericano-, pero también contra hegemónico (a pesar de que no todos sus integrantes presentaron este perfil), y, además, el Mercosur no resultó más un aspecto más de la política exterior de sus miembros, para este caso Brasil, sino que se hizo endógeno a la estrategia de política internacional de Brasil (ibídem). Por supuesto, sobre esta última característica se asienta nuestro interés por construir la estrategia de poder global del vecino. 


\title{
Cooperación regional
}

Si la cooperación es la característica definitoria de la interacción interestatal que se divorcia de la competencia y la anarquía realista, pues entonces nos coloca ante el otro polo del paradigma tradicional:

\begin{abstract}
El idealismo, inspirado en las nociones liberales de la bondad inherente a la naturaleza humana y de una armonía natural de intereses, trató de superar la anarquía por medio de la cooperación internacional en orden a realizar el verdadero potencial de la humanidad (Hazleton, 1987: 16 y 17$)^{167}$
\end{abstract}

No obstante, esta posición, la cooperación no queda capturada en los límites del utopismo. Al igual que cuando cancelamos más arriba el supuesto de anarquía -que conduce al caos- al momento de incorporar los regímenes internacionales realistas ${ }^{168}$, concebimos la cooperación en un ambiente signado por el poder. Islas de cooperación ${ }^{169}$ pueden efectivamente acontecer -por vía regímenes o no- en un medio

\footnotetext{
${ }^{167}$ Aun cuando la cooperación sea la antinomia del conflicto (Malamud, 2011), se diferencia de la armonía [automática] de intereses típica del liberalismo, dado que ella es producto de un esfuerzo de ajuste entre dos o más actores de demandas, intercambios y acuerdos diversos para concretarse. La coincidencia de intereses compartidos no la obra por sí misma, sino que, deberíamos pensarla como un mecanismo de superación del potencial conflicto o bien del inicio de relaciones y sinergias donde antes no las había (en presencia de una armonía por defecto).

${ }^{168}$ Es decir, a la luz de alguna estructura de poder, fuere la hegemonía de una potencia -como en el caso de la teoría de la estabilidad hegemónica- o de otra determinada estructura de poder.

${ }^{169}$ En palabras de Keohane: las relaciones entre actores pueden ser cuidadosamente estructuradas en algunas áreas, aunque permanezcan perdidas en otras (1984: 227)
} 
donde el poder también acontece como la lógica primal de funcionamiento del sistema internacional ${ }^{170}$. Es el pragmatismo, el mismo al que apelamos a la hora de recuperar el neofuncionalismo como el insumo teórico cooperativo (ergo, no-conflictivo) la base para pensar la integración regional, y el vector que nos permite referir ahora a la cooperación internacional como una conducta orientada a la promoción de ventajas recíprocas entre países (Keohane, 1984) ${ }^{171}$. Cooperar implica más un ajuste mutuo de intereses conflictivos y complementarios, antes que un estado donde los intereses comunes se sobreponen al conflicto (ibídem).

Esta es la razón por la cual la cooperación internacional no está ausente en políticas exteriores interesadas en la acumulación del poder y preservación de la seguridad. Sin lugar a dudas al servicio de una concepción realista de la interacción estatal: es decir, la defensa de intereses nacionales propios en el Estado alterno, manteniendo la lógica de acumulación de poder absoluta o relativa (Fagaburu, 2016). La evaluación resultará de pesar la mayor eficiencia de la cooperación internacional ante los costes de la dinámica político-diplomática y el uso de la fuerza (Prado Lallande, 2008; citado en Fagaburu, ibídem) para lograr los objetivos nacionales y mantener el statu quo. Y esto no es otra cosa que sostener el equilibrio de poder, fin último que no descarta

\footnotetext{
${ }^{170}$ Desde ya que nuestro interés en la inclusión de la teoría de los regímenes internacionales para el caso de la integración implica, también una relación obligada con la cooperación internacional: los regímenes implican condiciones favorables para la cooperación que permiten hacer converger a los actores en torno de expectativas (Keohane, 1984). No obstante, remarcar su estatus de condición suficiente y no necesaria.

${ }^{171}$ En realidad, Keohane considera tres patrones de interacción entre actores en el medio internacional: armonía, en que cada uno actúa según criterios internos sin afectar a los demás, sin desarrollo de cooperación. La cooperación cuando existe coordinación de políticas hacia objetivos comunes. Y la discordia, cuando existe conflicto explícito -militar-, o bien sus políticas exteriores poseen intereses contrapuestos.
} 
métodos (la cooperación incluida -fuere con ayudas que implican conductas determinadas en el receptor, o por el prestigio de iniciativas de corte humanitario, etc.-).

No sólo debemos desencajar la cuestión de la cooperación de la identificación con el utopismo, sino que ella tampoco debe quedar asociada a la integración regional por la vía de la no conflictividad. Es preciso no definir la una por la otra en dos dimensiones: la primera es la histórica. Y la segunda la conceptual.

En cuanto a la primera, es bueno señalar que la cooperación internacional surge, sin dudas, con anterioridad a la segunda posguerra, momento en que el impulso integrador se empieza a conformar (al igual que podemos encontrar antecedentes integrativos en el federalismo decimonónico, por lo que la integración regional como la concebimos no es una estrategia por entero nueva $)^{172}$. Dado lo que nos importa en este apartado, tal el caso del Mercado Común del Sur, un esquema con un sustento político original donde el avance del potencial integrador se basa efectivamente en la cooperación para la gestión colectiva y complementaria de problemas regionales (con el PICEAB de mediados de los ochentas), hablar de cooperación e integración del sur es casi un sinónimo.

\footnotetext{
172 No podemos olvidar formatos diferentes de los que vemos actualmente, como el caso de la cooperación política que implicó Sociedad de Naciones en la primera veintena del siglo pasado, las Conferencias Aliadas de 1941 a 1945, o el Proceso de Helsinki en la Europa a partir de 1973 (Pereira Castañares, 1999). Si miramos la cooperación económica, vemos que ha revestido diferentes formatos que en los que presentan los distintos intentos, entre los cuales encontramos, como un tipo más, los bloques de integración regional de la segunda postguerra del siglo pasado: aun cuando éstos hayan sido las expresiones de conducta cooperativa más importantes, no tenemos que eludir fenómenos como los de la década de los treinta, cuando se inició la fase multilateral del comercio (ibídem).
} 
En este sentido, al hacer foco sobre el rol de Brasil en nuestro período, nos ha interesado el criterio de La Fontaine y Seifert (2010), quienes han trabajado sobre el perfil de cooperación asentados sobre categorías que combinan la teoría de la dependencia ${ }^{173}$ y el neorrealismo (una combinación llamativa, dado que uno de los puntos más débiles del (neo)realismo reside, sin duda, en sus escollos para explicar las condiciones y posibilidades de interacción de los países periféricos).

Al indagar sobre las motivaciones -cooperación horizontal orientada a beneficios mutuos o bien cooperación unilateral basada en el cálculo de poder-, los autores destacan que el perfil autonomista inocula los criterios de Itamaraty como de movimientos y organizaciones sociales, pero señalan que esta posición no es exactamente la que imperó en las posiciones tercermundistas de los sesentas del siglo $X X^{174}$, sino la que impera desde principios de los noventas.

Y para avistar la cooperación internacional en la gestión Da Silva impera retroceder a esa década:

\footnotetext{
${ }^{173}$ Tal vez sería más adecuado plantear como autonomismo esta denominación, aunque preferimos respetar la referencia de los autores. Con la mención al autonomismo nos referimos a la prolífica producción académica de las décadas de 1970 y de 1980 que señalaba la necesidad de políticas exteriores más autónomas para América Latina tenían para reducir la vulnerabilidad que otorga la dependencia externa. Notable es, como señalan Battaglia et al (2016), que esos postulados continúan presentes en el debate académico y político de nuestra región, dada la aún necesaria búsqueda de desarrollo económico e industrialización, disminuyendo la dependencia externa para participar de manera no subordinada en el capitalismo global.

${ }^{174}$ Se apoyan para afirmar esto, en los trabajos de SOARES DE LIMA, M. (2005) 'A Política Externa Brasileira e os Desafios da Cooperação Sul-Sul'. Revista Brasileira de Política Internacional. Vol. 48 (1): pp. 24-59; y GOMES SARAIVA, Miriam-- (2008) 'A Cooperação Sul-Sul e a Política Externa do Brasil.' Entrevista a Miriam Gomes Saraiva, 5/XI/2008, Rio de Janeiro, Brasil.
} 
Desde 1993, somos testigos de una nueva etapa en la cooperación Sur-Sur que toma lugar después del fin de la era de la ISI, combinada con la inclusión de un sistema económico doméstico liberal, integración global de mercados y cooperación continua con países industrializados. En este sentido, son más las similaridades [sic] con el modelo del 'pragmatismo responsable' de la gestión Geisel en los setentas [del siglo XX] (De la Fontaine y Seifert 2010: 16 [traducción propia] ${ }^{175}$ )

El perfil y los actores de la cooperación de este período difiere del de dos décadas antes: en los noventas, cuando se asienta la impronta que encontraremos una década después, se abandonan los patrones bi y multilaterales con la región, para expandirse hacia fuera de ella ${ }^{176}$. Así surgen los vínculos con las potencias system affecting como India, China, Sudáfrica y otras, por igual interesadas por influenciar el sistema internacional, junto con otras naciones africanas.

En esencia, la búsqueda de poder brasileña se orientó por la hegemonía cooperativa en respuesta al interés nacional asentado en unas alianzas fuertes del hemisferio sur para aumentar su poder de negociación con los integrantes del norte y a la expansión

\footnotetext{
${ }^{175}$ Del original: since 1993 we are witnessing a new phase of South-South Cooperation, which is taking place after the end of the ISI era, combined with the introduction of a liberal economic domestic system, world market integration and continuous cooperation with the industrialized nations. In this sense there are more similarities with the approach of "responsible pragmatism" of the Geisel Administration in the 1970 s.

${ }^{176}$ Este cambio aparece también en el Mercosur, asentado sobre el PICEAB de los ochentas, de claro corte solidario entre países. Ya con el Mercado Común del Sur abandona el espíritu autonomista y la integración deja de girar en torno a articulación interindustrial basada en la gradualidad y flexibilidad para abrazar la liberalización comercial total (Battaglia, 2016). Esto vuelve a rotar en 2003, deviniendo en una herramienta del Grupo Río, al servicio de la capacidad de negociación latinoamericana. Esta nueva orientación al servicio de proyectos nacionales y del desarrollo de los miembros, se plasma en el modelo de inserción del Consenso de Buenos Aires y el Compromiso de Puerto Iguazú de 2003 y 2005, respectivamente (ibídem).
} 
de mercados (ibídem). Insistimos en esta cuestión como un fenómeno por entero de la gestión iniciada en 2003, pero es necesario destacar que tanto la cooperación regional como la interregional han sido prioritarias para la política exterior desde la administración Cardoso, y es el Mercosur un protagonista en ello (Miyamoto, 2010)).

A su vez, hilvana cuestiones que, como es de prever, implican a Estados Unidos, dado que la posición brasileña frente a la cooperación interregional (Mercosur - UE) ${ }^{177}$ no sólo facilita el comercio en múltiples niveles, sino que les daría capacidad de negociación a ambos bloques frente a Estados Unidos ${ }^{178}$.

Si bien es usual pensar la cooperación asociada a las grandes áreas de negociación de los países e identificada con la low politics, no debemos olvidar la cooperación técnica horizontal, la que también desliza cierto ejercicio de prevalencia en el tendido de lazos con otros pares en desarrollo del sur para que se beneficien del know-how brasileñoEl vecino también asumió también el rol de proveedor emergente (emerging donor) sureño capaz de articular sus intereses y los de sus aliados a un nivel internacional

\footnotetext{
${ }^{177}$ Thorstensen (2002) menciona que el Mercosur se erige aquí también como pilar de coto para una negociación donde el gobierno brasileño considera que Washington lo quiere diluido en el ALCA, y también cree que la UE posterior al acuerdo de cooperación interregional compartiría el interés en un Mercosur fuerte por las mismas razones, a la que suma que ambos conforman esquemas más profundos que meras ZLC.

${ }^{178}$ Miyamoto es claro en este sentido: Sobre a ideia de cooperação e integração inter-regional, a posição brasileira era de que o aprofundamento das relações entre blocos diferentes, como o Mercosul e a União Europeia só iria beneficiar a ambos, porque além de facilitar o intercâmbio em todos os níveis, aumentaria ainda a capacidade de cada um deles frente aos Estados Unidos, ampliando desta forma $o$ poder de barganha no cenário mundial. As negociações entre ambos, portanto, não apenas no setor privado, mas também na esfera governamental, se fundamentaram em interesses concretos, que se traduzem mutuamente em investimentos crescentes (2010: 129)
} 
(este es el caso, por ejemplo, de la producción de etanol a partir de caña de azúcar (Domínguez Ávila, 2009)).

Llegada la administración Da Silva, estos nuevos tendidos de aliados no eran sólo económicos sino también políticos, y se proponían la promoción de una evolución del sistema unilateral norteamericano hacia uno multipolar conducente con su actividad en foros multilaterales en cuestiones tan diversas como la liberación del comercio agrícola, el combate a la pobreza y la ampliación del Consejo de Seguridad (Soares Leite, 2011)):

En el primero gobierno de Lula. la meta fue más ambiciosa. Brasil se arrojó mayores responsabilidades en la cooperación Sur-Sur, comprendiendo que los beneficios recibidos por la coordinación de políticas con los países en desarrollo superaba los costos eventuales (...) en la acción internacional del país se concilió la utopía y la realidad, en los términos de Carr, al buscarse modificar la realidad sobre la observación y el análisis de las oportunidades ofrecidos por ella, con el objetivo de que el escenario externo reflejase los anhelos de los países en desarrollo y no sólo los de los desarrollados (Soares Leite, 2011: 206 [traducción propia] ${ }^{179}$ ).

\footnotetext{
179 Del original: no primeiro Governo Lula, a meta foi mais ambiciosa. O Brasil arrogou-se maiores responsabilidades na cooperação Sul-Sul, no entendimento de que os benefícios auferidos pela coordenação de políticas com os países em desenvolvimento superaram eventuais ônus (...). Conciliouse, na ação internacional do país, a utopia e a realidade, nos termos de Carr, ao buscar-se modificar a realidade, com base na observação e análise das oportunidades oferecidas por esta, afim de que o cenário externo refletisse os anseios não só dos países desenvolvidos, mas também dos países em desenvolvimento
} 
Pasemos ahora a la cuestión del ejercicio hegemónico regional, preservando en esta sección los aspectos conceptuales para volver a hacer algunas referencias a nuestro caso en la próxima parte de esta tesis. 
Capítulo IV. Hegemonía Regional

Sumario. En este capítulo, uno de los más cortos de estas páginas, planteamos una caracterización general de la noción de hegemonía. Agregaremos a este apartado una precisión sobre la noción de potencias regionales, con el fin de que ambas condensen la hegemonía regional. Incluimos este concepto en esta etapa del desarrollo por su alcance regional, aunque no por ello circunscribimos este patrón de relacionamiento a la integración regional, pues ésta no es una condición necesaria de aquella. 
«En vez de tratar de identificar una estructura de poder singular preponderante, los académicos deberían esforzarse por identificar múltiples estructuras de poder en diferentes áreas» David Baldwin, 2012

«Un poder hegemónico es hegemónico sólo si decide hacer uso del poder potencial que tiene a su disposición» Andrew Hurrell, 1993

Para avanzar hacia la construcción de la empresa de poder brasileña en la administración Da Silva existe una categoría que no podemos eludir, y no es otra que la de hegemonía regional. En primer lugar, debemos designar por actor hegemónico ${ }^{180}$ a una comunidad político-territorial (estatal o de otro tipo) que detenta supremacía en el sistema internacional gracias a algún/os atributos (preeminencia militar, económica, cultural, o una combinación de ellas), lo que le otorga la capacidad de condicionar las decisiones de sus pares menos poderosos en virtud de su coerción, intimidación y prestigio (Matteucci; Aricó; Soler; Tula, 2000). Otra vez tenemos que introducir la perspectiva multidimensional, también determinante a este concepto: Los atributos que señalamos no son necesariamente convertibles (lo que Baldwin (2012) llama fungibility). La mejor manera de exponer esta idea la encontramos en Nolte (2006): Estados Unidos no puede blandir su poder militar para resolver un conflicto comercial con la Unión Europea, del mismo modo que ésta no puede usar su poder comercial

\footnotetext{
${ }^{180}$ Entenderemos aquí por actores (internacionales) a aquella unidad del sistema internacional de cierta autonomía que moviliza recursos para alcanzar sus objetivos prefijado\} s mientras ejerce influencia sobre otros actores con diferentes objetivos, pero idénticas características (Barbé, 2003).
} 
para conflictos que requieren aproximación militar en zonas lejanas del globo. Por eso Nolte afirma que es preciso analizar la distribución del poder según diferentes categorías y niveles.

Para estas páginas es preciso despegar la condición hegemónica de los Estados nacionales, dado que ella puede predicarse de otras conformaciones como organizaciones internacionales, regímenes de integración regional (donde como ya mencionamos podemos concebir a la integración regional), organizaciones no gubernamentales internacionales, corporaciones trasnacionales, organizaciones criminales trasnacionales (como carteles de narcotráfico o células terroristas), organizaciones intergubernamentales, etcétera. La hegemonía se escabulle, así, de cualquier regulación o parámetro para oscilar en el gradiente dominación-influencia (ibídem).

Pero no por ello debemos considerarla en los términos más crudos del poder -es decir, sin dar cuenta de principio alguno-: Heimich Triepel, en 1938, destacó a la influencia ejercida por un estado hegemónico es muchas veces ejercida sin uso de fuerza, por lo que no debería escindirse de cierta legitimidad. No por eso afirmamos que la hegemonía es una forma de liderazgo, sino sólo que para el autor posee, efectivamente, un grado de dirección ${ }^{181}$, dado que precisa de una cuota de legitimidad mínima.

\footnotetext{
${ }^{181}$ Estas connotaciones nos dan una muestra de lo intercambiables y hasta confusos que resultan estos términos en la teoría de las relaciones internacionales.
} 
A diferencia del dominio o el imperio -que están respaldados por la fuerza-, la hegemonía es un poder situado a un nivel intermedio, en un gradiente que comienza en la influencia y culmina en la dominación; pero, a diferencia de ésta, la hegemonía es una forma de poder dotada de gran autocontrol por parte del hegemón (de hecho, para Triepel es una suerte de forma de liderazgo). El seguimiento de los pares menos poderosos a éste no está basado en alguna forma de cualidad intrínseca -cual carisma weberiano- sino en la relación costo-beneficio de hacerlo, evaluación que contiene una lectura de la propia debilidad (Destradi, 2010)).

El término hegemonía no resulta indemne a imprecisiones conceptuales o usos algo apresurados. Desde quienes no aceptan otra opción para el hegemón que un poderío máximo en el sistema internacional ${ }^{182}$, hasta quienes consideran que la competitividad de los productos de un Estado poderoso son algo así como el bien preferido por sus pares, como quienes creen que no implica un ejercicio de dominación cruda, sino mejor una suerte de compatibilidad de intereses entre el poderoso y quienes no lo $\operatorname{son}^{183}$.

Como hemos esbozado páginas atrás, retomemos la idea de Keohane y Nye (1989) donde la hegemonía se encarna en un Estado lo suficientemente poderoso como para asumir de manera deliberada la instauración de reglas basales que rigen las relaciones entre pares. Esta 'instauración deliberada' -una expresión por entero nuestra-, implica la organización, regulación y estabilización (Du Boff, 2003) del orden mundial.

\footnotetext{
${ }^{182}$ Cf. MEARSHEIMER, John (2001). The tragedy of a Great Power Politics. New York, Norton \& Company. ${ }^{183}$ Cf. COX, Robert (1996). Approaches to world order, Cambridge: Cambridge University Press.
} 
Las similitudes de la hegemonía con el liderazgo, residen en que la primera acompañada por legitimidad y prestigio. Eso implica que su iniciativa esté acompañada de compromisos (y no refrendada por de la fuerza, como el imperio). No obstante, es necesario diferenciarlos: ambas formas no coercitivas, si las miramos con detalle, son sencillas de diferenciar. Destradi (2010) ofrece un criterio asequible, al asentar al liderazgo como la conducción de un grupo de Estados en la realización/facilitación de sus propios objetivos (para lo que deberá portar legitimidad ante los pares y aportar recursos materiales y componentes ideológicos), mientras la hegemonía está anclada en su propio interés individual, en la inscripción de los pares como subordinados. La mejor manera de diferenciarlos es metodológica, y la ofrece la autora en un comentario aparentemente menor:

Pero lo realmente importante para este estudio es la pregunta 'ilos objetivos de quién son perseguidos por el hegemón, los propios o los de un grupo de Estados?'. La respuesta a esta pregunta, como veremos, marca la diferencia entre la hegemonía y liderazgo (Destradi, 2010: 914, nota al pie 65 [traducción propia] ${ }^{184}$ )

Es determinante que el hegemón sepa que su poder es un tema de interés entre sus pares menos poderosos: por eso, para mantener su preeminencia no debe olvidar conciliar sus intereses con los de aquéllos (o al menos, no amenazarlos), para que puedan asumir costos y compensen con los beneficios. Esto redunda en la

\footnotetext{
${ }^{184}$ Del original: ¿But what is really of interest for this study is the question of 'whose goals are pursued by the hegemón, its own ones or those of a group of states?' The answer to this question, as we shall see marks the difference between hegemony and leadership.
} 
construcción del componente de legitimidad -y el prestigio que ella otorga- también presentes en la hegemonía. Para alcanzar aquélla, precisa que sus valores hayan sido aceptados por los pares, para generar un marco de consensos y respeto de acuerdos, los que promueve a través de los incentivos adecuados. El componente de legitimidad da cuenta de la influencia del hegemón en cuestiones no materiales: la cultura y la ideología que inervan instituciones serán una amalgama determinante para las alianzas que opere, las que redundará en la mantención del status quo ${ }^{185}$ [hegemónico] (Mjoset, 1990):

El más fuerte nunca es lo suficientemente fuerte para ser siempre el amo, a menos que transforme su fuerza en derecho y la obediencia en deber (Mjoset, 1990: 46 [traducción propia] ${ }^{186}$ )

Esto implica una labor más de la que ocuparse para el hegemón. Aun cuando los costos de serlo sean (sobre) compensados con los beneficios de ser un actor hegemónico, existe un costo ineludible una vez alcanzada la hegemonía: la titánica tarea de mantenerla en el nivel en que los beneficios superen a los costos. Mantener la estabilidad que él mismo creó, no es, necesariamente, un trabajo sencillo (Kupchan, 2002).

\footnotetext{
${ }^{185}$ La conformación de la OTAN y la incorporación del Japón de posguerra al esquema occidental podría ser un buen ejemplo de esto.

${ }^{186}$ Del original: the strongest is never strong enough to be always the master, unless he transforms strength into right and obedience into duty.
} 
En su caracterización del ejercicio de la hegemonía al nivel del tipo de relacionamiento con los pares, podemos encontrar varias posibilidades: Destradi (2010) ofrece un gradiente dentro de las relaciones cooperativas que incluye a la hegemonía (subdividida en hegemonía dura, intermedia y blanda, e instrumentada por el uso de la recompensa) y el liderazgo (vehiculizado por socialización). Esto nos señala que el ejercicio hegemónico no es, en lo absoluto, unívoco o simple: podríamos pensarlo en un eje de coordenadas cartesiano, donde en el vertical correrá la naturaleza de la hegemonía (benevolente o coercitiva) y en el horizontal los medios para ejercerla: desde una perspectiva racionalista, los incentivos materiales -económicos y militaresbajo la forma de sanciones, recompensas o incentivos ${ }^{187} ; \mathrm{y}$, desde una perspectiva constructivista (y también neo estructuralista) centrada en los incentivos inmateriales (persuasión basada en la aceptación de normas/valores (Llenderrozas, 2012).

El ejercicio benevolente de la hegemonía puede ser rastreado en Kindleberger y su abordaje de la estabilidad hegemónica: el imperativo de autoayuda de cada actor conlleva la creación de un entorno estable para su desenvolvimiento, en el que invertirá recursos, no necesariamente de manera eficiente (este es el caso de los bienes públicos que quedan a disposición de pares polizones (free-riders), es decir, aprovecharán los beneficios sin afrontar $\operatorname{costos}^{188}$

\footnotetext{
${ }^{187}$ Es preciso no llevar este criterio al absoluto: si bien al diseñar un esquema de incentivos hablamos estrictamente de recursos materiales, al requerirse alterar ese esquema tal vez sea necesario apelar a cuestiones no-materiales (lo que podríamos llamar en sentido genérico 'ideacionales') para establecer algún consenso intermedio, transaccional (Destradi, 2010).

${ }^{188}$ Recordemos que esa provisión con asunción de costos es lo que Destradi señala como la causa de la confusión entre hegemonía y liderazgo
} 
La versión coercitiva de la acción hegemónica tiene por precursor a Gilpin, de corte neorrealista ${ }^{189}$, basada en la maximización de la utilidad marginal. Así acerca la hegemonía al interés nacional y las articula con dos bienes públicos: la estabilidad del sistema y la paz. Esto implica el reparto de los costos, lo que no vulnera necesariamente la legitimidad si, y sólo sí, ella está asegurada por los dos bienes públicos que el hegemón asegura (Rapkin, 1990). Existe una tercera opción de la power transition theory ${ }^{190}$, donde la jerarquía de poder del sistema internacional retoza en la distribución de recursos materiales con hegemones interesados en mantener ese status quo gracias a la cooptación de aliados menores ofreciéndoles un sistema de incentivos acorde (en bienes privados, claro).

Allende estas tres diferentes interpretaciones y roles teóricos para la hegemonía, como señala Destradi (ibídem), lo interesante es cotejar que el hegemón sigue su propio interés, involucrando de diferente manera a los pares menos poderosos para la realización de sus objetivos. $Y$ en este camino, combina incentivos materiales y no materiales: como la reformulación de reglas, la presión diplomática so pena de sanciones políticas ${ }^{191}$, cancelamiento de apoyo internacional en diferentes causas,

\footnotetext{
${ }^{189}$ Si bien Gilpin (1981) es claramente un autor neorrealista, no por ello tuvo la postura racionalista pura: reconoció la importancia de un componente normativo a la hora de establecer un orden hegemónico y así dio lugar al prestigio -tal vez con alguna influencia morgenthauniana-, asegurando que este provee la probabilidad de que un mandato sea seguido aún sin el ejercicio de poder alguno.

190 La Power transition theory (perspectiva teórica inaugurada por Organsky [Cf. su World Politics, editado en 1958 por Alfred Knopf en New York]), asevera que el sistema internacional se dispone con una potencia dominante que impone términos y vela por la estabilidad sistémica. Claro que seguida de otras grandes, medianas y un resto menos poderosas según la distribución de los recursos de poder asignados por el hegemón. No es la fuerza la que ordena el escenario, sino la cooperación.

${ }^{191}$ Es decir, actos simbólico-políticos como notas de protesta, alteraciones en las agendas de visitas, amenazas de retiro de agregados, etcétera.
} 
amenazas de exclusión de esquemas de negociación de diversa índole, revocación de acuerdos. 
"Para que un país sea considerado una potencia, tiene que tener estructura militar y es eso lo que está haciendo Brasil ahora, corriendo atrás de lo que no invirtió en los últimos treinta años»

Gunther Rudzit, 2010

La hegemonía regional, allende la manera en que se la conciba, implica un ejercicio de un tipo particular de potencias. Intentaremos en lo que sigue, precisar las características de una potencia regional, teniendo especial celo en la potencial confusión que existe entre éstas y las denominadas potencias medianas. Compartimos el criterio de diferenciar, taxativamente, las potencias hegemónicas de éstas: las medianas conforman la categoría de los Estados centrales, imbricadas al capitalismo más desarrollado (concretamente, al G7), mientras las regionales son en esencia semiperiféricas y por tanto semidesarrolladas (Rocha Valencia y Morales Ruvalcaba, 2010). Claro que poseen una jerarquía -y son las destacadas-, pero:

"Potencias medias" y "potencias regionales" son dos categorías diferentes de Estados, con posicionamientos estructurales desiguales y con roles distintos en el Sistema Político Internacional. Estas categorías de Estados se encuentran posicionadas estructuralmente entre las potencias mundiales (donde se incluye a las superpotencias) y los Estados menores o periféricos (Rocha Valencia y Morales Ruvalcaba, 2010: 266) 
Siguiendo a Nolte (2006) en concebir desde una perspectiva múltiple -y más complejaesta cuestión, debemos pensar la distribución de poder en el sistema internacional en diferentes aspectos y jerarquías (el orden internacional no está regido por una o unas potencias predominantes de manera absoluta). Si a esto sumamos el aporte de Lemke (2002), vemos que las jerarquías se tornan múltiples, y de este modo las estructuras de poder se superponen con subsistemas regionales subordinados a la potencia dominante -y otras grandes potencias- que asignan recursos políticos y económicos (este sería el caso Brasil, hegemón regional subordinado a grandes potencias). Y, por último, sumemos la característica de la autopercepción (Hurrell, 1995). El hegemón regional, asumido como potencia más allá de la región, busca recursos materiales y reconocimiento de pares -regionales y extra regionales- con potencial impacto en el sistema internacional (Buzan y Waever, 2003).

Nolte considera que sólo un modelo de múltiples niveles procede a una potencia regional donde se coteje las interacciones con otros estados en el mismo nivel, el desempeño extra regional -con todo tipo de actores estatales-, las relaciones con otras potencias regionales extra regionales, y, por último, el espacio global. Esta sobre posición de dinámicas, permite asistir al verdadero perfil del desempeño: es posible ver potencias regionales muy fuertes en su región, pero con baja preponderancia por fuera de ella (Brasil, por ejemplo). La transición de la hegemonía como fenómeno de orden global hacia el regional puede resultar, sólo en principio, una cuestión de escala: lo que la potencia global reflecta en el ámbito global, es equivalente a lo que la 
regional hace en su región. Lo cierto es que las potencias regionales no resignan el juego de poder global, acotándose sólo a su región:

¿Cuál es la diferencia entre una potencia regional y una potencia global? Concretamente, es la capacidad de proyectar su poder militar en diferentes regiones del mundo y de ejercer su influencia política en forma global. Por definición potencias regionales lo hacen en un principio solamente en el ámbito regional, aunque se les atribuye la intención de proyectar su poder más allá de la región en el ámbito global (Nolte, 2006: 13 [destacado nuestro])

Y, al interior de la región, las potencias regionales poseen:

Una serie de recursos económicos ${ }^{192}$, militares y políticos; cierta capacidad de contribución a la producción del orden internacional en el contexto regional o global; y cierto grado de cohesión interna y capacidad de acción estatal (Hurrell, 2006: 1; citado en Derghougassian, 2007)

De este modo, comparten con las globales la iniciativa -y el interés- en incrementar la influencia en asuntos mundiales. Y por supuesto, la influencia que consigan en la región: una de las vías de concreción reside en la regulación del grado de cooperación/conflicto (Destradi, 2010) junto con la promoción de la institucionalización regional y el tendido de coaliciones en el marco de organizaciones internacionales (Der Ghougassian, 2007).

\footnotetext{
192 Para que la expresión 'asignación de recursos' no resulte abstracta, mencionemos una dimensión concreta, la económica: el hegemón controla el acceso al capital y mercados, a materias primas, y posee ventajas competitivas en la producción de los bienes de mayor valor agregado (Keohane, 1984).
} 
Existen otras consecuencias prácticas para el funcionamiento del sistema internacional de estas formas regionales de ejercicio hegemónico: como señala Andrew Hurrell (2005) mantienen una tendencia a apartarse del conflicto y se valen de la competencia política en un marco globalizador que la aleja de la clásica dinámica realista de la raison d'état por una conducta más parecida a la raison systeme. Por esto no se ciñen al interés nacional como informador de la política exterior, sino que también apelan a nuevas formas de poder blando (Hurrell, 2006; en Derghougassian, 2007) como también nuevas formas de diplomacia como la diplomacia de nicho ${ }^{193}$ (Cooper, 1997), $y$, por las ventajas potenciales que puede traerles en términos de alianzas son apegados a todas las formas de multilateralismo (en donde dirimen conflictos y también construyen coaliciones con pares y organizaciones no gubernamentales para misiones humanitarias y de seguridad humana (Nolte, 2006)).

Incluso son el factótum de la forma más efectiva de regionalismo, dado que el regionalismo hegemónico ha sido históricamente más usual que el espontáneo (Hurrell, 1993):

Las instituciones no están sólo interesadas en propósitos liberales de resolución de problemas comunes o en la promoción de valores compartidos. Ellas son también espacios de poder que reflejan y afirman jerarquías de poder e intereses de los Estados poderosos. Es innegable que podríamos definir cada vez más a la soberanía no por la potestad de preservarse frente a influencias externas sino por el poder de participar

\footnotetext{
${ }^{193}$ La 'diplomacia de nicho' refiere a un particular ejercicio de la labor donde se busca incidir y adquirir preponderancia o protagonismo completo en temas y/o audiencias específicas o nichos (Azpiroz, 2004).
} 
efectivamente en instituciones internacionales de cualquier tipo (Hurrell, 2000: 3 y 4 [traducción propia] ${ }^{194}$ )

Refiriéndonos, ahora, a un Estado que se erige en potencia regional, tenemos que atender una serie de criterios que, en 1992, Neumann señaló, indicativamente, como: la capacidad de prevalecer frente a una coalición de pares de su región (para lo que precisa liderazgo); además, la influencia en asuntos regionales, como la delimitación geopolítica y construcción político ideológica -que incluye la exclusión de ciertos países-; y, por último, un rol considerable, atendible, globalmente.

Esto se traduce en un liderazgo regional dos componentes: 1) recursos de poder (militares, económicos, demográficos e institucionales -políticos e ideológicos(Schoeman, 2003), lo que se completa con interconexión(es) regionales -económicas, políticas y culturales-, donde se ejerce influencia a través de las diferentes estructuras de gobernanza regional); y 2) autopercepción (en este caso ${ }^{195}$, la categoría constructivista de autopercepción destacada por Hurrell (2000) refiere no sólo a una lectura de sí mismo, sino que incluye una construcción social con los pares y aquellas potencias bajo su influencia: la razón es sencilla, una potencia regional no puede prescindir de mutuos entendimientos, si lo hiciera, estaríamos en el espectro del imperio (Hurrell, 2000 citado en Nolte, 2006). Este liderazgo está principalmente

\footnotetext{
${ }^{194}$ Del original: Institutions are not just concerned with liberal purposes of solving common problems or promoting shared values. They are also sites of power and reflect and entrench power hierarchies and the interest of powerful states. Indeed sovereignty may be increasingly defined not by power to insulate one's state from external influences but by the power to participate effectively in international institutions of all kinds.

${ }^{195}$ Es decir, para el caso que menciona Nolte en boca de Hurrell. Más adelante volveremos sobre la autopercepción, pero en clave de realismo neoclásico.
} 
interesado en crear y garantizar la paz y orden regional para lo que precisa una agenda de seguridad regional.

Esa cuestión condensa el rol destacado, pero también estabilizador de la potencia: muestra su voluntad de ejercer su papel y ostenta la capacidad de garantizar la paz en la región (o acabar por imponerse), respectivamente. $Y$, por último -agregamos nosotros- una característica especialmente importante para nuestro caso: el tamaño. Desde ya, tomándolo en términos de su importancia relativa con la región y a la luz de las aspiraciones de poder global de la potencia regional:

A mayor tamaño relativo del Estado, mayor identificación de sus intereses con los intereses del sistema (...). Los Estados que tienen una participación lo suficientemente grande en el sistema actuarán por su bien, a pesar de asumir costos al hacerlo (Waltz, 1979: 198 [traducción propia] ${ }^{196}$ ).

Avancemos ahora, sobre la construcción de la noción de estrategia de poder global brasileña, con el fin de poder cotejar, en el capítulo siguiente, sobre la integración regional suramericana durante la administración Da Silva.

\footnotetext{
${ }^{196}$ Del original: The greater the relative size of a unit the more it identifies its own interests with the interests of the systemic (...) Units having a large enough stake in the system will act for its sake, even though they pay unduly in doing so.
} 
Segunda Parte

Análisis dinámico 
Capítulo V. Estrategia de Poder Global Brasileña (2003-2010)

Sumario. Este capítulo caracterizará la Estrategia de Poder Global Brasileña para el período 2003-2010. Nuestro fin principal reside, por un lado, en recortar, caracterizar y presentar un constructo teórico-analítico que reconsidere y caracterice la denominación del perfil de la política exterior brasileña de la literatura especializada para este período (que hasta ahora hemos condensado como '(neo)realismo' brasileño). Por el otro, en el capítulo siguiente, cotejaremos el rol de su titular en el Mercosur. Antes de esto, en lo tocante haremos una sumaria referencia a la política exterior en general para luego plantear la relación de la República Federal de Brasil con la región y Estados Unidos. Estos dos vectores de sus relaciones (medio subregional y hegemón) serán útiles a nuestro planteo de su estrategia de acumulación de poder. 
"Las políticas externas no son elaboradas basadas en abstracciones. Son el resultado de concepciones prácticas del interés nacional que emergen a partir de requerimientos inmediatos 0 de fundamentos esenciales, en perspectiva histórica. Cuando son mantenidas el tiempo suficiente, expresan esperanzas, temores, objetivos de seguridad y engrandecimiento que se tornarán dominantes en la conciencia nacional» Charles Hughes, 1923

«(...) que la historia es el despliegue de sucesivas posibilidades, que una nación es una continuidad necesaria, que cada cambio de gobierno no inaugura una historia y que el presente es siempre una vía que nos ha abierto un largo pasado» Guillermo Jiacovella, 1998

En lo tocante nos dedicaremos a una construcción analítica que seguirá una progresión de tres pasos: el primero, centrado en recuperar unas notas generales de la política exterior brasileña para el período seleccionado, con el fin de sentar una base mínima acerca de ella para nuestro decurso. El segundo, centrado en recuperar algunos análisis que sindican el estilo de ejercicio de política externa brasileña dentro de lo que aquí denominamos con la expresión '(neo)realismo' (para condensar todas las denominaciones similares de la literatura); y, por último, presentar lo que entendemos por estrategia de poder global brasileña (2003-2010). De este modo, si bien haremos en lo tocante una breve referencia a la teoría de la política exterior, este capítulo no tiene por fin caracterizarla de la misma manera que hicimos con el realismo en la primera parte, sino destacar algunos componentes de ella que permiten reforzar el perfil de acumulación de poder que consideramos presentó en la gestión Da Silva. 
Centrarnos en esto permitirá que podamos desembarazarnos de las decisiones concretas/contingentes de todas las capas que posee una política externa del vecino, para retener la característica siempre presente: la preeminencia regional, el aumento de perfil hemisférico y la aspiración de empoderamiento global.

Hasta aquí hemos abordado insumos teóricos que necesitamos para comprender el devenir de la integración regional del sur de América en relación a su socio mayoritario, para lo que no sólo expusimos las notas que consideramos determinantes en el realismo y el neorrealismo, avanzamos con la noción de interés nacional y de allí hacia la política de poder. No sólo nos interesamos por el realismo, sino que también asumimos un interés por él (lo pensamos preeminente a los paradigmas alternos). Pero esta división es diferente si incorporamos la política exterior: la división de aguas entre posiciones no es tan clara. Así es como Wilhelmy (1987) menciona que el paradigma tradicional -idealismo y realismo- comparte la visión estadocéntrica y la anarquía del medio internacional:

Aunque en el núcleo del idealismo y del realismo hay nociones encontradas acerca de la naturaleza humana, ninguno de estos enfoques enfatiza la necesidad de estudiar la política exterior. En cambio, el carácter anárquico de las interacciones estatales provee el principal punto focal de sus investigaciones, lo que deja la política exterior más en calidad de factor determinado que de factor determinante en las relaciones internacionales (Hazleton, 1987: 16. Los destacados son nuestros)

Es en aras de la consistencia teórica que buscamos en la primera parte colocando al realismo con preeminencia teórica por sobre otras teorías, la política exterior no revestirá un papel central en nuestro análisis. Nuestro interés queda acotado a lo que 
las relaciones internacionales son -no a aquello que pueden ser- (ibídem), por eso, presupondremos menos variación, menos de grados de libertad, en un ecosistema internacional regido por el poder. Aquí un actor central procura su acumulación como medio para concretar un fin mediato, junto con aumentar su preponderancia, y proyectarse en el escenario global. Para alcanzarlo y sostenerlo, debe estar abocado a transformar al poder en un fin en sí mismo. El vector para lograrlo sería la agencia por antonomasia del medio internacional: la política exterior. Esta es la manera en que el Estado se relaciona con sus pares sin considerar su conducta, con una formulación de políticas como tantas otras (un diseño, una implementación y una evaluación de un curso de acción):

La forma en que un Estado lleva sus relaciones con otros Estados, se proyecta hacia el exterior (...) desde el interior de un Estado, vistas desde la perspectiva del Estado, sin atender a la sociedad internacional como tal (Del Arenal, 1994: 22)

El estudio de las relaciones internacionales y la política exterior siempre ha sido una empresa ecléctica (Olsti, 1989). Las dificultades teóricas de su definición (Deutsch, 1976; Pereira, 2003), junto con la posición del realismo, nos obligan a esbozar dos ideas generales. La primera: la política exterior sólo puede predicarse de los Estados (Deutsch, 1988). Si bien muchas veces, tal vez con alguna liviandad, se habla de la 'política exterior' de otros actores internacionales -como los bloques regionales-, son solamente los estados quienes están habilitados a ella, dada su capacidad jurídica reconocida en la comunidad internacional y su capacidad política plena (soberana), autónoma y eficaz (Pereira, 2003). La segunda idea: la política exterior se encuentra 
incardinada como un sector más de la política general de cada Estado, dentro de la órbita de decisiones y acciones por medio de las cuales se definen unos objetivos y se utilizan unos medios que aquél posee, para crear, cambiar o suspender sus relaciones con otros actores de la sociedad internacional (ibídem). Es en este sentido en que puede ser relacionada a la política doméstica: son dos facetas de la misma realidad política nacional institucional y social (su diferencia residirá en los mecanismos y formas institucionales que participan en la elaboración de cada una, por un lado; y en sus destinatarios, por el otro). A diferencia del reduccionismo realista -que divorcia la política doméstica de la externa-, aquí recuperamos la posición que mencionamos en el apartado del poder realista: más cercanos al realismo neoclásico, no veremos un hiato absoluto entre ambas y nos asentaremos en la preponderancia de la situación externa, pero en consistencia con la toma de decisiones interna (operación que contendrá la información inscripta en el interés nacional). Esa articulación y permanente relación entre 'lo externo' y 'lo interno' influye las decisiones de los funcionarios, incluso aunque sea de manera residual (Olsti, 1989; Rosenau, 1994). Pero, no por esto, estamos afirmando que veremos a la una como reflejo de la otra:

El estado-nación se puede también conceptualizar como un actor unitario. Dado que los problemas centrales de los estados los define claramente el carácter del sistema internacional, sus acciones son esencialmente reacciones a la dinámica política exterior más que a la interna. En el mejor de los casos, ésta sirve poco para explicar las decisiones de política exterior (...) los realistas clásicos a veces le dan importancia también a la política interna como una variable residual para explicar las desviaciones de la política racional (Olsti, 1989: 529) 
Desde la perspectiva del analista en relaciones internacionales, nadie dudaría en afirmar que ellas son más que la suma de las políticas exteriores (Wilhelmy, 1988), pero, así como planteamos cierta predominancia relativa de la esfera exterior también debemos reconocerle alguna 'interioridad' en su trazado (ibídem), que exige cotejar la perspectiva nacional específica, por medio de dos operaciones de su hechura: las acciones y las decisiones (Hazleton, 1987). La secuencia de ellas -es decir, actuar y decidir-, son vehiculizadas institucionalmente, exigen una planificación seria y una atención constante (caso contrario, el Estado sólo podrá tener una actitud reactiva a los avatares que se sucedan en el escenario internacional). Las acciones refieren al comportamiento práctico, suceden en el medio físico, y puede resultar diferentes de las decisiones iniciales. Éstas, tienen lugar en las mentes de los actores -son intenciones para determinar un curso de acción-, y acontecen a la hora de identificar un problema y producir una plétora de alternativas para intervenir sobre él (ibídem). Pero no son sólo caminos diferentes para la continuación de la acción, sino que están presentes en todas las etapas del proceso -incluso en la implementación de la política exterior-. A esto debemos sumar, también, sus cualidades, que pueden ser de procedimiento y sustantivas:

Hay 'decisiones de decidir', decisiones incompatibles y agentes de decisión que evaden las decisiones. Todo esto es parte del proceso de toma de decisiones (Hazleton, 1987: 32) ${ }^{197}$

Hazleton recupera a Rosenau, afirmando:

\footnotetext{
${ }^{197}$ Sin poder solucionar esta cuestión aquí, la mencionamos para dejar planteada la complejidad que reviste la hechura e implementación de esa política pública tan particular, como es la política exterior.
} 
La conservación o modificación de situaciones en el exterior de ordinario no depende de una elección única entre cursos de acción alternativos, sino que es consecuencia de una serie de decisiones, y cada una es una función de los resultados de decisiones previas (Rosenau, 1971; en Hazleton, 1987) ${ }^{198}$

La decisión en política exterior reviste la manera en que los Estados usan sus recursos en consistencia con sus objetivos, junto a la pericia y la habilidad de las instituciones específicas: Van Klaveren (1992) muestra una de las condiciones externas que determinan la política exterior en la política de poder, donde las acciones de otros actores resultan los factores condicionantes de las decisiones (lo que trae aparejado la acción estatal con independencia de las fuerzas sociales para priorizar la búsqueda de intereses nacionales (ibídem)).

Si bien la seguridad nacional prima aquí, ya en clave de nuestro caso, debemos ver que las otrora existentes rivalidades de nuestra región comenzaron a combinarse con esquemas de cooperación a fines del siglo pasado (ibídem). Y esta es una de las grandes excepciones con el caso de Brasil (aspecto que retomaremos en las conclusiones): mientras más adelante veremos su estilo de acumulación de poder típico de un perfil realista de política exterior-, elementos que no le son propios también se encuentran presentes en su espectro. Tal el caso de las coaliciones de intereses domésticas que otorgan un rol específico para organizaciones no gubernamentales competentes (movimientos sociales y sindicales) aliadas al gobierno y con un grado de incidencia determinado en la política exterior (Hirst; Soares de Lima; Pinheiro, 2010).

198 En referencia a su obra The Scientific Study of Foreign Policy, Nueva York, Free Press, 1971. 
Estas particularidades podrían verse en la mismísima asunción de Da Silva, en la que su Canciller, Celso Amorim, afirma la necesidad de reinterpretar las premisas de la política exterior, bajo una estrategia de inserción diferente a la de Cardoso (signada como 'entreguista' y 'alineada' con Estados Unidos). De hecho, la propia designación de Amorim como canciller ya tenía consecuencias: mostraba que la política exterior no era un área más de la gestión -Amorim es un diplomático de carrera conocido por su postura autonomista en los foros multilaterales (Ferreira, 2009), y por su orientación progresista-). Así, en la perspectiva petista, debía existir articulación entre el entramado de coaliciones sociales partidarias de construir un rol destacado para Brasil en el mundo (la política exterior activa y altiva tan mentada) vis a vis los apremios y particularidades de la inserción periférica para países en desarrollo (ibídem). Mientras en la era Cardoso había imperado el paradigma logístico -asociado al liberalismo en el plano externo y al desarrollo en el plano interno (fundiendo el capitalismo con el estructuralismo (Cervo, 2003))-, la autonomía, en un mundo interdependiente, adviene por la integración regional. Mientras, se apunta a superar las asimetrías con el nivelamento nacional y la provisión estatal de la estabilidad económica, por vía de la defensa de intereses sectoriales (ibídem). Ferreira (2009) afirma que Da Silva perfecciona el paradigma logístico, porque lo sobrepone a las vulnerabilidades externas:

Es inadmisible que ante las fuerzas internacionales los gobiernos sean incapaces de gobernar. Dado que Brasil constituye una sociedad organizada, articulando en confederaciones de clases a industriales, agricultores, banqueros, trabajadores, comerciantes y consumidores, con un 
Estado que apoya la realización de esos intereses sectoriales, velando por el bienestar colectivo. Como ello depende de la dimensión interna y externa, el Estado se impone con el peso de la dimensión nacional sobre la política exterior y deviene agente de gobernanza global. Esa evolución, para los autores, es lo que permitió a la política exterior de la era Lula caminar hacia la madurez (Ferreira, 2009: 105 y 106 [traducción propia] ${ }^{199}$ )

Con el fin de ordenar la observación de la política exterior, Van Klaveren propone atender el área militar, el desarrollo económico y el estatus diplomático.

[la política exterior] Abarca tres dimensiones analíticamente separables: político-diplomática, estratégico-militar y económica-comercial, que se proyecta al ámbito externo frente a una amplia gama de actores $e$ instituciones gubernamentales y no gubernamentales, tanto en el plano bilateral como en el multilateral (Russell, 1992: 255).

Creemos que, para considerar el caso brasileño en nuestro período, debemos atender a unas notas generales de ella -multilateralismo, cooperación, alianzas estratégicas y el pragmatismo (Cervo, 2008)-. Por una cuestión de espacio, y como una solución de compromiso expositiva que no nos aleje de nuestro fin, aquí condensaremos esos actores en dos vectores, en dos planos (que oficiarán como interlocutores): uno horizontal -el medio subregional-, y el otro vertical -la relación con Estados Unidos de América-. Utilizaremos estos vectores para acotar nuestro análisis, por lo que ambos representarán el recorte de la dimensión multilateral (extendida sólo a la región) y bilateral (alcanzando la relación de Brasil con el hegemón), respectivamente.

\footnotetext{
199 Del original: Não se admite que diante das forças internacionais os governos sejam incapazes de governar, visto que o Brasil se apresenta como sociedade organizada, com suas federações de classe articulando industriais, agricultores, banqueiros, operários, comerciantes e consumidores, cabendo ao Estado apoiar a realização dos interesses desses segmentos, zelando pelo bem-estar coletivo. Como isso tudo depende do interno e do externo, o Estado entra com o peso do nacional sobre a política exterior $e$ torna-se agente da governança global. Essa evolução, para os autores, é o que permite a política exterior da era Lula caminhar rumo à maturidade.
} 
Medio subregional

Es necesario ver el proyecto estratégico brasileño como una circunstancia geográfica (Domínguez Ávila, 2009) ${ }^{200}$, que deviene una identidad ${ }^{201}$ (el autor cita a Celso Lafer aseverando que la América del Sur es parte constitutiva del yo-diplomático brasileño $)^{202}$. La atención en Suramérica signa a la diplomacia brasileña de nuestro período, y erige a aquella en escenario de sus capacidades político-militares, económicas y simbólicas (emergente de esto es la creación de la CSN y su redefinición en 2008, en Unasur (ibídem)). En el mismo contexto y período, Brasil promueve las Cumbres de América Latina y el Caribe (2007) que devendrá, a posteriori, en la constitución de la CELAC (con la incorporación del Grupo Río) hacia el año 2011 (Mellado, 2013).

Creemos que, allende la circunstancia geográfica y sus consecuencias, la relación de Brasil con la región es una ingeniería en dos niveles (o en dos tiempos): el primero al interior de ella, en relación a la conformación de bloques y por tanto el incremento de la multilateralidad regional. Y el segundo, inescindible del primero, acerca de la

\footnotetext{
200 El autor completa el proyecto estratégico brasileño con otras dimensiones: un país occidental en desarrollo, americano, amazónico, mercosureño (ibídem: 83).

${ }^{201}$ El devenir de una identidad, es un juicio, una expresión, por entero nuestra. Implica un anclaje, una suerte de autopercepción que Brasil asume (hacemos esta aclaración, tal vez pecando de exceso de celo, para no ser presa de connotaciones constructivistas, y comenzar a esbozar aspectos del realismo neoclásico que más adelante utilizaremos en nuestro análisis).

202 De LAFER, Celso. La identidad internacional de Brasil. Buenos Aires, FCE, 2002.
} 
proyección que estos constructos reflejan al exterior, con el fin de abrevar en su aspiración de global player. Por supuesto, esto retorna como refuerzo a la región, solidificando su pretensión hegemónica.

Ante todo, lo que se debe remarcar es que el camino del activismo 2003-2010 no ha sido tan lineal ni fluido como podría parecer (o como Brasil podría necesitar): El activismo de su política exterior llevó a conformar grandes y ambiciosos esquemas pero con bajo compromiso por su profundidad institucional (Bernal-Meza, 2010), lo que mostraba una suerte de impulso expansivo, pero sobre una estructura maleable, más apta para los (re)ordenamientos propios del juego de la política de poder externa al servicio de los intereses coyunturales nacionales, que a la construcción de esquemas que trazaran un futuro regional estable y cada vez más sólido. Sin mencionar que su rol era el de la iniciativa política, no económica: Brasil nunca se presentó como el paymaster (Mattli, 1999) de proyectos que requieren infraestructura -con obras ejecutadas por empresas nacionales no alcana para serlo-, desarrollo técnico por áreas, y apoyo en el aspecto financiero (Almeida, 2007)).

A esto se agrega la permanencia en el rol del líder hegemónico (que no sólo de líder), papel que requiere de una legitimidad mínima provista por los pares, antes que autoproclamada (Malamud, 2009). Por supuesto que nada de esto es inocuo en la caja de resonancia regional: si bien existen quienes reconocen un 'liderazgo natural' en Brasil (Hirst, 2006) -lo que haría esperar responsabilidad política y económica para ejercerlo-, hay quienes recelan de ello -como Argentina- por el interés que ha 
mostrado en Estados Unidos (ibídem). El resquemor a reconocerlo como líder hegemónico no reviste sólo una rivalidad infantil: Brasil no posee una renta per cápita mayor que sus vecinos, y ostenta grandes contradicciones internas (Sorj y Fausto, 2011). Como mencionábamos más arriba, Argentina resultó uno de los factores de recelo ante la unilateralidad de Brasil en diferentes áreas -con el programa nuclear, sus relaciones con Irán o con Francia-, como también con respecto a la actuación de grandes empresas brasileñas en el exterior (ibídem).

Las pretensiones globales de cualquier actor se encuentran encajadas con la legitimidad obtenida de la región: claro que aquéllas precisan de elementos objetivos recursos- que ostente y de su autopercepción, pero también precisan del reconocimiento de otros, tanto pares como más poderosos (Soares de Lima, 2007). Para el caso de Brasil tenemos que sumar algunas capas más: en primero lugar, la de las potencias medias, que deben demostrar una promoción de cohesión y estabilidad del sistema mundial (Jordan, 2003; citado en Malamud, 2009). A esto, hay que agregarle la capa que corresponde a las emergentes -aparentemente pobres, con problemas estructurales, reformistas y orientadas regionalmente-. Brasil cumple con todos estos requisitos, salvo por uno fundamental: la región no adelanta el reconocimiento necesario para que ejerza a sus anchas el rol (Malamud, op. cit.).

La política exterior brasileña para la región ha sido juzgada (y muchas veces criticada) bajo dos prismas contrapuestos (Paz Dos Santos, 2014): Ideológico y el pragmático. El primero, por causa de la extracción partidaria de Da Silva, refrendada por su énfasis en 
las relaciones Sur-Sur y la relación con la progresía latinoamericana de la década pasada. No obstante, también ha sido juzgada de una política exterior pragmática -en el sentido de menos ideologizada de lo que se presumiría para Da Silva-, y consistente con la tradición diplomática brasileña, y, de hecho, menos diferente de lo que parecería con la de Cardoso, quien dio importancia a la integración regional y a Latinoamérica toda (Actis, 2014). Tal vez el hecho de haber avanzado tan decididamente hacia ingenierías más ambiciosas -UNASUR, CELAC- combinadas -o basadas- en el multilateralismo, es lo que ha hecho que Da Silva se diferencie de la anterior presidencia (Paz Dos Santos, 2014).

Es posible detectar otra crítica, que pone al pragmatismo e ideologización en tensión: la añoranza de una profesionalización diplomática ya perdida. Hirst (2006) señala:

Una percepción nostálgica de la política exterior brasileña, concebida en base a una acción "profesional", anti intervencionista, apolítica y marcada por una prudente distancia frente a las crisis de gobernabilidad de los países vecinos (página 138).

Creemos que se podría relacionar esta nostalgia como correlato de la ideologización consonante con el giro hacia la izquierda de los demás países de la región-. Si efectivamente fuese así, Brasil sigue conservando una particularidad en relación a los demás países de Latinoamérica: siempre preservó un perfil desarrollista y autonomista combinado con una visión instrumental de la política externa (ibídem). Y esto último nos vuelve a hacer pensar en la viabilidad del efectivo pragmatismo de ella. 
No es el fin de este apartado zanjar esta cuestión, sino simplemente plantear una consideración que los análisis especializados $-y$ la opinión pública-, tuvo sobre la actividad en política exterior de entonces. Pero, no está de más comentar que escogemos deliberadamente esa consideración de Hirst: nos permite mostrar que ambos perfiles estuvieron presentes en la gestión Da Silva. Mientras se afirma el alejamiento de las posiciones apolíticas (que abre paso a la ideologización), al mismo tiempo, se mantiene el perfil instrumental (que da vía libre al pragmatismo). Consideramos que la política exterior brasileña no fue lo uno o bien lo otro, sino que, como Jano, mantuvo constantemente ambas caras.

Cualquiera fuese el juicio, la región es el quid para ampliar y profundizar la proyección brasileña en América del Sur, mientras conservase la capacidad de iniciativa y aspiración por encima del resto de los países de la región. Hirst (2006) sostiene que la primera presidencia de Da Silva reflejó esto en tres premisas: al tener mayor presencia en la región -privilegiando la relación con Argentina-, al tomar como propia la estabilidad democrática de Suramérica -sobre todo en crisis institucionales-, en la intensificación de los programas de cooperación (científico, sanitario, educativo y hasta militar). Todo ello, por supuesto, con el fin de que ese protagonismo le redituase de cara a ganar preponderancia en el globo. En el primero, Argentina no resultó simple. En el segundo, las crisis andinas resultaron sensibles, no del todo predispuestas, a la intervención definitiva de Brasil. En el tercero, era difícil que 
surgiesen escollos. Y en cuanto a la proyección global -sobre todo, en el aspecto del Consejo de Seguridad de la ONU- el apoyo, pues tampoco sobró (ibídem).

La decisión del gobierno de Lula de priorizar los vínculos con Sudamérica generó controversias en cuanto a la conveniencia de esta estrategia, además de alentar tanto las expectativas de liderazgo como las rivalidades regionales. En las últimas décadas, los acuerdos de los dos socios mayores no cumplieron con las expectativas creadas por ellos mismos, ya sea en la promoción de una receta institucional modesta pero eficaz, de una política subregional de desarrollo sustentable o de un liderazgo político que ofrezca [sic] ventajas reales para los países de menor peso relativo (Hirst, 2006: 137)

En este sentido, y abonando nuestra posición de la bivalencia ideológico-pragmática al mismo tiempo, agregamos un criterio más a los expuestos por Hirst: Ferreira (2009), menciona que al comienzo de la gestión -en el Foro de Davos de 2003-, el Presidente afirmó su diferencia con el modelo neoliberal, pero sin alejarse de una economía de mercado (posición que compartía con Amorim, sobre todo en la desconfianza del desarrollo con igualdad a partir de la apertura irrestricta):

Queremos el libre comercio, pero libre comercio que se caracterice por la reciprocidad (Cervo y Bueno, 2008: 496; citado en Ferreira, 2009 [traducción propia ${ }^{203}$ )

Es interesante bucear el activismo brasileño en sí mismo, para poder ver que no fue uniforme, ni estuvo presente en todo aspecto de la política exterior, como tampoco en

\footnotetext{
${ }^{203}$ Del original: Queremos o livre comércio, mas um livre comércio que se caracterize pela reciprocidade
} 
todas las dimensiones del quehacer regional: Spektor (2010) menciona la falta de abordaje multilateral -o siquiera compartido- de problemas regionales. Si bien el sentido que le adosa el autor al activismo es la protección de amenazas externas y preservación del espacio de maniobra nacional, el regionalismo es, también, una herramienta útil de contención: mantiene la región en calma, en un marco de cooperación económica e institucionalización entre países (ibídem). Acorde el autor, Brasil no habría hecho de este criterio una prioridad. A lo anterior, agregamos nosotros: es bastante lógica esta 'selectividad' brasileña a la hora de no practicar un multilateralismo estricto al interior de la región, dado que, asumido como hegemón regional, hacerlo sería resignar preponderancia. En este sentido, un comentario más: el pragmatismo suele estar divorciado de la 'consistencia' típica de un principio. Es la coyuntura la que dicta la norma, que no un principio, y aquélla suele ser variante. Por definición revisará costo-beneficio variables en el tiempo.

La segunda cuestión que señala el autor, refiere al rédito nacional de la estrategia regional: Da Silva aseguró que los problemas estructurales de Brasil no le impidiesen protagonismo en la esfera internacional, pero sus capacidades tampoco se lo aseguraron. Para Spektor, el dilema de todo Estado con aspiraciones globales reside en conciliar sus intereses nacionales con la provisión de algún bien público y la resolución de algunos de los dilemas de acción colectiva típicos de las relaciones internacionales. Spektor agrega otra cuestión, muy interesante: Brasil no percibió ni promovió un ethos suramericano regionalista en su ejercicio multilateral, ni promovió uno genuinamente brasileño. El anteúltimo aspecto que agrega el autor es evidente, y ya lo mencionamos 
en boca de otros autores: el recelo de la vecindad (que trae aparejado la necesidad de considerar iniciativas de bandwagoning ${ }^{204}$ regional si no se tomaban cartas en las asimetrías de los Estados pequeños). Y, por último, el factor ineludible en la estrategia brasileña: Estados Unidos. A vista de Itamaraty, la cordialidad con la potencia del norte era tan necesaria como la distancia con ella (por eso mantiene a Washington comprometido con la región, pero diseña el CSD en 2008, para reducir la injerencia norteamericana en conflictos regionales).

\footnotetext{
204 La maniobra ofensiva de bandwagoning implica la alianza de los débiles (generalmente free-riders) con la coalición dominante, con el fin de preservar su seguridad y aventajarse con ganancias relativas (no es gratis: asumirán un riesgo -y esto implica pagar un costo- pero será menor y por eso costeable (Clulow, 2013)). En la otra polaridad del espectro encontramos una estrategia defensiva, el balancing, a quien Waltz señaló como la alianza con los débiles para prevenir tentativas hegemónicas (1979). El fin es preservar el equilibrio y que nadie domine el tablero mundial.
} 
Roberto Russell junto a Juan Tokatlian (2009), presentan cinco modelos de política exterior hacia Estados Unidos, y sindican el caso brasileño bajo un perfil de oposición limitada. Es decir, funcionando bajo una política mixta hacia el país del norte:

Combinando desacuerdo y colaboración, concertación y obstrucción, deferencia y resistencia (Russell y Tokatlian, 2009: 232)

Casi un lustro después (2013), los autores expusieron que las dos grandes vertientes de política exterior latinoamericana han sido la de la autonomía y la de la aquiescencia (típica de los países subordinados). Los aquiescentes, no tan alejados de una lógica de vasallaje, procuran el apoyo de Estados Unidos para obtener activos materiales o simbólicos mientras construyen una convivencia estable con Washington, combinando autorrestricción y protección para sostener la coalición en el poder. ${ }^{205}$

Bajo este devenir, la integración regional es considerada esencial para poder aumentar el poder negociador conjunto, y por ello los vínculos con los vecinos y países cercanos importan en la medida que luego resulten en un fortalecimiento del diálogo

205 Cf. RUSSELL, Roberto y Juan TOKATLIAN (2013). América Latina y su gran estrategia: entre la aquiescencia y la autonomía, Revista Cidob d’Afers Internacionals, $\mathrm{N}^{\circ} 104$. pp: 157-180 
diplomático con Washington. En este modelo, se propugna un tipo de desarrollo heterodoxo, neo-desarrollista y sensibilizado a la cuestión social, para lo cual el Estado es el conductor principal (tanto económico cuanto político), procurando cambios más profundos en la estructura económica y financiera internacional inequitativa. Brasil ve, según los autores, un poder dual -una combinación de amenaza y oportunidad- en Estados Unidos, mientras le otorga importancia estratégica a los vínculos con la región ${ }^{206}$. Eso lo coloca en un papel particular: debe mantener su aspiración de liderazgo regional y proyección extra-hemisférica, lo que le exige diferenciarse de Washington para erigirse como poder sub-hemisférico, pero también acercarse, para que se facilite su ascenso internacional ${ }^{207}$.

Muchas veces, para caracterizar un período, es preciso retroceder y ponernos en perspectiva. Una década antes del ascenso de Da Silva la relación de Brasil con Estados Unidos estaba imbricada con las de sus socios sudamericanos, ya involucrados en procesos de cooperación e integración (Sombra Saraiva, 2001). Lo cierto es que luego de la caída del muro de Berlín, la nueva hegemonía norteamericana acarreó nuevas vulnerabilidades a Brasil: adopción de nuevos patrones de protección al trabajo, medio ambiente, protección al consumidor, etc. Sumados, por supuesto, a los previamente existentes como, por ejemplo, la cuestión de la exploración amazónica (Bernal-Meza,

\footnotetext{
${ }^{206}$ No es la única dualidad que encarna Brasil: para fines del siglo XX, continuaba siendo una sociedad dual, con un sector pudiente asimilable a varios países desarrollados con otro en extremo pobre. De aquí el mote Belinda brasileña, es decir, la fusión de Bélgica con India (Actis, 2014).

207 Domínguez Ávila (2009) recupera una configuración atávica, la 'alianza no escrita' entre Estados Unidos y Brasil, una Entente Cordiale para liderar en el norte y sur americano, respectivamente (la expresión 'alianza no escrita' proviene de Bradford Burns [Cf. A Aliança não escrita. O Barão do Rio Branco e as relações Brasil-Estados Unidos, Rio de Janeiro, EMC, 2003]).
} 
2002). El acercamiento Brasil-Estados Unidos de entonces -en derredor del proyecto del ALCA- también contaba con el interés de impulsar iniciativas multilaterales, la integración y la cooperación en seguridad. Esa era la salida del período tercermundista hacia un replanteo de la relación con Estados Unidos y con la Argentina. Ambas direcciones de la política exterior no fueron sencillas: con el primero, afloró la oposición entre el ALCA/TLCAN-ALCA con el autonomismo industrial junto con rispideces en la política de seguridad; y, para la segunda, las diferentes visiones de la relación con al propio Estados Unidos de la última década del siglo pasado (ibídem).

Durante ese período, la política exterior brasileña osciló entre un perfil globalista asociado al desarrollismo autonomista-, y el americanismo -de corte más liberal, con Estados Unidos como eje- (Actis, 2014). Los esquemas de cooperación permitieron articular los intereses nacionales de Brasil sin provocar resquemores en los vecinos. El fino equilibrio donde se obtiene autonomía sin sumergirse en el aislacionismo (que previo a la caída del muro de Berlín, se había obtenido por vía de la distancia), es reconfigurada por la administración Cardoso por una posición bien diferente con mecanismos distintos: Sombra Saraiva (2001) recupera al embajador Gelson Fonseca Jr., señalando que la autonomía a costa de la distancia es renovada por una visión más realista, donde la autonomía se obtiene por vía de la integración, y por tanto, las decisiones se toman luego de la coordinación con los aliados. Mercosur, ALCSA y el acuerdo con la UE eran, hacia el inicio del milenio, el dispositivo regional que lo concretaba (sumemos a esto la insistencia brasileña por hacer de la ONU el espacio multilateral por antonomasia para la gestión global). Saraiva remarca los beneficios de 
evitar la transnacionalización de la globalización en un solo actor -Estados Unidos-, para que Brasil no cayese en la trampa de extrapolar los intereses nacionales ajenos y hacerlos propios, sobre todo, a través del ALCA. Desde ya que la cuestión del ALCA en los noventas del siglo pasado fue, en Brasil, materia de discusión política, técnica y académica. Aquí lo mencionamos casi de soslayo -por cuestiones de espacio y pertinencia-, pero podemos mencionar que, hacia inicios del milenio, imperaba la recusación del área hemisférica por sus implicaciones económicas, sosteniendo al Mercosur (articulado con la UE) como la solución de costo menor (Almeida, 2001). No obstante, la posición de Brasil no fue siempre esa: con Felipe Lampreia de Canciller, el ALCA gozó de la consideración de convergencia positiva, aun cuando el discurso continuaba impregnado de desarrollismo y autonomía (Bernal-Meza, 2006b).

Por su lado, Estados Unidos no resultó del todo consistente con sus señales hacia la política exterior brasileña (Hirst, 2006): es de su agrado el rol estabilizador que ha desarrollado en la región, pero le resulta antipático el rol soberano en algunas cuestiones de cooperación. Durante los noventas del siglo pasado -y desde ya que antes también- las relaciones con Washington determinaron las posiciones de Brasil ante el globo (a medida que el segundo milenio avance, serán las posiciones regionales las que comiencen a ocupar este rol determinante, e influyen el desempeño para con aquél (ibídem)). Con el cambio de milenio, la cuestión cambia: Estados Unidos imprimió, en su política exterior posterior a septiembre de 2001, la centralidad de su lucha contra el terrorismo, y esto luego lo subsume casi por completo en sus escenarios bélicos. Eso le permitió a Brasil mayor grado de libertad para trabajar sobre 
la región y fortalecerse en ella (bajo la dinámica que Carlos Escudé (2004) catalogó como río revuelto ${ }^{208}$ )

Con la administración Da Silva en pleno funcionamiento, lejos de resultar discursiva y políticamente confrontativa con Estados Unidos, Brasil decidió asentarse sobre las ganancias de credibilidad obtenidas en la era Cardoso (Soreanu Pecequillo, 2008). Eso derribó el preconcepto norteamericano de una alianza con Chávez ante el perfil contra hegemónico de ambos gobiernos (aunque el primero tuvo corte socialista, y el segundo un perfil más cercano a la socialdemocracia, según Soreanu Pecequillo (ibídem):

\begin{abstract}
Lula y Bush mantuvieron contactos de alto nivel en 2002, 2003, 2005 y 2007, sin contar los viajes de la Secretaría de Estado, Condoleezza Rice, en 2005 y 2008, como los del Canciller brasileño, Celso Amorim, y del Secretario de Relaciones Exteriores, Samuel Pinheiro Guimarães. Estos encuentros desmitificaron la figura de Lula ante los neocons (estableciendo una buena relación personal con Bush [hijo]) (Soreanu Pecequillo, 2008: 97. Traducción propia] ${ }^{209}$ )
\end{abstract}

\footnotetext{
208 Escudé entendió, en 2004, que las restricciones globales de esa coyuntura de desorden global mostraban una ingobernabilidad creciente, un desajuste del orden, que otorgó a Brasil más grados de libertad (lo que también dá cuenta de la reducción de costos en la confrontación con el hegemón). Cf. ESCUDÉ, Carlos. A Río revuelto: autonomía periférica en un contexto de desorden global. En Agenda Internacional, Año 1 Número 1, junio-julio-agosto de 2004

${ }^{209}$ Del original: Lula e Bush mantiveram contatos de alto nível em 2002, 2003, 2005 e 2007, sem contar as viagens da secretária de Estado, Condoleezza Rice, em 2005 e 2008, bem como as do chanceler brasileiro, Celso Amorim, e do secretário de Relações Exteriores, Samuel Pinheiro Guimarães. Estes encontros desmistificaram a figura de Lula frente aos neocons (estabelecendo uma boa relação pessoal com Bush).
} 
El tendido de cooperación Sur-Sur brasileño de los últimos años -antes de la gestión Da Silva junto con ella- configuró, también, la relación de Brasil con Estados Unidos: al haber fortalecido las alianzas fuera de la región, y potenciado el peso dentro de ella, se consagró como un equilibrador regional a la vista norteamericana (Vizentini, 2003; citado en Soreanu Pecequillo, 2008). Pero también a nivel global: las alianzas dentro y fuera de la región fueron también vistas en clave de equilibrio global, en un marco de un multilateralismo asertivo. De hecho, Rice lo reforzó como una cláusula en su viaje de 2005: 'Estados Unidos concibe a Brasil como líder regional y aliado global', lo que se corona unos meses después, cuando Bush y Da Silva formalizan un acuerdo bilateral en 2005, y, para 2007, el acuerdo abocado a biocombustibles (Feres, 2010)) ${ }^{210}$ :

En la época de mi elección presidencial, muchos previeron el deterioramento [sic] de las relaciones entre Brasil y Estados Unidos. Se equivocaron rotundamente. Al contrario, nuestras relaciones atraviesan hoy uno de sus mejores momentos. Las relaciones económicas y comerciales se ampliaron mucho y nuestro diálogo político incrementó su calidad [...] Vemos con entusiasmo la disposición norteamericana de incluir a Brasil entre los países con los cuales mantiene un diálogo estratégico privilegiado (Da Silva, 2005 en Arruda Sampaio, 2015 [traducción propia] ${ }^{211}$ )

El autonomismo de Da Silva con respecto a Estados Unidos tiene que ser pensado en un tándem con las alianzas estratégicas: subordinar las relaciones con Washington a

\footnotetext{
${ }^{210}$ No por esto queremos plantear un panorama libre de conflictos: diferencias como las posiciones en la OMC, la cuestión del Consejo de Seguridad, las trabas al ingreso del alcohol están, también, entre las más determinantes.

${ }^{211}$ Del original: Na época da minha eleição para a Presidência, não foram poucos a prever a deterioração das relações entre o Brasil e os Estados Unidos. Equivocaram-se redondamente. Ao contrário, nossas relações atravessam hoje um de seus melhores momentos. As relações econômicas e comerciais se ampliaram muito e nosso diálogo político ganhou qualidade superior (...) vemos com entusiasmo a disposição norte-americana de incluir o Brasil entre os países com os quais mantêm um diálogo estratégico privilegiado.
} 
los intereses nacionales implicó priorizar la región, diversificar el comercio allende el Mercosur y procurar la reforma del multilateralismo (Arruda Sampaio, 2015). Ese autonomismo estaba, según el autor, depositado en algunos supuestos de la gestión Da Silva, no necesariamente verdaderos: 1) subordinación de las relaciones exteriores al interés nacional (que cortaba con la tradición de alineamiento automático al hegemón hemisférico), 2) concebir el cambio de la política externa como reflejo del cambio en la doméstica (del neoliberalismo al neodesarrollismo); 3) la creencia que la constitución y el perfil de los BRIC posibilitaba una nueva dinámica en las negociaciones internacionales; 4) otorgar importancia determinante al activismo, probada con hechos como la negociación ante Irán, las tropas a Haití, la actividad en conflictos continentales, la OMC y el G20; 5) enfocar el nuevo liderazgo regional brasileño a través de la promoción del Mercosur, la creación de la UNASUR y el CDS, con el fin de neutralizar la ofensiva militar y comercial estadounidense-, lo que efectivamente habría otorgado un nuevo estatus geopolítico (global). De esa nueva preeminencia sería emergente la aspiración al asiento en el Consejo de Seguridad de la ONU. 6) asumir que este viraje permitió la superación de la dependencia económicodiplomática de Estados Unidos y 7) la construcción de un diálogo estratégico con Norteamérica y BRIC en el mismo nivel (el refrendo de esto es la declaración de Rice en 2005 citada ut supra, y la afirmación referida de Da Silva, en encuentro con Bush hijo (ibídem)).

Cualquiera fuese el juicio, el fin de instrumentar ambos aspectos (subordinar las relaciones con Washington a los intereses nacionales priorizando la región, y 
diversificación del comercio allende el Mercosur con reforma del multilateralismo), fue lograr dos objetivos: 1) uno global, como fue la generación de un nuevo sistema multipolar para que Sudamérica constituya un polo independiente del hegemón hemisférico (Guimarães, 2006; citado en Arruda Sampaio, 2015). Y 2) otro regional, norteado en disputar y ganar la hegemonía subregional a Estados Unidos (BernalMeza, 2006b), a través del Mercosur (para lo que también necesita que el primero objetivo esté activo y así ostentar la cualidad de potencia emergente y regional a un mismo tiempo). 
«El interés nacional corresponde a la esencia de la política» Hans Morgenthau, 1948.

"El interés nacional es el concepto clave de la concepción realista de la política exterior»

Charles Lerche, 1956

"El interés nacional es el concepto clave en la política exterior» Joseph Frankel, 1964

La política exterior brasileña durante la gestión Da Silva ha estado signada de diferentes maneras, tanto en la literatura especializada como en análisis de índole periodística: términos como realpolitik, realismo, neorrealismo y hasta maquiavelismo han sido predicados de su perfil. En este capítulo indagaremos con detalle dicho perfil, intentando desgranar el contenido, consistencia y viabilidad de la mentada política de poder brasileña en dicho período.

Existen, también, quienes han adjetivado el (neo)realismo brasileño: tal el caso de Sanahuja (2012) al concebirlo como híbrido ideologizado antes que un ejercicio externo puramente 'realista'. Sanahuja (2012) señala las particularidades de los sectores que constituyen su aspiración multilateral como una plétora de actores semipúblicos y privados -manufactureros, transporte y automotriz-, que acompañan al gobierno y el cuerpo diplomático en esta labor (a lo que se debe sumar el Banco del Sur, el impulso en seguridad regional, el involucramiento del BNDES para con el IIRSA). Sanahuja señala que la posición de Brasil puede, según Ayllón y Viola (2006; citado en 
Sanahuja, 2012), verse como realismo, pero es ineludiblemente ideologizado: una política exterior combinada con el regionalismo intergubernamental de baja institucionalización (González, 2011; citado en Sanahuja, 2012), que articula el enfoque westfaliano de Itamaraty y el portoalegrense del Partido Trabalhista, de corte nacionalista y autonomista (Gomes Saraiva, 2010).

Y, ya por fuera del realismo, existen quienes lo signan más cooperativo, y por tanto de corte multilateral y grociano:

La búsqueda de liderazgo no implica, en modo alguno, aspecto hobbesiano expansionista - militarista, pues esa hipótesis lo tornaría definitivamente inaceptable e impresentable dentro y fuera del país (...) se fundamentaría en la hegemonía suave y la emergencia pacífica (Domínguez Ávila, 2009:84).

No es el lugar de extendernos demasiado, pero señalemos sumariamente al grocianismo $^{212}$ como una perspectiva del funcionamiento de las relaciones internacionales en clave de sociedad de Estados (Del Arenal, 1994), contenidos en reglas e instituciones comunes. En este enfoque los intereses no están necesariamente en conflicto, sino que la lógica de funcionamiento indica un juego distributivo y productivo de las interacciones entre Estados. Su configuración se desencadena con el feudalismo (Bull, 2002), donde la red de sujeción y vasallaje determinaba obligaciones y deberes entre feudos descentralizados. La viabilidad del sistema residía en el cristianismo, un lenguaje cultural, un ethos sólido que asignaba a cada uno un rol,

\footnotetext{
${ }^{212}$ Denominación que recibe de Hugo Grocio, influido por escuelas del derecho natural y de gentes de Vitoria y Suárez en el siglo XVI y XVII.
} 
objetivos e intereses determinados, sin incertidumbre ni lugar a comportamientos estratégicos. El modelo grociano muestra un sistema de unidades autónomas articulado en una comunidad de valores, donde se implantan reglas en común (es el avance de la modernidad -la secularización, la diplomacia nacional- que da nacimiento al realismo). Es necesario aclarar que, la existencia de la compartición de valores no lo identifica con el utopismo, dado que el grocianismo no cree necesariamente en su eficacia: no sostiene que la mera instauración de principios provoque patrones de comportamiento diferentes, razón por la cual, tampoco enarbola los arreglos jurídicos (Del Arenal, 1994).

No obstante, lo anterior, hagámonos eco aquí de quienes señalan la posición brasileña como realismo (sin adjetivos que lo separen del paradigma clásico). Este cambio drástico en la política exterior vinculó a Da Silva con Rio Branco (Bernal-Meza, 2013), viendo el juego de poder combinado con la baja política (así se revivió el realismo en Brasil y en toda América Latina después de décadas, con un multilateralismo absorbido por la lógica del poder, por lo que el riobranquismo atávico recibió, y no haría problema en aceptarlo, una pátina grociana (ibídem) ${ }^{213}$ ).

Es inevitable articular este perfil brasileño con el Estado logístico, el post-desarrollismo interesado en superar las asimetrías y toda vulnerabilidad externa, procurando una acumulación de poder planteada en clave de reciprocidad y dispersión multipolar (por supuesto que con el fin de contrapesar la incidencia del hegemón hemisférico y

\footnotetext{
${ }^{213}$ Un multilateralismo -a la Nye- como medio, al que, por cierto, Brasil también pretendía reformar.
} 
global). El paradigma logístico implica la afirmación y promoción de la agenda multilateral en el sistema internacional junto con la autonomía en política exterior (Cervo y Bueno, 2002). También defiende una posición estratégica del Estado ante los desafíos de la globalización (Vergani, 2009), esbozado con Cardoso de manera algo ecléctica (por su apego al neoliberalismo), más consolidado con Da Silva. Operativamente, intentó disminuir la dependencia tecnológica y financiera, junto con una fuerte intervención sobre la desigualdad social (Cervo, 2008). Esto implica, obviamente, una coordinación entre el desarrollo interno y la acción estratégica de Brasil, que no puede alcanzarse si no se potencia su incidencia en el orden global (Bernal-Meza, 2013). Así, las herramientas para la construcción de poder extra fronteras (la cooperación internacional, las alianzas estratégicas, la integración regional), subsumidas en la dinámica logística, hicieron del Estado brasileño una plataforma de lanzamiento ante un medio globalmente interdependiente (donde Estados Unidos pierde estabilidad hegemónica unilateral). Nada de esto es menor, como señala Bernal-Meza, dado que llega a quitar a Brasil de la periferia atávica. Y deviene, así, un Estado en transición a poder codearse con los integrantes más poderosos del sistema internacional (el G20, la OMC, los BRICs y la política de foro desplegada).

Al adjetivar la política exterior de Da Silva como '(neo)realista', implícitamente se alude al paradigma tradicional y a su reelaboración waltziana, pero en ambos casos, esto no consigna necesariamente todas las categorías que implica y que cruzan el desempeño 
brasileño en este período. A la hora de caracterizar el (neo)realismo brasileño de la gestión da Silva, existen tres componentes que consideramos deben estar reflejados: la autonomía, la diplomacia presidencial y la autopercepción. Los primeros dos son usualmente citados, sólo que con diferente intensidad en los análisis. En cuanto al tercero, constituye una de las características que necesitamos para asentar de manera preponderante la EPGB. Más allá de su funcionalidad analítico-expositiva aquí, es necesario aclarar que esta tríada es constitutiva de la manera en que vemos el denominado (neo)realismo del Brasil de Da Silva. En otras palabras, creemos que no hablamos de cualquier perfil de acumulación de poder, sino que hablamos de uno que se proyecta desde la combinación de estos tres componentes. 


\section{Autonomía}

Al introducir la perspectiva autonomista en la política exterior del vecino luso parlante, no es preciso detenernos en una sesuda aclaración teórico-epistemológica. El autonomismo y el realismo gozan de una compatibilidad fluida ${ }^{214}$ :

La Doctrina de la Autonomía es una visión 'realista' de las Relaciones Internacionales (Bernal-Meza, 1989, 1994, 2005; Simonoff, 2012). Los conceptos y categorías usadas son los del realismo, donde la noción de juego de suma-cero en la política internacional implica disputa de poder (...) significa ampliar el margen de decisión propia (...) avanza el antiguo cliente; retrocede el antiguo dominante (Bernal-Meza, 2013: 49 [traducción propia] ${ }^{215}$ )

La autonomía, antónimo de dependencia, alude también a una cuestión de perspectiva: está asentada en la periferia, de la estructura de poder mundial: BernalMeza (ibídem) recupera a Simonoff al señalar que el planteo de Puig refería al desarrollo del Interés Nacional, objetivado racionalmente, en un marco de asimetría entre América Latina y Estados Unidos. Ese interés nacional, en manos de la élite a cargo del Estado-nación, debía acontecer en el espacio que la generación de márgenes

\footnotetext{
214 Incluso, puede tener consecuencias teórico-ideológicas, como menciona Schenoni (2015): la convergencia del desarrollismo con el realismo neoclásico podría derivar en una suerte versión progresista del realismo. Creemos que es un aspecto interesante para enriquecer el acervo del paradigma.

215 Del original: The Autonomy Doctrine is a "Realist" vision of International Relations (Bernal-Meza 1989, 1994, 2005; Simonoff 2012). The concepts and categories uses are those of realism, where the idea of zero-sum game in world politics is about power dispute.
} 
de maniobra le otorgase (Simonoff, 2012; en Bernal-Meza, 2013). Es interesante atender una síntesis de esta perspectiva a manos de Juan Carlos Puig (Bernal-Meza, 2013). Puig concebía la autonomía en un gradiente, un continuum, que recorría desde la subordinación -indeseable- hasta la plena autonomía, típica del sistema internacional integrado por individuos soberanos. La subordinación disminuye los grados de libertad de manera inversa al de los de la potencia dominante (si bien no toda imposición necesariamente es injusta, la práctica demuestra que la mayoría de las veces la justicia está ausente para el subordinado (Puig 1986: 40 en ibídem)). En menos palabras, la autonomía implica la máxima capacidad de decisión propia que se puede lograr, teniendo en cuenta los condicionamientos objetivos del mundo real (Bologna, 1989: 293 en Bernal-Meza, 2013: 50).

Es por esto que es necesario destacar dos aspectos de la concepción de Puig: por un lado, la práctica autonomista a partir de una comprensión de la realidad internacional, en este caso, optar por la mayor capacidad de acción en el sistema; y por el otro lado, la relación entre viabilidad, autonomía e integración. Esto último no es otra cosa que la relación entre recursos y el convencimiento de la elite de avanzar hacia la autonomía, y desde allí hacia la integración. Alcanzarla, instaura una entidad basada en un destino solidario de valores comunes ostentables ante el sistema internacional (que no necesariamente tienen que ser los de éste (ibídem), y lo más probable es que no lo sean). 
Para Actis (2014), la autonomía es el aspecto de continuidad de la política exterior brasileña más destacable entre la administración Da Silva y las predecesoras. Decidir en base a necesidades y objetivos propios sin limitaciones externas (Russell y Tokatlian, 2013), ha sido un objetivo que incluso imperó durante las dos décadas de dictadura militar:

El imperativo del desarrollo económico, la búsqueda de la paz, la extensión del alcance geográfico de las relaciones exteriores, la restricción del poder de las grandes potencias -particularmente de Estados Unidos-, así como la construcción de un orden internacional más equitativo han sido aspectos presentes en el histórico accionar externo de Brasil. Ahora bien, las estrategias de Brasil para obtener una mayor libertad de maniobra en el sistema internacional han ido cambiando en las últimas décadas (Actis, 2014: 198 y 199$)$.

Desde el 2003 la autonomía adopta otra topología, por así decirlo: Vigevani y Cepaluni (2007) Ilamaron 'autonomía por diversificación' a la desagregación de opciones estratégicas, diversificando las alianzas. La dinámica no implica necesariamente resistir al avance de los regímenes internacionales por medio de la afirmación soberana y el fortalecimiento endógeno de mercados interno, sino que es, en realidad, proclive a los regímenes internacionales, y asume la posibilidad de influenciar sus principios y normas. Así, las alianzas con otros países en desarrollo pretenden cambiar la asimetría con el mundo desarrollado (Actis, 2014), evitando todo alineamiento con hegemones (de cualquier alcance). Para el caso de la administración Da Silva, esto implicó las alianzas Sur-Sur, las regionales, los acuerdos con aliados no tradicionales como Asia Pacífico, África, Europa Oriental, China. Esto materializa el principio universalista de la política exterior brasileña, en tanto que voluntad de mantener relaciones con todos los 
países, allende su posición geográfica, régimen político-económico y relación a los poderes globales (Gomes Saraiva, 2011: 54, en Actis, 2014).

El fin es constante: aumentar la capacidad negociadora con los poderosos (Vigevani y Capulini, 2007). Pero la lógica, no parece tan colectiva, o al menos, no implica la formulación de un conjunto de países que juntos pujaran posiciones. Antes, por el contrario, Brasil debería ser, entre ellos, su líder:

La administración Lula Da Silva colocó sin mostrarlo, el tema en el debate político brasileño. El deseo de obtener un papel destacado en la región y entre los países en desarrollo fue introducido, $y$, en parte se constató el costo que Brasil afrontó de parte de los países sudamericanos (Vigevani y Capulini, 2007: 324 [traducción propia]) $)^{216}$

Esto maridó con un cambio de percepción de la opinión pública, que comenzó a ver un Brasil con una proyección global ya no reducida a lo económico, sino a una inserción sociopolítica digna de global player (Actis, 2014).

\footnotetext{
${ }^{216}$ Del original: A administração Lula da Silva colocou não ostensivamente o tema no debate político brasileiro. $O$ desejo de obter um papel de destaque na região e entre os países em desenvolvimento foi introduzido e, em parte, tem se constatado uma maior cobrança por parte dos países sul-americanos em relação ao Brasil.
} 


\section{Diplomacia presidencial}

Es bueno comenzar afirmando que la diplomacia presidencial no reviste un factor demasiado novedoso para la RFdB: iniciada con Cardoso, Da Silva sólo tomó la posta. Aunque antes precisemos algunas cuestiones, para luego retomar esta cuestión.

Como señala Sérgio Danese (1999), la diplomacia presidencial alcanza la:

Conducción personal de asuntos de política exterior, además de las competencias o atribuciones de oficio, por parte de la presidencia o, en el caso de un régimen parlamentarista, por el jefe de estado y/o por el primer ministro (Danese, 1999: 51 [traducción propia] ${ }^{217}$ )

La noción de 'conducción' puede resultar ambigua, tal vez vaga. En realidad, hemos intentado respetar la traducción, sin evitarnos problemas, para que la literalidad nos permita hacer esta aclaración: Danese refiere a lo que en la gestión pública (doméstica) se define como responsabilización, una solución de compromiso para traducir la voz anglosajona accountability, sin equivalente castizo ${ }^{218}$. Para el autor, el fenómeno de la diplomacia presidencial acontece cuando el poder ejecutivo nacional

\footnotetext{
${ }^{217}$ Del original: Condução pessoal de assuntos de política externa, fora da mera rotina ou das atribuições ex officio, pelo presidente, ou, no caso de um regime parlamentarista, pelo chefe de estado e/ou pelo chefe de governo.

${ }^{218}$ Alude, en concreto, al deber de las administraciones públicas de rendir cuentas ante la ciudadanía, basado en el derecho que ésta goza de controlar la acción de los gobiernos (Cf. CLAD (2000). La Responsabilización ("accountability") en la Nueva Gestión Pública Latinoamericana. Caracas, Venezuela: Centro Latinoamericano de Administración para el Desarrollo.)
} 
se involucra directa e intensamente en el proceso decisorio, allende los límites de lo habitual, sin descartar un uso por fuera de su objetivo, como es la promoción interna del mandato. Andrés Malamud agrega el mecanismo de la negociación directa como el recurso en el que es ineludible una interlocución a cargo del/la mandatario/a. Esto acerca su oficio a la diplomacia de cumbre ${ }^{219}$-alejando el dispositivo del estamento profesional/burocrático-, y permite poner en juego cuestiones domésticas (como también -creemos- puede hacer más permeable la política exterior a la opinión pública). Claro que también la posibilitan cualidades de diseño institucional: el presidencialismo contribuye a su ejercicio (ibídem), por lo que cuando le sumamos la diplomacia presidencial obtenemos el interpresidencialismo (Malamud, 2005), un dispositivo que involucra negociaciones directas entre poderes ejecutivos nacionales a la hora de tomar decisiones críticas o solucionar conflictos. Esta cuestión resulta imprescindible de recuperar, dado que el Mercosur es, desde su inicio, un esquema power-oriented en lugar de rule-oriented (Malamud y Rodríguez, 2013: 117). De hecho, en otro trabajo (2010), el mismo autor relaciona la proyección del perfil institucional todos los miembros del bloque son presidentes-, con el magrísimo desarrollo institucional regional.

Vale mencionar que cualquier alejamiento de la diplomacia tradicional implica, en países presidencialistas, cierto grado de presidencialidad en el ejercicio diplomático, y

\footnotetext{
219 Jarque et al (2009) señalan que este dispositivo diplomático ha tenido un importante desarrollo en la región a partir de los setentas del siglo pasado desarrollando mecanismos de cooperación vinculados a la integración (por nombrar algunas: la Cumbre de las Américas, Iberoamericana, la Cumbre América Latina y el Caribe - UE, la del Grupo de Río y la Cumbre del APEC). Sin duda que nada novedosas, ya que bajo la configuración westfaliana encontramos la de Viena de 1815, las de postguerra decimonónicas, las de las conflagraciones mundiales y, por supuesto, aquellas bajo la esfera de la ONU.
} 
el aspecto crítico no reside ya en la participación del jefe de Estado, sino en las expectativas que su ejercicio críe, en la presión política y en la visibilidad que otorgue con su actividad (Danese, 1999). Pero no por esto toda actividad presidencial acarrea una diplomacia de su tipo: existen competencias protocolares (usualmente establecidas por ley) que imperan sobre el cargo, por lo que el Poder Ejecutivo tendrá que cumplirlas sin excepción. Sin mencionar que, allende ésas competencias, la actividad presidencial en asuntos de política exterior -especialmente a la hora de interactuar con otros mandatarios- estuvieron siempre presentes en la diplomacia tradicional: el relacionamiento entre Estados precisa de este acto de alto contenido simbólico $^{220}$, por fuera de toda obligación formal. De este modo, es momento de introducir un aspecto propio -y nada menor- de la diplomacia presidencial: ella reacciona e informa a la opinión pública. Como menciona Falcão Preto (2006), lo hará al intentar cooptar sus fines, impresionar o dialogar con ella con algún propósito. La autora asevera que incluso, algunas decisiones son tomadas exclusivamente en función de la opinión pública, aspecto que fisura de manera brutal la interioridad de la política exterior que abordamos en boca de Kennan y Kissinger más arriba ${ }^{221}$.

Acorde Barnabé (2012), esta diplomacia es un emergente de las complejas -y asimétricas- relaciones de interdependencia del mundo desde hace unos cuarenta

\footnotetext{
${ }^{220}$ Nos referimos, en concreto, a todo el universo de prácticas protocolares insertas en el ceremonial público de una Primera Magistratura.

${ }^{221}$ No por esto podemos omitir las posiciones divergentes con respecto a su potencialidad explicativa: Guilhon Albuquerque (1996) desconfía del concepto de diplomacia presidencial, asegurando que, si pensamos en un Poder Ejecutivo actuando de manera activa en las relaciones internacionales por medio de foros, negociaciones o declaraciones, el concepto resulta poco prolífico, porque agregaría poco a la comprensión de un rol que las y los Primeros Mandatarios ejercen como parte de su investidura.
} 
años ha, junto con la multipolaridad cambiante posterior a la Guerra Fría, la conformación de las 'G' (G-4, G-20, etc.) y la búsqueda de soluciones conjuntas a problemas globales o regionales. Todo esto facilita el surgimiento de la diplomacia de cúpula, por lo que los presidentes adquieren protagonismo eclipsando incluso a las cancillerías (reducidas a roles más acotados).

Aquí sostenemos que cualquiera fuese el juicio sobre el concepto, si acordamos que existe una porción de la diplomacia que excede a la que acontece en la de cúpula y aún recae en la figura presidencial, tenemos que tener en cuenta algunas cuestiones: por un lado, arrastra a la agenda internacional a centrarse en la figura del Ejecutivo. Y, por otro lado, exige una labor más en la Primera Magistratura, que resta tiempo para su dedicación a cuestiones domésticas (pensemos tan sólo en las consecuencias derivadas de tomar en primera persona esta función: el tiempo asignado a viajes, el costo de los mismos, etcétera).

En cuanto a la práctica brasileña, como decíamos más arriba, no es Da Silva quien inaugura esta etapa de hiperactividad diplomática presidencial, sino su predecesor (y, de hecho, fue una impronta típica de Rio Branco al inicio del siglo pasado (Barnabé, 2012)). Cardoso, intelectual reconocido extra fronteras, tomó en sus manos la conducción del devenir externo del país y:

El gobierno de Fernando Henrique Cardoso fue una gran e inédita muestra de la diplomacia presidencia en Brasil [...] fue una combinación exitosa de, por un lado, un mayor poder nacional de país, gracias a la estabilización y a los atractivos representados por sus dimensiones económicas, incluyendo su 
participación en el Mercosur y por la apertura de su economía; y, por otro lado, la vocación y disposición personal del Presidente para protagonizar una diplomacia presidencial del estilo consagrado en la actualidad por los mejores liderazgos mundiales (Danese, 1999b: 9 [traducción propia] ${ }^{222}$ )

En el caso de Da Silva, el dinamismo es llevado a un mayor nivel (Barnabé, 2012). Si bien el término 'diplomacia presidencial' no es aludido por el Presidente o su equipo posiblemente para diferenciarse de su predecesor-, el mentado activismo diplomático implica un carácter dinámico y multipresencial [sic] de Da Silva (ibídem). De hecho él decidió, en primera persona, hacer de la política exterior un asunto de su gestión política en sentido amplio -es decir, a imbricar deliberadamente aquella con la política doméstica-: Podemos afirmarlo sin temor a partir de la articulación de idénticos objetivos domésticos y globales, como el desarrollo o la equidad social nacional duplicados en su promoción extra-frontera (Marcondes de Souza Neto, 2012) ${ }^{223}$.

Pasemos ahora, pues, al tercer componente de (neo)realismo brasileño.

\footnotetext{
222 Del original: O governo Fernando Henrique Cardoso colocou em grande e inédita evidência a diplomacia presidencial no Brasil [...] foi a combinação feliz de, por um lado, um maior poder nacional do país, graças à estabilização e aos atrativos representados pelas suas dimensões econômicas, incluindo sua participação no Mercosul e pela abertura de sua economia; e, de outro, a vocação e a disposição pessoais do Presidente para protagonizar uma diplomacia presidencial no estilo hoje consagrado pelas melhores lideranças mundiais.

${ }^{223}$ A esto debemos sumar la actividad menos visible, más especializada: Da Silva también compartió con Itamaraty la formulación y la ejecución de la política exterior con sus asesores presidenciales directos (ibídem)
} 


\section{Autopercepción}

Creemos que, en perfil de la política exterior de Da Silva, la cuestión de la autopercepción de Brasil, es una un aspecto determinante:

La forma en que los hacedores de política perciben al mundo y el lugar y rol de su país en el mundo (autopercepción) son importantes a la hora de entender algunas conductas del Estado en materia de política exterior (Actis, 2014: 199, nota al pie)

La cosmovisión condiciona -y da cuenta de- unas creencias activas en el diseño de la política exterior. Cuando las creencias versan sobre el titular y no aquello que le rodea, es decir, su autopercepción, se suma un componente inmaterial al análisis del comportamiento de un Estado en el medio internacional. Antes de presumir un viso constructivista en esta afirmación, es necesario destacar que, si bien este componente teórico puede no parecer a primera vista compatible con lo que hasta ahora hemos denominado (neo)realismo, la razón de esto es que encontramos muchas coincidencias con la perspectiva waltziana (aspecto que tal vez se denote más adelante en este análisis). Pero, asimismo, dentro de éste encontramos el denominado realismo neoclásico, donde también las capacidades repartidas en el sistema internacional son determinantes en las políticas exteriores, pero ellas no prescinden de percepciones, capacidades y la operatividad doméstica (Mijares, 2015). 
El neorrealismo se preocupó por desembarazarse de la intuición, de la fuente histórica y de los análisis basados en el criterio del autor para abrazar el método científico cualicuantitativo que aportó la impronta behaviorista de los sesentas del siglo pasado. Esta ganancia para el paradigma más sólido de las relaciones internacionales, dejó de lado la impronta tradicional (apegada al análisis histórico-intuitivo) mientras se presenciaba el impulso de otros paradigmas de creciente importancia a partir de los ochentas. Con la vertiente neoclásica, reingresa al herramental analítico realista aspectos que suelen ser asociados al constructivismo como la psicología, la antropología y otras perspectivas cualitativas (ibídem). Creemos que este tipo de inclusiones van abriendo, cada vez más, la rigidez que se le achaca al paradigma, y esto deconstruye, echa luz a la black box estatal neorrealista.

Pensemos, ahora, el aspecto de la autopercepción para nuestro caso. Si recuperamos la consideración de Amorim (2016) al considerar que la posesión de recursos naturales, energéticos y la capacidad de producción de alimentos coloca a su país como poseedor de un inestimable patrimonio de valor estratégico. Un valor al que debe defender (ibídem), y, al igual que la política exterior, una defensa que no es delegable. La política externa, a su vez, está asociada a la provisión de bienes públicos -por vía de la paz mundial-, lo que compele a Brasil a no permitirse ser mero espectador al sistema internacional, allende las distancias geográficas que lo separen de los poderes centrales (Albuquerque, 2005). Apela a Maquiavelo, para hacer de los problemas del mundo una materia que Brasil no debería ignorar: 
Pienso, aquí, en la advertencia de Maquiavelo, que dijo en sus discursos: Los otros poderosos, que están distantes y no tiene relaciones con aquéllos, cuidarán del asunto como algo lejano, que no los afecta. Error en el que se mantienen hasta que el incendio se les aproxima, y cuando llega, no hay más remedio que apagarlo con las propias fuerzas, que ya no alcanzan, dado que aquél se tornó poderosísimo (Amorim, 2016: 79 [traducción propia] ${ }^{224}$ )

Esta afirmación que Amorim coloca en el orden global interpelando a Brasil, alcanza a la política de defensa nacional. Asegura que, para instrumentarla, Brasil apela a la disuasión y la cooperación: la primera pretende minimizar el riesgo de hostilidades de adversarios eventuales (mientras asegura que Brasil no tiene enemigos), ante una posible injerencia por recursos $u$ otro atentado a sus intereses. Retomaremos esta cuestión en el próximo apartado.

El (neo)realismo brasileño ha sido señalado por Actis (2014) como el factor de discontinuidad en su política exterior (donde la continuidad residió, impertérrita, en la búsqueda de autonomía). Dado que a través de Amorim nos hicimos eco de lo que es, en realidad, una combinación de la lectura del medio internacional con la autopercepción de Brasil sobre su coyuntura, el análisis de Actis, al echar mano del realismo neoclásico nos ha resultado notablemente adecuado. Si tomamos la autopercepción y la cosmovisión de los hacedores de política exterior como la variable interviniente de ingreso de la dimensión sistémica a la unidad, y pensamos en el

\footnotetext{
224 Del original: Penso, aqui, na advertência feita por Maquiavel, que dizia em seus discursos: Os outros poderosos, que estão distantes e não têm relações com eles, cuidarão da coisa como de algo longínquo, que não Ihes diz respeito. Erro em que laboram até que o incêndio se aproxime deles; e, quando este chega, não há remédio senão apagá-lo com suas próprias forças, que já não bastam, visto que aquele se tornou poderosíssimo.
} 
cambio producido por la llegada de Da Silva en 2003 -en un mundo donde afloran las multipolaridades ${ }^{225}$-, el presupuesto de que el orden internacional dista del consenso (como lo fue para el perfil multilateral de Cardoso) se encarnó en el pensamiento del equipo de gobierno y el propio Poder Ejecutivo (ibídem). De aquí a una política de acumulación de poder nada restaba para poner en práctica su perspectiva de la política global.

La lógica de la correlación de fuerza que impone el poder, involucró a la gestión en la búsqueda de grietas que permitieran ingresar a Brasil en el globo a pesar de la imposición de sus intereses nacionales de los poderosos (Marcondes de Souza Neto, 2015). Claro que el multilateralismo también fue un pilar de la gestión que inicia en 2003 -a los fines de sus diferentes concepciones del funcionamiento del globo, carente de principismo-y se lo subordinó al objetivo del cambio de relación de fuerzas vigente. Esta es la raíz de la reciprocidad que mencionamos más arriba en boca de Da Silva para el libre-comercio (su apuesta a una economía capitalista, sólo que de acuerdos igualitarios), que no expresa otra cosa que la búsqueda de reciprocidad en las relaciones interdependientes de la baja política (Cervo, 2008).

En este sentido, la mentada democratización de las relaciones internacionales, multipolar, poseía una característica nada menor, y tal vez destacable: contacto y conciencia de las capacidades. Este realismo -que no hace del poder un aspecto

\footnotetext{
${ }^{225}$ Es decir, el tránsito a un nuevo equilibrio con nuevas potencias (Schenoni, 2015).
} 
normativo y mantiene contacto con la circunstancia estructural de Brasil-, fue invocado por Da Silva en unas palabras inaugurales por $2005^{226}$ :

Brasil es un país con problemas sociales y sin medios importantes de proyección de poder militar en el plano internacional, entonces no podría aspirar a ser globalmente un actor pleno. (...) Es evidente que riqueza y fuerza militar son expresiones de poder. Ellas no agotan, en tanto, la capacidad de acción e influencia que puede disponer un país [...] nuestro desafío es intentar entender cómo Brasil puede colaborar para la construcción de una nueva relación de fuerzas en la esfera internacional (Actis, 2014: 203)

Creemos que esta posición de Da Silva padecía de una contradicción interna: mientras era consciente de las menores capacidades del país, a la hora de proyectarse en el medio internacional, parecía olvidar esta diferencia. Esto decantó en un sesgo optimista (que podríamos verlo en la pretensión de la altivez) que Brasil veía plausible poder ejercer, sólo sustentado en el interés de jugar un rol, sin dar cuenta de las posibilidades que el sistema le deje implementar:

En enero de 2003 cuando volvía de Davos le dije a Celso Amorim (...) Celso, nosotros estamos en condiciones de cambiar la geopolítica comercial y la política mundial (ibídem: 205)

Como menciona Actis, Brasil no modificó sus capacidades de poder, lo que sin duda varió, fue su autopercepción. Y agregamos: no es en la grandeza del país donde varió aquella -otros mandatarios han conocido las potencialidades de Brasil, por cierto, bastante evidentes-, sino que la variación estuvo, en concreto, en su pretensión de

\footnotetext{
${ }^{226}$ Este discurso lo recupera el autor de un seminario llamado 'Brasil, Actor Global' realizado en París, hacia el 13 de julio de 2005.
} 
capacidad, basada en su autopercepción. El quid de la cuestión reside en este aspecto crítico que el país (se) arrogue a partir de esa percepción, y el grado de ajuste que ella tengan con el diagnóstico del sistema (a lo que habría que sumar la incidencia presidencial en las decisiones -que no por ello desplaza ciento por cien a Itamaraty ${ }^{227}$. ).

En pocas palabras, creemos existe un punto de fuga de la autopercepción. El de los deseos versus la realidad, que no es otro que los objetivos y la plausibilidad de ellos. Por definición, el Estado que comete este error en la estimación de las capacidades, allende las aspiraciones, el coto aparecerá a la hora de no poder concretarlas: el caso de la pretensión brasileña de alcanzar el Consejo de Seguridad, para lo que debería contar con apoyos regionales -obtenidos por vía de la hegemonía o la construcción de algún tipo de liderazgo regional-, ilustra el desacople entre los objetivos de Brasil y sus capacidades para desplegar y concretar las estrategias que lo acercan a él.

Este no es el único problema que acarreó el mentado (neo)realismo brasileño: Schenoni (2015) asegura con tino, invocando el criterio de Waltz de la primacía de los incentivos sistémicos a favor de un equilibrio, que los movimientos de Brasil darían lugar a un nuevo equilibrio multipolar. Ello implica, de suyo, grandes desequilibrios en los niveles sub-sistémicos/regionales. Por eso creemos que es atinado volver, una vez

\footnotetext{
227 Hemos mencionado más arriba la particularidad de la política exterior de Da Silva con la incorporación de actores no tradicionales como las coaliciones de interés domésticas, sindicales y los movimientos sociales. Sólo que este componente no tradicional no jugó el rol de un tercer actor de la política exterior a la par de los dos primeros. Sólo pudieron tener una injerencia mediata, a través de la posición portoalegrense de la hechura de la política exterior (Malamud y Rodríguez, 2013).
} 
más, sobre la consistencia interna del perfil de acumulación de poder de la política exterior brasileña en la era Da Silva: si su interés hacia el globo no podía prescindir de la dimensión regional, resulta difícil ver la viabilidad de este fin (la emergencia global), si para alcanzarlo desordena el medio (la dimensión sub-sistémica). En otras palabras, puede ser desde complicado hasta imposible, llegar a una meta si para ello es necesario alterar la configuración del camino a ella.

Antes de abandonar este tercero componente, es precisa una aclaración con múltiples implicancias en estas líneas: hemos abordado aquí, la importancia de la autopercepción en la conformación de objetivos de política exterior. Para eso nos valimos del realismo neoclásico, en aras de la consistencia del camino recorrido en este paradigma en estas líneas. Pero la ruta analítica requiere, por supuesto, construir una determinada autopercepción para la gestión Da Silva. Creemos que ella es rastreable con mucha facilidad en los discursos del Poder Ejecutivo, en la producción teórica de cancilleres y especialistas relacionados con Itamaraty, junto con la pátina que imprime la extracción petista. También creemos, que esta es una suerte de 'primera capa' de la construcción de esa autopercepción, es decir, la que trasparece en esos dispositivos discursivos políticos y coyunturales del período, a manos de los mismos hacedores de la política exterior, o bien de analistas versados en el tema. Sólo para mostrar ejemplos: para la justificación del accionar de Brasil basado en atributos clásicos de poder -territorio, población, estructura económica-, encontramos el trabajo de 2006 de Souto Maior que recuperamos en la introducción: 
Es normal que un país de las dimensiones territoriales, demográficas y económicas de Brasil aspire a tener, en el escenario internacional, un papel más destacado de aquél que ha asumido hasta ahora. En este sentido, es aún más natural que, por su peso relativo, se perciba en cualidad de primus inter pares en América del Sur (página 57 [traducción propia] ${ }^{228}$ )

Vale remarcar que la autopercepción es meramente descriptiva. En el caso de Da Silva, ha sido lo suficientemente altiva como para no dar cuenta de su tendón de Aquiles (las capacidades estatales), pero puede, sin duda, ser también motivo de limitación, si informa a los hacedores de política exterior que el Estado se encuentra fuera de posibilidades para tomar ciertas decisiones o asumir algún/nos rol/es:

\begin{abstract}
Itamaraty, consciente de las debilidades que el país aún posee, evita adoptar prácticas regionales que permitan a las potencias grandes actuar de la misma forma con él. Tal vez en este punto reside la explicación para la paradoja de un país que aspira a ejercer el liderazgo subregional, pero renuncia a comportarse como líder: la consciencia de las debilidades sociales, de un país gigantesco. Una debilidad estructural que, desde la época de la esclavitud, limita nuestra inserción internacional. Este es el elemento oculto que fundamenta la noción de soberanía y no-intervención manifestada por Río Branco, San Tiago Dantas y Araujo Castro, y que aún posee gran apoyo en el Estado y la sociedad brasileña (Vizentini, 2001: 65 y 66 [traducción propia] ${ }^{229}$ )
\end{abstract}

\footnotetext{
${ }^{228}$ Del original: É normal que um país com as dimensões territorial, demográfica e econômica alcançadas pelo Brasil aspire a ter, na cena internacional, um papel mais marcante do que aquele que lhe tem cabido até agora. Dentro da mesma ordem de ideias, é ainda mais natural que, pelo seu peso relativo, se percebe na posição de primus inter pares na América do Sul.

${ }^{229}$ Del original: Itamaraty, consciente das debilidades que o país ainda possui, evita adotar práticas na região que possibilitem às grandes potências agir da mesma forma contra ele. Talvez neste ponto resida a explicação para o paradoxo de um país que aspira à liderança sub-regional, mas recusa-se a comportar como líder: a consciência das debilidades sociais, de um país gigantesco. Uma debilidade estrutural que, desde a escravidão, limita nossa inserção internacional. Este é o elemento oculto que fundamenta a noção de soberania e não intervenção explicitada por Rio Branco, San Tiago Dantas e Araújo Castro, e que ainda possui forte apoio no Estado e na sociedade brasileiras.
} 
Pero que, en cualquier caso, arroja a Brasil a un determinado curso de acción, para el que asume apto. Escogemos una acción al azar:

\begin{abstract}
Para demostrar de modo evidente que se trataba de una demanda seria y justificada, era necesario probar, concretamente, que el país estaba decidido a asumir alguna responsabilidad en la mantención del orden internacional. Brasil asume la conducción de la Fuerza de Paz multinacional en Haití (MINUSTAH) [...]. Las tropas brasileñas tienen una tradición de participación en las misiones de paz de la ONU, pero nunca con esta relevancia y responsabilidad (Valladão, 2009: 183 [traducción propia] ${ }^{230}$ )
\end{abstract}

El punto determinante aquí reside, a nuestro juicio, en que a través de estos dispositivos discursivos políticos no se completa la construcción de la autopercepción que informa la política exterior en un momento dado. Es, como dijimos más arriba, solamente la primera capa. Y por lo tanto debe ser sustentada en análisis más profundos, munidos de disciplinas y estudios externos a las relaciones internacionales. Una vez construidas esas percepciones (el plural no es casual) imbricadas, es necesario volver a 'encajarlas' en los parámetros del realismo neoclásico con el fin de no responder a otras perspectivas (como el constructivismo). Esta labor, onerosa a estas páginas -ahonda el análisis en un aspecto de uno de los componentes y puede, por el celo de avanzar en esa dirección granular, dispersar el punto de atención de aquél-,

\footnotetext{
${ }^{230}$ Del original: Para demonstrar de modo patente que se tratava de uma demanda séria e justificada, era necessário provar, concretamente, que o país estava decidido a arcar com alguma responsabilidade na manutenção da ordem internacional. O Brasil assumiu, portanto, o comando da força de paz multinacional no Haiti (MINUSTAH) (...). As tropas brasileiras têm uma tradição de participação nas missões de paz da ONU, mas nunca em igual posição de relevo e responsabilidade.
} 
creemos debe ser tenida en cuenta a la hora de incorporar este componente en desarrollos ulteriores.

Por último, un agregado más: En este tramo de nuestro desarrollo ya tendremos que dejar de referirnos a la posición brasileña durante la gestión Da Silva como meramente '(neo)realista'. La razón reside en que en lo tocante presentaremos el perfil de política exterior brasileña de nuestro período en clave de acumulación de poder (en los términos que en la primera parte denominamos power politics). Habiendo construido lo que entendemos por realismo brasileño a través de estos tres últimos componentes, ahora debemos ponerlo en juego, es decir, cotejar de manera dinámica en que ese realismo actúa, y eso será la estrategia de acumulación de poder del año 2003 al 2010, a lo que nos dedicaremos en el próximo apartado.

Por último, dadas las limitaciones de espacio, al presentar la Estrategia de Poder Global Brasileña -una construcción analítica de un proceso macro estratégico externo que tiene diversos componentes de enorme complejidad y magnitud-, sólo nos abocaremos al que es pertinente a estas líneas, la integración regional suramericana. 
"Los teóricos académicos apuntan a la comprensión; los políticos prácticos deben elegir cursos de acción. Los primeros intentan prescindir de los acontecimientos de todos los días, los segundos no pueden" Manfred Wilhelmy, 1988

"Los modelos para el estudio de los problemas mundiales de los últimos siglos que no le otorguen el papel principal al estado-nación son tan deficientes como un análisis de Hamlet que no tome en cuenta al protagonista y sus motivaciones» Ole Holsti, 1989

Es preciso plantear la manera en que Brasil ha desplegado esa acumulación de poder de manera dinámica a lo largo de todo el período. Dado que los fines de estas páginas están acotadas por una hipótesis, aquí sólo planteamos la generalidad de ese despliegue, para luego abocarnos al caso del Mercosur exclusivamente.

Así, pues, denominaremos Estrategia de Poder Global Brasileña (EPGB) a la decisión política $^{231}$ de la administración Da Silva de construir una política exterior de acumulación de poder signada por la power politics, con el fin de recolocar el rol y la posición de Brasil en la estratificación global.

231 Con la expresión decisión política a la capacidad de cualquier gestión de gobierno de decidir la dirección y los componentes de la política exterior. No estamos refiriendo -y lo remarcamos al máximoa la denominación 'ideológica' de la política exterior de la gestión Da Silva (como más arriba mencionamos) y asociada a la impronta del PT -su historial político-, o a la impronta portoalegrense en Itamaraty. Aquí sólo referimos a esa decisión legítima de avanzar hacia un norte (informado por componentes ideológicos, también, pero) que expresa el interés nacional, con o sin continuidades con las precedentes. 
Esa acumulación, identificada con el interés nacional por vía de la autopercepción, implicó el despliegue de una ingeniería de autonomía diversificada (Vigevani y Cepaluni, 2007) de fuerte impronta presidencial, anclada en atributos de poder clásicos (esto es, el territorio, población y la solidez de la economía, tal como lo plantean Soares de Lima y Hirst (2006)).

La EPGB se sustenta en dos aspectos:

1) el estructural, en el que Brasil instrumenta un atributo clásico -el territoriocombinado con el poder ${ }^{232}$, posado sobre actores de magra incidencia individual, que serán aunados en la esfera de influencia brasileña con el fin de obtener réditos capitalizando la sumatoria de esa incidencia en su lógica de acumulación.

- Con un componente acotado, en la dimensión regional y sub-hemisférica México hacia el sur-, representado por: a) el despliegue regional preexistente el Mercosur-, la esfera de influencia directa brasileña que permite ampliar su ya generoso territorio a los bordes del bloque (lo que pone énfasis en el componente territorial por sobre el poder, pero éste, también, se ve impactado por la autopercepción brasileña de su tamaño relativo, lo que implica una mayor ostentación de poder. En menos palabras: el Mercosur constituye los límites territoriales de influencia directa de $B^{2}{ }^{233}$. Y b) el regionalismo

\footnotetext{
232 Aquí tampoco está ajeno el componente de autopercepción: recordemos la afirmación de Souto Maior (2006: 51) que recuperamos en la introducción, acerca de la naturalidad de que Brasil se proyecte al mundo.

${ }^{233}$ Esto no quiere decir que haya contribuido al impulso y sostenimiento de la manera que el bloque precisaba para crecer a lo largo de casi una década.
} 
brasileño (Bernal-Meza, 2010), donde la UNASUR es el ejemplo por antonomasia. Aquí el poder es un componente preponderante al territorio (fuerte inversión en el componente político-estratégico, bajísima institucionalidad, fortalecimiento de las relaciones en la región, clara toma de posición por la autonomía hacia el exterior de la región y gran injerencia de actores brasileños con miras estratégicas regionales (Sanahuja, 2012)). Al igual que en el Mercosur, el componente relegado no está ausente: ese poder extiende la influencia y por lo tanto, resulta tan fuerte como lo es de extenso su territorio. En menos palabras: la UNASUR inflama las ostentaciones de poder brasileñas al exterior de la región. $Y$, de hecho, condensa la estrategia de poder brasileña con mayor completitud y de manera más fiel que el Mercosur: constituyen el verdadero eje, el verdadero espacio intermedio, la explanada entre el Brasil ampliado (Brasil + Mercosur) y el globo ${ }^{234}$.

- Con otro componente extendido, un tendido de relaciones y redes en territorios no contiguos, representado por el tendido de relaciones y alianzas de diferente tipo alrededor del globo -como el G20, BRIC, IBSA-, la cooperación internacional, ayuda humanitaria y mediación para la paz.

2) el focal, anclado en diferentes ecosistemas de centros de poder mundial OMC, ONU y otros foros, relación bilateral con Estados Unidos- en los que desplegó una estrategia de participación e involucramiento activo -acorde sus

\footnotetext{
${ }^{234}$ La UNASUR pone en evidencia la Estrategia de Poder Global Brasileña, su cordón vital (Mercosur) y su espacio de ostentación (UNASUR), que no concluía en la conformación del bloque, sino que también precisaba del tendido estratégico que representaba la IIRSA, junto con otros aspectos infraestructurales, financieros y de defensa en los que Brasil estuvo dedicado la década pasada.
} 
capacidades-, en un juego de baja política -comercio y misiones de diferente cualidad $^{235}$

Ambos aspectos, además de concomitantes, están imbricados: el aspecto estructural implica la condición previa y sustento que Brasil considera preciso para legitimar su acción focalizada ${ }^{236}$. Y los rendimientos de su labor focalizada deberían tornarse un retorno en términos de poder ( $\mathrm{y}$ eventual legitimidad) para que ese aspecto estructural le permite ejercer el rol de hegemón (y eventual líder) en los diferentes escenarios estructurales.

Lo anterior precisa de una aclaración acerca de la perspectiva que tomamos a la hora de la construcción de la EPGB. Estamos posicionados según el titular, esto es, desde Brasil hacia el mundo (una lectura que quedaría por completo trastocada si pensamos esta misma estrategia desde la perspectiva de Argentina, desde la de Estados Unidos o desde la de un aliado estratégico en el Sur). Ello implica una consecuencia analítica que puede resultar obvia, pero preferimos remarcar aun a costo de agotar: la EPGB es una carrera de acumulación de poder nacional hacia el globo porque implica la acumulación de poder inserta en la política exterior de un país en un momento dado del tiempo ${ }^{237}$. Y, si es así, sus componentes están imbuidos de esa acumulación en

\footnotetext{
${ }^{235}$ En los términos que Russell y Tokatlian (2013) se refieren al soft balancing. Es decir, la utilización de las instituciones internacionales, instrumentos legales y diplomáticos para contener el poder de las potencias mientras se afirman el/los intereses/es propios.

${ }^{236}$ Con esto nos referimos a su concepción clásica de los atributos del poder (especialmente el territorial). Líneas más adelante volveremos sobre esto.

${ }^{237}$ Por esto mismo, la EPGB no reproduce ni es sinónimo de la política exterior brasileña en ese período, sino que pretende reconstruir la dinámica más general de la acumulación de poder que la atravesó. No
} 
términos egoístas: la concepción de las alianzas estratégicas se desembaraza de todo utopismo y aspiración de acción conjunta, lo regímenes sólo se instrumentan para hacer previsible el medio externo, la integración sólo sirve como medio de provisión de un bien público u obtención de alguna ventaja -como la de índole territorial-, pero no hay viso de otra lógica que no sea la del interés nacional. Queremos exponer aquí un Brasil que pone sobre la mesa una serie de herramientas y estrategias para engrandecer su rol y reubicarse en el globo. Se trata de Brasil y del poder con el que cuente -y el que se pueda proveer-, no se trata del engrandecimiento de la región o de algún socio. Retomaremos esta cuestión en la exposición final y pondremos nombre al medio procurado (el poder) y al fin que se le otorga -los grados de libertad creciente en la asimetría global-, gracias a unas herramientas que Brasil toma para sí.

Por último, algo insoslayable: el uso que aquí haremos de ella. No podremos desarrollar por completo todas las caras de la EPGB. Hacerlo, nos expulsaría de nuestra hipótesis. El fin de estas líneas será utilizar la estrategia de acumulación de poder del vecino, para ver el impacto que esa acumulación tuvo en el Mercado Común del Sur. Por eso haremos foco a partir de ahora, en esta perspectiva que imprimimos a su política para con la región, con el fin de encontrar las razones que expliquen su cooperación hegemónica superficial en la integración suramericana.

es su diseño ni su reproducción: es sólo su perfil, la manera en que Brasil se dedicó a acumular poder, un dispositivo signado por una autopercepción, signado por la búsqueda de autonomía con la diplomacia presidencial a su servicio. 
Capítulo VI. Mercosur y Estrategia de Poder Global Brasileña (2003-2010)

Sumario. En este capítulo expondremos el despliegue de la hegemonía cooperativa brasileña en el Mercado Común del Sur, a la luz de la Estrategia de Poder Global Brasileña. 
«El Tratado de Asunción de 1991 (...) coincidió con el cambio de dirección de la política comercial e industrial de Brasil. La percepción de que el multilateralismo comenzaría a convivir con iniciativas de consolidación de los espacios regionales reforzó la propuesta de integración sudamericana como componente esencial de la ascensión de Brasil al escenario internacional》》

Lia Valls Pereira, 2013

"La política exterior es barata. Es una inversión muy chica para un retorno muy grande, porque la ganancia de prestigio y la proyección que se tiene con un ministerio profesionalizado como el nuestro es enorme》)

Matías Spektor, 2014

Nuestra hipótesis se resuelve en dos instancias, dos momentos. El primero, ya lo expusimos, y tiene que ver con la manera en el poder y el territorio se combinan en la dimensión subregional de la EPGB (dimensión acotada del componente estructural). Aquí, la integración mercosureña oficia como un Brasil expandido cual lebensraum - un primero cordón concéntrico de influencia cooperativa superficial, con el fin de apropiarlo y fagocitarlo en un interés nacional que mira al escenario global. Esto se articula con la UNASUR que avanza a un atenuado hinterland ${ }^{238}$ (suerte de zona de influencia con preeminencia -que no regencia completa- brasileña). Y un segundo cordón, menos denso, pero no por ello menos asertivo, determinado a expandir la influencia -que no la regencia completa- de Brasil y que pudo haber sido usado para implementar otras estrategias como algún tipo de soft balancing.

\footnotetext{
${ }^{238}$ Tomamos ambos términos de la manera más laxa posible y despojados de todas las connotaciones históricas que tuvieron desde el siglo XIX a esta parte: el primero sólo como una estrategia de influencia regional, el segundo como un resultado postrero del éxito de esa influencia. No obstante, somos conscientes que sólo pueden ser usados como analogías: por ejemplo, el lebensraum establece una relación población/territorio que no aplica para el Mercosur.
} 
El segundo momento para resolver la hipótesis hace al nuevo rol para el Mercosur que le imprime la acumulación de poder que asume Brasil, y esto no es otro que lo que más arriba denominamos hegemonía cooperativa superficial. Tomamos esta denominación hegemonía cooperativa de los análisis de Pedersen $(2002,2004)$ y le agregamos el adjetivo superficial para definir, caracterizar cómo y en qué términos ejerció su preeminencia en la región.

Para comenzar, es preciso separar sus aspiraciones de sus resultados efectivos de acumulación de poder neta:

La teoría tradicional de estabilidad hegemónica retrata, por supuesto, a los hegemones como Estados poderosos, los que imponen holgadamente su voluntad por medios unilaterales y sin necesidad de establecer instituciones sólidas. Pero [¿்]qué acontece con los Estados relativamente poderosos, faltos de altos recursos o enfrentados a restricciones en su libertad de acción unilateral? (Pedersen, 2002: 681 [traducción propia] ${ }^{239}$ )

Brasil inserta en su acumulación de poder global una lógica de preeminencia relativa en un medio de baja institucionalización como el Mercosur. Este tipo de hegemonía, de corte cooperativo en clave de Pedersen $(2002,2004)$, requiere de tres aspectos: un hegemón que comparte poder (power sharing) con los miembros más pequeños del bloque en la dimensión institucional (que debe ser también estable); que además conjuga poder (power aggregation), es decir, el apoyo de otros Estados de la región; y,

\footnotetext{
${ }^{239}$ Del original: the traditional theory of hegemonic stability of course portrays hegemons as powerful states, which impose their will largely by unilateral means and without establishing strong institutions. But what about moderately powerful states lacking in superior resources or facing constraints on their unilateral freedom of action?
} 
además, actuar como un hegemón que se compromete a una estrategia política regional a largo plazo (con compromisos plasmados institucionalmente). Ninguno de estos componentes son estancos, todos pueden variar en intensidad acorde las ventajas que el hegemón obtenga a partir de lo que brinde a la región, en cuatro aspectos: a) adquisición de escala por la unificación de mercado -que redundará en eficiencia-, b) mayor estabilidad en términos de seguridad, c) ventajas a partir de la inclusión en obtención de recursos, y por último a partir de la difusión, como puede ser d) una región donde proyectar ideas (ibídem) ${ }^{240}$.

Más allá de las diferencias de perfil, las intensidades de cada aspecto, las ventajas que obtenga, el fin es constante: el hegemón echa mano de un armado institucional (cooperativo) porque servirá a sus intereses sin apelar a la fuerza. Por cierto, no referimos a una mera subordinación. Es decir, Brasil no echa mano del Mercosur sólo porque le permite engrandecerse en términos económico-territoriales y así ostentar el poder que requiere un nuevo rol externo. La dinámica no resulta tan lineal, porque el poder no está sólo del lado de Brasil. Recordemos que Hurrell (2005) mencionaba los intereses relacionados con el poder (power related interests) a la hora de llevar adelante un proyecto de integración regional. El poder existe, corre por y sostiene a la integración entre todos los miembros. Por eso, el poderoso precisa de la legitimación

\footnotetext{
${ }^{240}$ Alencar Domingues (2012) relaciona la hegemonía cooperativa con el concepto de Sean Burges de hegemonía consensual. De hecho, afirma que la una no funciona sin la otra, dado que la segunda implica la aplicación de presión indirecta o la creación de condiciones que harían, en apariencia, de las medidas políticas futuras una acción de los pares en pos de su propio interés. Esta persuasión normativa, requiere de la difusión de ideas por parte del hegemón que converjan a las suyas, y atender, concomitantemente, la definición de patrones de conducta aceptables (que definirán, por supuesto, sus agendas).
} 
de los otros, que es, la forma de poder de los débiles, por así decirlo (legitimar es una forma de poder, sólo que pasiva).

Brasil ha logrado contemplar la primera condición (power sharing), pero es difícil encontrar las otras: no ha contado con apoyo en la región para su EPGB focal (como en el caso del apoyo Argentino para el Consejo de Seguridad (Cervo, 2006; Malamud, 2005, 2010)), y los compromisos institucionales duraderos en el bloque del sur fueron crecientes pero no del todo consistentes (Giacobone, 2016) ${ }^{241}$.

El regionalismo implica, para el Brasil de Da Silva [una de las formas de] expresión del interés nacional y [una de] las estrategias globales del más poderoso. El horizonte regional resulta un complemento de su inserción internacional. Para eso debería esmerarse en construir un proyecto atractivo para los vecinos, que implica una construcción de un orden regional determinado (Pedersen, 2002; en Alencar Domingues, 2012), concretado según dos posibles estrategias: la hegemonía unilateral de la potencia regional, y así evitar toda interferencia decisoria de los pares salvo por las que imponga la dimensión doméstica (claro que esto estimula la resistencia de pares y el free-riding). Aquí Brasil estaría sólo preocupado por su carrera global. Por supuesto, no eligió este camino, oneroso, e imposible para sus capacidades. Y la otra opción -la intentada-, más cercana al liderazgo, desplegada asociativamente,

${ }^{241}$ Es muy interesante lo que afirma acerca de esta dinámica: si la idea de una institucionalidad parecía estar presente (...) [en] un proceso diseñado desde y para los gobiernos nacionales y con escasa voluntad supranacional. Es así que algunos autores prefieren hablar de "aluvión" institucional, para dar cuenta de un crecimiento cuantioso, pero disperso y en ocasiones desordenado, del MERCOSUR (Cf. GIACOBONE, Gabriel (2016). Del 'Mercosur comercial' al 'Mercosur social'. Rupturas y continuidades. En Informe Integrar 95, febrero). 
coordinando un orden conjunto con los vecinos (que disminuye de suyo el free-riding, porque los costos y riesgos se encuentran repartidos -aún cuando lo estén asimétricamente-). Esta estrategia se apoya en reglas legítimas y estables -que las hará más sustentables en el tiempo-, lo que redunda en previsibilidad y permite la sinergia de poder intrarregional (recursos, prestigio) que puede traducirse en acción colectiva en el sistema internacional (ibídem).

Este el ejercicio indirecto sobre terceros, sucede sobre un dispositivo en que Brasil no se predispuso: la inversión sobre instituciones regionales. Curiosamente, Pedersen afirma que esta decisión, incide sobre el mantenimiento de su condición (es decir, el orden regional que el hegemón precisa) sin enfrentarse a los pares directamente. Aquí reside la superficialidad con que juzgamos el perfil de hegemonía cooperativa brasileña: Despliega una estrategia de poder -que, como está acorde a sus capacidades, en apariencia resulta 'más benevolente'-, pero no provee medios para cumplirla. Algo que por cierto lo favorecería, sería tan oneroso como retribuido: la titánica inversión de un sistema de incentivos y compensaciones regionales retornaría por la previsibilidad regional de la conducta de los pares, y así mantener a la región lo suficientemente sujecionada, mientras la utiliza a sus fines.

Creemos que este aspecto aparece impedido por la asignación de recursos (esfuerzo, tiempo) que requiere en el tiempo la construcción del regionalismo brasileño (BernalMeza, 2009) del que sólo desplegó la UNASUR, y por los condicionantes que imprimen la temporalidad de esta construcción (es decir, la decisión propia de la gestión Da Silva 
de implementar la acumulación de poder). Establecer incentivos adecuados y fructíferos, sortear dificultades, invertir en instituciones, son procesos que muchas veces exceden un período tan corto como menos de una década. De hecho, creemos que la opción de la gestión Da Silva de construir un regionalismo propio por fuera del Mercosur, y de baja incidencia institucional, guarda relación con esto: si vemos en la dimensión [sólo] política y escasamente institucional de la UNASUR un aspecto derivado -antes que una 'deficiencia'-, entendemos que este perfil era la manera más eficiente -para un corto plazo-, de obtener réditos idénticos a partir de una conformación regional de esas magnitudes. Construir institucionalmente la UNASUR llevaría varias gestiones, negociaciones y acomodamientos en diferentes escenarios (regional, hemisférica y global) en aspectos comerciales y no comerciales. Dotar de contenido político a un esquema le da una entidad más rápida que la construcción lenta, con marchas y contramarchas, compleja y plagada de contingencias que implica construir un régimen de integración regional.

Brasil atinó a un solo componente de la hegemonía cooperativa, por lo que ella no superó la superficie, la nata. Esta magra intensidad -determinada por la elusión del rol de paymaster y promotor institucional-, acontece traccionada por su decisión de acumulación de poder: una EPGB que debía hacer del Mercosur su zona de influencia, su espacio intermedio hacia el globo, requeriría de la atención necesaria para fortalecerlo. Pero hacerlo implicaba uno de los costes que señala Pedersen: el hegemón cede soberanía al ponderar la institucionalidad conjunta y limita así sus grados de libertad. Brasil quedaría, así, enredado en una paradoja: necesita de la 
región para acceder al globo, pero no la atiende y se debilita (aspecto con que se topará a la hora de necesitar una legitimidad de sus pares). Lo curioso es que tampoco puede decidir la estrategia contraria -invertir tiempo y recursos en la coordinación institucional-, porque, de ser exitosa, no podría poner al Mercosur al servicio de su interés nacional, dado que la fortaleza institucional se lo impediría.

Es necesario asentar, para terminar, que las decisiones estratégicas no están basadas sólo en el voluntarismo brasileño (o en sus atributos para ejercer una posición dominante). También están en la herramienta que utiliza: el Mercosur. Un bloque que ostenta componentes contradictorios: fundado en un marco de regionalismo abierto para reemplazar al proteccionismo del PICAB (Bernal Meza, 2010), tuvo por objeto la creación de un mercado común (Ouro Preto, 1994) y un subsistema internacional (el Acuerdo Marco Interregional de Cooperación con la UE), pero que no lograría una potente creación de comercio sin desarrollo industrial y tecnológico (ibídem). Tampoco se dotó de una política exterior común -o al menos coordinada-, y ello lo dejó reducido a una función económica, reducida sólo a aspectos comerciales. Este esquema queda, en 2003, a disponibilidad de Brasil $^{242}$.

\footnotetext{
${ }^{242}$ Por supuesto que con esto no afirmamos que el Mercosur se redujo a mera herramienta de la acumulación de poder brasileña. El bloque siguió funcionando -bien o mal- bajo sus propios términos, pero sus debilidades -sobre todo de eficacia institucional- no hacen nada por evitar que el poder del miembro con más envergadura se imponga.
} 
Epílogo 
«El problema con el ego es que puede poner cualquier cosa a su servicio, incluso la espiritualidad》)

Chögyam Trungpa, 1973

Hemos recorrido una progresión conceptual que nos permitió cotejar el rol que la RFdB imprimió al Mercosur en el período de la gestión Da Silva. Desde el prefacio -al recorrer el camino que nos permitió elaborar un problema de investigación-, hemos intentado mostrar los perfiles de la integración latinoamericana en los últimos cincuenta años (y la del Mercosur en la mitad de ese período). La integración regional, un proceso dinámico, ha variado sin cesar desde sus inicios: Si pensamos en los objetivos de cooperación del atávico PICEAB, deberemos aceptar que éstos no se mantuvieron en el tiempo. Los perfiles de integración variaron, la finalidad de ella evolucionó -tal vez menos de lo esperado en términos de profundidad-, y si bien en todo momento estuvo atravesada por cuestiones relativas al poder -a su exterior o bien a su interior, es decir, en sus miembros-, siempre sostuvo sus intenciones en las ventajas colectivas de sostenerse. En la exposición inicial de nuestro problema vimos que, en el regionalismo post-liberal, se daba especial importancia al valor estratégico y autoafirmación autonomista. Pero, de suyo, esto involucraba a la región de cara al hemisferio -es decir, ante Estados Unidos-, y el mundo. La región suramericana, proveía así, un espacio donde tomar decisiones autonómicas sinérgicas -aun cuando tuviese un miembro más poderoso-. Que este miembro preeminente tome decisiones 
nacionales para con la región no fue más que hacer lo que todos los miembros siempre hicieron: los países se integran, ingresan en negociaciones regionales para obtener un amplio espectro de ventajas concretas en diferentes aspectos. Pero que las aspiraciones nacionales no se detengan en las ventajas del regionalismo y sea la propia región la que resulte al servicio de intereses nacionales, no parece ser algo comparable al autonomismo post-liberal, o a cualquiera de los otros dos regionalismos anteriores.

Hemos decidido aquí, presentar la integración regional en su anclaje conceptual neofuncionalista. Decidimos así, priorizar la consistencia conceptual con el realismo tradicional y el revisado, y así lograr una progresión que por vía del pragmatismo nos llevase a los regímenes internacionales sin dejar de presentar consistencia en la perspectiva. Podríamos haber escogido un enfoque intergubernamentalista tal vez articulado con algún enfoque neorrealista. Esta estrategia hubiese seguido el criterio de la aproximación analítica con el Mercado Común del Sur -de suyo intergubernamentalista- $y$ hubiese atado sin fisuras el desarrollo conceptual de la integración al bloque del Sur. No obstante, preferimos sea el pragmatismo lo que nos divorció de todo viso de utopismo reflejado en la integración (esto también nos salvó de la inconsistencia teórica: hemos intentado imprimir en este desarrollo una pátina donde la política internacional y la conducta de los Estados nacionales no dependa de principio alguno -aun cuando pueda apelar a ellos instrumentalmente-). Pero, dado que en este apartado nos consideramos fuera del corset de nuestra hipótesis, podemos pensar en un aspecto de esta cuestión que se desarrolló, y se (nos) hizo manifiesto, a lo largo de la escritura de estas líneas: 
Sabemos que, por un lado, podemos pensar la integración regional en clave pragmática -lo que aquí hicimos-, y ver el comportamiento de acumulación de poder de un país como una manera más de conducirse en un espacio internacional donde, allende la complejización de los últimos cuarenta años, algunas cuestiones relacionadas con el poder no han cambiado. Concebir la integración regional en clave pragmática, nos permite también, ver islas de conducta cooperativa, y así pensar en mecanismos más acotados que funcionan con viabilidad de largo plazo en otra clave que la de la acumulación de poder (como puede ser la cooperación internacional).

Los actores nacionales -aunque no estén solos en el medio internacional-, siguen encauzando sus relaciones de acuerdo a posiciones relativas asentadas en aspectos tan complejos y disímiles como su estructura socioeconómica, su posición en las negociaciones multilaterales, su potencial bélico, etc. Pero al hablar de integración regional también podemos -debemos- dar lugar a una perspectiva apegada al liberalismo y hacer hincapié sobre el incentivo integrador de la baja política. La integración reviste aquí un conjunto de reglas que, sin necesariamente responder a un trasfondo principista abstracto -hablamos de intereses económicos de grupos preeminentes-, reconoce la posibilidad de conformar bloques cooperativos sostenidos por aspectos que no necesariamente constituyen reglas del juego que permiten condicionar comportamientos -algo que no dudaremos en llamar utopismo-, pero sí se basan en aspectos que no orbitan en lo político-estratégico y la acumulación de poder. Y aquí es donde tenemos que recuperar de nuevo a Brasil, de nuevo a la impronta de 
acumulación de poder de Da Silva, y las consideraciones acerca de la utilización de un espacio cooperativo al servicio de la power politics (no utilizamos el término alta política, porque, justamente, Brasil intenta preparar con su estrategia de poder global un espacio de acción que lo incluya entre quienes ingresan al juego de la alta política. Un escenario que aún al final de la segunda gestión le resultaba aún una aspiración, que no una realidad).

Si bien al referirnos al Mercosur estamos en el horizonte de la baja política, el punto al que queremos llegar no se altera: y éste no es otro que el de las relaciones entre un mecanismo cooperativo, asociable a algún grado de interdependencia antes que al neorrealismo. En otras palabras -pero en el mismo sentido-, nos referimos a mecanismos por igual pragmáticos, pero con una diferencia metodológica, por así decirlo: en el primero, neoliberal, la integración regional procura unos objetivos a través de la sinergia con otros pares; y en el otro, las opciones que ofrece el (neo)realismo, donde los objetivos serán alcanzados o bien de manera individual o bien en un rango (acotado) de cooperación sustentada en mecanismos hegemónicos.

Cualquiera fuese la posición en este espectro, una variable sigue constante: el poder. No nos desembarazamos de él. El poder que está presente en el espacio internacional, el que está presente en la dimensión doméstica. Su presencia hace, exactamente lo mismo que reza el epígrafe de este acápite: pone cualquier mecanismo a su servicio. Si quien lo detenta cuenta con una o alguna de las condiciones que le permiten ejercerlo, pues estará presente, y obrará bajo su propia lógica (es decir, al servicio del titular). 
Pondrá los mecanismos cooperativos más puramente colectivos (e incluso otros, que promuevan objetivos alejados del pragmatismo y asentados en ventajas en apariencia más altruistas), y los llevará a sus dominios. En este sentido, el problema con el poder es que puede poner cualquier cosa a su servicio, incluso la integración regional. Si es la última ratio de la política, pues debe tener la capacidad de malear lo que acontece en ella. Si no lo tuviese, no sería el instrumento más efectivo para vehiculizar, y compartiría su utilidad con otro u otros mecanismos. $Y$ esto vale para mecanismos propios de la baja política -que sólo en apariencia parecen ser más cooperativos-, o bien los principios que integran un régimen internacional y otorgan zonas de (mayor) certeza a la conducta de los actores internacionales. En todos anida el poder, en todo corre esa una energía social. Incluso en los mecanismos legales o las buenas prácticas que tildaríamos de claramente utopistas. Aún en este último caso, la misma lógica podrá sostener lo que puede ser señalado como un valor moral: el poder de uno o unos interesados en un determinado status quo (existente o proyectado) pondrá el poder al servicio de afirmar ese principio como el motivo de su conducta.

Cuando este principio lo pensamos a la luz de nuestro caso, encontramos otras particularidades: es un miembro de un bloque el que comienza a ejercer preeminencia sobre sus pares integrados corriéndose de la lógica del liderazgo, mientras también asume la importancia determinante (es decir, del orden del interés nacional) de un rol activo y mayor grado de libertad para su injerencia global. La única manera de lograrlo es acumulando poder y haciendo que la región resulte un Brasil ampliado, un Brasil reconfigurado con una mayor zona de influencia. Cualquiera haya sido el decurso y los 
éxitos/fracasos de esta estrategia, los fines fueron por entero nacionales, e imbricados en la lógica del activo que los posibilita (el poder). 
Son varias las cuestiones que han quedado pendientes en este extenso desarrollo. La primera de ellas es evidente, y ya la hemos comentado colateralmente: la Estrategia de Poder Global Brasileña está constituida por diversos componentes -todos señalados en las páginas anteriores, sólo que no desarrollados-. La integración regional del sur americano es sencillamente uno de sus componentes, y ni siquiera completa todo el espectro de la integración latinoamericana. Llenar de contenido cada uno de esos componentes nos mostrará con mayor profundidad y completitud la estrategia de acumulación de poder del vecino luso parlante.

El segundo aspecto pendiente, es metodológico. Si se tomase la ruta de definir con detalle cada componente de la estrategia de acumulación o si sólo se siguiese trabajando sobre la dimensión regional, se podría escoger otra manera de resolverlo: seguir un perfil más cuantitativo es una opción interesante. De este modo, resolver con indicadores de diferente índole el impacto de la política exterior activa y altiva en la profundización de la integración suramericana, es un trabajo atendible, que, a su vez, puede incorporar análisis propios de cada uno de esos indicadores. Por ejemplo, poner en relación las negociaciones brasileñas en la esfera de la OMC y la 
complementariedad -o no- del comercio intrarregional, junto con otras variables que vayan construyendo la consistencia del devenir de política exterior brasileño con su correlato regional en el Mercosur. Llenar de contenido la EPGB sobre insumos cuantitativos -que no excluyan análisis cualitativos-, nos parece del todo interesante. $Y$ es una labor que se puede articular el desarrollo seguido en esta tesis por completo.

De hecho, esta cuestión nos permite señalar un aspecto que es posible haya sido por demás evidente en estas líneas: nos hemos visto forzados, por la estrategia explicativa y expositiva que escogimos, a mantenernos en un grado de generalidad constante. En todo momento estuvimos argumentando acerca de consistencia paradigmática, grandes tendencias de la política exterior o posiciones de escuelas de considerable magnitud, como puede ser el neofuncionalismo. Hayamos o no logrado el objetivo, mantener(se) en esos niveles de generalidad es algo que, además de requerir atención constante para no apelar intermitentemente a menos generalidad y tirar por tierra la línea argumentativa, puede resultar demasiado abstracto para un abordaje de integración latinoamericana. Es por esto que incluimos este apartado donde repasamos las maneras de hacer más fuertes y de una mayor potencialidad explicativa la labor presentada.

La tercera cuestión es teórico-analítica, y aquí nos llevó a una suerte de dilema expositivo que enfrentamos al presentar los tres aspectos ineludibles del perfil de acumulación de poder brasileño (autonomía, diplomacia presidencial y autopercepción). Creemos que la autopercepción es, sin duda, el más complejo, 
profundo y multidimensional de las tres. No es difícil demostrarlo: inerva aspectos (reales o fantaseados) que implican componentes históricos, territoriales, sociológicos, culturales y hasta artísticos. Esto nos dice que a diferencia de los otros dos, se encuentra desfasado del espacio disciplinar de las relaciones internacionales y seguramente sería imposible acotarlo a un sólo campo de estudio. Por eso escogimos la estrategia utilizada más arriba (rastrear la autopercepción en discursos públicos de los protagonistas), la que no dudamos en calificar de solución de compromiso.

Era necesario anclar la autopercepción de la gestión Da Silva en alguna nota concreta y eludir la exposición de un aspecto tan complejo que nos hacía entrar en una suerte de dilema expositivo: o bien lo podríamos abordar in extenso haciendo el recorrido de nuestra hipótesis oneroso en tiempo y espacio; o bien podríamos abordarlo de manera sintética (tal vez, apelando en exceso al neorrealismo clásico para eludir recuperar aspectos que exceden al campo de las relaciones internacionales), y presentar unas notas magras. Esta última opción nos pareció deslucida e inútil en términos analíticos. En abordajes futuros, creemos se debería saldar la deuda de caracterizar, precisar, operacionalizar, y así darle el debido lugar a este componente.

$\mathrm{Y}$, por último, creemos que sería interesante trabajar al interior de cualquiera de los componentes de la EPGB a la luz de continuidades y diferencias con predecesores y sucesores. Es decir, se podría rastrear en parte -seleccionando algún sector de la EPGBo en su totalidad, la dimensión de la acumulación de poder en las respectivas políticas exteriores. Seguramente existan continuidades y rupturas interesantes en las 
respectivas improntas de la política externa brasileña, ya que algunos de los componentes más determinantes no son privativos de la administración Da Silva. 


\section{Referencias}

- ACTIS, Esteban (2014). Cambios dentro de la continuidad. Un análisis de la reciente política exterior brasileño (1990-2010), Íconos 50, Quito, septiembre, pp. 195208

(2015). La relación bilateral entre Argentina y Brasil (20112014). La confluencia de factores sistémicos y domésticos para una menor intensidad relativa en las interacciones, Estudos Internacionais, vol. 3 nro. 1 enero-junio 2015 p. 27-44.

- $\quad$ agencia española de la coOperación INTERNACIONAL (2015): América Latina: Nuevos y viejos esquemas. Incertidumbres a futuro, Documento de Trabajo, Dirección de Cooperación con América Latina y el Caribe: Madrid

- $\quad$ ALAgAPPA, Muthiah (1995). Regionalism and Conflict Management: A Framework for Analysis, Review of International Studies, núm. 21, s/d.

- $\quad$ alencar domingues, Reinaldo (2012). Uma Potência Regional em Construção? O Brasil na América do Sul durante os anos Lula (2003 - 2010). En Revista Política Hoje, 2a edición, vol. 22. pp. 231-248 
- ALONSO, José (2013) Cooperación con países de renta media: en enfoque basado en incentivos. AECl: Madrid.

- AMORIM, Celso (2016). Grande Estratégia do Brasil. Discursos, artigos e entrevistas da gestão no Ministério da Defesa. FUNESP - Fundação Alexandre Gusmão, Brasília.

- $\quad$ ANZOLA GIL, Marcela; CABALLERO SIERRA, Gaspar y Luis CORRAL STRASSMAN (2002): De la OMC al ALCA: bases para la negociación, Confecámaras, Bogotá.

- $\quad$ ARON, Raymond (1979): Paz e Guerra entre as Nações, Brasília: Universidade de Brasília.

- $\quad$ ARRUdA SAMPAIO Jr., Plínio de (2015). A relação Brasil-EUA: o mito da política externa independente en REBELA, vol.5, nro. 1. enero-marzo

- ASHLEY, Richard (1984). The poverty of neorealism. En International Organization, Ginebra, vol 38.

- $\quad$ AZEVÊDO, Roberto. Los Acuerdos Comerciales Regionales no pueden sustituir al sistema multilateral del comercio, Discurso de cierre Seminario Cuestiones Transversales, Organización Mundial del Comercio, Ginebra, 25 de septiembre de 2014.

- AZPIROZ MANERO, María (2011). La diplomacia pública estadounidense de la 'Guerra contra el terror': análisis y evaluación de su influencia en la prensa española. Tesis doctoral, Facultad de Comunicación, Universidad de Pamplona.

- $\quad$ BACA OLAMENDI, Laura (2000): El Léxico de la Política, México: FLACSO.

- $\quad$ BALDWIN, Robert (1993). Neorealism and Neoliberalism, Columbia University Press, New York 
International Economics, vol. 88, núm. 1, pp. 16-33.

- $\quad$ BARBÉ, Esther (1987). El 'equilibrio del poder' en la teoría de las Relaciones Internacionales, Revista CIDOB d'Afers Internacionals, 11, pp. 5-17.

- _ (1989). Cooperación y conflicto en las relaciones internacionales: la teoría del régimen internacional, Revista CIDOB d'Afers Internacionals 17. pp -55-67

- BAtTAglinO, Jorge Mario. The coexistence of peace and conflict in South America: toward a new conceptualization of types of peace. Revista Brasileira de Política Internacional, Brasília, v. 55, n.

- $\quad$ BHAGWATI, Jagdish. 1999. The World Trading System at Risk. Princeton, N.J.: Princeton University Press.

- $\quad$ BHAGWATI, Jagdish. 1993. "Regionalism and Multilateralism: An Overview," en New Dimensions in Regional Integration. Jaime de Melo and Arvind Panagariya, eds. pp. 22-51.

- $\quad$ BHAGWATI, Jagdish; GREENAWAY, David y PANAGARIYA, Arvind (1998): Trading Preferentially: Theory and Policy. En The Economic Journal, vol. 108, número 449. pp: $1128-1148$.

- $\quad$ BANKS, Michael. (1985). The inter-paradigm debate. En Light, Margot y Groom, A. J. (eds) "International Relations. A Handbook of Current Theory". Londres, Frances Pinter.

- $\quad$ BARBÉ, Esther (1987): El Papel del Realismo en las Relaciones Internacionales (La Teoría de la Política Internacional de Hans Morgenthau) en Revista de Estudios Políticos Nueva Época, Buenos Aires, \#57, septiembre. pp: 149-176. 
(2003): Relaciones Internacionales, Madrid; Editorial Tecnos.

- BARBeiro, Alan y CHAloult Yves (2003). Poder e déficit democrático do Mercosul: Estado, centrais sindicais e sociedade civil. EDIPUCRS: São Paulo

- $\quad$ BARTESAGHI, Ignacio (2014): La estrategia de inserción internacional seguida por Estados Unidos y la Unión Europea en América Latina: Impactos para el Mercosur, tesis doctoral, IRI-FCJyS, Universidad Nacional de La Plata: La Plata

- $\quad$ BATtAglia, Matías: GRANATO, Leonardo y Nahuel ODDONE (2016). Teoría de la autonomía: ¿Aún vigente para analizar los procesos de cooperación e integración en América Latina? En Teoria \& Pesquisa, Revista de Ciência Política,25 (1). pp: 153-175

- $\quad$ BAUMANN, Renato (org.): Mercosur. Abanicos e desafios da integração. CEPAL. Brasília, 2001

- BARNABÉ, Roberto (2012). O Itamaraty e a Diplomacia Presidencial nos governos FHC e Lula, en Contextualizaciones Internacionales, año 4, número 7, juliodiciembre

- Bernal-MeZA, Raúl (1994): América Latina en la Economía Política Mundial, Buenos Aires: GEL.

(1998). As relações entre Argentina, Brasil, Chile e Estados

Unidos: política exterior e Mercosul, en RBPI, Brasília: Instituto Brasileiro de Relações Internacionais; ano 41, \#1. pp.89-107.

$\bullet$ (1999) Políticas Exteriores Comparadas De Argentina E Brasil Rumo Ao Mercosul. Brasília: RBPI, v. 42, \#2, 1999.

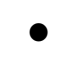
(2000). Sistema Mundial y MERCOSUR. Globalización, Regionalismo y Políticas Exteriores Comparadas, Buenos Aires: Nuevo Hacer-UNCPBA. 


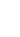
(2001). El Mercosur y las contradictorias políticas de Argentina y Brasil en Carta Internacional, São Paulo: USP-Política Internacional (e FUNAG); Año IX, № 102, agosto 2001; pp. 7-10. (2002). A Política Exterior do Brasil: 1990-2002. RBPI, v. 45,

n. 1.

(2005). América Latina en el Mundo. El Pensamiento Latinoamericano y la Teoría de las RRII, Buenos Aires: GEL.

(2006a). Política y economía en la segunda mitad del siglo XX: una interpretación sobre la evolución de la integración latinoamericana. En Revista del CESLA, núm. 8. pp. 139-158

$\bullet$ (2006b) Cambios y continuidades en la política exterior brasileña en Lateinamerika Analysen 13, febrero, Hamburg: IIK. pp: 69-94 (2007). “Cambios Y Continuidades En La Política Exterior Brasileña. El Consejo De Seguridad: ¿El Retorno Del Realismo? Sus Impactos En El Cono Sur"; en COSTA Sérgio, SANGMEISTER Hartmut y Sonja STECKBAUER (comps.): “O Brasil na América Latina. Interações, Percepções, Interdependências", São Paulo: Annablume, 2007. pp. 11-38.

$\bullet$ (2008). Argentina y Brasil en la Política Internacional: Regionalismo y Mercosur (Estrategias, Cooperación y Factores de Tensión) en RBPI \#2, v. $51 . p p: 154-178$ (2009). El Regionalismo: Conceptos, paradigmas y procesos en el Sistema Mundial Contemporáneo, en Aportes para la Integración Latinoamericana, año 15, \#21, diciembre. pp: 1-29 


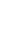
(2010). International thought in the Lula era. en Revista

Brasileira de Política Internacional (ISSN 1983-3121), volumen 53, pp. 193-2013. Consultado el 27 de enero de 2017, de http://dx.doi.org/10.1590/S0034$\underline{73292010000300012}$

$\bullet$ (2013). Heterodox autonomy doctrine: realism and purposes, and its relevance. RBPI, volumen 56, año 2. Pp: 45-62.

- $\quad$ BERNAL-MEZA, Raúl y Gustavo MASERA (2005). Economía mundial y desarrollo regional. Nuevohacer GEL, Buenos Aires.

- BERTOGLIO CARDOSO, Rodrigo (2008). O conceito de soberania nos realistas clássicos: Aron, Morgenthau e Carr, Universidade Federal do Rio Grande do Sul UFRGS, s/d.

- $\quad$ BEW, John (2016). Realpolitik. A history. Oxford University Press, New York.

- BIZZOZERO REVELEZ, Lincoln (2008): El proceso regional del MERCOSUR en el siglo XXI: del regionalismo abierto a la prioridad estratégica sudamericana, Revista Aportes para la Integración Latinoamericana, Año XIV, № 19.

- BOTTO, Mercedes (2004): La Integración Regional en América Latina ¿Una Alternativa para el Crecimiento? en Manual de Gestión de Asociaciones Juveniles, Montevideo: Foro Latinoamericano de Juventud.

- BOUZAS, Roberto y José FANELLI (2002): Mercosur. Integración y Crecimiento, Anagrama: Buenos Aires

- BOUZAS, Roberto (2003). Acerca de la cuatros falacias, Revista TODAVía Número 5, consultada el 10 de noviembre de 2016 en: http://www.revistatodavia.com.ar/todavia21/5.bouzasnota.html 
de las Américas. Un Enfoque Menos Indulgente, en Revista de la CEPAL, abril, \#85. pp: 7-18.

(2009): Mercosur: ¿Crisis económica o crisis de la integración? documento presentado en la Reunión La Crisis Económica y la Integración Regional en las Américas. noviembre 2009, Red Mercosur, Washington. Consultado el 27 de noviembre de 2016 y disponible en http://www19.iadb.org/intal/intalcdi/PE/2009/02452a01.pdf

- BRICEÑO-RUIZ, José (2001). De la integración autonómica al regionalismo abierto: crisis y resurgimiento del regionalismo latinoamericano, Cuadernos Americanos, UNAM, Vol. 5, № 89, septiembre-octubre. pp. 98-128 (2006). Regionalismo estratégico e interregionalismo en las relaciones externas del Mercosur. Revista Aportes para la Integración Latinoamericana, Año XII, № 15/diciembre 2006, pp. 2842

(2007). La integración regional en América latina y el Caribe.

Procesos históricos y realidades comparadas, Mérida: Vicerrectorado Académico, Universidad de los Andes.

(2013). Ejes y modelos en la etapa actual de la integración económica regional en América Latina en Estudios Internacionales 175, Instituto de Estudios Internacionales - Universidad de Chile.

- BRICEÑO RUIZ, José y SIMONOFF, Alejandro (2017). La Escuela de la Autonomía, América Latina y la teoría de las relaciones internacionales. Estudios Internacionales, Santiago, vol. 49, número 186, pp.39-89. 
- BULL, Hedley (1966). International Theory: The Case for a Classical Approach, World Politics, XVIII, abril.

_ (2002). A sociedade anárquica. São Paulo: Imprensa Oficial de São

Paulo, 2002

- BURGESS, Michael (2000). Federalism and European Union: The Building of Europe, 1950-2000, Nueva York, Routledge.

- BURGES, Sean (2008). Consensual Hegemony: Theorizing Brazilian Foreign Policy after the Cold War. International Relations, vol. 22. pp.65-84.

- BURTON, James (1965). International relations: a general theory, Cambridge University Press.

- $\quad$ BUZAN, Barry; JONES, Charles y Richard LITTLE (1993). The logic of anarchy. Neorealism to structural realism. New York. Columbia University Press.

- BUZAN, Barry y Ole WAEVER (2003). Regions and Powers: the structure of International Security. Cambridge-UK, Cambridge University Press.

- $\quad$ CABARCAS, Sharon; GALOFRE CHARRIS, Oriana y Roberto GONZÁLEZ ARANA (2013) Procesos de integración regional en América latina: un enfoque político en Revista de Economía del Caribe, No 11: enero-junio de 2013

- $\quad$ CARDONA MONTOYA, Giovanny (2013): ¿Es Mercosur una Unión Aduanera Imperfecta? Análisis conceptual y aplicado de la realidad y el potencial de la integración entre los países del Cono Sur, Escenarios: Empresa y Territorio No.2, ISSN 2322-6331, enero- diciembre de 2013. pp.55-70

- $\quad$ CARR, Edward ([1938] 2001). Twenty years of crisis, Perennial, New York. 
- CAstelo branco Rebello hORTA, luiz Fernando (2012). o conceito de Diplomacia Presidencial. Primeiro Seminário Nacional de Pós-Graduação em Relações Internacionais-FINATEC, julio de 2012, Brasília.

- $\quad$ CASTRO, Thales (2012). Teoria das relações internacionais, Fundação Alexandre de Gusmão - Ministérios das Relações Exteriores, Brasília

- CASTRO, Gustavo y Paula NIELSEN (1992). Relações internacionais e pesquisa para a paz. Novos paradigmas. Pesquisa para a Paz na América Latina, Fundação Ford CNPq, Brasília.

- $\quad$ CAUGHEY, Carol (1967) An inquiry into the ethical position of the political realist school of Hans Morgenthau, Tesis de maestría presentada ante la California State College, agosto.

- CEPAl (1994). El regionalismo abierto en América Latina y el Caribe. La integración económica al servicio de la transformación productiva con equidad. Santiago de Chile, 28 de enero de 1994.

- CERVO, Amado (1997): Hegemonia Coletiva E Equilíbrio: A Construção Do Mundo Liberal. En SARAIVA, José: Relações Internacionais Contemporâneas. Da Construção do Mundo Liberal à Globalização (de 1815 a nossos dias). Brasília: Paralelo 15. pp: $67-102$ (2000). Sob O Signo Neoliberal: As Relações Internacionais Da América Latina. RBPI, ano 43, \#2. pp. 5-27.

- _ (2007). Inserção Internacional. Formação Dos Conceitos Brasileiros, São Paulo, Editora Saraiva. 
- $\quad$ CERVO, Amado y Mario RAPOPORT (1998): História do Cone Sul, Rio de Janeiro: Revan, Brasília.

- $\quad$ CERVO, Amado Luiz y BUENO, Clodoaldo (2002). História da Política Exterior do Brasil. 2a. ed. Brasília: UnB, 525 p.

- $\quad$ CERVO, Amado y SARAIVA, José (orgs.). Le Brésil Et Le Monde; Pour Une Histoire Des Relations Internationales Des Puissances Émergentes. Paris: Harmattan, 1998.

- $\quad$ COLOMBO, Silvana (2007): Estado, soberania e poder: uma visão a partir da sociedade internacional, Relações Internacionais no Mundo Atual, Curitiba, n.7, p. 91112,2007

- $\quad$ COMPARATO, Gabriel (2013). ALBA y UNASUR. Una propuesta comparativa a la luz de ciertas discusiones conceptuales. En Informe Integrar N80 (ISSN 1859-6445), agosto.

- COOPER, Andrew (1997). Middle Powers after the Cold War. McGraw Hill, London

- $\quad$ COSTA VAZ, Alcides (1999). Parcerias Estratégicas no Contexto da Política Exterior Brasileira: Implicações para o Mercosul. RBPI, Brasília, v. 42, \#2.

- COUTO, Leandro (2002). Relações Brasil-América do Sul: a construção inacabada de parceria com o entorno estratégico. En Lessa e Altemani, "Parcerias estratégicas do Brasil”. Belo Horizonte: Fino Traço, 20.

- $\quad$ CLULOW, Germán (2013). Una visión introductoria a los principios del realismo político. Documento de investigación, Universidad ORT Uruguay. 
- DA MOTTA VEIGA, Pedro y Sandra RIOS (2006). América do Sul: A integração pode sobreviver ao nacionalismo econômico? En Latin American Trade Network, FLACSO Série Brief, № 32, julio

- $\quad$ DANESE, Sérgio (1999). Diplomacia presidencial. Topbooks, Rio de Janeiro.

- (2009). A Escola da Liderança: ensaios sobre a política externa e a inserção internacional do Brasil. Rio de Janeiro: Record.

- DE ALMEIDA, Paulo (2001). Cenário econômico e político do debate hemisférico, Meridiano 47 Nro. 13, IBRI, Brasília

$\bullet$ (2016). O renascimento da política externa, in Revista Interesse Nacional, ano 9, número 34, julho-setembro.

- DE ALMeIdA, Paulo y Antônio POLI NAVEgA (s/d). Bases Conceituais de uma política externa nacional: uma contribuição para a definição de uma agenda diplomática condizente com o princípio do interesse nacional. Consultado el 8 de $\begin{array}{lllll}\text { febrero } & \text { de } & 2016 & y & \text { disponible }\end{array}$ http://www.publicadireito.com.br/conpedi/manaus/arquivos/anais/brasilia/04_372.p

df

- DEL ARENAL, Celestino (1989): La teoría de las relaciones internacionales hoy: debates y paradigmas. Estudios Internacionales 22 (86). pp. 153-182

(1990): La Teoría de las Relaciones internacionales hoy: Debates y Paradigmas, en Revista de Relaciones Internacionales de la UNCR, \#3233. pp: $9-20$ (1994): Introducción a las Relaciones Internacionales, Tecnos, Madrid. 
(s/d): La Nueva Sociedad Mundial Y Las Nuevas Realidades Internacionales: Un Reto Para La Teoría Y Para La Política (s/d). Disponible en:

http://www.mexicodiplomatico.org/lecturas/La\%20Nueva\%20Sociedad\%20Mundial R ealidades\%20Inter_Un\%20reto.pdf

(2003): Introducción a las Relaciones Internacionales,

Madrid: Tecnos Editorial.

- DE LA FONTAINE, Dana y Jurek SEIFERT (2010). The Role of South-South Cooperation in present. Brazilian Foreign Policy: Actors, Interests and Functions, Stockholm Papers LAS, s/d. Consultado el 25 de abril de 2017 y disponible en http://www.lai.su.se/polopoly fs/1.135252.1368796865!/menu/standard/file/STCHL

\section{PAPERS LatAm 2010 dana\%20et\%20al.pdf}

- DE LA REZA, Germán (2015). Art. XXIV del GATT-OMC: la relación entre regionalismo y multilateralismo, Desarrollo, México, v. 46, n. 181, junio. pp. 185-204 junio 2015

- DERGHOUGASSIAN, Khatchik (2007): IBSA No Gubernamental: Movilización Social, Diplomacia Ciudadana y Gobernabilidad de Seguridad en la Integración Sur-Sur en Juan Tokatlian: India, Brasil y Sudáfrica: El Impacto de las Nuevas Potencias Regionales, Buenos Aires: Ediciones del Zorzal.

- DESDRADI, Sandra (2001). Regional powers and their strategies: empire, hegemony and leadership, Review of International Studies, Volume 36, Issue 04.

- DEUTSCH, Karl (1976): Política y Gobierno: Cómo el Pueblo Decide su Destino, México: Fondo de Cultura Económica. 
Prentice Hall Inc (Division of Simon \& Schuster)

(1990). El análisis de las relaciones internacionales. Buenos

Aires, Paidós

- DOMínGUEZ ÁVILA, Carlos (2009). Brasil, el Gran Caribe y la reconfiguración, FI XLIX-1, enero - marzo. s/d.

- DOUGHERTY James Y Robert PFALTZGRAFF (1990): Contending theories of international relations: A comprehensive survey, Harper and Row, New York

- $\quad$ DU BOFF, Richard (2003). US Hegemony: continuing decline, enduring danger. Monthly Review, vol. 55, número 7, diciembre

- DUNCAN, Snidal (1985): The Limits of Hegemonic Stability Theory en International Organization, \#34, vol. 4, otoño. pp: 560-589

- $\quad$ ESCOREL DE MORAES, Lauro (1986). O Conceito de "Interesse Nacional" e a Responsabilidade de Diplomacia Brasileira, aula inaugural Faculdade de Direito da Universidade de São Paulo, 3 de março de 1986

- ESCUDÉ, Carlos (1995): El Realismo de los Estados Débiles. La Política Exterior del Primer Gobierno Menem Frente a la Teoría de las Relaciones Internacionales; Buenos Aires: GEL.

(1992). Realismo periférico. Fundamentos para la nueva Política Exterior Argentina. Planeta: Buenos Aires.

- FAGABURU, Débora (2016). Afinidades entre Afinidades entre la cooperación internacional y la integración regional en América latina, Espectros, año 2, número. Buenos Aires. 
- FALK, Richard (1971). This Endangered Planet. Prospects and Proposals for Human Survival, McGraw Hill, New York.

- FERREIRA, Walace (2009). Política externa do governo Lula: Coalizões ao Sul como alternativa multilateral. Revista Debates, Porto Alegre, vol. 3, nro. 1, p. 100-125, enero-junio 2009

- FLEMES, Daniel (2010). A visão brasileira da futura ordem global. Revista Contexto Internacional, vol 32, n.02, p. 403-435.

- FONSECA-SILVA, Maria da Conceição; FONSECA-NUNES, Vinícius y Edvania GOMES DA SILVA (2011): Política externa e deslizamento de sentido nos discursos dos governos FHC e Lula. En Estudos da Língua (gem), Vitória da Conquista v. 9, nro. 2., diciembre. pp. 27-38

- $\quad$ FRAGA IKIBAKNÍ, Manuel (1958). Política exterior y guerra en la era nuclear y en el sistema internacional bipolar en Revista de Política Internacional 40, Madrid. pp. $37-66$

- $\quad$ FRASSON-QUENOZ, Florent y Olmer MUÑOZ SÁNCHEZ (2011): El realismo en el siglo XX y XXI, Analecta polit, vol. 1, No. 1. Julio - diciembre. pp: 81-106

- GARCIA PICAZO, Paloma (2010). El sistema mundial: perspectivas políticas y sociológicas. Temas abreviados. UNED, Madrid

- GARRIDO CARRASCO, Janett (2008). El nuevo regionalismo: características y diferencias, en Informe Integrar (IIL-UNLP) número 47, febrero.

- GASPARINI, Cintia (2014). Integración regional y cooperación en el Mercosur, Avances, retrocesos y oportunidades. Documento de trabajo $\mathrm{N}^{\circ} 1, \mathrm{SPEEyPD}$, Ministerio de Economía, Buenos Aires. 
- GRABENDORFF, Wolf (2010). Brasil: de coloso regional a potencia global, en Nueva Sociedad N²26, 3-4.

- $\quad$ GRANATO, Leonardo; O’DONNE, Nahuel y Matías BATTAGLIA (2016). Teoría de la autonomía: ¿Aún vigente para analizar los procesos de cooperación e integración en América Latina? En Teoria e Pesquisa em Ciência Política, 25 (1). pp 153-175

- GEUS, Alex de (2011). Las caras de IIRSA: ¿integración regional o interconexión Sudamericana para la explotación de recursos naturales a favor de Brasil y/o del empresariado mundial, Universidad Complutense de Madrid, s/d.

- GIACALONE, Rita (2002): La Integración Regional en la Historia, Conferencia Inaugural del Congreso de Historia Regional y Local, San Cristóbal (Venezuela), 25 de septiembre de 2002 (material suministrado por la Universidad de Los Andes, Mérida, Venezuela).

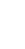
(2006): Región y Regionalismo en los Acuerdos de Integración Económica: de Latinoamérica a Sudamérica, en Jean Monnet/Robert Schuman Paper Series Vol. 6, \#19.

$\bullet$ (2008). Motivaciones políticas para la constitución de la Comunidad Sudamericana de Naciones. Análisis de convergencia/divergencia en el discurso de Brasil, Venezuela y Argentina en Rita Giacalone (ed.) "La integración sudamericana. Un complejo proceso inconcluso". Mérida: FACES-ULA, pp. 17-49.

$\bullet$ (2009): Identidad y motivaciones políticas en la integración suramericana, en Cuadernos Latinoamericanos, año 20, nro. 35, enero-junio. pp: 47-73 $\bullet$ (2013) La integración sudamericana - entre el modelo europeo y la política exterior brasileña en Améndola Adalgiso (et al) Regionalismo 
Latinoamericano: dimensiones actuales Repensando la integración y las integraciones, Bogotá, Universidad Externado de Colombia.

- GILPIN, Robert (1975). Power and the multinational corporation. New York: Basic Books.

(1981). War and Change in World Politics. Cambridge

University Press, New York

- (1986). The Richness of the Tradition of Polítical Realism, en

Robert KEOHANE (comp.) en 'Neorealism and its Critics', Columbia University Press, New York, pp. 316-321

- GINESTA, Jacques (1989). Sobre paradigmas, modelos y propuestas en la integración latinoamericana, en Estrategia Latinoamericana, Instituto de Integración Latinoamericana, Universidad Nacional de La Plata.

- $\quad$ GLASER, Carl (1997). The Security Dilemma Revisited en World Politics, Vol. 50, №1. pp: 171-201

- GOLDSTEIN, Judith y FINNEMORE Martha (2013): Back to basics: State Power in a Contemporary World, Oxford Scholarship Online.

- GONZÁLEZ, Mónica (2001): La Teoría de las Relaciones Internacionales en los Albores del Siglo XXI: Diálogo, Disidencia, Aproximaciones en Revista Cidob D'afers Internacionals \#56 (Miscelánea), pp. 7-52.

- GONZALEZ-ARIAS, Dolores (2013). El proceso de implementación del Arancel Externo Común en el Mercosur desde el Tratado de Ouro Preto (1994) hasta el 2012, Tesis de grado, Universidad de San Andrés: Buenos Aires. 
- GOULART MENEZES, Roberto (2009). O espaço sul-americano na política externa do governo Lula. Ponencia ante el XXVII Congreso de la Asociación Latinoamericana de Sociología y VIII Jornadas de Sociología de la Universidad de Buenos Aires. Asociación Latinoamericana de Sociología, Buenos Aires.

- GRIFFITHS, Martin (2004). Cinqüenta Grandes Estrategistas de Relações Internacionais. São Paulo: Contexto.

- GUILhON AlbuQUerQue, José (1996). A Presidência na linha de frente da diplomacia. En Carta Internacional 35, enero.

- $\quad$ HAAS, Ernst (1958). the Uniting Europe: political, social, and economic process 1950-1957, Stanford University Press.

$\bullet$ (1975). On systems and international regimes, World Politics, vol. 27 , n. 2, enero.

(1982). Words can hurt you; or who said what to whom about regimes en International Organization, vol. 36, n. 2, primavera. pp. 207-244.

- HALPERIN, Marcelo (2011). Spaghetti bowl o el multilateralismo en cuestión. Informe Integrar $N^{\circ} 67$, junio de 2011

- HASENCLEVER, Andreas; MAYER, Peter y Volker RITTBERGER (1999). Las teorías de los Regímenes Internacionales, en Foro Internacional, México DF, El Colegio de México, no 158, octubre-diciembre, pp. 499-526.

- HAZLETON, William (1987): Procesos de decisión y políticas exteriores, en WILHELMY, Manfred (comp). La formación de la política exterior. Los países desarrollados y América Latina, RIAL-GEL, Buenos Aires. 
- HETTNE, Björk (1996). Development, security and World Order: A regionalist approach. The European Journal of Development Research, vol. 9. Nro. 194. pp. 83-106 - (2002) El Nuevo regionalismo y el retorno a lo político. Comércio Exterior, 52 (11), 954-965.

- HIRST, Mónica (2006) Los desafíos de la política sudamericana de Brasil. Nueva Sociedad 205. pp $131-140$

- HIRST, Mônica; PINHEIRO, Letícia y Regina SOARES DE LIMA (2010) A política externa brasileira em tempos de novos horizontes e desafios, Nueva Sociedad en español, diciembre.

- HOFFMANN, Stanley (1991). Jano y Minerva: Ensayos sobre la guerra y la paz. GEL. Buenos Aires

- HOLSTI, Kalevi (1964). The Concept of Power in the Study of International Relations, Background, 7 (febrero).

_ (1967) International Politics: A Framework for Analysis, Englewood Cliffs, N. J. Prentice-Hall.

- HOLSTI, Ole (1989): Modelos de relaciones internacionales y política exterior en Foro Internacional, vol. 29, 4 (116) (abril-junio). pp. 525-560.

- HURRELL, Andrew (1993). Os blocos regionais nas Américas. En Revista Brasileira de Ciências Sociais, São Paulo, ano 8, número 22, p. 98-118. Consultado el 9 $\begin{array}{llll}\text { abril de } & 2016 & \text { en }\end{array}$ http://www.anpocs.org.br/portal/publicacoes/rbcs $00 \quad 22 /$ rbcs22 $06 . h t m$ 
Abraham y TREVERTON, Gregory (comps.) América Latina en el Mundo Nuevo, México DF: Fondo de Cultura Económica. pp: 199-226.

(1995). Regionalism In Theoretical Perspective en Louise Fawcett y Andrew Hurrell (eds.) "Regionalism in World Politics. Regional Organization and International Order", Continental Drift, Basingstoke. Palgrave.

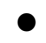
(2000). Some Reflections on the Role of Intermediate Powers in International Institutions, en: Hurrell, Andrew et al., Paths to Power: Foreign Policy Strategies of Intermediate States, Latin American Program. Woodrow Wilson International Center,

\section{$\bullet$}

(2005): Global Community: The Role of International Organizations in the Making of the Contemporary World en "Journal of Cold War Studies", Vol. 7, \# 1, (invierno). pp: 186-189

- IBÁÑEZ, Josep (2000): El nuevo regionalismo latinoamericano en los años noventa, Revista Electrónica de Estudios Internacionales, s/d.

- JAGUARIBE, Hélio (1982) Brasil-Argentina: Breve análisis de las relaciones de conflicto y cooperación, Estudios Internacionales, IEI (Universidad de Chile), año 15, número 57 (enero-marzo)

- JARque, Carlos; ORTIZ, María Salvadora y Carlos QUENAN (eds.). América Latina y la Diplomacia de Cumbres, Fondo Mexicano de Cooperación Internacional para el Desarrollo con Iberoamérica - SGI, México DF, 2009.

- JIMENEZ GONZALEZ, Claudia (s/d). Las teorías de la cooperación dentro de las relaciones internacionales, en Revista Polis 3, volumen 2. pp 115-147 
- $\quad$ KAGAN, Robert (2003). Of Paradise and Power. America and Europe in the New World Order, Alfred A. Knopf, New York.

- KALINSKY, Beatriz y Roberto RUSSELL (1986). Ideas políticas y unidad latinoamericana: hacia una superación de la dicotomía utopismo-pragmatismo, en "Ideas en Ciencias Sociales", Universidad de Belgrano, número 5.

- KAPLAN, Norton (1964). Sistema y proceso en la política internacional, Tecnos, Madrid.

- KEATING, Michael (1993). Regionalismo, autonomía y regímenes internacionales. Working Paper No. 244, s/d, University of Western Ontario.

- KEOHANE, Robert (1984). After Hegemony. Cooperation and Discord in the World Political Economy. Princeton: Princeton University Press.

(1986) Theory of World Politics: Structural Realism and Beyond, en Robert Keohane (ed) Neorealism and its Critics. New York: Columbia University Press, 1986

- KEOHANE, Robert (2009). La obra de Robert O. Keohane y la disciplina de las relaciones internacionales. En Borja Tamayo (comp.) "Ensayos escogidos de Robert O. Keohane. Interdependencia, cooperación y globalismo". México, CIDE

- KEOHANE, Robert y Joseph NYE (1989). Power and interdependence. Harvard: Harpercollins Publishers

- KEOHANE, Robert y Stanley Hoffman (1991). Institutional change in Europe in the 1980s, en "The New European Community". Boulder: Westview Press.

- KISSINGER, Henry (1973). Un mundo restaurado, La política del conservadurismo en una época revolucionaria, UNAM, México DF. 
(1996). Diplomacia. Ediciones B, Barcelona.

- KNORR, Klauss (1970). Power and Wealth: Military Power and Potential, Lexington Mass, D.C. Heath.

(1975). The Power of Nations: The Political Economy of International Relations, Nueva York, Basic Books

(1981). El poder de las naciones. Buenos Aires, Editorial

Belgrano.

- LAFER, Celso (2002). La identidad internacional de Brasil. Buenos Aires, FCE, 2002

- LANCI, Leandro (2007). Globalización y Mercosur en Armagnague, Juan y Enrique Gutiérrez-Roig (comp.) "Estudios sobre el Mercosur", Mendoza: Ediciones Jurídicas Cuyo.

- LEMKE, Douglas (2002): Regions of War and Peace. Cambridge New York: Cambridge University Press.

- LLENDERROZAS, Elsa (2009): UNASUR: Desafíos geopolíticos, económicos y de política exterior, en Pensamiento Propio 42, s/d. pp: 195-214

(ed): Teoría de Relaciones Internacionales, Buenos Aires:

EUDEBA

- $\quad$ LERCHE, Charles Jr. (1956). Principles of International Politics, Oxford University Press.

- LESSA, Antônio Carlos (1998). A Diplomacia Universalista Do Brasil: A Construção Do Sistema Contemporâneo De Relações Bilaterais. Brasília: RBPI, v. 41, número especial. 
- LINDBERG, Leon (1963) The political dynamics of European Economic integration, New York, Stanford.

(1970). Political integration as a multidimensional phenomenon requiring multivariate measurement. En 'International Organization', año 4, nro. 24. pp. 649-731

- MAESSO CORRAL, María (2011). La Integración Económica en "Información Comercial Española, Revista de Economía”, Madrid, ICE, número 858, Ene-Feb. 2011.

- MAGHROORI Ray y Bennett RAMBERG (1982): Globalism versus Realism. International Relations Third Debate, Westview Boulder, 1982

- MALAMUD, Andrés (2011). Conceptos, teorías y debates sobre la integración regional, en Revista Norteamérica vol. 6, nro. 2 México julio-diciembre

- MALAMUD, Andrés y Julio RODRIGUEZ (2013). Com um pé na região e outro no mundo: O dualismo crescente da política externa brasileira, Estudios Internacionales, vol. 1 nro. 2 julio-diciembre. pp. 167-183

- MATTEUCCI, Nicola; ARICÓ, José; SOLER, Martí y Jorge TULA (2000): Diccionario de Política (Vol. 1). Siglo XXI Editores: Buenos Aires.

- MAYER, Peter; RITTBERGER, Volker y Michael ZÜRN (1997). Regime theory: State of Art and perspectives en V. Rittberger (ed) Regime theory and international relations, New York, Oxford University Press.

- MEARSHEIMER, John (1990): 'Back to the Future: Instability in Europe After the Cold War,' en International Security, Vol. 15, \# 1. p.13. 
United States the Door - It's Not a Pretty Picture, en: Foreign Policy, January-February. pp. 47-50.

- MELLADO, Noemí (2006): Mercosur, convergencias y divergencias en Hummer Waldemar (org.) y Noemí Mellado (coord.) "Cooperación y conflicto en el Mercosur", Universidad Nacional de Córdoba.

$\bullet$ (coord.): MERCOSUR-ALCA. Articulación contradictoria o virtuosa de las negociaciones internas y externas, EDULP-Universidad Nacional de la Plata, 2007 (2013). Regionalismo sudamericano: sus características. En Revista de la Secretaría del Tribunal Permanente de Revisión. Año 1, Nro. 1, 137 - 159. Consultado el 4 de abril de 2017, y disponible en: http://www.revistastpr.com/index.php/rstpr/article/view/18/11

- MIJARES, VÍCTOR (2015). Realismo neoclásico: ¿El retorno de los estudios internacionales a la ciencia política? Revista de Ciencia Política, Santiago, año 35, vol 3, $581-603$

- MINISTÉRIO DAS RELAÇÕES EXTERIORES (2003): Resenha de Política Exterior do Brasil, Centro de Documentação do MRE, vol. 92, primeiro semestre. Pp: 13-20

- MJOSET, Lars (1990). The turn of two centuries: a comparison of British and US hegemonies. En David RAPKIN “World leadership and hegemony”, Boulder: Rienner.

- MOLINA, Franklin (2007). Visiones del regionalismo y la regionalización en América del Sur en el nuevo milenio. En Revista Venezolana de Economía y Ciencias Sociales, vol.13, nro. 3 (septiembre-diciembre). pp. 13-32. 
- MONIZ BANDEIRA, Luiz Alberto (2003). Brasil, Estados Unidos y los procesos de integración regional. Nueva Sociedad 186, Buenos Aires

- MORAVCSIK, Andrew (1998). The Choice for Europe. Social Purpose and State Power from Messina to Maastricht. Cornell University Press, New York

- MORgenthaU, Hans (1963) La lucha por el poder y por la paz. Buenos Aires, Cancino.

(2003): A Política Entre As Nações: A Luta Pelo Poder E Pela Paz. Brasília: Editora Universidade de Brasília.

- MUÑOZ ALONSO; Alejandro (2006). Política exterior e interés nacional, en Cuadernos de Pensamiento Político (s/d), abril-junio. pp 133-144

- MURILLO ZAMORA, Carlos (2004). Aproximación a los regímenes de integración regional, en Revista electrónica de estudios internacionales, 8.

- $\quad$ MIYAMOTO, Shiguenoli (2000). O Brasil e as negociações multilaterais. Revista Brasileira de Política Internacional, Ano 43, no 1, pp. 119-137.

- NEUMANN, Iver (1992). Regional Great Powers in International in International Politics Basingstoke: St. Martin's Press (2003): A Region-Building Approach to Northern Europe' en Review of International Studies, vol. 20, № 1 (enero). pp: 53-74

- NIEBURG, Harold (1969). Political Violence. The Behavioral Process. Nueva York, St. Martin's Press.

- NIEMANN, Mark (2000). A Spatial Approach to Regionalism in the Global Economy. London, MacMillan Press. 
- NOLTE, Detlef (2006): Potencias Regionales en la Política Internacional: Conceptos y Enfoques de Análisis, Working Paper \#30 - GIGA, Hamburgo, Alemania.

- NYE, Joseph (1969). Integración regional comparada: concepto y medición. En Revista de la Integración; BID-INTAL Nro. 5, Buenos Aires. pp: 50-86

- _ (1970). Comparing Common Markets: A Revised Neofunctionalist Model. En International Organization, 24:4, 1970.

- OLSON, Williams y Nicholas ONUF (1985), The growth of a discipline: reviewed en SMITH (ed.) 'International Relations, British and American Perspective, Oxford.

- ORgANIZACIÓN MUNDIAL DEL COMERCIO (2013): Disposiciones sobre trato especial y diferenciado establecidas en los acuerdos y decisiones de la OMC (WT/COMTD/W/196), Comité de Comercio y Desarrollo (13-3101), Ginebra.

- OROzCO, Gabriel (2005) El concepto de la seguridad en la Teoría de las Relaciones Internacionales, Revista CIDOB d'Afers Internacionals, núm. 72. pp. 161-180 - PAlOMARES LERMA, Gustavo (1991). Hegemonía y cambio en la teoría de las Relaciones Internacionales en Revista CIDOB d'Afers internacionals, No. 22. pp. 19-51.

- PADELFORD, Norman y George LINCOLN (1969): International Politics. Foundations of International Relations, McGraw Hill, Nueva York.

- $\quad$ PAZ dOS SANTOS, Raquel (2014). A revitalização do Mercosul no contexto da diplomacia de Lula para a América do Sul en Polis, Revista Latinoamericana, volumem 13, № 39, 2014, pp. 63-82.

- PEARSON, Frederic y Martin ROCHESTER (2004). Relaciones Internacionales: situación global en el Siglo XXI. McGraw Hill. 
- PEDERSEN, Thomas (2002). Cooperative Hegemony. Power, Ideas and Institutions in Regional Integration, en: Review of International Studies, No. 28, pp. 677-696.

- PENTLAND, Charles (1976). Neofunctionalism, The Year Book of World Affairs, 27. New York

- PEÑAS ESTEBAN, Francisco (2005). ¿Es posible una teoría de las relaciones internacionales? en Revista Académica de Relaciones Internacionales, núm. 1, marzo de 2005, GERI - UAM

- PereiRA, Juan Carlos (2003): La Política Exterior de España (1800-2003): Historia, Condicionantes y Escenarios, Madrid: Editorial Ariel

- PEREIRA CASTAÑARES, Juan Carlos (1999). Un siglo de cooperación y conflicto, números de Historia Contemporánea 21. pp: 17-62.

- PUCHALA, David (1971). International Transactions and Regional Integration en Leon LINDEMBERG and S. SCHEINGOLD (eds) "Regional Integration Theory and Research", Harvard University Press, Cambridge.

- PUCHALA, Donald y Raymond HOPKINS (1982) International Regimes: Lessons from Inductive Analysis. En International Organizations, vol. 36, nro. 2. pp. 246-47.

- RAPKIN, David (1990). The Contested Concept of Hegemonic Leadership, en David Rapkin (ed.) "World Leadership and Hegemony", London: Lynne Rienner.

- REMIRO BROTÓNS, Antonio (1999). Universalismo, multilateralismo, regionalismo y unilateralismo en el Nuevo Orden Mundial, en Revista Española de Derecho Internacional LI (1), pp: 11-57 
- REZENDE, Lucas (2013). Sul, uma teoria realista ofensiva. Tese de doutorado, PPGCP, UFRGS, Rio Grande del Sur.

- RIgIROZZI, Pía (2010). Region, Regionness and Regionalism in Latin America. Towards a new Synthesis, LATN Working Paper № 130, abril.

- ROCHA VALENCIA y Daniel MORALES RUVALCABA (2010) Potencias medias y potencias regionales en el sistema político internacional: dos modelos teóricos. Geopolítica(s). Revista de estudios sobre espacio y poder, vol. 1, núm. 2, 251-279.

- $\quad$ ROCHESTER, Martin (1986). The rise and fall of international organization as a field of study, International Organization, vol. 40, n. 4, otoño.

- RODRÍGUeZ SUÁREZ, Manuel (2012): Regionalismos en el marco de las relaciones internacionales del siglo XXI, en Revista Nómadas, Universidad Autónoma de Puebla, vol. 2, número 24.

- ROSENAU, James (1994): Pre-teorías y Teorías sobre la Política Exterior, en VÁZQUEZ, John, 'Relaciones Internacionales. El Pensamiento de los Clásicos', México: Limusa.

- ROSENTHAL, Gert (1991). Un informe crítico a 30 años de integración en América Latina, Revista Nueva Sociedad, n‥ 113 mayo-junio 1991. pp. 60-65.

- RÖSH, Félix; BEHR Hartmut y Hans MORGENTHAU (2012): The concepto of the Political, Palgrave Macmillan, New York

- RUBIO GARCÍA, Leandro (1974): Interés nacional y política internacional en Revista de Política Internacional 132, marzo-abril. pp. 61-80 (1976). La tensión «idealismo-realismo» en la vida internacional, Revista de Política Internacional 134, noviembre-marzo, pp.55-76 
- $\quad$ RUEDA JUNQUERA, Fernando. (2006). European Integration Model: Lessons for the Central American Common Market, Jean Monnet/Robert Schuman Paper Series, vol. 6 No. 4, February . (2009): Qué se Puede Aprender del Proceso de Integración Europeo? La Integración Económica de Europa y América Latina en Perspectiva Comparada en Nueva Sociedad \#209, enero-febrero. pp: 59-75

- RUGGIE, John (2009). Epistemología, ontología y el estudio de los regímenes internacionales en Relaciones Internacionales GERI-UAM, número 11, junio.

- RUSSELL, Roberto (1992): Enfoques teóricos y metodológicos para el estudio de la política exterior, Buenos Aires: Grupo Editor Latinoamericano.

- RUSSELL, Juan y TOKATLIAN, Roberto (2009): Modelos De Política Exterior Y Opciones Estratégicas. El Caso De América Latina Frente A Estados Unidos, Revista Cidob D’Afers Internacionals, 85-86. pp: 210-149

(2013). América Latina y su gran estrategia: entre la aquiescencia y la autonomía, Revista Cidob d’Afers Internacionals, $N^{\circ}$ 104. pp: $157-180$

- SAlOMÓN GONZÁleZ, Mónica (2001). La teoría de las Relaciones Internacionales en los albores del siglo XXI: diálogo, disidencia, aproximaciones, Revista CIDOB Revista CIDOB d’Afers Internacionals, núm. 56, pp. 7-52.

- SANAHUJA, José (2010), La construcción de una región: Suramérica y el regionalismo post-liberal, en Cienfuegos, Manuel y José Antonio Sanahuja (eds.), Una región en construcción. UNASUR y la integración en América del Sur, Madrid: Fundación CIDOB, pp. 87-136. 
Sudamérica: el caso de UNASUR en SERBIN, Andrés; MARTÍNEZ, Laneydi; y Harldo RAMANZINI (coord.) “El regionalismo post-liberal en América Latina y el Caribe: nuevos actores, nuevos temas, nuevo desafíos". CRIES, Buenos Aires. pp 19-72

- $\quad$ SANTOS CARRILlO, Francisco y Pedro CALDENTEY DEL POZO (2014). Las implicaciones para América Latina de la renovación de paradigmas sobre regionalismo e integración. Ponencia ante el Congreso REDES, s/d, 2014

- SARAIVA José Flávio Sombra (2001). Relações internacionais. Dois Séculos de História. Brasília: IBRI, 2 vols. 8

(2007). As Estratégias De Cooperação Sul-Sul Nos Marcos Da Política Externa Brasileira De 1993 A 2007. Brasília: RBPI, v. 50, n. 2.

- SCARTASCINI DEL RíO, Juan (2007): La (Re)Inserción Báltica en la Comunidad Internacional, a través del ingreso a la Unión Europea, Buenos Aires: CAEI.

- SCHAPOSNIK, Carlos (1989). La crisis de la integración latinoamericana (editorial) en Estrategia Latinoamericana, Instituto de Integración Latinoamericana, Universidad Nacional de La Plata.

- SCHELKLE, Waltraud (2000). Regional Integration Among Less Developed Economies: Discordant Variations on an Evergreen en M. METZGER y B. REICHENSTEIN (eds) "Challenges for International Organizations in the 21st Century", St. Martin's Press, New York.

- SCHENONI, Luis (2012). Ascenso y hegemonía: pensando a las potencias emergentes desde América del Sur, RBPI, año 55 Nro. 1. pp 31-48 
- $\quad$ SCHENONI, Luis y Esteban ACTIS (2014). Argentina y Brasil: una unipolaridad regional con sesgo económico. Revista SAAP, Vol. 8, № 1, mayo, 207-235

- SCHMITTER, Philippe (1969). Three neofunctional hypotheses about international integration. En "International Organization", vol. 23. pp. 161-166

- $\quad$ SCHWARZENBERGER, Georg (1951). Power Politics. A study of international society, London Institute of World Affairs. New York: Frederick A. Praeger.

- $\quad$ SCHWELLER, Randall (2004). Unanswered threats. A neoclassical realist theory of underbalancing en International Security, vol. 29, número 2, otoño.

- SEANN, William (2008): Consensual Hegemony: Theorizing Brazilian Foreign Policy After the Cold War en International Relations, vol. 22 No 1, 3.

- SERRANO, Lorena (2008). Sobre la naturaleza de la integración regional: teorías y debates. En Revista de Ciencia Política, Santiago, v. 28, n. 2. pp. 95-113.

- $\quad$ SIMONOFF, Alejandro (2005): Te Quiero Mucho, Poquito, Nada: Las Relaciones Argentino-brasileñas en la era de Kirchner y Lula, en Revista Relaciones Internacionales, IRI-UNLP.

- SCHIM, Stefan (2010). Leaders in need of followers: Emerging powers in global governance. European Journal of International Relations, Vol 16, p. 197-221

- $\quad$ SCHOEMAN, Max (2003): South Africa as an Emerging Middle Power: 19942003, en: Daniel, John; Habib, Adam; Southall, Roger (eds.), State of the Nation: South Africa 2003-2004, Cape Town: HSRC Press, pp. 349-367

- $\quad$ SMITH, Joseph (1986). Realist Thought from Weber to Kissinger. Louisiana State University Press. Londres. 
- SOARES DE LIMA, Maria Regina (2005). Aspiração internacional e política externa. Revista Brasileña de Política Exterior, número 82, año 19. p 4-19.

(2007) Brasil como país intermedio: imprecisión conceptual y dilemas políticos. En: Juan Tokatlian (org). India, Brasil y Sudáfrica: El impacto de las nuevas potencias regionales. Buenos Aires: Libros del Zorzal, 2007, pp.169-190.

- SOARES LeITE, Patrícia (2011). O Brasil e a Cooperação Sul-Sul em três momentos de política externa: os governos Jânio Quadros/João Goulart, Ernesto Geisel e Luiz Inácio Lula da Silva. Fundação Alexandre Gusmão, Brasília.

- SOMBRA SARAIVA, José Flávio (2001) As relações Brasil-EUA na construção da integração hemisférica, Meridiano 47 nro.7, IBRI, enero.

- SOREANU PECEQUILO, Cristina (2008) as relações bilaterais Brasil-Estados Unidos (1989-2008), Nueva Sociedad, Especial Portugués, Buenos Aires.

- SORJ, Bernardo y Sérgio FAUSTO (2011). O papel do Brasil na América do Sul: estratégias e percepções mútuas. Plataforma Democrática, Working paper 12, julio.

- SOUtO MAIOR, Lu (2006). O Brasil E O Regionalismo Continental Frente A Uma Ordem Mundial Em Transição. Brasília: RBPI, v. 49, \#2.

- SNYDER, Glenn y Paul DIESING (1977). Conflict among Nations: Bargaining, decision making and system structure in international crises. Princeton. Princeton University Press

- STRANGE, Susan (1986). What about International Relations? en Strange Susan (comp.) "Paths to International Political Economy", Londres, Allen \& Unwin, pp. 183197. 
- TAMMEN, Ronald et al. (2000): Power Transitions Strategies for the 21st Century, New York: Chatham House Publishers.

- THORSTENSEN, Vera (2002). O Brasil diante de um tríplice desafio: negociações simultâneas da OMC, da ALCA e do acordo CE/Mercosul, en Política Externa, vol. 10, nro. 3. Diciembre-febrero.

- $\quad$ TOKATLIAN, Gabriel y Rodrigo PARDO (1990). La teoría de la interdependencia ¿Un paradigma alternativo al realismo? en Estudios Internacionales, vol. 13, nro. 91. pp: $339-382$

- TOKATLIAN, Juan (2007): India, Brasil y Sudáfrica: El Impacto de las Nuevas Potencias Regionales, Buenos Aires: Ediciones del Zorzal.

- TOMASSINI, Luciano (1991): Política internacional en un mundo posmoderno, RIAL-GEL, Buenos Aires.

- TUCKER, Robert (1952). Professor Morgenthau's Theory of political realism in defense of the National Interest: a critical study of American Foreign Policy by Hans Morgenthau, en Political Science Review, Vol.46, número 1, marzo. pp. 214-224.

- TUSSIE, Diana y Mercedes BOTTO: De la rivalidad a la cooperación: límites y desafíos de un contacto creciente, en 'La percepción de Brasil en el contexto internacional: Perspectivas y desafíos', FLACSO, Buenos Aires. pp: 41-77

- VAN KLAVEREN, Alberto (1992). Entendiendo las Entendiendo las políticas exteriores latinoamericanas: un modelo un modelo para armar. Revista del IEI UNC. AÑO 25, nro. 98, abril - junio. Pp. 169-217

- VÁZQUEZ, John (1983). The Power of Power Politics. A Critique. Londres, Frances Pinter. pp. 13-15. 
- VERA-FLUIXÁ, Ramiro (2000): Principios de Integración Regional en América Latina y su Análisis Comparativo con la Unión Europea, Bonn: Discussion Paper, C 73, Rheinische Friedrich Wilhelms-Universität.

- VIGEVANI, Tullo y Gabriel CEPALUNI (2007). A política externa de Lula da Silva: a estratégia da autonomia pela diversificação. En Contexto Internacional, Rio de Janeiro, diciembre, vol. 29, nro. 2. pp. 273-335.

- VIOLA, Donatella (2000): International relations and european integration theory: the role of European Parliament, Jean Monnet Working Papers in Comparative and International Politics - University of Catania. Consultado el 22 de febrero de 2017 y disponible aquí: http://aei.pitt.edu/401/1/jmwp26.htm

- VIZENTINI, Paulo Fagundes (1998). A política externa do Regime Militar brasileiro: multilateralização, desenvolvimento e a construção de uma potência média (1964 - 1985). Porto Alegre: Editora UFRGS.

- WALTZ, Kenneth (1979a). Teoría de la política internacional, Reading Mass, New York.

$\bullet$ (1979b). Theory of International Politics, Addison-Wesley Publishing Company, Sidney.

- (2000). Structural Realism after de Cold War, en International Security, vol 25, nº 1 . pp 5-41

$\bullet$ (1988). The Origins of War in Neorealist Theory, en 'The Journal of Interdisciplinary History', vol. 18, número 4. pp: 615- 628.

- WIGHT, Martin (1951). Power politics, Oxford University Press, Londres. 

(1960). Why is there no international theory? en International Relations II, abril.

- WIGHT, Martin (2002). Política de poder, Universidade de Brasília, Instituto de Pesquisa em Relações Internacionais.

- WILHELMY, Manfred (1988). Política Internacional. Enfoques y realidades. CINDA, GEL, Buenos Aires.

- YOUNG. Oran (1991). Political Leadership and Regime Formation: On the Development of Institutions in International Society. En International Organization, Vol. 45, No. 3, verano, pp. 281-308 